PNNL-23038

RPT-STMON-009

Prepared for the U.S. Department of Energy under Contract DE-AC05-76RL01830

\title{
Assessment of the Revised 3410 Building filtered exhaust stack Sampling Probe Location
}

$X-Y Y u$

KP Recknagle

JA Glissmeyer

December 2013 


\title{
DISCLAIMER
}

This report was prepared as an account of work sponsored by an agency of the United States Government. Neither the United States Government nor any agency thereof, nor Battelle Memorial Institute, nor any of their employees, makes any warranty, express or implied, or assumes any legal liability or responsibility for the accuracy, completeness, or usefulness of any information, apparatus, product, or process disclosed, or represents that its use would not infringe privately owned rights. Reference herein to any specific commercial product, process, or service by trade name, trademark, manufacturer, or otherwise does not necessarily constitute or imply its endorsement, recommendation, or favoring by the United States Government or any agency thereof, or Battelle Memorial Institute. The views and opinions of authors expressed herein do not necessarily state or reflect those of the United States Government or any agency thereof.

\author{
PACIFIC NORTHWEST NATIONAL LABORATORY \\ operated by \\ BATTELLE \\ for the \\ UNITED STATES DEPARTMENT OF ENERGY \\ under Contract DE-AC05-76RL01830 \\ Printed in the United States of America
Available to DOE and DOE contractors from the Office of Scientific and Technical Information,
P.O. Box 62, Oak Ridge, TN 37831-0062;
ph: (865) 576-8401
fax: $(865)$ 576-5728
email: reports@adonis.osti.gov
Available to the public from the National Technical Information Service 5301 Shawnee Rd., Alexandria, VA 22312 ph: (800) 553-NTIS (6847)
email: orders@ntis.gov <http://www.ntis.gov/about/form.aspx>
Online ordering: http://www.ntis.gov



PNNL-23038

RPT-STMON-009

\title{
Assessment of the Revised 3410 Building filtered exhaust stack Sampling Probe Location
}

\author{
X.-Y. Yu \\ K. P. Recknagle \\ J. A. Glissmeyer
}

December 2013

Prepared for the U.S. Department of Energy under Contract DE-AC05-76FL01830

Pacific Northwest National Laboratory

Richland, Washington 99352 


\section{Completeness of Testing}

This report describes the results of work and testing specified by test plan TP-STMON026. The work and any associated testing followed the quality assurance requirements outlined in the test specification/plan. The descriptions provided in this test report are an accurate account of both the conduct of the work and the data collected. Test plan results are reported. Also reported are any unusual or anomalous occurrences that are different from expected results. The test results and this report have been reviewed and verified.

\section{Approved:}

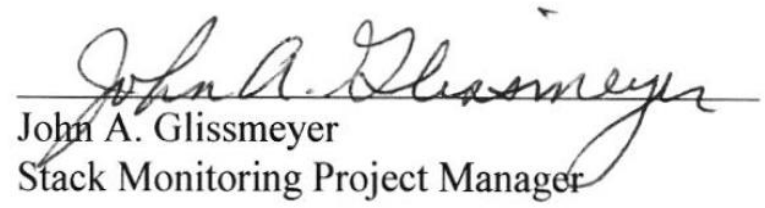

Date

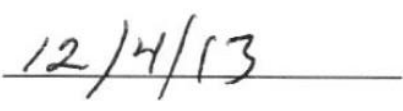




\section{Summary}

In order to support the radioactive air emissions permit for the 3410 Building, Pacific Northwest National Laboratory performed a series of tests in the exhaust air discharge from the reconfigured 3410 Building filtered exhaust stack (EP-3410-01-S). The objective was to determine whether the location of the air sampling probe for emissions monitoring meets the applicable regulatory criteria governing such effluent monitoring systems. In particular, the capability of the air sampling probe location to meet the acceptance criteria of ANSI/HPS N13.1-2011 ${ }^{\mathrm{a}}$, Sampling and Monitoring Releases of Airborne Radioactive Substances from the Stack and Ducts of Nuclear Facilities was determined. The qualification criteria for these types of stacks address 1) uniformity of air velocity, 2) sufficiently small flow angle with respect to the axis of the duct, 3) uniformity of tracer gas concentration, and 4) uniformity of tracer particle concentration. Testing was performed to conform to the quality requirements of NQA-1-2000. Fan configurations tested included all fan combinations of any two fans at a time. Most of the tests were conducted at the normal flow rate, while a small subset of tests was performed at a slightly higher flow rate achieved with the laboratory hood sashes fully open.

The qualification criteria for an air monitoring probe location are taken from ANSI/HPS N13.1-2011 and are paraphrased as follows with key results summarized:

1. Uniform Air Velocity: The acceptance criterion is that the coefficient of variation $(\mathrm{COV})^{\mathrm{b}}$ of the air velocity must be $\leq 20 \%$ across the center two-thirds of the area of the stack. Our results show that the COVs of the air velocity across the center two-thirds of the stack are smaller than $2.9 \%$ for all testing conditions.

2. Angular Flow: The average air velocity angle must not deviate from the axis of the stack or duct by more than $20^{\circ}$. Test results show that the mean angular flow angles at the center two-thirds of the ducts are smaller than $4.0^{\circ}$ for all testing conditions.

3. Uniform Concentration of Tracer Gases: The uniformity of the concentration of potential contaminants is first tested using a tracer gas to represent gaseous effluents. The tracer is injected downstream of the fan outlets and at the junction downstream fan discharges meet. The acceptance criteria are that 1 ) the COV of the measured tracer gas concentration is $\leq 20 \%$ across the center two-thirds of the sampling plane and 2) at no point in the sampling plane does the concentration vary from the mean by $>30 \%$. Our test results show that 1 ) the COV of the measured tracer gas concentration is $<2.8 \%$ for all test conditions and 2) at no point in the sampling plane does the concentration vary from the mean by $>6.7 \%$.

4. Uniform Concentration of Tracer Particles: Tracer particles of $10-\mu \mathrm{m}$ aerodynamic diameter are used for the second demonstration of concentration uniformity. The acceptance criterion is that the COV of particle concentration is $\leq 20 \%$ across the center two-thirds of the sampling plane. Test results indicate that the COV of particle concentration is $<9.9 \%$ across the center two-thirds of the sampling plane among all testing conditions.

The reconfigured 3410 Building filtered exhaust stack was determined to meet the qualification criteria given in the ANSI/HPS N13.1-2011 standard. Changes to the system configuration or operations

\footnotetext{
a ANSI/HPSN13.1-2011 and ANSI/HPSN13.1-1999 have essentially the same technical content. ANSI/HPS13.12011 contained some editorial revisions that were not included in ANSI/HPS N13.1-1999.

${ }^{\mathrm{b}}$ Coefficient of variation (COV) is considered "dated" terminology. The modern terminology is percent relative standard deviation. However, because the standard uses the older terminology, it will likewise be used here.
} 
outside the bounds described in this report (e.g., exhaust stack velocity changes, relocation of sampling probe, and addition of fans) may require re-testing or re-evaluation to determine compliance. 


\section{Acronyms}

$\begin{array}{ll}\text { acfm } & \text { actual cubic feet per minute } \\ \text { AD } & \text { aerodynamic diameter } \\ \text { ANSI } & \text { American National Standards Institute } \\ \text { ASME } & \text { American Society of Mechanical Engineers } \\ \text { CFR } & \text { Code of Federal Regulations } \\ \text { COV } & \text { coefficient of variation } \\ \text { DIA } & \text { number of duct diameters, distance divided by duct diameter } \\ \text { DOE } & \text { U.S. Department of Energy } \\ \text { DV } & \text { hydraulic diameter and the mean velocity } \\ \text { EPA } & \text { U.S. Environmental Protection Agency } \\ \text { EMSL } & \text { Environmental Molecular Sciences Laboratory (EMSL) } \\ \text { FA } & \text { flow angle test run } \\ \text { HDI } & \text { "How Do I...?" } \\ \text { HPS } & \text { Health Physics Society } \\ \text { M\&TE } & \text { materials and testing equipment } \\ \text { NQA } & \text { Nuclear Quality Assurance } \\ \text { PNNL } & \text { Pacific Northwest National Laboratory } \\ \text { PSF } & \text { Physical Sciences Facility } \\ \text { QA } & \text { quality assurance } \\ \text { R\&D } & \text { research and development } \\ \text { scfm } & \text { standard cubic feet per minute } \\ \text { STMON } & \text { Stack Monitoring Project } \\ \text { TI } & \text { Test Instruction } \\ \text { VT } & \text { velocity uniformity test run } \\ & \end{array}$





\section{Acknowledgments}

This work was supported by Project 52849, a U.S. Department of Energy (DOE) funded project to develop, design, and construct the Environmental Molecular Sciences Laboratory (EMSL) Physical Sciences Facility (PSF). Pacific Northwest National Laboratory (PNNL) is operated for the U.S. DOE by Battelle under Contract DE-ACO5-76RL01830.

Preparing and executing these tests involved a number of PNNL staff members. We would like to particularly acknowledge the support of our quality engineer, Kirsten Meier, and administrative support from Mona Champion and Chrissy Charron. Yin-Fong Su, Bradley Fritz, Mikhail Pekour, Julia Flaherty, and Matthew Barnett provided technical support for these tests. We also like to thank Curtis Nichols, Douglas McManamon, Brian Greenaway, Mark Hartzell, Josh Byrd, and Angelo Genetti for providing programmatic and logistical support. In addition, Carmen Arimescu and Matthew Barnett provided technical reviews. Meredith Willingham provided editorial support for this report. 



\section{Contents}

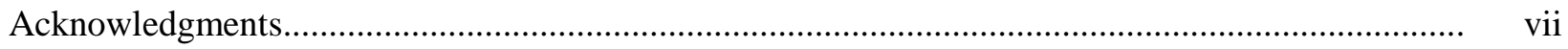

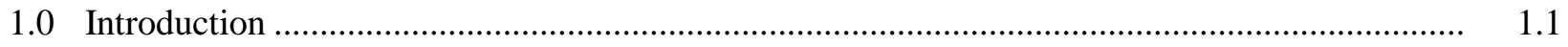

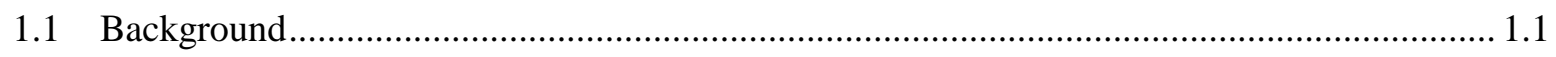

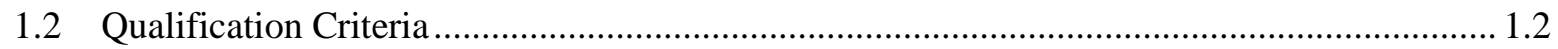

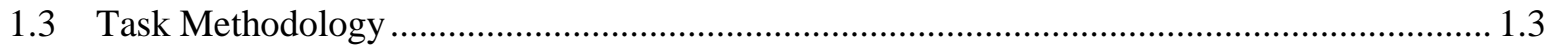

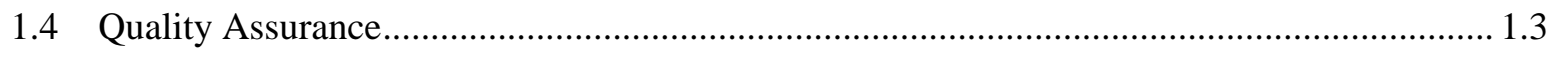

1.5 Building 3410 Filtered Exhaust System Geometry and Flow ......................................... 1.5

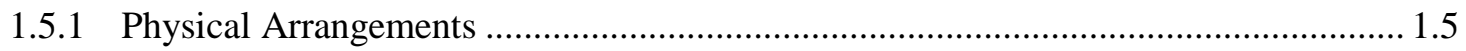

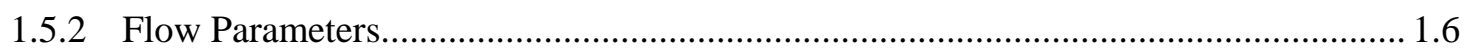

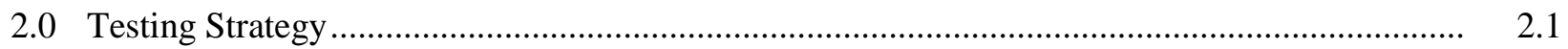

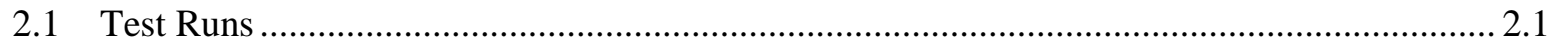

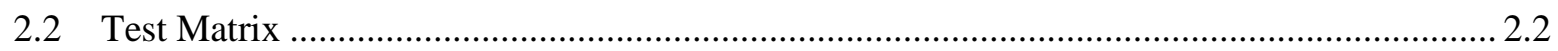

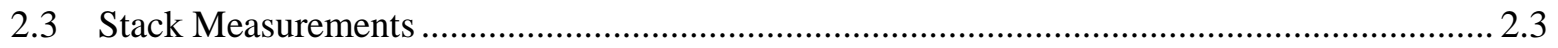

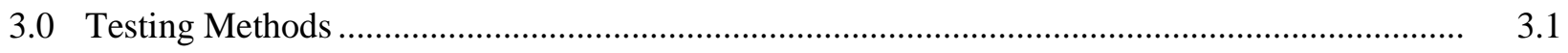

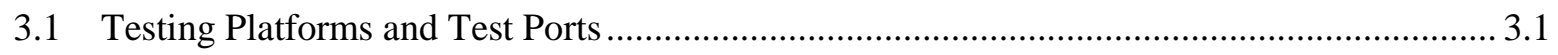

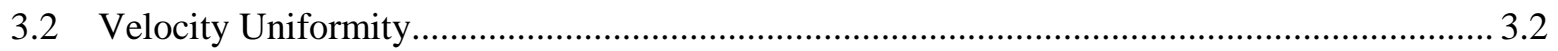

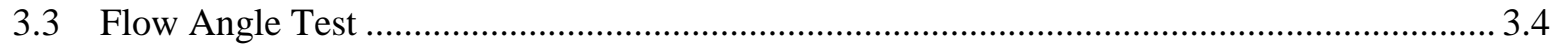

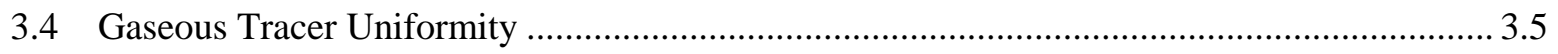

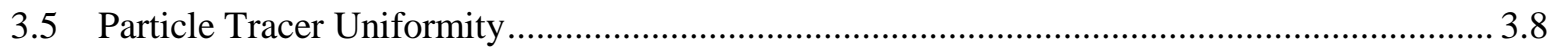

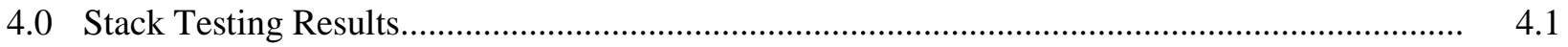

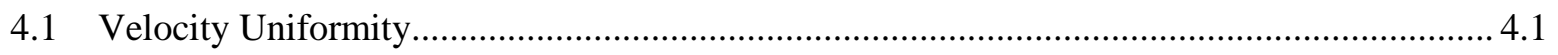

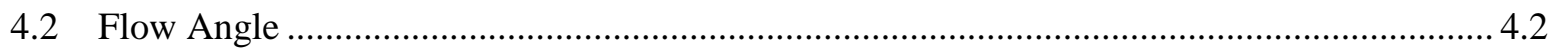

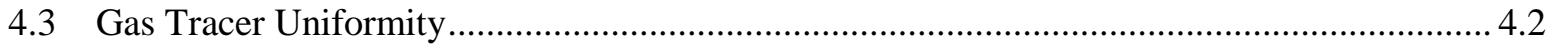

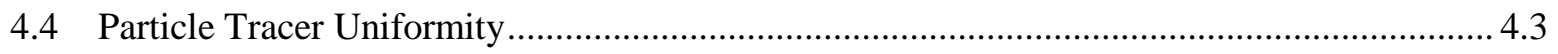

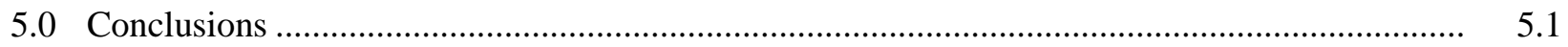

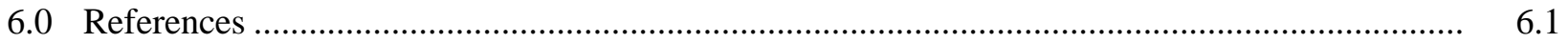

Appendix A: The CFD Model Report............................................................................... A.1

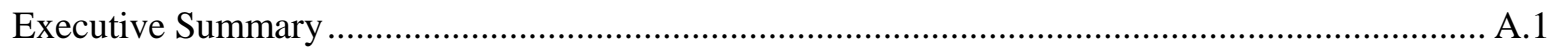

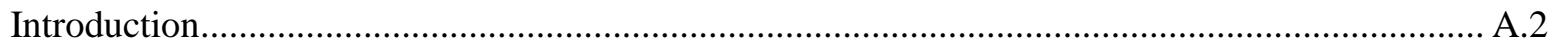

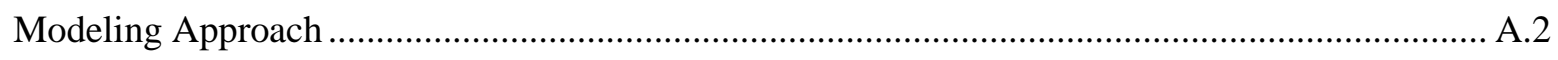

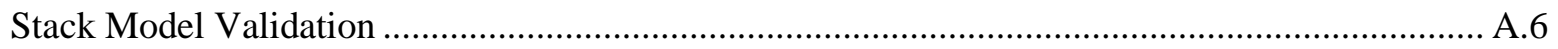

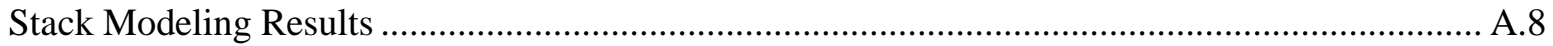

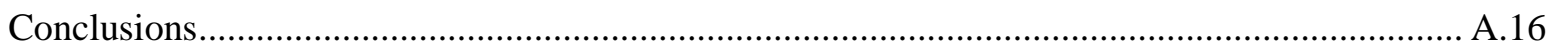

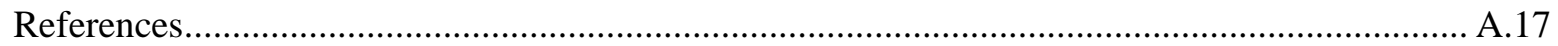

Appendix B: Data Sheets .................................................................................................. B. 
Velocity.

B. 1

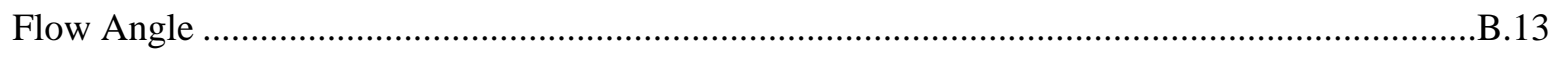

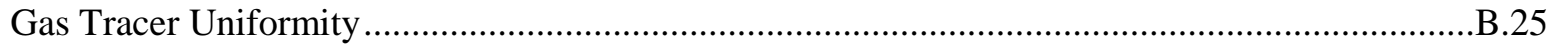

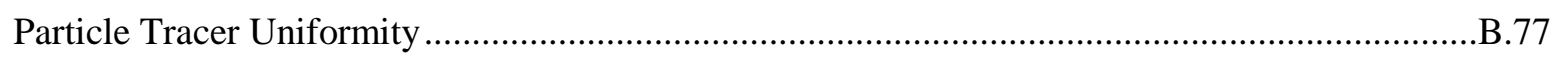




\section{Figures}

Figure 1.1 The New Stack Layout for Building 3410.

Figure 2.1. The Geometry of the Modified 3410 Building filtered exhaust stack System. Insert shows the details of the air blender.

Figure 2.2. A Photo Showing the Fan and the Damper on the Roof of the 3410 Building.............2.2

Figure 2.3. Cross-Section of the Duct at the Testing Ports with Measurement Points ..................2.4

Figure 3.1. Layout of Testing Platforms for the 3410 Stack Testing............................................. 3.1

Figure 3.2. a) Layout of the Side Test Ports; b) Layout of the Top Test Port................................ 3.2

Figure 3.3. The S-Type Pitot Tube and Manometer used on the 3410 Stack for the Top Traverse

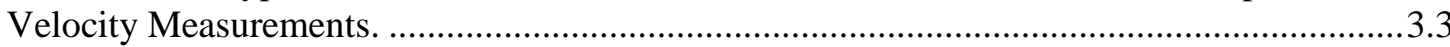

Figure 3.4. Flow Angle Indicator, Dwyer Manometer, and the S-Type Pitot Tube Installed on 3410 Stack for the Side Traverse Measurements. The test port is behind the angle indicator and invisible from the angle that the photo was taken. The white arrow indicates flow direction inside the stack.

Figure 3.5. Photo Showing Tracer Injection Port Location on the Stack Downstream of Fan A. The injection port was 3" in diameter. An injection port was added to each fan. The white arrow indicates the direction of air flow in the duct.

Figure 3.6. Pattern and Dimensions for Wall Injection Points During Gas Tracer Testing..... 3.7

Figure 3.7. Equipment and Setup for the Gaseous Tracer Injection in the 3410 Building Stack

Testing for the Side Traverse. The white arrow indicates the flow direction inside the stack.3.7

Figure 3.8. Equipment and Setup for the Gaseous Tracer Injection in the 3410 Building Stack

Testing for the Top Traverse. The white arrow indicates the flow direction inside the stack.3.8

Figure 3.9. Equipment and Setup Used for the Particle Injection Downstream of Fan B. Two aerosol generators were used and their output was merged to increase the particle injection and obtain reasonable measurement sensitivity at the sampling port.

Figure 3.10. Probes Used for the Particle Sampling

Figure 3.11. Equipment and Setup Used for the Particle Tracer Testing for the Side Traverse.

The white arrow indicates the flow direction inside the stack.

Figure 3.12. Equipment and Setup Used for the Particle Tracer Testing for the Top Traverse.

The white arrow indicates the flow direction inside the stack. ...............................................11

Figure 3.13. a) The sampling port for the reference OPC and connection to the OPC; b) The reference OPC during testing.

\section{Tables}

Table 1.1. 3410 Building Stack Operating Parameters ........................................................... 1.5

Table 2.1. Velocity Uniformity and Flow Angle Test Runs Performed ......................................2.2

Table 2.2. Gas and Particle Tracer Test Runs Performed ............................................................ 2.3

Table 4.1. 3410 Duct Depth Measurements ............................................................................... 4.1

Table 4.2. Summary of Velocity Uniformity Tests ................................................................. 4.2 


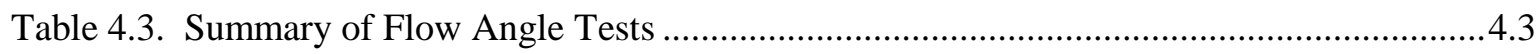

Table 4.4. Summary of Tracer Gas Uniformity Tests................................................................ 4.4

Table 4.5. Summary of Particle Uniformity Tests .......................................................................5 


\subsection{Introduction}

The new construction of the Physical Sciences Facility (PSF) at the Pacific Northwest National Laboratory (PNNL) incorporated three laboratory buildings that house PNNL radiological capabilities, namely 3410,3420 , and 3420 Buildings. After the initial stack qualification tests in 2010, a third fan was added to augment the effluent capability as a result of newly expanded laboratory needs in the 3410 Building. This physical change made the previous stack qualification assumption and results invalid due to the fact that new configuration deviates largely from the scale model stack and verification tests used to qualify the original stack in the 3410 Building.

As a result, the purpose of this series of tests was to document the extent to which the location of the stack sampling probe on the air exhaust stack of the 3410 Building would meet the applicable regulatory criteria $^{c}$ governing such effluent monitoring systems. In particular, the capability of the air sampling probe location to meet the acceptance criteria of ANSI/HPSN13.1-2011, Sampling and Monitoring Releases of Airborne Radioactive Substances from the Stack and Ducts of Nuclear Facilities, ${ }^{d}$ was determined. This was accomplished through a series of tests as described in the standard. This standard requires that a series of tests be performed to demonstrate the acceptability of the location of the air sampling probe in the system. Full scale testing on the actual exhaust system was performed. The data reported here will be used to support the air emissions permit for the 3410 Building.

Work has been performed to meet the quality requirements of American Society of Mechanical Engineers (ASME) NQA-1-2000, Quality Assurance Requirements for Nuclear Facility Applications, Part 1, Requirements for Quality Assurance Programs for Nuclear Facilities, and ASME NQA-1-2000, Part IV, Subpart 4.2, Graded Approach Application of Quality Assurance Requirements for Research and Development. These quality requirements were implemented through the Stack Monitoring Project (STMON) QA Plan (QA-STMON-0001, QAP). This project was graded as technology level "Development Work" in accordance with the quality assurance (QA) program. This project has developed a detailed project plan (PP-STMON-031) and a test plan (TP-STMON-026). Testing was executed according to these plans and detailed technical instructions (TIs).

\subsection{Background}

One of the following three approaches may be chosen to demonstrate compliance with the federal standards: 1) perform a full test series on the actual exhaust system; 2) perform the full test series on a scale model of the exhaust system, followed by a partial test of the actual exhaust system to verify the validity of the model results, or 3) adopt the results from previously performed full test series for a system with similar configuration, followed by a partial test of the actual exhaust system to verify the applicability of the previous test results.

In the first stack qualification testing for 3410 Building in 2010, the third approach was selected to evaluate the acceptability of the location of the air sampling probe in the 3410 Building filtered exhaust stack and to monitor discharged air for radionuclides because of the similarity between the old

\footnotetext{
${ }^{\mathrm{c}}$ Washington Administrative Code 246-247.

${ }^{\mathrm{d}}$ The American National Standards Institute delegates the writing, publication and maintenance of this standard to the Health Physics Society, McLean, Virginia.
} 
configuration and a scale model that had been thoroughly tested for a different project. Consequently, a limited series of tests was performed on the actual exhaust system using the criteria for qualifying the location of a stack monitoring probe and the configuration of the 3410 Building filtered exhaust stack, as described in the report PNNL-19562. ${ }^{\mathrm{e}}$

For the 3410 Building re-testing project, a full scale test was performed because of 1) lack of existing scale model or results, 2) comparable cost effectiveness between scale model and full scale testing, and 3) extended time necessary to build a scale model. Tests on the 3410 Building, also known as the Materials Science and Technology Laboratory, were conducted between April and June 2013. Test data sheets reporting velocity uniformity, flow angle, gas tracer uniformity, and particle tracer uniformity tests are included in this report.

Also included in this report is a technical summary reporting computational fluid dynamics (CFD) modeling results, evaluating whether the stack would meet the qualification criteria prior to conducting full scale testing. The preliminary CFD results indicated insufficient mixing at the probe location especially for the simulated particle tracer uniformity tests after adding the third fan. After careful technical discussions, an air mixer was chosen as an engineering solution that would not require extensive reconfiguration or construction of the stack, which could further delay the unobstructed operation of the 3410 Building. Additional CFD calculations were done to understand the effect of the recommended change and whether sufficient mixing was achieved after adding the air mixer. More detailed description of the CFD results was included in Appendix A: The CFD Model Report.

\subsection{Qualification Criteria}

The qualification criteria for a stack air monitoring probe location are taken from ANSI/HPSN13.12011 and are paraphrased as follows:

1. Uniform Air Velocity: It is important that the gas velocity be fairly uniform across the stack cross-section where the sample is extracted. Consequently, the velocity is measured at several points in the stack at the position of the sampling nozzle. The uniformity is expressed as the variability of the measurements about the mean. This is expressed using the COV, which is the standard deviation divided by the mean and expressed as a percentage. As the COV value becomes lower, the velocity becomes more uniform. The acceptance criterion is that the COV of the air velocity must be $\leq 20 \%$ across the center two-thirds of the area of the stack.

2. Angular Flow: Sampling nozzles are usually aligned with the axis of the stack. If the air travels up the stack in cyclonic fashion, the air velocity vector approaching a sampling nozzle could be misaligned with it enough to impair the extraction of particles. Consequently, the flow angle is measured in the stack at the elevation of the sampling nozzle. The average air velocity angle must not deviate from the axis of the stack or duct by more than $20^{\circ}$.

3. Uniform Concentration of Tracer Gases: Uniform contaminant concentration in the sampling plane enables the extraction of samples that represent the true concentration. The uniformity of the concentration is first tested using a tracer gas to represent gaseous effluents. The tracer is injected downstream of the fan and also at the junction of the ducts. The acceptance criteria are that 1 ) the COV of the measured tracer gas concentration is $\leq 20 \%$ across the center two-thirds of

\footnotetext{
${ }^{\mathrm{e}}$ Assessment of the 3410 Building filtered exhaust stack Sampling Probe Location, John Glissmeyer and Julia
} Flaherty, July 2010, PNNL-19562. 
the sampling plane and 2) at no point in the sampling plane does the concentration vary from the mean by $>30 \%$.

4. Uniform Concentration of Tracer Particles: A second set of tests addressing contaminant concentration uniformity at the sampling position uses tracer particles large enough to exhibit inertial effects. Tracer particles of $10-\mu \mathrm{m}$ aerodynamic diameter (AD) are used by default unless it is known that larger contaminant particles will be present in the airstream. The acceptance criterion is that the COV of particle concentration is $\leq 20 \%$ across the center two-thirds of the sampling plane.

Tests were conducted to determine if criteria 1 to 4 are met. They were conducted on the exhaust ductwork and stacks, from the fans to the position of the sampling probe.

\subsection{Task Methodology}

Compliance with each qualification criterion is demonstrated through performing a specific PNNL test procedure and a TI. The basic series of tests include the following:

- Velocity uniformity test

- Flow angle test

- Gas tracer uniformity test

- Particle tracer uniformity test.

The testing methods were based on the requirements of ANSI/HPS N13.1-2011. A test plan, TP-STMON-026, 3410 Building Stack Monitoring Project Test Plan, was prepared by the testing team and approved by internal reviewers and EMSL project management. This plan referenced the use of PNNL procedures, which define how the test should be conducted in general. A TI was prepared for each test type. These TIs contain specific instructions pertaining to the tests that are not addressed in the general procedures. Such information includes the following:

- Layout of measurement points

- Location of tracer injection points

- List of equipment and instrumentation

- Safety requirements

- List of test runs

- Test description and measurement data sheets with hand entries

- Table of preliminary results.

The QA program implemented for this project was described in details in the project plan.

\subsection{Quality Assurance}

The PNNL QA program was based on the requirements defined in the U.S. Department of Energy (DOE) Order 414.1D, Quality Assurance, and 10 CFR 830, Energy/Nuclear Safety Management, and 
Subpart A-Quality Assurance Requirements (a.k.a., the Quality Rule). PNNL has chosen to implement the following consensus standards in a graded approach:

- ASME NQA-1-2000, Quality Assurance Requirements for Nuclear Facility Applications, Part I, "Requirements for Quality Assurance Programs for Nuclear Facilities" (ASME 2001).

- ASME NQA-1-2000, Part II, Subpart 2.7, Quality Assurance Requirements for Computer Software for Nuclear Facility Applications (ASME 2001).

- ASME NQA-1-2000, Part IV, Subpart 4.2, Graded Approach Application of Quality Assurance Requirements for Research and Development (ASME 2001).

The procedures necessary to implement the requirements are documented through PNNL's "How Do I...?" (HDI), which is a system for managing the delivery of laboratory-level policies, requirements, and procedures.

The STACK MONITORING PROJECT (STMON) implements an NQA-1-2000 QA program, using a graded approach presented in NQA-1-2000, Part IV, Subpart 4.2. The STMON QA manual (QA-STMON-002) describes the technology life cycle stages under the STMON QA plan (QA-STMON0001). The technology life cycle includes the progression of technology development, commercialization, and retirement in process phases of basic and applied research and development $(R \& D)$, engineering and production, and operation until process completion. The life cycle is characterized by flexible and informal QA activities in basic research, which becomes more structured and formalized through the applied R\&D stages. The work described in this project plan will be completed under the QA Technology level of Developmental Work as the data will be used for applying air discharge permits.

- BASIC RESEARCH: Basic research consists of research tasks that are conducted to acquire and disseminate new scientific knowledge. During basic research, maximum flexibility is desired to allow the researcher the necessary latitude to conduct the research.

- APPLIED RESEARCH: Applied research consists of research tasks that acquire data and documentation necessary to confirm the satisfactory reproducibility of results. The emphasis during this stage of a research task is on achieving adequate documentation and controls necessary to be able to reproduce results.

- DEVELOPMENTAL WORK: Development work consists of research tasks moving toward technology commercialization. These tasks still require a degree of flexibility, and there is still a degree of uncertainty that exists in many cases. The role of quality on Development Work is to make sure that adequate controls exist to support movement into commercialization.

- RESEARCH AND DEVELOPMENT SUPPORT ACTIVITIES: Support activities are those that are conventional and secondary in nature to the advancement of knowledge or development of technology, but allow the primary purpose of the work to be accomplished in a credible manner. An example of a support activity is controlling and maintaining documents and records. The level of quality for these activities is the same as for Development Work.

STMON addresses internal verification and validation activities by conducting an independent technical review of the final data report in accordance with STMON's procedure QA-STMON-0601, 
Document Preparation and Change. This review verifies that the reported results are traceable, that inferences and conclusions are soundly based, and the reported work satisfies the test plan objectives.

\subsection{Building 3410 Filtered Exhaust System Geometry and Flow}

\subsubsection{Physical Arrangements}

Figure 1.1 shows the approximate arrangement of the actual stack for Building $3410 .{ }^{f}$ Each feeder duct, with its exhaust fan and heat recovery coil, is located on the roof of the building. Two existing fans designated as A and B draw air from the heat recovery coil and discharge into a short horizontal duct that connects to another horizontal duct at a $45^{\circ}$ angle. The new fan (C) and duct are also shown. The discharge velocity from the fan is $4101 \mathrm{ft}$./min assuming full airflow. The bottom of the duct is 6' $5^{\prime}$ " above the roof grade. The duct of the new fan merges with the duct of fan B.

The air sampling probe flange is shown located 10 duct diameters downstream from the last duct junction. Two or three duct diameters downstream from this point, the duct turns $90^{\circ}$ upward into a short vertical stack that ends $20 \mathrm{ft}$. above the roofline. The stack used to end in a concentric reducer that increased the discharge velocity; however, it was removed as part of the stack upgrade. A static mixer was installed just downstream of where the discharge from Fan A joins the stack. This was used to increase the mixing of the air from the different ducts. The mixer exacts a small energy and flow rate penalty.

Table 1.1. 3410 Building Stack Operating Parameters.

\begin{tabular}{||l|l|l||}
\hline Operating Parameters & New & Old \\
\hline \hline Duct diameter at sampling probe (in.) & 40 & 40 \\
\hline No. of duct diameters from upstream disturbance to sampling probe & abt. 7 & 10 \\
\hline No. duct diameters from sampling probe to downstream disturbance & 3 & 3 \\
\hline Discharge diameter (in.) & 40 & 32 \\
\hline Single fan capacity $\left(\right.$ actual $\left.\mathrm{ft}^{3} / \mathrm{m}, \mathrm{acfm}\right)$ & 21,200 & 21,200 \\
\hline No. of operating fans & 2 & 1 \\
\hline Total available fans & 3 & 2 \\
\hline Maximum flow rate $(\mathrm{acfm})$ & 42,400 & 19,900 \\
\hline Operating flow rate $(\mathrm{acfm})$ & 31,840 & 17,000 \\
\hline Reynolds number & $1.42 \mathrm{E}+05$ & $6.69 \mathrm{E}+04$ \\
\hline Air temperature at exit $\left({ }^{\circ} \mathrm{F}\right)$ & $40-75$ & $40-75$ \\
\hline \hline
\end{tabular}

According to the supplied documents, the air exhausted from the 3410 Building via this stack is a combination of building ventilation and laboratory exhaust air.

\footnotetext{
${ }^{\mathrm{f}}$ The complete drawings are seen in the Flad Architects Drawing of Mechanical Roof Plan RAD Exhaust Stack for Building 3410 .
} 


\subsubsection{Flow Parameters}

Table 1.1 provides operating information for the new and old configurations of the stack. Table 1.1 shows the range of expected operational flow rates for the 3410 Building stack. This table lists operating parameters such as flow rates (actual cubic feet per minute, e.g., $\mathrm{ft}^{3} / \mathrm{min}$, or acfm) and the resulting Reynolds number. Standard conditions were taken as 1 atmosphere and $70^{\circ} \mathrm{F}$. 


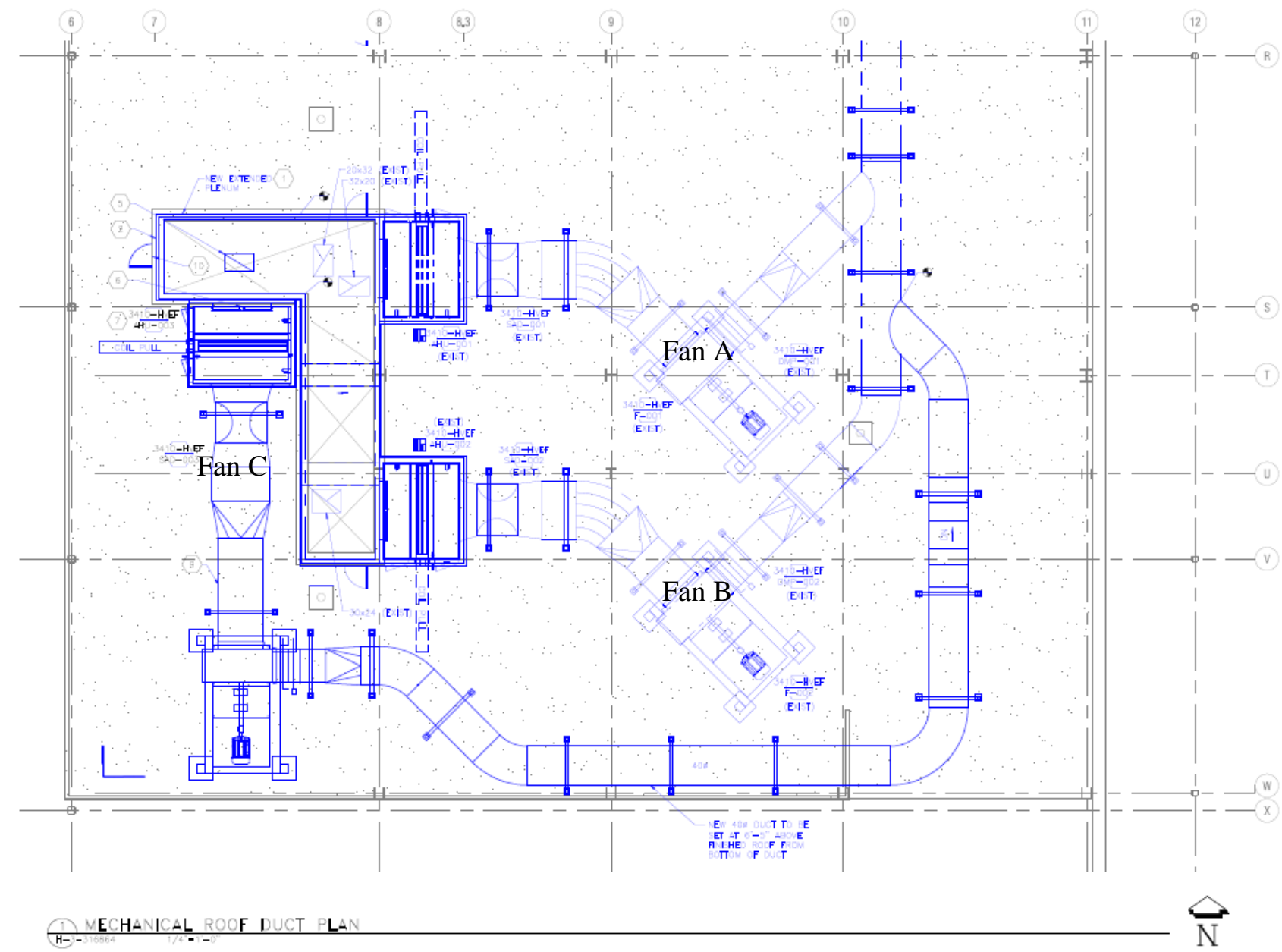

Figure 1.1. The New Stack Layout for Building $3410^{\mathrm{g}}$.

\footnotetext{
${ }^{g}$ The mechanical drawing was prepared by the M/E/P Engineer and FLAD ARCHITECTS.
} 


\subsection{Testing Strategy}

This chapter provides details of the testing strategy including the designed test runs and the testing matrices that were used to guide testing.

\subsection{Test Runs}

The basic series of tests include velocity uniformity test, flow angle test, gas tracer uniformity test, and particle tracer uniformity test. The applicable instructions on tracer injections in the ANSI/HPSN13.1-2011 (Clause 5.3) are as follows:

"The degree of mixing for aerosol particles shall be tested with particles of $10 \mu \mathrm{m} \mathrm{AD}$, or other selected size if there can be a significant fraction of the aerosol mass or activity associated with sizes larger than $10 \mu \mathrm{m} \mathrm{AD.} \mathrm{The} \mathrm{aerosol} \mathrm{may} \mathrm{be} \mathrm{introduced} \mathrm{at} \mathrm{only} \mathrm{one} \mathrm{location,} \mathrm{which} \mathrm{is} \mathrm{at} \mathrm{the} \mathrm{center} \mathrm{of}$ a stack or duct as far upstream as possible of the sampling plane, yet downstream of feeder ducts, fans, and air pollution control equipment. As in the case of a gas, the particles are demonstrated to be well-mixed by sampling over the cross-section at the proposed sampling location."

If "feeder ducts" are defined as upstream of the fans, then the fan injection points are satisfactory. If "feeder ducts" are defined as those coming from the fans before they join the stack, then the last junction nearest the sampling point would be the injection location. In the 3410 Building stack re-testing project, the injection point was located either at the junction of the ducts from the fans or downstream of the backdraft damper of each fan as illustrated in Figure 2.1. Figure 2.2 depicts a real example of the fan and the damper on the roof of the 3410 Building.

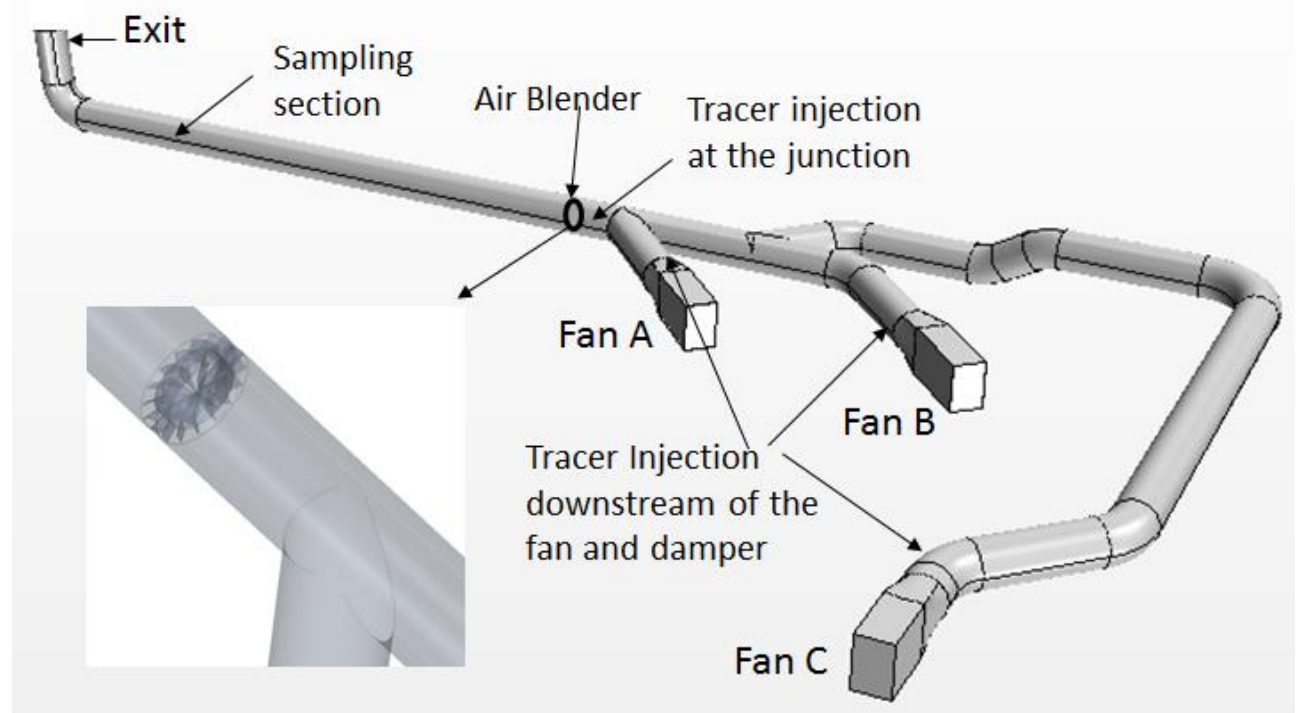

Figure 2.1. The Geometry of the Modified 3410 Building Filtered Exhaust Stack System. Insert shows the details of the air blender. 


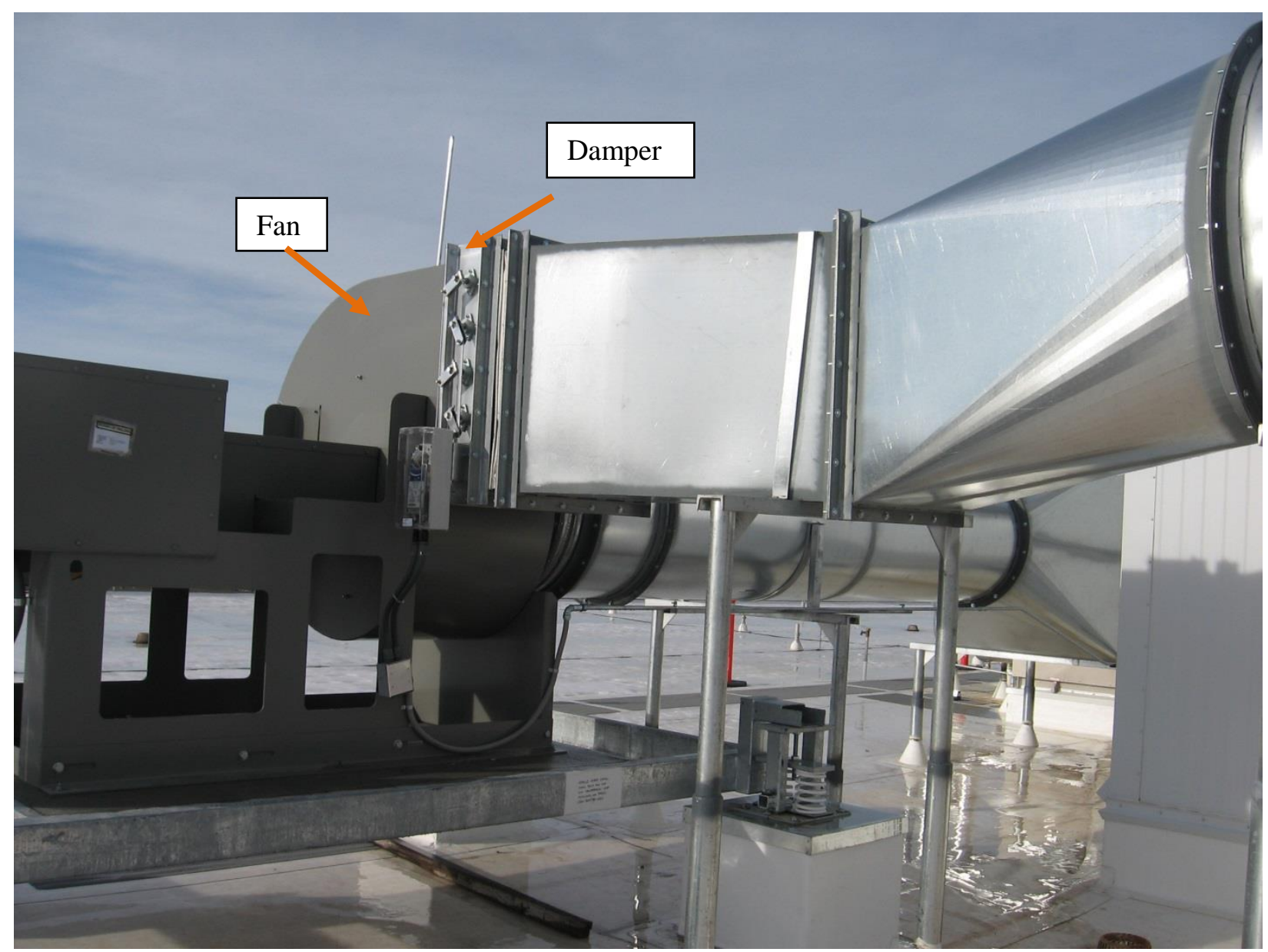

Figure 2.2. A Photo Showing the Fan and the Damper on the Roof of the 3410 Building.

\subsection{Test Matrix}

Table 2.1. Velocity Uniformity and Flow Angle Test Runs Performed Table 2.1 lists the test runs performed by test type. Some tests were replicated to provide an indication of the variability of the results when needed.

Table 2.1. Velocity Uniformity and Flow Angle Test Runs Performed

\begin{tabular}{|c|c|c|c|c|}
\hline \multicolumn{3}{|c|}{ Test Configuration } & \multicolumn{2}{c|}{ Number of Test Runs } \\
\hline Fan Pairs & Flow Conditions $^{\#}$ & No. & Flow Angle & Velocity \\
\hline Fan A \& B & normal & 1 & 3 & 3 \\
\hline Fan A \& C & normal & 2 & 3 & 3 \\
\hline Fan B \& C & normal & 3 & 3 & 3 \\
\hline Fan A \& C & sashes open & 4 & 3 & 3 \\
\hline \multicolumn{3}{|c|}{ Total } & 12 & 12 \\
\hline \multicolumn{2}{|c|}{ Grand Total } \\
\hline
\end{tabular}

\#: Normal refers to the planned typical operational flow condition, although some gas tracer repeat runs were performed with sashes open to provide higher flow conditions. 
The tracer injection ports were installed just downstream of the fans and dampers, referred to as "Fan" in the test matrix. Another injection port was installed just after the junction of ducts from fans closest to the sampling probe, also referred to as "Junction" (see Figure 2.1).

Table 2.2. Gas and Particle Tracer Test Runs Performed.

\begin{tabular}{|l|l|l|l|l|c|c|}
\hline \multicolumn{5}{|c|}{ Test Configuration } & \multicolumn{2}{c|}{ Number of Test Runs } \\
\hline Fan Pairs & $\begin{array}{l}\text { Flow } \\
\text { Conditions }\end{array}$ & No. & $\begin{array}{l}\text { Injection } \\
\text { Port }\end{array}$ & $\begin{array}{l}\text { Injection } \\
\text { Position }\end{array}$ & $\begin{array}{l}\text { Gas } \\
\text { Tracer }\end{array}$ & Particle \\
\hline Fans A \& B & normal & 1 & Junction & Center* & 6 & 1 \\
\hline & normal & 2 & Fan A & Center* & 5 & 1 \\
\hline & normal & 3 & Fan B & Center & 1 & 1 \\
\hline Fans B \& C & normal & 6 & Junction & Center & 1 & 1 \\
\hline & normal & 7 & Fan B & Center* & 5 & 1 \\
\hline Fans A \& C & normal & 8 & Fan C & Center* & 5 & 1 \\
\hline & normal & 11 & Junction & Center* & 5 & 1 \\
\hline & normal & 12 & Fan A & Center & 1 & 1 \\
\hline Worst Case Fan Pair & normal & 13 & Fan C & Center* & 6 & 1 \\
\hline Worst Case Fan Pair & normal & 16 & Junction & Center* & 5 & 1 \\
\hline \multicolumn{7}{|l}{ Total } \\
\hline
\end{tabular}

\#: Normal refers to the planned typical operational flow condition, although some gas tracer repeat runs were performed with sashes open to provide higher flow conditions.

${ }^{\dagger}$ : The injection port is either downstream of the damper of each fan or at the junction location shown in Figure 2.1.

${ }^{*}:$ These tests involve injecting the tracer gas at the four perimeter points and center of the cross-section at the injection location.

\subsection{Stack Measurements}

Before conducting the qualification tests the major features of the stack were measured. The longitudinal distance from the fans to the bends, duct reducers, and ports was determined in addition to the duct diameter at each measurement port. Measurements were made at specific locations within the duct for each of the four qualification criteria tests described in the following sub-sections. The number and distance between measurement points were based on the U.S. Environmental Protection Agency (EPA) procedure 40 CFR 60, Appendix A, Method 1, for circular stacks. For a 40-inch duct diameter, eight traverse points are required and they must be at the relative positions shown in Figure 2.3.

Measurements were made at the center point. The minimum distance from the wall to a measurement point was 0.5 inch. The measurement point closest to the port is Point 1 , while the point farthest from the port is Point 8 . For each of the tests, measurements were taken at each point along the top traverse and the side traverse. Each traverse point was repeated three times to obtain measurement precision.

The fans would be used in combinations of two, namely, fans A \& B, fans A \& C, and fans B \& C. In the interest of time, most tests were conducted using the center point injection position and at the normal operation flow conditions. Tracers were injected at the junction and downstream of each fan. The junction position was chosen because earlier computational fluid dynamics (CFD) simulations suggest 
that tracer injection at the junction point seemed to provide less ideal results unless a static mixer was installed at that point. ${ }^{\mathrm{h}}$

For the worst case scenarios of the gas tracer tests including both injections at the Junction and the Fans, a more detailed study was conducted that required at least five test runs - each run with the tracer injected at one of the five required injection points in the selected cross-section of the duct. The five injection points were at the centerline and at four perimeter points. For round ducts, the four perimeter points were equally spaced around and near the perimeter. Some test runs were replicated to determine measurement reproducibility. As to the particle uniformity tests, the test matrix was similar to that of the gas tracer tests. The only difference is that only a single injection point at the center of the stack was used for each injection location.

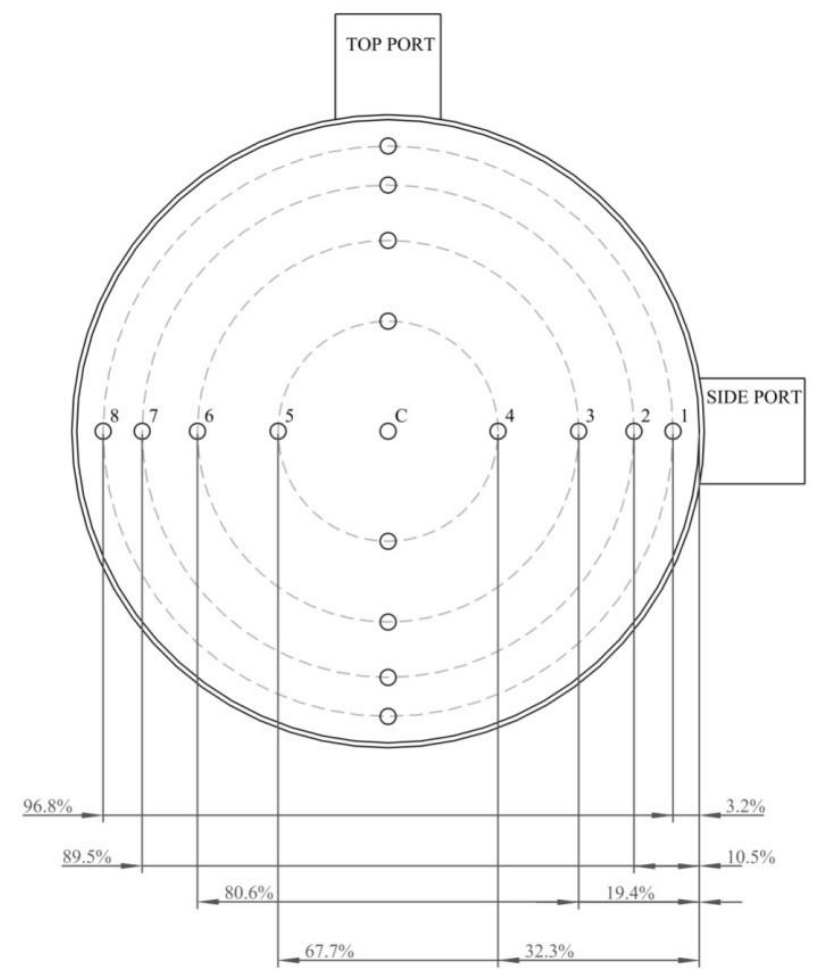

Figure 2.3. Cross-Section of the Duct at the Testing Ports with Measurement Points.

\footnotetext{
${ }^{\mathrm{h}}$ Modeling the air flow in the 3410 Building filtered exhaust stack system with three-dimensional computational fluid dynamics models, Kurt Recknagle and Sarah Suffield, Project Report, November, 2012
} 


\subsection{Testing Methods}

\subsection{Testing Platforms and Test Ports}

Because of the challenge to conduct the particle tracer and gas tracer uniformity tests at the full scale stack, a temporary platform was constructed to permit physical access to the top sampling port safely. Figure 3.1 and Figure 3.2 show the layout of the 3410 duct at the location of the air sampling probe and test ports used in this testing.

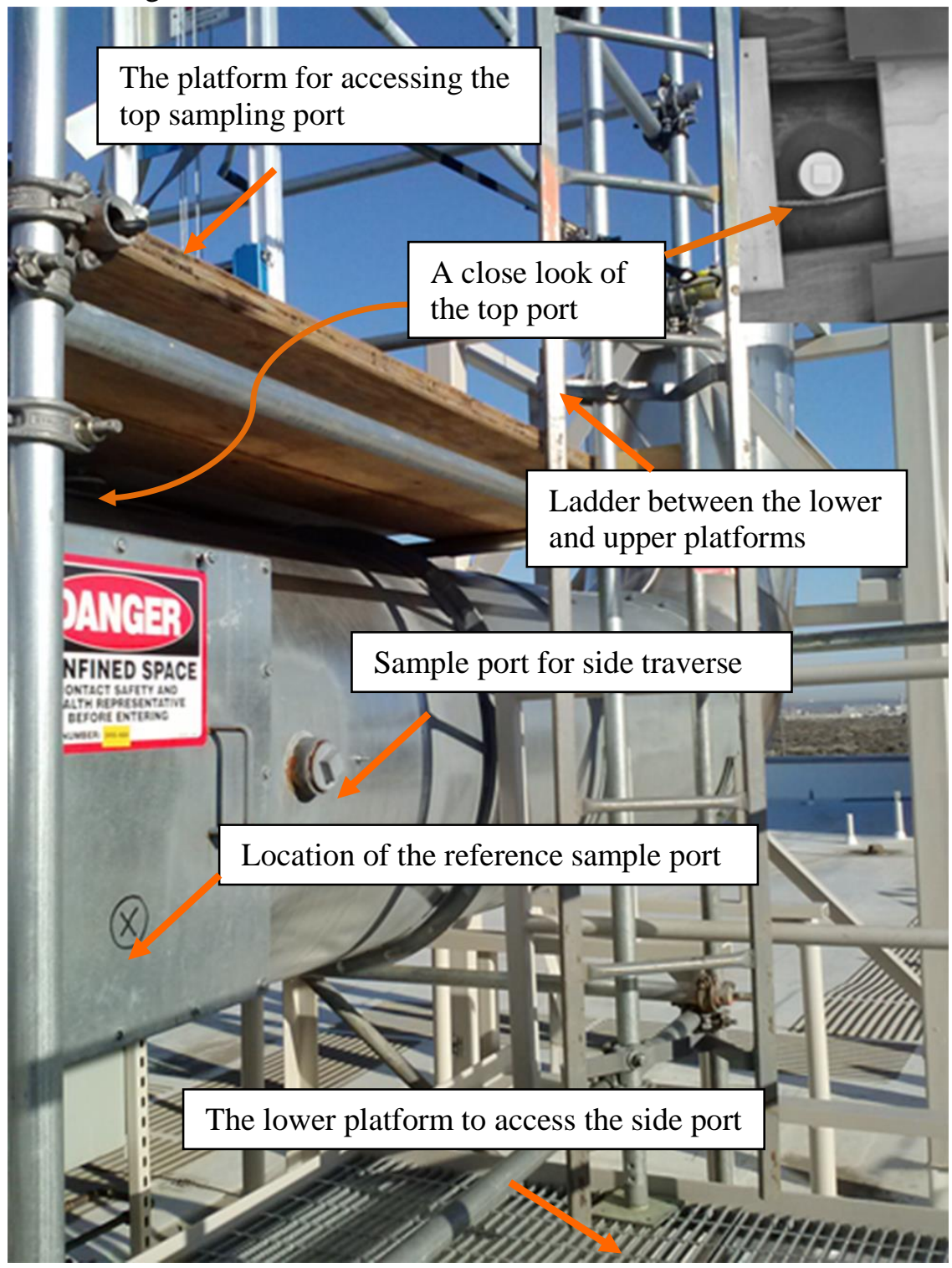

Figure 3.1. Layout of Testing Platforms for the 3410 Stack Testing.

The existing lower level platform was used to provide direct access to the side port as depicted in Figure 3.1. 


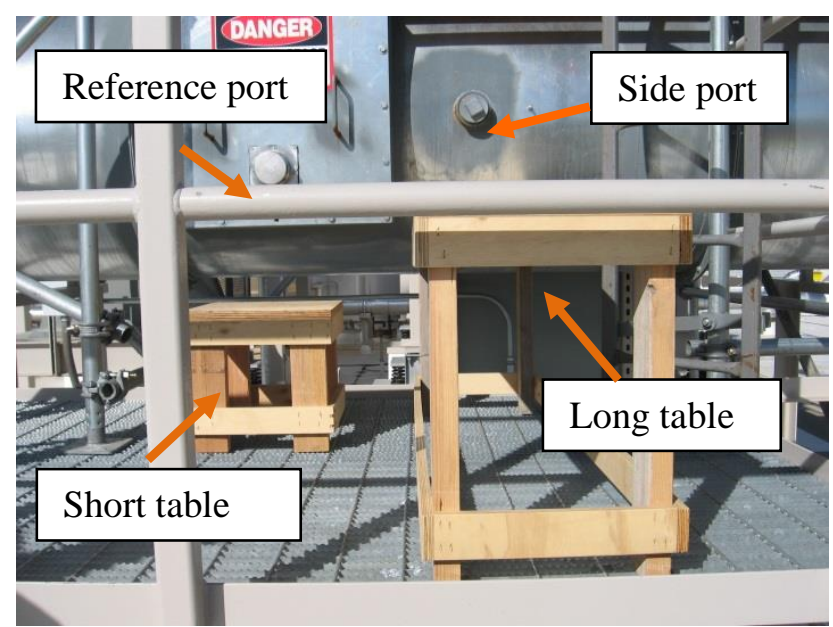

Figure 3.2. a) Layout of the Side Test Ports.

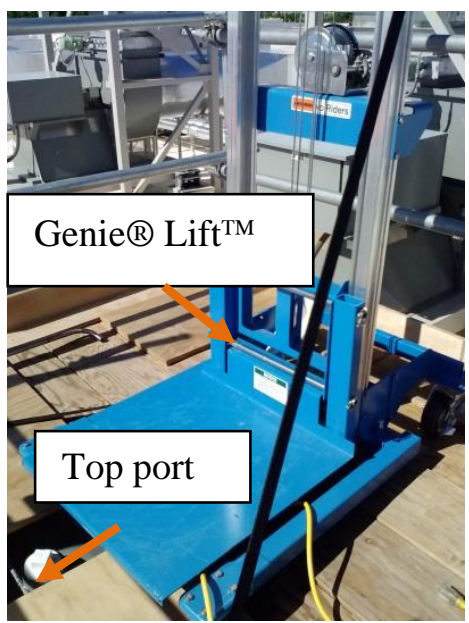

b) Layout of the Top Test Port.

Compared to the top port, the access to the side port is simpler. However, unlike the velocity, flow angle, or gas tracer uniformity tests, the particle tracer uniformity tests demand stricter geometry between the sample port, probe and the particle counting instrument due to the following, 1) generally, the sample probe needs to travel throughout the whole diameter (e.g., 40 in) freely; 2) the sampling probe needs to enter the optical particle counter (OPC) inlet either directly or via a $90^{\circ}$ bend to reduce particle loss; and 3 ) the OPC needs to sit stably on a flat surface during measurements.

Figure 3.2 provides a closer look of the side test port and top test port and how these geometry requirements were met. Two benches were made for placing the OPC instruments during testing. The longer table was made to accommodate the full length of the side traverse of the stack for the sampling OPC to slide by. A short table was placed below the reference port, located slightly below the centerline of the stack. This was used to insert a short sampling probe to provide reference particle counts monitored by a second OPC. The reference sample port was designed not to obstruct the flow in the stack yet provide a constant reference measurement point during the particle tracer testing (see Figure 3.2a). To accommodate the geometry at the top port, a Genie ${ }^{\circledR}$ Lift $^{\mathrm{TM}}$ with sufficient height extension was stabilized on the scaffolding platform. The sample OPC was placed on the extension arms of the Genie ${ }^{\circledR}$ Lift $^{\mathrm{TM}}$ during measurements. Each traverse point from the top sampling port was obtained by cranking the Genie ${ }^{\circledR}$ Lift ${ }^{\mathrm{TM}}$ up and down across the stack duck diameter (see Figure 3.2b).

The velocity, flow angle, and gas tracer uniformity testing are relatively simpler for the experiment setup compared to the particle uniformity tests. Among those tests, only the side and top sampling ports were used. In addition, because some flexible tubes were used to make connections between the testing apparatus and the sampling port, the placement of the instrument was not as confined as that in the particle tracer testing. More details for each test are provided below.

\subsection{Velocity Uniformity}

The uniformity of air velocity at the stack monitoring location indicates whether the momentum in the stack is well-mixed. The method used to conduct the velocity uniformity tests was based on 40 CFR 60, Appendix A, Method 1. The criterion for qualification from the velocity uniformity test is that the 
$\%$ COV should be less than $20 \%$ in the center two-thirds of the duct (measurement points 2-7, see Figure 2.3).

For each run, three air velocity readings were obtained at each of the measurement points across the cross-section of the duct. The measured velocity is the average of the three readings. The measured velocity for each point is used to determine the mean and standard deviation of the velocity across the cross-sectional plane. The \% COV (also known as the percent relative standard deviation) is calculated as 100 times the standard deviation divided by the mean.

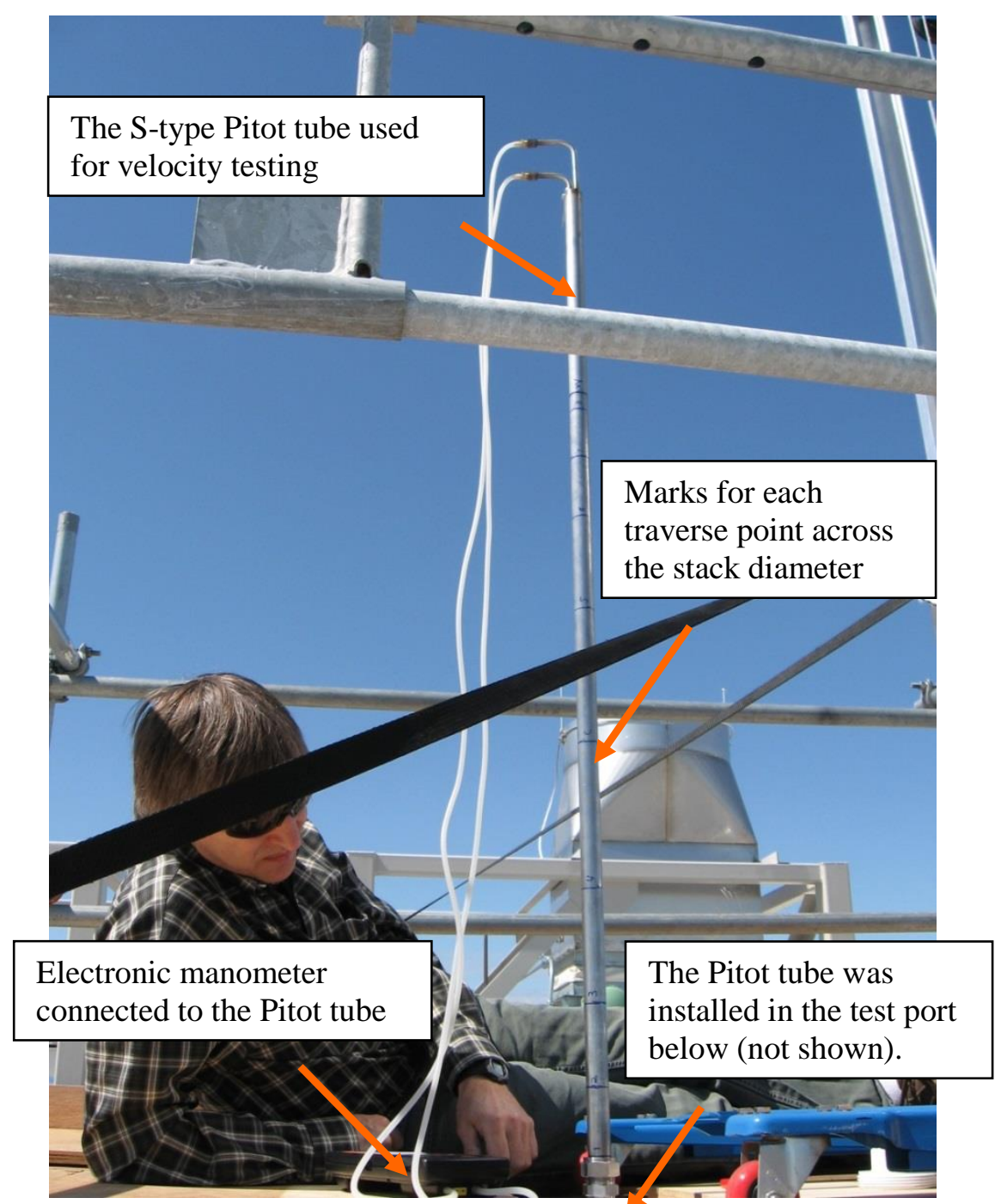

Figure 3.3. The S-Type Pitot Tube and Manometer used on the 3410 Stack for the Top Traverse Velocity Measurements.

Each air velocity measurement was made using an S-type Pitot tube connected to a calibrated electronic manometer (GrayWolf, Zephyr II+, Shelton, CT) by flexible tubing. Duct air temperature measurements were made with a handheld thermal anemometer (TSI, Model 8360, Shoreview, MN). Figure 3.3 shows the equipment and setup used for velocity uniformity testing. In this test, the S-type Pitot tube was positioned so that the planes of the two openings at the tip were parallel with the axis of the duct. Although the principle of operation differs between the Pitot tube and thermal anemometers, they 
were used with up-to-date calibrations and no instrument-related biases were encountered in the analysis of testing results. The PNNL operating procedure EMS-JAG-04 and the test instruction TI-STMON-027 were followed to conduct the full scale test in the 3410 Building. The velocity readings obtained from the S-type Pitot tube were corrected according to manufacturer recommendations before they were reduced as final results in this report.

\subsection{Flow Angle Test}

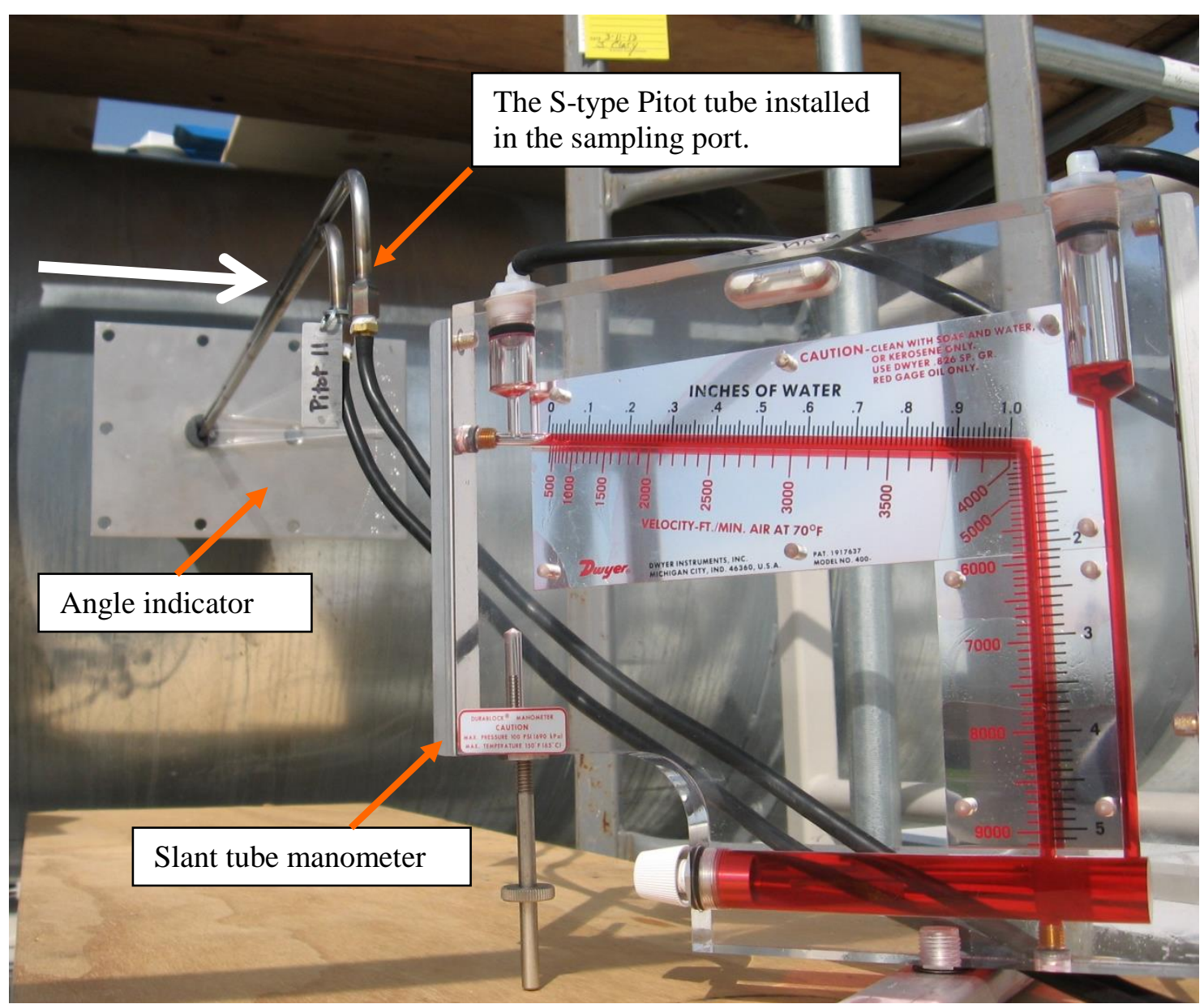

Figure 3.4. Flow Angle Indicator, Dwyer Manometer, and the S-Type Pitot Tube Installed on 3410 Stack for the Side Traverse Measurements. The test port is behind the angle indicator and invisible from the angle that the photo was taken. The white arrow indicates flow direction inside the stack.

The air velocity vector approaching the sample nozzle should be aligned with the axis of the nozzle within an acceptable deviation angle so that the sample extraction performance is not degraded. The test method to determine the air velocity vector is based on 40 CFR 60, Appendix A, Method 1, Section 11.4, "Verification of the Absence of Cyclonic Flow." The term "flow angle" refers to the average angle between the velocity vector of the flow in the duct and the axis of the sampling nozzle. For the stack testing activities, the flow angle was measured at an array of 17 points in a cross pattern in the crosssection of the duct as illustrated in Figure 2.3. (The layout of points was the same as used for all of the velocity and tracer measurement.) The criterion for acceptance from the flow angle test is that the average angle must be $<20^{\circ}$. 
The flow angle measurements were made using an S-type Pitot tube (Dwyer Instruments, 160S-72, Michigan City, IN) attached by flexible tubing to a slant-tube manometer (Dwyer Instruments, 400-5, Michigan City, IN) and a custom-made angle-indicating device attached to the sampling port as shown in Figure 3.4. For this test, the S-type Pitot tube was rotated so that the planes of the two openings at the tip of the tube were parallel to the flow in the duct. The Pitot tube was considered perpendicular to the flow in this position. The large metal plate in Figure 3.4 is the angle-indicating device. It has markings at every degree from -30 degrees to 30 degrees. When the pressures on both tubes of the S-type Pitot tube were equal (as indicated by the manometer), the angle shown on the angle-indicating device was recorded as the reading. The manometer was placed on a stable surface to reduce interferences such as vibrations from the fans during testing. The PNNL operating procedure EMS-JAG-05 and the Test Instruction TISTMON-028 were used to conduct this test.

\subsection{Gaseous Tracer Uniformity}

The gas tracer uniformity was demonstrated using the tracer gas nitrous oxide $\left(\mathrm{N}_{2} \mathrm{O}\right)$. A compressed gas cylinder and a flow controller were used to deliver a constant stream of $\mathrm{N}_{2} \mathrm{O}$ into the duct. Since $\mathrm{N}_{2} \mathrm{O}$ is a component of the earth's atmosphere, its background concentration potentially could make data interpretation difficult. This could be a significant interference, if the injected tracer amount was not enough. The injection volume was chosen to be at least 50 times of the ambient concentration of the $\mathrm{N}_{2} \mathrm{O}$ for each test. Pure $\mathrm{N}_{2} \mathrm{O}(99.5 \%)$ were used for tracer gas injection as depicted in Figure 3.5.

Prior to each gas tracer run, the system background was collected and recorded to ensure that there was no interference in the gas tracer measurements. The $\mathrm{N}_{2} \mathrm{O}$ ambient background concentration was in the range of $250-400 \mathrm{ppb}$ for all test runs. A mass flow controller (ALICAT, MC-20SLPM-D, Tucson, AZ) of up to $20 \mathrm{lpm}$ capacity was used for $\mathrm{N}_{2} \mathrm{O}$ injection upstream of the injection port. In order to keep the $\mathrm{N}_{2} \mathrm{O}$ delivered at a controlled relative humidity of about $4 \%$ and prevent freezing or malfunctioning of cylinder regulators, an electric heater for specialty gases including $\mathrm{N}_{2} \mathrm{O}$ and $\mathrm{CO}_{2}$ (Scott Specialty Gases, Electric Heater, Model 86, Longmont, CO) was used adjacent to the regulator on the compressed air cylinder.

The gaseous tracer was typically injected into the duct at a point just downstream of the fans. Figure 3.5 shows the injection locations with an injection probe positioned in the port. 


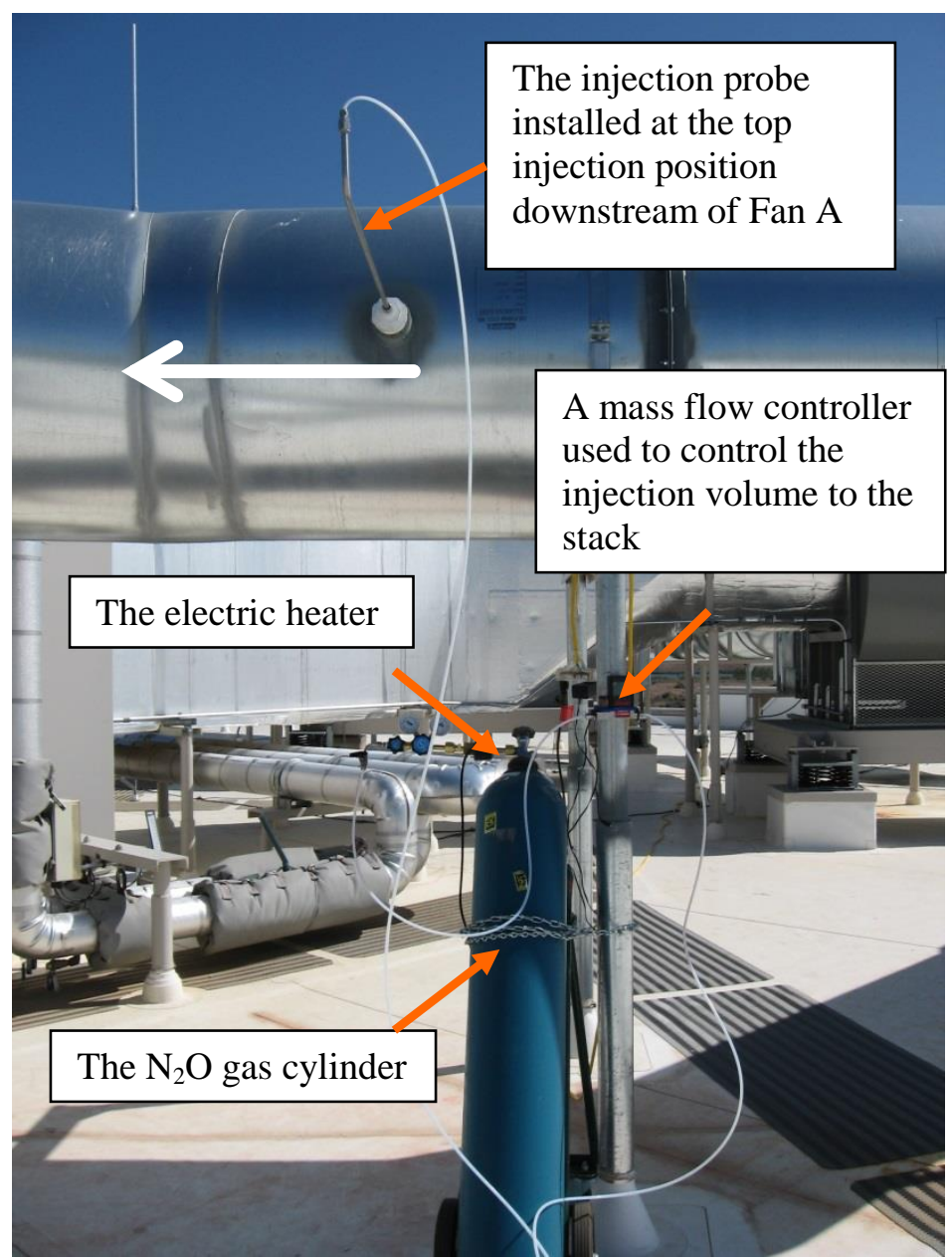

Figure 3.5. Photo Showing Tracer Injection Port Location on the Stack Downstream of Fan A. The injection port was 3" in diameter. An injection port was added to each fan. The white arrow indicates the direction of air flow in the duct.

For test runs at a specific injection port, the injection probe is usually positioned at five different locations through the port including the centerline and four positions near the corners if the duct is rectangular, or near the wall if the duct is circular as depicted in Figure 3.6. For the 3410 circular stack, injections were performed at the center and four corners. A "wall" location is within $25 \%$ of a hydraulic diameter of the wall. For a 40-inch round duct, that means within 8-inches of the wall. Figure 3.6 shows the pattern of injection points. It also shows the calculation for the principal duct sizes as in the 3410 stack. For practical purposes, injection occurred at about 1-inch of the wall. An L-shaped probe was used for gas tracer injection. For the run depicted in Figure 3.5, the injection position was near the top of the duct.

A simple probe was used to extract the sample and deliver it to the gas analyzer. A small pump drew air from within the stack through the probe. The gas analyzers then sampled the air from the sample line for analysis. A photoacoustic gas analyzer (Brüel \& Kjær, Model 1302, Ballerup, Denmark) was used to measure tracer gas concentrations at each point for the side and top traverses. Figure 3.7 and Figure 3.8 provide additional setup details for the side and top traverse, respectively, in gas tracer uniformity testing. 


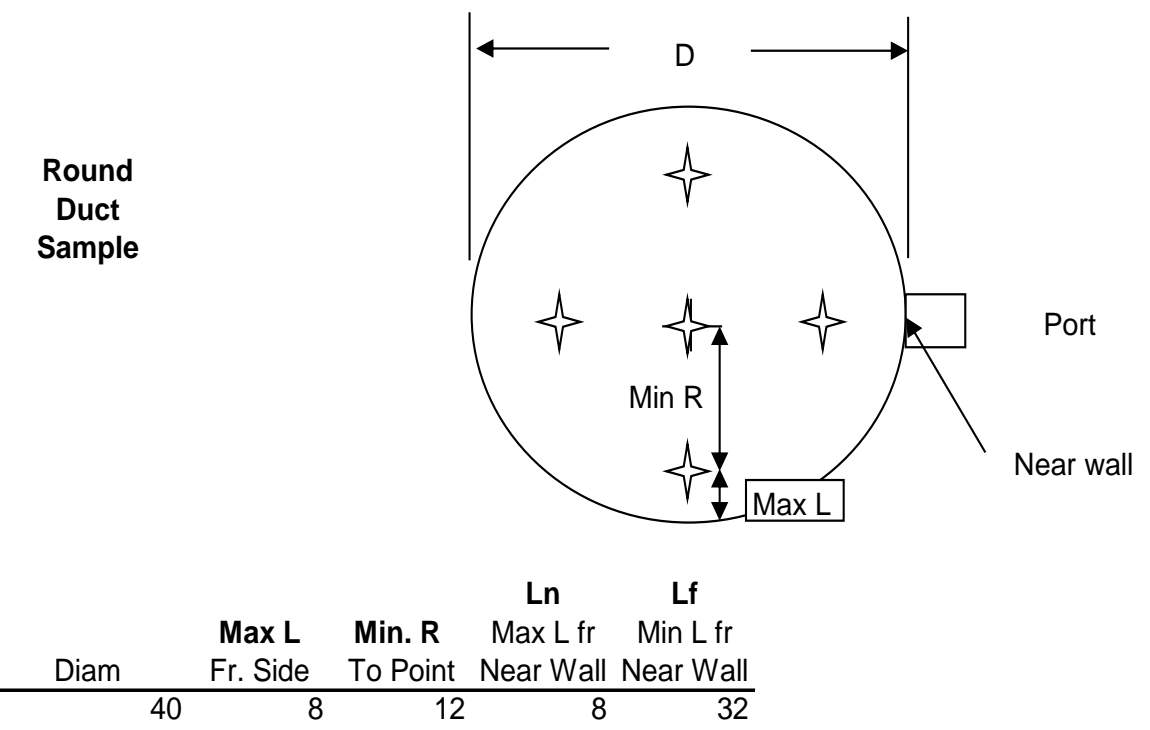

Figure 3.6. Pattern and Dimensions for Wall Injection Points During Gas Tracer Testing.

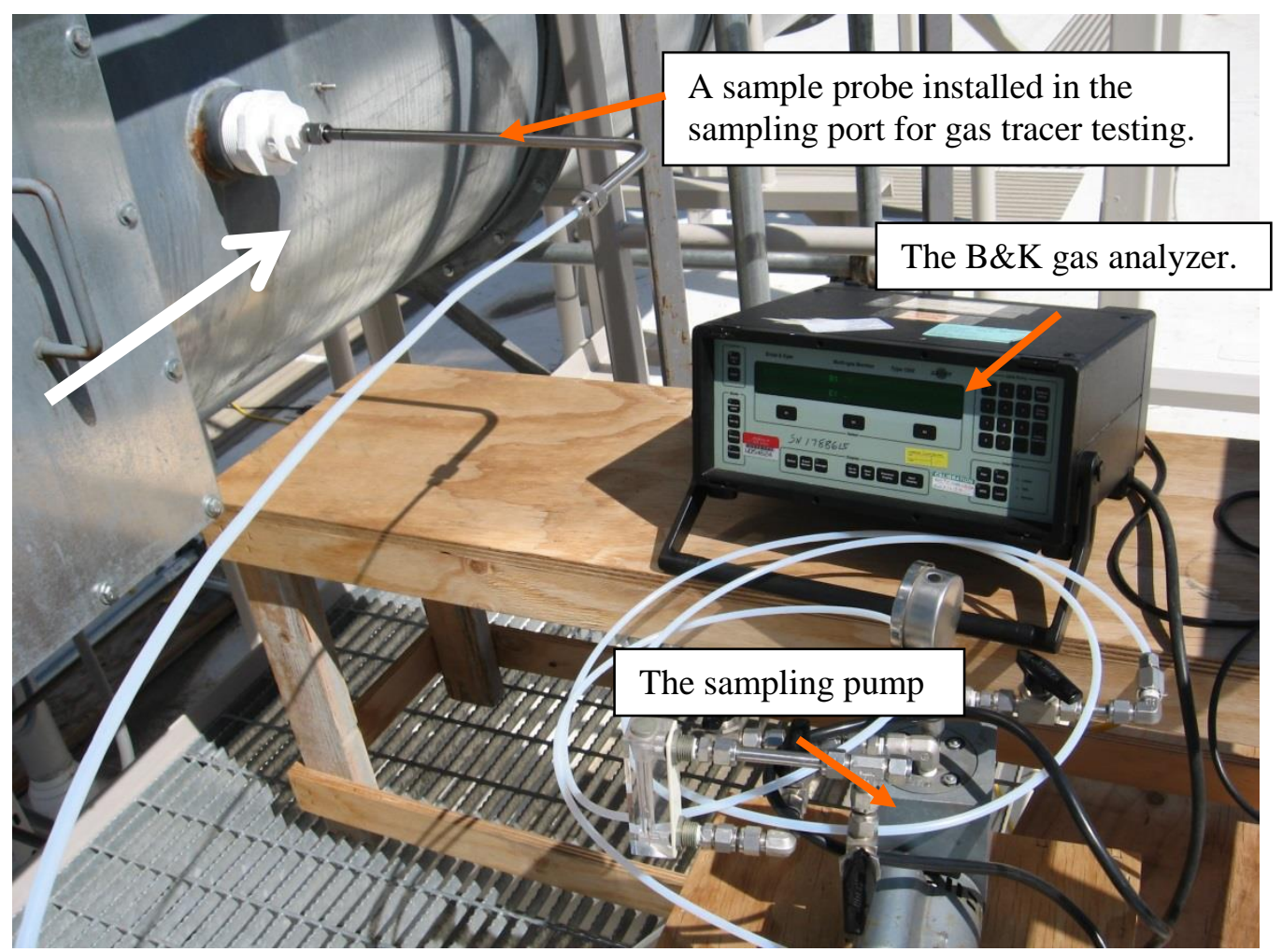

Figure 3.7. Equipment and Setup for the Gaseous Tracer Injection in the 3410 Building Stack Testing for the Side Traverse. The white arrow indicates the flow direction inside the stack. 


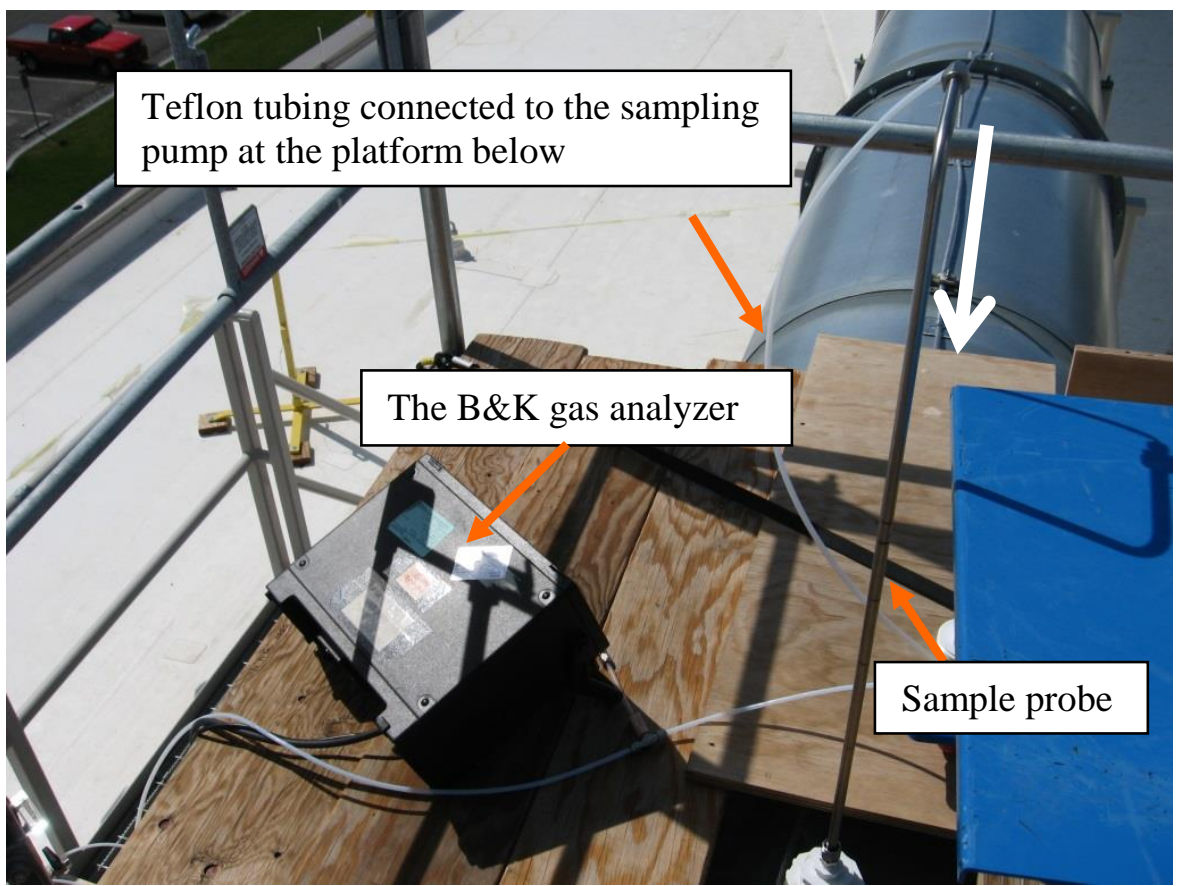

Figure 3.8. Equipment and Setup for the Gaseous Tracer Injection in the 3410 Building Stack Testing for the Top Traverse. The white arrow indicates the flow direction inside the stack.

For each test run, the tracer concentration was measured three times at each of the traverse points across the duct. The measured concentration for each point was the average of the three readings. These measured concentrations were used to calculate the overall mean, standard deviation, and \%COV. These calculations were also performed just for the measurement points in the center two-thirds of the duct. The criteria for qualification for the gaseous tracer test are that 1) the \%COV should be $\leq 20 \%$ within the center two-thirds of the duct, and 2) the concentration at any measurement point should not deviate from the overall mean by more than $30 \%$.

The concentration variation was the important result for this test, so calibration bias was not important in the test results. However, the analyzer response was checked with calibration standards before and after conducting the test series (as well as weekly during the test series) to verify that the instrument provided an adequate instrument response. For $\mathrm{N}_{2} \mathrm{O}$ calibration, $2 \mathrm{ppm}$ and $60 \mathrm{ppm}$ certified master class standard gases balanced with air (Air Liquide America Specialty Gases LLC, Longmont, $\mathrm{CO}$ ) were used. When conducting weekly $\mathrm{N}_{2} \mathrm{O}$ calibrations, a Nafion ${ }^{\circledR}$ dryer/humidifier (Perma Pure LLC, Model PD-50T-12MPP, Toms River, NJ) was used to ensure consistent humidity of the $\mathrm{N}_{2} \mathrm{O}$ entering the gas analyzer. The instrument response was considered acceptable if the concentration from the instrument was within $10 \%$ of the calibration standard.

In addition, the PNNL operating procedure EMS-JAG-01 and the Test Instruction TI-STMON-030 were used to conduct this test.

\subsection{Particle Tracer Uniformity}

The uniformity of the particulate contaminant concentration was demonstrated using $10-\mu \mathrm{m}$ AD polydisperse oil particles as a particle tracer. Vacuum pump oil was drawn into a spray nozzle (driven by compressed air) housed in a stainless steel chamber depicted in Figure 3.9. 
These aerosol particles were injected into the duct air at an injection point downstream of each fan as well as at the junction. For particle tracer testing, injections were only introduced at the center of the duct. The stainless steel metal chamber and spray nozzle assembly was referred to as the aerosol generator. The aerosol generators were grounded to ensure that static electricity would not cause any potential safety concerns. Two aerosol generators were deployed for the full scale testing. The output of each aerosol generator was merged using a stainless steel Tee to obtain sufficient particle tracer injection into the stack. The particle injection output of the aerosol generator was roughly controlled by tuning the output pressure on the pancake regulator. In order to avoid overwhelming the optics in the OPC, the sampling particle number concentration of the $10 \mu \mathrm{m}$ particles were controlled to be in the range of 1500 -2000 particles $/ \mathrm{ft}^{3}$. Prior to each particle tracer run, the system background was collected and recorded to ensure that there was no interference in the particle tracer measurements. The stack background particle number concentration was smaller than 20 particles $/ \mathrm{ft}^{3}$ for all test runs.

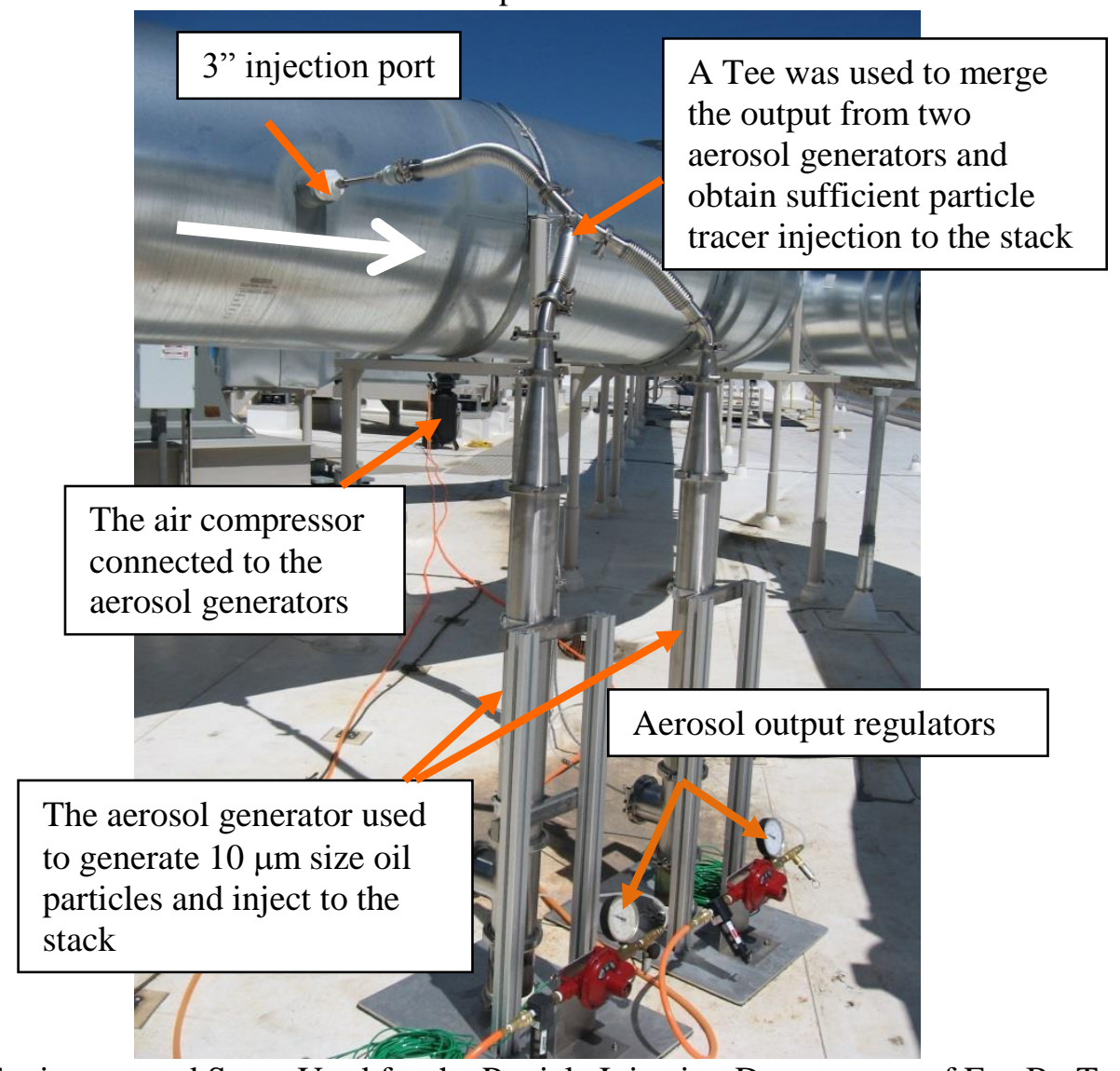

Figure 3.9. Equipment and Setup Used for the Particle Injection Downstream of Fan B. Two aerosol generators were used and their output was merged to increase the particle injection and obtain reasonable measurement sensitivity at the sampling port. 


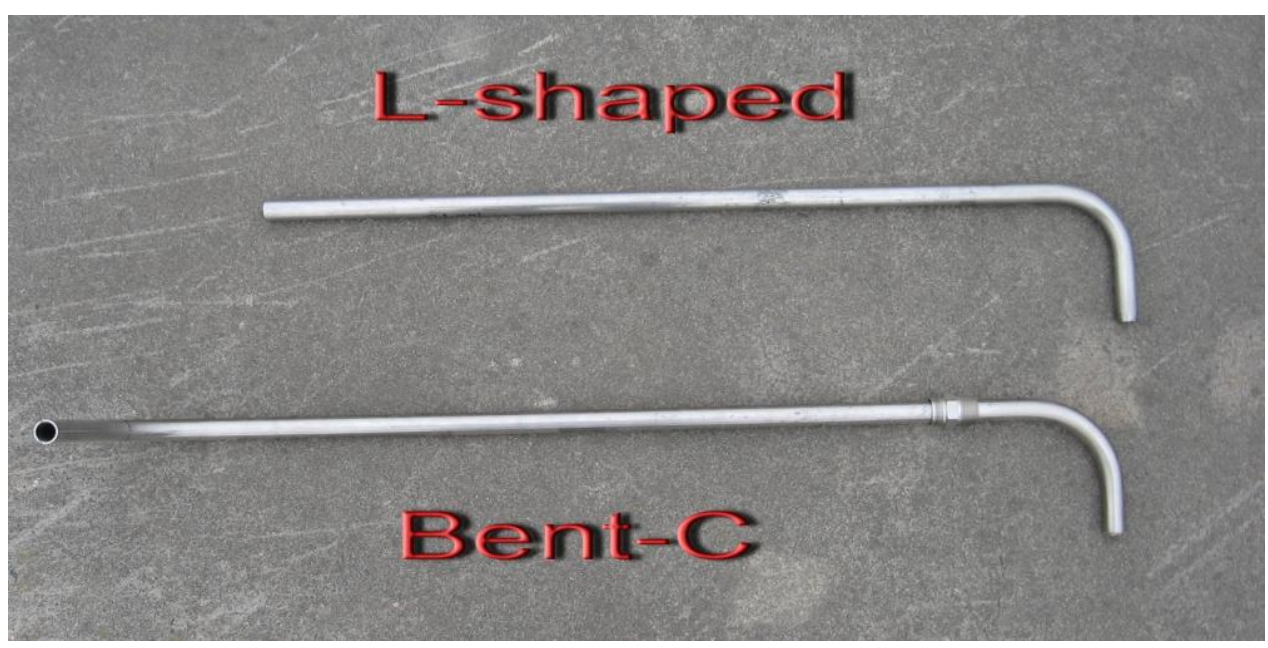

Figure 3.10. Probes Used for the Particle Sampling.

The concentration of the particles was measured at the sampling grid points with a calibrated OPC (Met-One Model 3415, Hach Instruments, Loveland, CO). A simple probe was used to extract the sample and deliver it to the OPC. Figure 3.10 shows the two types of sampling probes used for particle sampling in the 3410 stack testing. The OPC sorts the particles into six size channels. As mentioned in Section 1.1, the particles of interest have an $\mathrm{AD}$ of $10 \mu \mathrm{m}$. Therefore, only data in the 9- to $11-\mu \mathrm{m}$ channel of the OPC were used.

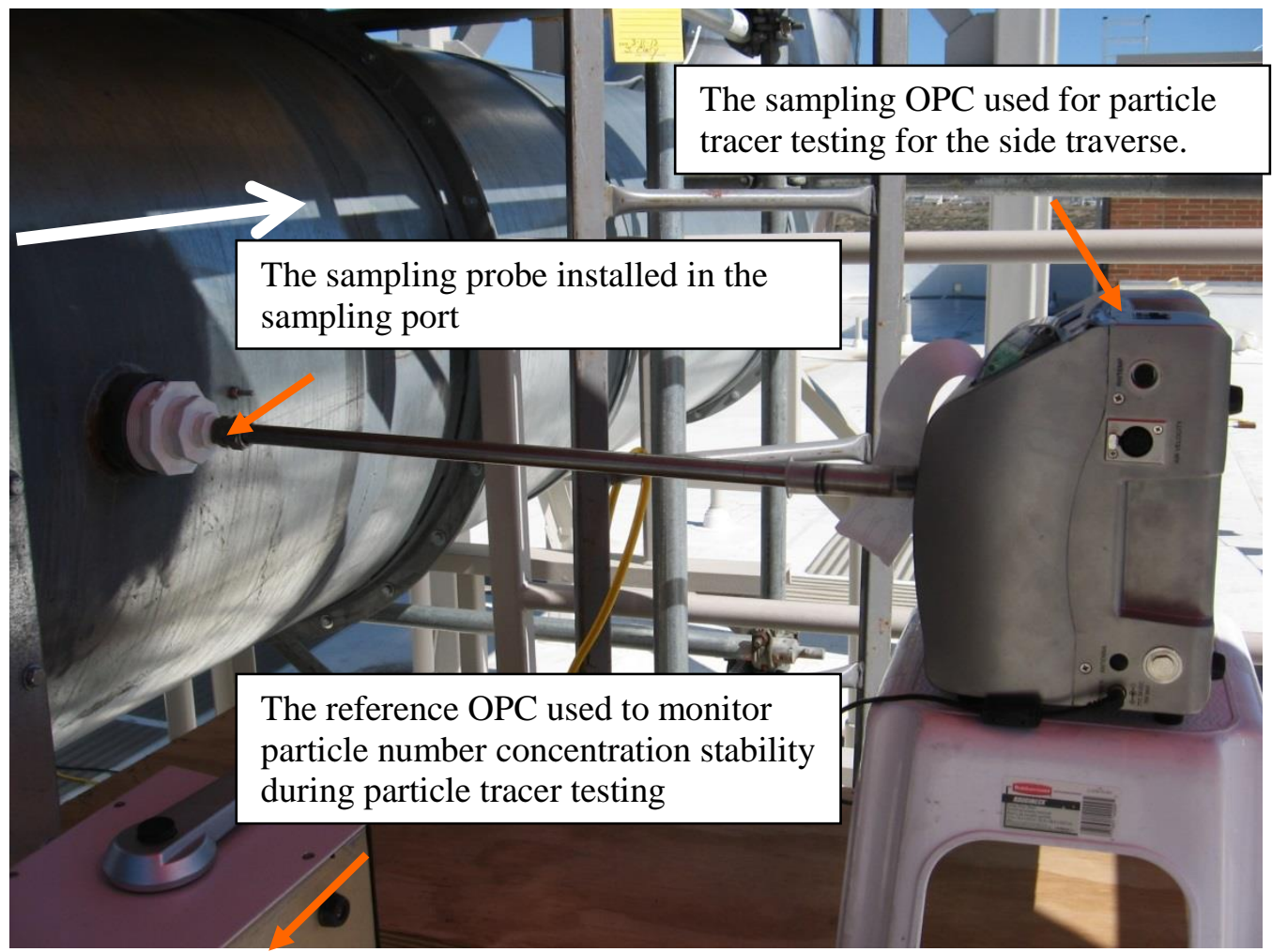

Figure 3.11. Equipment and Setup Used for the Particle Tracer Testing for the Side Traverse. The white arrow indicates the flow direction inside the stack. 


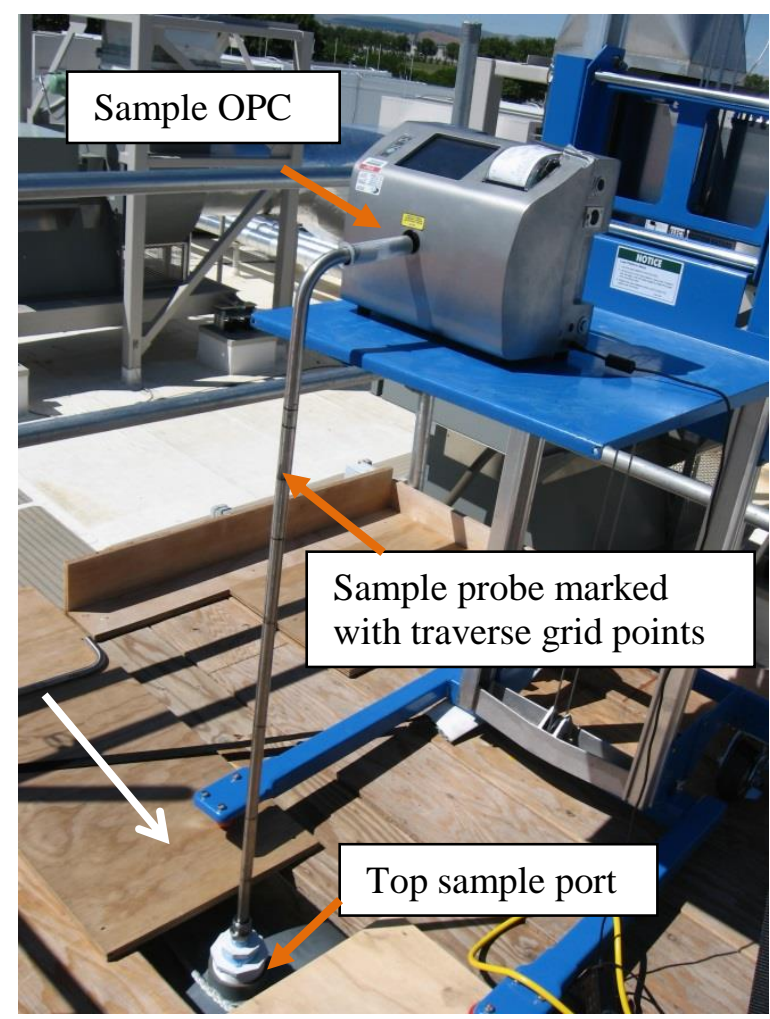

Figure 3.12. Equipment and Setup Used for the Particle Tracer Testing for the Top Traverse. The white arrow indicates the flow direction inside the stack.

Figure 3.11 and Figure 3.12 depict the sampling setup with the simple probe connected to the OPC for side and top traverse measurements, respectively. The particle counter was in its "vertical" position for the side traverse and it was in the "horizontal" position for the top traverse measurements.

A second OPC was simultaneously used to sample from the reference port at a fixed location to monitor the consistency of the aerosol input. This reference port was placed on the access cover near the sampling probe (Figure 3.13).

The particle concentration was read three times at each of the measurement points across the crosssection of the duct. The measured concentration for each point was the average of the three readings. From these measurements, the overall mean standard deviation, and \% COV was calculated for all of the points. The same statistics were also calculated for those points within the center two-thirds of the duct. The qualification criterion for the particle tracer test is that the \% COV should be less than or equal to $20 \%$ within the center two-thirds of the duct. The PNNL operating procedure EMS-JAG-02 and the Test Instruction TI-STMON-029 were used to conduct this test. 


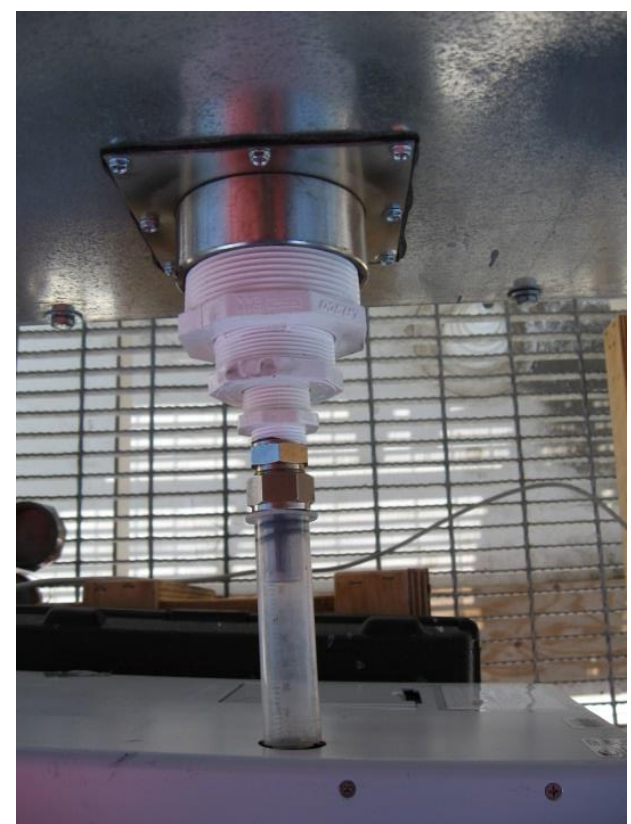

Figure 3.13. a) The sampling port for the reference OPC and connection to the OPC.

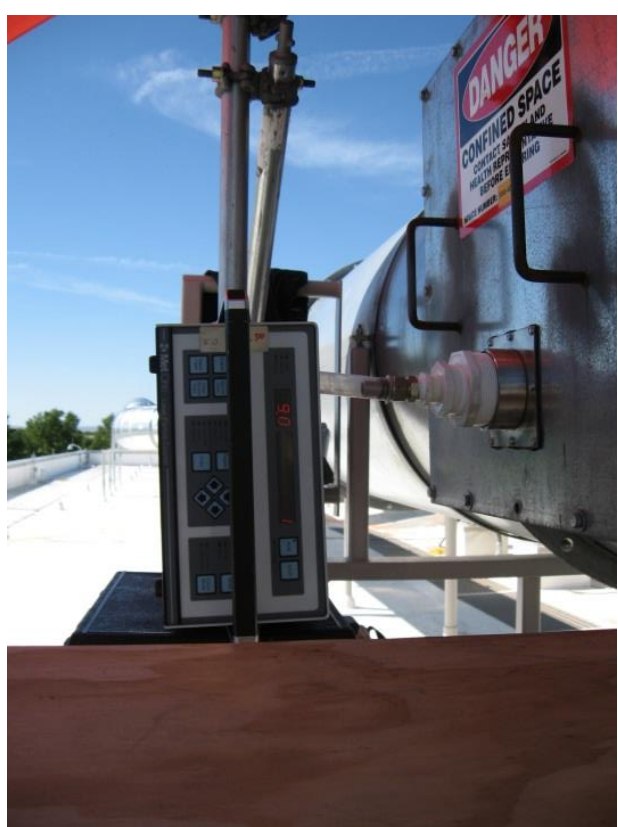

b) The reference OPC during testing. 


\subsection{Stack Testing Results}

The duct diameters were measured at the test ports. They were confirmed to be 39.75 in and listed in Table 4.1. The distance from the test ports to the nearest upstream disturbance (the junction of the ducts from the three fans) was $53.5 \mathrm{ft}$. These test ports were located 16 duct diameters ${ }^{\mathrm{i}}$ downstream of the duct junction.

Table 4.1. 3410 Duct Depth Measurements.

\begin{tabular}{||c|c||}
\hline $\begin{array}{c}\text { Direction across } \\
\text { duct }\end{array}$ & $\begin{array}{c}\text { Measured Duct } \\
\text { Diameter, in. }\end{array}$ \\
\hline Vertical & 39.75 \\
\hline Horizontal & 39.75 \\
\hline
\end{tabular}

\subsection{Velocity Uniformity}

Table 4.2 lists the results for the velocity uniformity tests performed on the 3410 Building exhaust duct. The conditions for the velocity uniformity test runs (VT) included a typical normal flow condition with all fume hood sashes closed and a possible higher flow condition with all new fume hood sashes open. The flow rate measured with the Zephyr II+ provided results in actual cubic feet per minute (acfm) whereas the airflow displayed in the air sampling cabinet was in standard cubic feet per minute (scfm). Because the airflow monitor was out of order and was in need of replacement, comparison between the Zephyr manometer and the airflow monitor was not possible during all testing. For convenience of comparisons, the measured velocity in scfm is converted to air flow in acfm.

The acceptance criterion is that the COV of the air velocity must be $\leq 20 \%$ across the center two-thirds of the area of the stack. Our results show that the COVs of the air velocity across the center two-thirds of the stack are smaller than $2.9 \%$ for all testing conditions.

\footnotetext{
${ }^{\mathrm{i}}$ Duct diameter or DIA is defined as linear distance divided by duct diameter.
} 
Table 4.2. Summary of Velocity Uniformity Tests

\begin{tabular}{|c|c|c|c|c|c|}
\hline \multicolumn{2}{|c|}{ Test Configuration } & \multicolumn{4}{c|}{ Test Results } \\
\hline \hline Fans & Flow Conditions $\dagger$ & Run No. & $\begin{array}{c}\text { Mean Flow* } \\
\text { acfm }\end{array}$ & $\begin{array}{c}\text { Mean Vel, } \\
\text { scfm }\end{array}$ & $\begin{array}{c}\text { \% COV, } \\
\text { center 2/3 }\end{array}$ \\
\hline Fan A \& B & normal & VT-1 & 25327 & 2939 & 2.3 \\
\hline & & VT-2 & 25383 & 2945 & 2.9 \\
\hline & & VT-3 & 24836 & 2882 & 1.8 \\
\hline Fan A \& C & normal & VT-4 & 25185 & 2922 & 2.2 \\
\hline & & VT-5 & 24925 & 2892 & 2.0 \\
\hline Fan B \& C & normal & VT-6 & 24812 & 2879 & 2.0 \\
\hline & & VT-7 & 24547 & 2848 & 2.0 \\
\hline & & VT-8 & 24575 & 2852 & 2.3 \\
\hline Fan A\& C & Sashes opened ${ }^{\ddagger}$ & VT-10 & 27436 & 3184 & 2.3 \\
\hline & & VT-11 & 27496 & 3191 & 2.4 \\
\hline & & VT-12 & 27463 & 3187 & 2.4 \\
\hline
\end{tabular}

*: Mean flow was spot checked approximately at the center of the stack using a calibrated TSI ${ }^{\mathrm{TM}}$ VelociCalc digital anemometer. The stack airflow measured by the air monitor was not trustworthy, because the setting was erroneous. This was not fixed until all testing was finished.

$\dagger$ : Normal refers to the operational flow conditions as summarized in Table 1.1.

: Sashes in the new laboratory 1604 and 1606 were opened to allow higher flow in the stack.

\subsection{Flow Angle}

Table 4.3 lists the results for the flow angle test runs (FAs) performed on the 3410 Building exhaust duct. The average flow angle of $4.0^{\circ}$ is acceptable as it is well within the criterion of average flow angle values less than $20^{\circ}$.

\subsection{Gas Tracer Uniformity}

Table 4.4 lists the results for the gas tracer test runs (GTs) performed on the 3410 Building exhaust duct. The uniformity of the concentration is first tested using a tracer gas to represent gaseous effluents. The fan is a good mixer, so injecting the tracer downstream of the fan provides worst case results. Alternately, injections were made at the junction downstream after the ducts from each fan meet. The acceptance criteria are that 1 ) the COV of the measured tracer gas concentration is $\leq 20 \%$ across the center two-thirds of the sampling plane and 2) at no point in the sampling plane does the concentration vary from the mean by $>30 \%$. Test results show that 1 ) the COV of the measured tracer gas concentration is < $2.8 \%$ for all test conditions and 2) at no point in the sampling plane does the concentration vary from the mean by $>6.7 \%$. The two worst cases for the fan pair and junction injection were repeated. The results were grouped for each test configuration for ease of comparisons. 
Table 4.3. Summary of Flow Angle Tests

\begin{tabular}{||c|c|c|c|c|c|c||}
\hline \multicolumn{3}{|c|}{ Test Configuration } & & \multicolumn{3}{c|}{ Test Runs } \\
\hline Fans & $\begin{array}{c}\text { Flow } \\
\text { Conditions } \dagger\end{array}$ & No. & Test Port & Run No. & $\begin{array}{c}\text { Mean Flow } \\
\text { acfm }\end{array}$ & $\begin{array}{c}\text { Mean of abs } \\
\text { values ( }\end{array}$ \\
\hline Fan A \& B & normal & 1 & At Probe & FA-1 & 25561 & 3.2 \\
\hline & & 2 & & FA-2 & 28017 & 2.5 \\
\hline & & 3 & & FA-3 & 27345 & 2.6 \\
\hline Fan A \& C & normal & 4 & At Probe & FA-4 & 31024 & 2.6 \\
\hline & & 5 & & FA-5 & 26784 & 1.9 \\
\hline Fan B \& C & normal & 7 & At Probe & FA-7 & 26509 & 1.4 \\
\hline & & 8 & & FA-8 & 29301 & 4.0 \\
\hline & & 9 & & FA-9 & 29275 & 1.7 \\
\hline Fan A \& C & normal ${ }^{\ddagger}$ & 10 & At Probe & FA-10 & 28844 & 2.9 \\
\hline & & 11 & & FA-11 & 27793 & 2.4 \\
\hline & & 12 & & FA-12 & 30559 & 1.8 \\
\hline
\end{tabular}

*: Mean flow was spot checked approximately at the center of the stack using a calibrated TSI ${ }^{\mathrm{TM}}$ VelociCalc digital anemometer. The stack airflow measured by the air monitor was not trustworthy, because the setting was erroneous. This was not fixed until all testing was finished.

$\dagger$ : Normal refers to the operational flow conditions as summarized in Table 1.1.

: Sashes in the new laboratory 1604 and 1606 were opened to allow higher flow in the stack.

\subsection{Particle Tracer Uniformity}

Table 4.5 lists the results for the particle concentration uniformity (PTs) performed on the 3410 Building exhaust duct. Tracer particles of $10-\mu \mathrm{m}$ aerodynamic diameter were used for the second demonstration of concentration uniformity. The acceptance criterion is that the COV of particle concentration is $\leq 20 \%$ across the center two-thirds of the sampling plane. Our test results indicate that the COV of particle concentration is $<9.9 \%$ across the center two-thirds of the sampling plane among all testing conditions. The two worst cases for the fan pair and junction injection were repeated. The results were grouped for each test configuration for ease of comparisons. 
Table 4.4. Summary of Tracer Gas Uniformity Tests.

\begin{tabular}{|c|c|c|c|c|c|c|c|}
\hline \multicolumn{5}{|c|}{ Test Configurations } & \multicolumn{3}{|c|}{ Test Runs } \\
\hline Fans & $\begin{array}{c}\text { Flow } \\
\text { Conditions }\end{array}$ & $\begin{array}{l}\text { Run } \\
\text { No. }\end{array}$ & Injection Port $^{\dagger \dagger}$ & $\begin{array}{l}\text { Injection } \\
\text { Position }\end{array}$ & $\begin{array}{c}\text { Mean } \\
\text { Flow", } \\
\text { acfm }\end{array}$ & $\begin{array}{l}\text { Max } \\
\text { Dev. }\end{array}$ & $\mathrm{COV} \%$ \\
\hline \multirow{11}{*}{ Fan A \& B } & \multirow{11}{*}{ normal } & GT-1 & Junction Center & \multirow{5}{*}{$\begin{array}{c}\text { Center and } \\
4 \text { Perimeter } \\
\text { Points }\end{array}$} & 26267 & $-2.5 \%$ & 1.3 \\
\hline & & GT-2 & Junction Top & & 26491 & $1.8 \%$ & 1.0 \\
\hline & & GT-3 & Junction Bottom & & 27918 & $1.5 \%$ & 0.6 \\
\hline & & GT-4 & Junction Far & & 27586 & $1.5 \%$ & 0.8 \\
\hline & & GT-5 & Junction Near & & 28883 & $2.3 \%$ & 1.3 \\
\hline & & GT-D & Junction Center & center & 28107 & $-3.7 \%$ & 0.6 \\
\hline & & GT-6 & Fan A Center & \multirow{5}{*}{$\begin{array}{c}\text { Center and } \\
4 \text { Perimeter } \\
\text { Points }\end{array}$} & 28137 & $-1.5 \%$ & 0.9 \\
\hline & & GT-7 & Fan A Top & & 27284 & $-2.4 \%$ & 0.8 \\
\hline & & GT-8 & Fan Bottom & & 27551 & $2.8 \%$ & 0.6 \\
\hline & & GT-9 & Fan A Far & & 28370 & $-3.2 \%$ & 1.6 \\
\hline & & GT-10 & Fan A Near & & 29185 & $-3.0 \%$ & 1.8 \\
\hline \multirow{5}{*}{$\begin{array}{c}\text { Worst Case } \\
\text { Fan Pair } \\
\text { A\&B }\end{array}$} & \multirow{5}{*}{ sashes open ${ }^{\ddagger}$} & GT-39 & Fan A Center & \multirow{5}{*}{$\begin{array}{c}\text { Center and } \\
4 \text { Perimeter } \\
\text { Points }\end{array}$} & 29512 & $1.8 \%$ & 0.9 \\
\hline & & GT-40 & Fan A Bottom & & 29409 & $2.3 \%$ & 0.7 \\
\hline & & GT-41 & Fan A Top & & 28228 & $-1.8 \%$ & 1.0 \\
\hline & & GT-42 & Fan A Near & & 28215 & $1.6 \%$ & 0.9 \\
\hline & & GT-43 & Fan A Far & & 28008 & $-2.5 \%$ & 1.4 \\
\hline Fan A \& B & normal & GT-11 & Fan B Center & Center & 27758 & $2.2 \%$ & 1.0 \\
\hline \multirow{5}{*}{ Fan A \& C } & \multirow[t]{5}{*}{ normal } & GT-12 & Junction Center & \multirow{5}{*}{$\begin{array}{c}\text { Center and } \\
4 \text { Perimeter } \\
\text { Points }\end{array}$} & 28426 & $-1.9 \%$ & $\overline{1.2}$ \\
\hline & & GT-13 & Junction Top & & 29353 & $1.6 \%$ & 0.9 \\
\hline & & GT-14 & Junction Bottom & & 27655 & $1.7 \%$ & 0.9 \\
\hline & & GT-15 & Junction Near & & 28155 & $2.6 \%$ & 1.5 \\
\hline & & GT-16 & Junction Far & & 26504 & $1.4 \%$ & 0.7 \\
\hline \multirow{5}{*}{$\begin{array}{c}\text { Worst Case } \\
\text { Fan Pair } \\
\text { A\&C }\end{array}$} & \multirow[t]{5}{*}{ sashes open $^{t}$} & GT-34 & Junction Center & \multirow{5}{*}{$\begin{array}{c}\text { Center and } \\
4 \text { Perimeter } \\
\text { Points }\end{array}$} & 30615 & $-3.4 \%$ & 1.5 \\
\hline & & GT-35 & Junction Top & & 30744 & $2.3 \%$ & 0.9 \\
\hline & & GT-36 & Junction Bottom & & 28982 & $1.5 \%$ & 0.7 \\
\hline & & GT-37 & Junction Near & & 28818 & $-4.3 \%$ & 1.6 \\
\hline & & GT-38 & Junction Far & & 28577 & $1.2 \%$ & 0.6 \\
\hline \multirow{7}{*}{ Fan A \& C } & \multirow[t]{5}{*}{ normal } & GT-17 & Fan C Center & \multirow{5}{*}{$\begin{array}{c}\text { Center and } \\
4 \text { Perimeter } \\
\text { Points }\end{array}$} & 26220 & $1.5 \%$ & 0.8 \\
\hline & & GT-18 & Fan C Top & & 28547 & $1.4 \%$ & 0.8 \\
\hline & & GT-19 & Fan C Bottom & & 26703 & $-1.9 \%$ & 0.6 \\
\hline & & GT-20 & Fan C Far & & 27146 & $-2.0 \%$ & 0.5 \\
\hline & & GT-21 & Fan C Near & & 26276 & $-2.9 \%$ & 1.9 \\
\hline & normal & GT-22 & Fan A Center & Center & 26836 & $-3.0 \%$ & 1.1 \\
\hline & sashes open & GT-44 & Fan C Near & near & 28125 & $6.7 \%$ & 2.8 \\
\hline \multirow{7}{*}{ Fan B \& C } & \multirow{7}{*}{ normal } & GT-23 & Fan B Center & \multirow{5}{*}{$\begin{array}{c}\text { Center and } \\
4 \text { Perimeter } \\
\text { Points }\end{array}$} & 25578 & $-2.6 \%$ & 0.9 \\
\hline & & GT-24 & Fan B Bottom & & 25720 & $1.8 \%$ & 1.0 \\
\hline & & GT-25 & Fan B Top & & 26414 & $2.6 \%$ & 1.1 \\
\hline & & GT-26 & Fan B Far & & 27108 & $-2.2 \%$ & 0.9 \\
\hline & & GT-27 & Fan B Near & & 27668 & $2.1 \%$ & 0.7 \\
\hline & & GT-28 & Fan C Center & \multirow{2}{*}{$\begin{array}{l}\text { Center and } \\
4 \text { Perimeter }\end{array}$} & 25910 & $1.8 \%$ & 1.2 \\
\hline & & GT-29 & Fan C Bottom & & 26535 & $1.4 \%$ & 0.7 \\
\hline
\end{tabular}




\begin{tabular}{|c|c|c|c|c|c|c|c|}
\hline \multicolumn{5}{|c|}{ Test Configurations } & \multicolumn{3}{|c|}{ Test Runs } \\
\hline Fans & $\begin{array}{c}\text { Flow } \\
\text { Conditions }\end{array}$ & $\begin{array}{l}\text { Run } \\
\text { No. }\end{array}$ & Injection Port $^{\dagger \dagger}$ & $\begin{array}{l}\text { Injection } \\
\text { Position }\end{array}$ & $\begin{array}{c}\text { Mean } \\
\text { Flow, } \\
\text { acfm }\end{array}$ & $\begin{array}{l}\text { Max } \\
\text { Dev. }\end{array}$ & COV\% \\
\hline & & GT-30 & Fan C Top & \multirow[t]{3}{*}{ Points } & 26625 & $2.8 \%$ & 1.8 \\
\hline & & GT-31 & Fan C Near & & 25974 & $1.3 \%$ & 0.7 \\
\hline & & GT-32 & Fan C Far & & 28146 & $-1.3 \%$ & 0.6 \\
\hline Fan B \& C & normal & GT-33 & Junction Center & Center & 27448 & $1.8 \%$ & 0.9 \\
\hline
\end{tabular}

*: Mean flow was spot checked approximately at the center of the stack using a calibrated TSI ${ }^{\mathrm{TM}}$

VelociCalc digital anemometer. The stack airflow measured by the air monitor was not trustworthy, because the setting was erroneous. This was not fixed until all testing was finished.

†: normal refers to the operational flow conditions as summarized in Table 1.1.

: Sashes in the new laboratory 1604 and 1606 were opened to allow higher flow in the stack.

${ }^{\dagger}$ : The injection port was either downstream of the damper of each fan or at the junction location shown in Figure 2.1.

Table 4.5. Summary of Particle Uniformity Tests.

\begin{tabular}{|c|c|c|c|c|c|}
\hline \multicolumn{4}{|c|}{ Test Configurations } & \multicolumn{2}{|c|}{ Test Runs } \\
\hline Fans & $\begin{array}{c}\text { Flow } \\
\text { Conditions }\end{array}$ & $\begin{array}{l}\text { Run } \\
\text { No. }\end{array}$ & $\begin{array}{c}\text { Injection } \\
\text { Port }^{\dagger \dagger}\end{array}$ & Mean Flow*, acfm & $\begin{array}{c}\text { Normalized } \\
\text { COV\% }\end{array}$ \\
\hline \multirow[t]{3}{*}{ Fans A \& B } & normal & PT-1 & Junction & 33679 & 8.28 \\
\hline & normal & PT-2 & Fan A & 29103 & 8.93 \\
\hline & normal & PT-3 & Fan B & 29060 & 7.77 \\
\hline \multirow[t]{3}{*}{ Fans B \& C } & normal & PT-4 & Junction & 28228 & 7.01 \\
\hline & normal & PT-5 & Fan B & 28344 & 8.53 \\
\hline & normal & PT-6 & Fan C & 28540 & 9.56 \\
\hline Worst Case (B\&C) & normal & PT-11 & Fan $\mathrm{C}$ & 28896 & 6.52 \\
\hline \multirow[t]{3}{*}{ Fans A \& C } & normal & PT-7 & Junction & 29352 & 9.87 \\
\hline & normal & PT-8 & Fan A & 29081 & 9.16 \\
\hline & normal & PT-9 & Fan $\mathrm{C}$ & 28540 & 8.46 \\
\hline Worst Case (A\&C) & normal & PT-10 & Junction & 29689 & 7.74 \\
\hline
\end{tabular}

*: Mean flow was spot checked approximately at the center of the stack using a calibrated TSI ${ }^{\mathrm{TM}}$

VelociCalc digital anemometer. The stack airflow measured by the air monitor was not trustworthy, because the setting was erroneous. This was not fixed until all testing was finished.

${ }^{\dagger}$ : Normal refers to the operational flow conditions as summarized in Table 1.1.

$\pitchfork$ : The injection port was either downstream of the damper of each fan or at the junction location shown in Figure 2.1. Injection was always at the center of the stack. 


\subsection{Conclusions}

In order to support the air emissions permit for the 3410 Building, PNNL performed a series of tests in the exhaust air discharge from the reconfigured 3410 Building filtered exhaust stack. The objective was to determine whether the location of the air sampling probe for emissions monitoring meets the applicable regulatory criteria governing such effluent monitoring systems. In particular, the capability of the air sampling probe location to meet the acceptance criteria of ANSI/HPSN13.1-2011, Sampling and Monitoring Releases of Airborne Radioactive Substances from the Stack and Ducts of Nuclear Facilities was determined. The qualification criteria for these types of stacks include metrics concerning 1) uniformity of air velocity, 2) sufficiently small flow angle with respect to the axis of the duct, 3) uniformity of tracer gas concentration, and 4) uniformity of tracer particle concentration. Testing was performed to conform to the quality requirements of NQA-1-2000. Fan configurations tested included all fan combinations of any two fans at a time. Most of the tests were conducted at the normal flow rate, while a small subset of tests was performed at a slightly higher flow rate achieved with the laboratory hood sashes fully open.

The qualification criteria for an air monitoring probe location are taken from ANSI/HPSN13.1-2011 and are paraphrased as follows with key results summarized:

Uniform Air Velocity: The acceptance criterion is that the COV of the air velocity must be $\leq 20 \%$ across the center two-thirds of the area of the stack. Our results show that the COVs of the air velocity across the center two-thirds of the stack are smaller than $2.9 \%$ for all testing conditions.

Angular Flow: The average air-velocity angle must not deviate from the axis of the stack or duct by more than $20^{\circ}$. Our test results show that the mean angular flow angles at the center two-thirds of the ducts are smaller than $4.0^{\circ}$ for all testing conditions.

Uniform Concentration of Tracer Gases: The uniformity of the concentration is first tested using a tracer gas to represent gaseous effluents. The fan is a good mixer, so injecting the tracer downstream of the fan provides worst case results. Alternately, injections can be made at the junction downstream after the ducts from each fan meet. The acceptance criteria are that 1) the COV of the measured tracer gas concentration is $\leq 20 \%$ across the center two-thirds of the sampling plane and 2) at no point in the sampling plane does the concentration vary from the mean by $>30 \%$. Our test results show that 1 ) the $\mathrm{COV}$ of the measured tracer gas concentration is $<2.8 \%$ for all test conditions and 2) at no point in the sampling plane does the concentration vary from the mean by $>6.7 \%$.

Uniform Concentration of Tracer Particles: Tracer particles of 10- $\mu \mathrm{m}$ AD are used for the second demonstration of concentration uniformity. The acceptance criterion is that the COV of particle concentration is $\leq 20 \%$ across the center two-thirds of the sampling plane. Our test results indicate that the COV of particle concentration is $<9.9 \%$ across the center two-thirds of the sampling plane among all testing conditions.

Thus, the reconfigured 3410 Building filtered exhaust stack was determined to meet the qualification criteria given in the ANSI/HPSN13.1-2011 standard. Changes to the system configuration or operations outside the bounds described in this report (e.g., exhaust stack velocity changes, relocation of sampling probe, and addition of fans) may require re-testing or re-evaluation to determine compliance. 


\subsection{References}

10 CFR 830, Subpart A. 2008. "Quality Assurance Requirements.” Code of Federal Regulations, U.S. Department of Energy.

40 CFR 60, Appendix A, Method 1. 2008. "Sample and Velocity Traverses for Stationary Sources." Code of Federal Regulations, U.S. Environmental Protection Agency.

40 CFR 61, Subpart H. 2002. "National Emission Standard For Emissions of Radionuclides other than Radon from Department of Energy Facilities." Code of Federal Regulations, U.S. Environmental Protection Agency.

ASME-American Society of Mechanical Engineers. 2000a. NQA-1-2000, Quality Assurance Requirements for Nuclear Facility Applications, Part 1, "Requirements for Quality Assurance Programs for Nuclear Facilities." New York, New York.

ASME-American Society of Mechanical Engineers. 2000b. NQA-1-2000, Part II, Subpart 2.7, "Quality Assurance Requirements for Computer Software for Nuclear Facility Applications.” New York, New York.

ASME-American Society of Mechanical Engineers. 2000c. NQA-1-2000, Part IV, Subpart 4.2, "Graded Approach Application of Quality Assurance Requirements for Research and Development." New York, New York.

ANSI/HPS - American National Standards Institute/Health Physical Society. 1999. Sampling and Monitoring Releases of Airborne Radioactive Substances from the Stack and Ducts of Nuclear Facilities. N13.1-1999. Health Physics Society, McLean, Virginia.

ANSI/HPS - American National Standards Institute/Health Physical Society. 2011. Sampling and Monitoring Releases of Airborne Radioactive Substances from the Stack and Ducts of Nuclear Facilities. N13.1-2011. Health Physics Society, McLean, Virginia.

DOE Order 414.1C. “Quality Assurance.” U.S. DOE, Washington, D.C.

Glissmeyer JA. 2013, EMS-JAG-01. Rev. 4. Test to Determine Uniformity of a Tracer Gas at a Sampler Probe.

Glissmeyer JA. 2009, EMS-JAG-02. Rev. 2. Test to Determine Uniformity of a Tracer Aerosol at a Sampler Probe.

Glissmeyer JA. 2009, EMS-JAG-04. Rev. 2. Test to Determine Uniformity of Air Velocity a Sampler Probe.

Glissmeyer JA. 2009, EMS-JAG-05. Rev. 2. Test to Determine Flow Angle.

TI-STMON-027. 2013. Velocity Uniformity Test of Filtered Exhaust at 3410 Building after Adding the Third Fan. Pacific Northwest National Laboratory, Richland, Washington.

TI-STMON-028. 2013. Flow Angle Test of Filtered Exhaust at 3410 Building after Adding the Third Fan. Pacific Northwest National Laboratory, Richland, Washington. 
TI-STMON-029. 2013. Particle Uniformity Test of Filtered Exhaust at 3410 Building after Adding the Third Fan. Pacific Northwest National Laboratory, Richland, Washington.

TI-STMON-030. 2013. Gas Tracer Mixing Test of Filtered Exhaust at 3410 Building. Pacific Northwest National Laboratory, Richland, Washington.

TP-STMON-026, 3410 Building Stack Monitoring Project Test Plan, Pacific Northwest National Laboratory, Richland, WA 99352.

PP-STMON-031, 3410 Building Stack Monitoring Project Plan, Pacific Northwest National Laboratory, Richland, WA 99352. 


\section{Appendix A: The CFD Model Report}

\section{Modeling the Air flow in the 3410 Building Filtered Exhaust Stack System}

KP Recknagle, JM Barnett, SR Suffield

November, 2012

\section{Executive Summary}

Additional ventilation capacity has been designed for the 3410 Building filtered exhaust stack system. The updated system will increase the number of fans from two to three, and will include ductwork to incorporate the new fan into the existing stack. Stack operations will involve running various two-fan combinations at any given time. The air monitoring system of the existing two-fan stack was previously found to be in compliance with the ANSI/HPSN13.1-2011 standard, however it is not known that the modified (three fan) system will comply. Subsequently, a full scale threedimensional (3-D) computational fluid dynamics (CFD) model of the modified stack system has been created to examine the sampling location for compliance with the ANSI/HPSN13.1-2011 standard.

The CFD modeling results show good agreement with testing data collected from the existing 3410 Building stack, and suggest that velocity uniformity and flow angles will remain well within acceptance criteria when the third fan and associated ductwork is installed. This includes two-fan flow rates up to $31,840 \mathrm{cfm}$, for any of the two-fan combinations. For simulation cases in which tracer gas and particles are introduced in the main duct, the model predicts that both particle and tracer gas COVs may be larger than the acceptable 20\% criterion of the ANSI/HPSN13.1-2011 standard for each of the two-fan, 31,840 cfm combinations. Simulations in which the tracers are introduced near the fans result in improved, though marginally acceptable COV values for the tracers.

Due to the remaining uncertainty that the stack will qualify with the addition of the third fan and high flow rates, a stationary air blender from Blender Products, Inc. is considered for inclusion in the stack system. A model of the air blender has been developed and incorporated into the CFD model. Simulation results from the CFD model that includes the air blender show striking improvements in tracer gas mixing and tracer particle dispersion. The results of these simulations suggest the air blender should be included in the stack system to ensure qualification of the stack. 


\section{Introduction}

The 3410 Building at the Pacific Northwest National Laboratory (PNNL) houses PNNL radiological capabilities. As such, air discharged from the Building filtered exhaust stack system must be monitored for radionuclides. The air monitoring system must comply with applicable federal regulations, which subsequently require a sampling probe in the exhaust stream to conform to the uniformity criteria of the ANSI/HPSN13.1-2011. The criteria include: the uniformity of flow velocity, the average angle between the flow and duct axis, the uniformity of tracer gas, and the uniformity of tracer particles. The uniformity is expressed by the COV, defined as the standard deviation divided by the mean. For a sampling location to be acceptable, COVs for velocity, tracer gas concentration, and tracer particle concentration must be $<20 \%$. Additionally, the average flow angle must be $<20^{\circ}$ from the duct axis to ensure the flow is not cyclonic. The ANSI/HPSN13.1-2011 standard requires that testing be performed to demonstrate the compliance of the duct and sampling probe for meeting these uniformity criteria.

An option in the ANSI/HPSN13.1-2011 standard allows the adoption of results from a previously performed full test series for a stack system of similar configuration as the basis of compliance with the standard. Compliance is then confirmed by partial testing performed on the actual stack system. This approach was used to qualify the location of the monitoring probe and configuration of the original two-fan 3410 Building filtered exhaust stack as documented by Glissmeyer and Flaherty, 2010 (PNNL-19562). This testing performed on the actual system included flow velocity uniformity and flow angle measurements. The previous full test series applied as the basis for compliance was that performed on a scale model of the Waste Treatment Plant's HV-C2 air exhaust stack (Glissmeyer and Droppo, 2007). The HV-C2 stack with two fans entering a horizontal main duct, both at $45^{\circ}$ angles, is very similar to the original two-fan configuration of the 3410 Building exhaust stack.

The original testing of the HV-C2 scale model by Glissmeyer and Droppo had been performed to establish the sampling probe location for the actual HV-C2 stack. The scale model showed good velocity uniformity and small flow angles. However tracer gas/particle test COV values were greater than $20 \%$ at all but the test port furthest downstream. This furthest test port on the HV-C2 scale model is similar in scaled distance to that of the 3410 Building sampling location. Thus in the two-fan stack configuration all of the main duct length, of the 3410 Building exhaust system, would be needed to provide sufficient mixing of tracer gas and tracer particles.

The 3410 Building exhaust stack system will be updated with additional ventilation capacity. The updated system will incorporate a third fan and adjoining ductwork to integrate the new fan into the existing stack. As a result, the stack configuration will be changed substantially. The average overall flow rate will also be increased significantly. In the absence of data from a similar system, it is not well known if the updated three fan system will qualify as readily as the two-fan system. Testing will ultimately be required to prove the stack system and sampling location comply with the ANSI/HPSN13.1-2011 standard. Before making a final decision on installation of the proposed design modeling would be used to gain more insight into the expected performance of the modified stack.

\section{Modeling Approach}


The purpose of modeling the 3410 Building stack system is to simulate the stack flow, including the distributions of gas and particle tracers, to assist in determining if the modified system will satisfy the ANSI/HPSN13.1-2011 standard. To provide accurate predictions of flow, tracer gas, and tracer particle distributions (at the sampling location) requires an accurate prediction of the turbulent air flow with mixing and transport of the tracer species within it. The geometry and flow field of the exhaust stack system is complex and highly three-dimensional (3-D). Therefore a representative boundary fitted, 3-D flow model is also required. The commercially available, computational fluid dynamics (CFD) flow simulation code, STAR-CCM+ (CD-Adapco, 2012) was selected for creation of the model geometry and the flow simulations (Recknagle et al., 2009).

\section{Flow Model}

The stack sampling methodology assumes isothermal conditions exist within the stack, thus this assumption is adopted in the flow model. Computations for the isothermal, steady state flow solutions in STAR-CCM+ are performed using a traditional formulation for conservation of mass, gas mixture species, and momentum:

$$
\begin{aligned}
& \frac{\partial}{x_{j}}\left(u_{j}\right)=0 \\
& \frac{\partial}{\partial x_{j}}\left(\rho u_{j} Y_{k}+F_{k, j}\right)=S \\
& \frac{}{x_{j}}\left(\begin{array}{ll}
u_{j} u_{i} & { }_{i j}
\end{array}\right)=\frac{p}{x_{i}}
\end{aligned}
$$

where $u_{i}$ is the absolute fluid velocity component in coordinate direction $x_{i}(\mathrm{i}=1,2,3)$, repeated subscripts (jj) denote summation, $\mathrm{j} \rho$ is the gas mixture density, $p$ is the pressure, $Y_{k}$ is the gas species mass fraction, $F_{k, j}$ is the gas diffusional flux component, and $S_{k}$, is the gas species source term. The fluid stress tensor $\tau_{\mathrm{ij}}$ for turbulent flows is represented by

$$
{ }_{i j}=2 \quad i j \quad \frac{2}{3} \quad \frac{u_{k}}{x_{k}}{ }_{i j}-\overline{u_{i} u_{j}}
$$

Here $\mu$ is the dynamic viscosity, $\sigma_{i j}$ is the rate of strain tensor, $u_{i}$ and $u_{j}$ are fluctuations about the average velocity, and the overbar indicates the averaging of the fluctuations. The right-most term (in eqn A.4) represents the additional Reynolds stresses due to turbulent motion. These are linked to the mean velocity via the turbulence model being used. In the simulations for this work, the generation and dissipation of turbulence was accounted for using the standard $\kappa-\varepsilon$ turbulence model for large Reynolds number flow as described in the STAR-CMM+ User Guide (CD-Adapco, 2012, Bellevue, Washington). In the present work, a turbulence model comparison found the large Reynolds number $\kappa-\varepsilon$ model to be the most suitable for use in simulating duct flow, a finding corroborated by (Jenson, 2007).

j e.g., $\frac{\partial \rho u_{j}}{\partial x_{j}}=\frac{\partial \rho u_{1}}{\partial x_{1}}+\frac{\partial \rho u_{2}}{\partial x_{2}}+\frac{\partial \rho u_{3}}{\partial x_{3}}$ 


\section{Oil Droplet Model}

A Lagrangian dispersed two-phase flow model was used for the oil droplet transport simulations. The Lagrangian methodology considers the interactions of mass, momentum, and energy between the continuum and dispersed phases. In general, motion of the dispersed phase is influenced by that of the continuous phase, and vice versa. The strength of the phase interactions depend on the dispersed particle's size, density, and number density. For the present work, droplet concentrations were small, as was the nominal particle size, thus momentum transfer from droplets to air was negligibly small. In the model, the momentum equation for a droplet, given by Newton's second law was:

$$
m_{d} \frac{d u_{d}}{d t}=F_{d r}+F_{p}+F_{b}
$$

where the subscript $d$ refers to the dispersed droplet phase, $F_{d r}$ is the drag force, $F_{p}$ the pressure force, and $F_{b}$ is body forces including effect of the gravity and angular velocity vectors. Surface vapor pressure and mass transfer between phases was not considered here. The problem was considered isothermal and did not involve electrically charged flow, therefore thermophoresis and electrostatic effects were not included. Because of the low number density of the oil droplets, separation and coalescence models were left aside as well.

\section{Model Geometry}

A design drawing of the 3410 Building exhaust stack system was used to create a 3-D geometry model of the modified stack system. The model geometry for the system is shown in Figure A.1. Air mixing upstream of the fans is not included in the models. Instead, the model domains include the ductwork from just downstream of the fans to the stack exit. To approximate the circumferential motion created by the fans, curved duct segments were added in the orientation of the actual system. The overall computational mesh is sufficiently refined to enable resolution of the turbulent flow field throughout the system. The computational mesh was developed in a process that tested the solution sensitivity for several mesh resolutions. The final computational mesh for the three fan system contains 913,628 elements; Figure A.2a provides a close up view of the mesh near Fan 1, including a rectangular extension of the fan inflow boundary that helps establish flow solution stability. Resolution throughout the volume mesh is similar to that shown in Figure A.2b. 


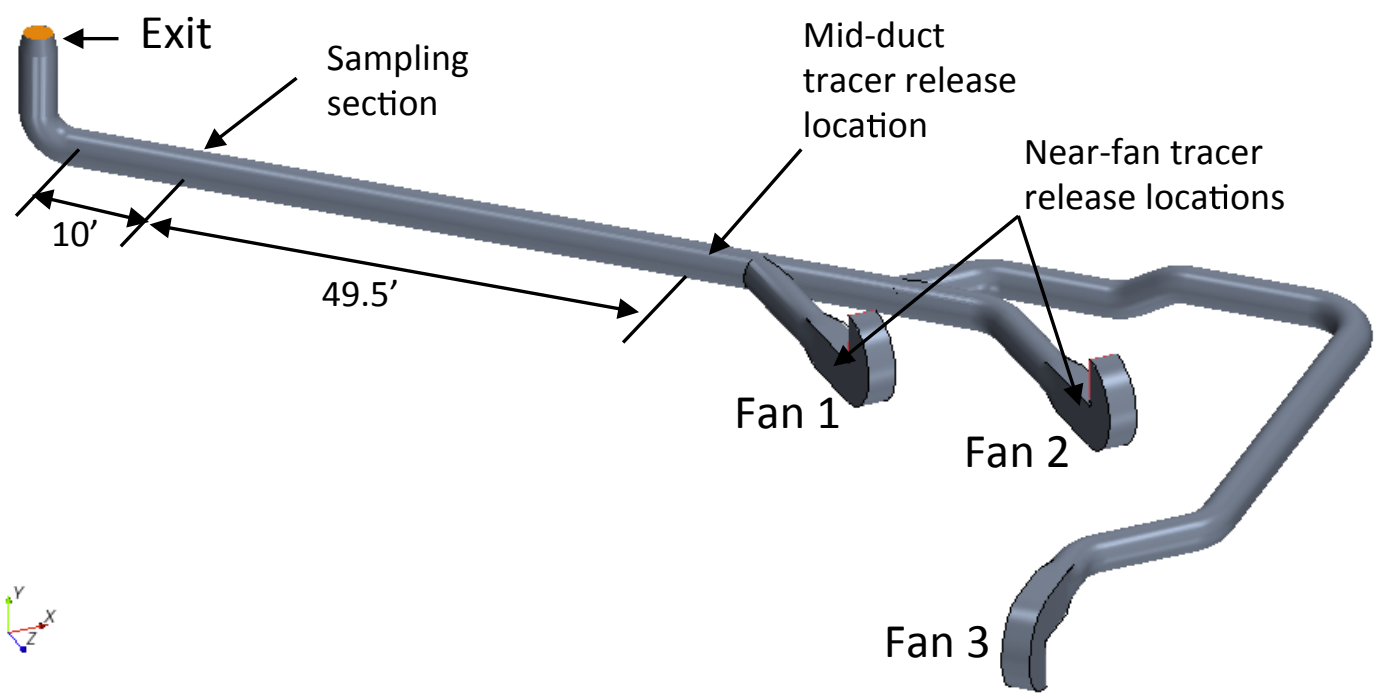

Figure A.1. Model geometry for the modified 3410 Building filtered exhaust stack system.

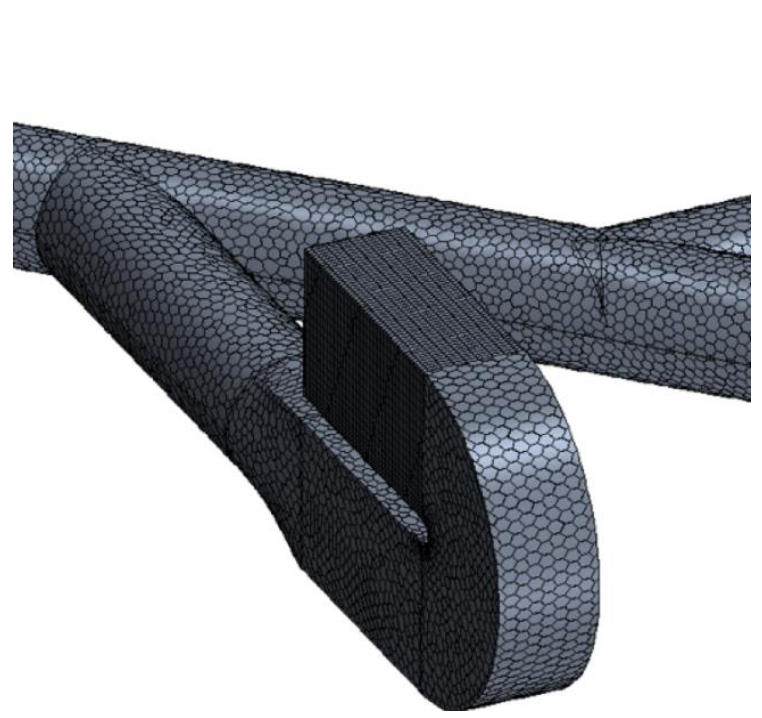

a)

Figure A.2. Detail of computational mesh at the: a) surface mesh near Fan 1, and b) typical crosssection of the volume mesh in the main duct.

\section{Boundary Conditions}

Mass inflow boundaries with uniform velocity distributions are established at the duct inlets, including turbulence intensity and turbulent viscosity ratio settings. A pressure boundary with 1 atmosphere absolute pressure is used at the stack exit. Duct walls are modeled as smooth surfaces with zero slip flow boundary conditions. 


\section{Stack Model Validation}

The first simulation cases presented are to validate the capability of the model to replicate flow angle and velocity uniformity measurements taken from the actual 3410 Building stack. As validation, the modeled flow uniformity, as indicated by the COV of velocity uniformity at the side and top sampling ports, is compared to measured data. Per the design drawing of the 3410 Building exhaust stack system, the top and side sampling ports are located $10 \mathrm{ft} .0 \mathrm{in}$., upstream of the $90^{\circ}$ elbow near the stack exit as shown in Figure A.1. This is the location used in the model to extract velocity information for comparison with the measured data. This location is 49.5' (or 15 duct diameters) downstream of main duct release location near the junction of fans 1 with the main duct.

A substantial length of duct is required to achieve a fully developed velocity profile (fully developed flow). For turbulent flow this hydrodynamic flow development length $\left(\mathrm{x}_{\mathrm{fd}}\right)$ is considered to be roughly independent of the Reynolds number, ranges from 10- to 60-diameters, and is typically assumed to be at least 10-diameters (Incropera and DeWitt, 1985). A more conservative relation for $\mathrm{x}_{\mathrm{fd}}$ considers the Reynolds number dependence such that:

$\frac{x_{f d}}{D}=4.4(R e)^{1 / 6}$

Using this expression, $\mathrm{x}_{\mathrm{fd}}$ would range from 37-diameters for a flow (in the 40-inch duct) of 10,000 $\mathrm{cfm}$, to 45-diameters for a flow of 31,840 cfm (2 fans at 15,920 cfm). With this Reynolds number dependence in mind, and the actual length available in the duct for flow development, we sought to gain validation of the model from measured data from a range of flow cases. Glissmeyer and Flaherty (PNNL-19562 RPT-STMON-005, 2010) measured velocity profiles for flows of 20,450 and $12,351 \mathrm{acfm}$, in tests VT-3 and VT-4 respectively. Simulation cases using the full scale CFD model of the existing system were run to replicate the conditions tested in VT-3 and VT-4.

Figure A.3 shows the modeled velocity magnitude profile at the sampling section for a) VT-4 and b) VT-3. The location of maximum velocity, skewed low and to the left of center, is similar for both flow rate cases. The skewed flow at the sampling location is due to a slight swirling effect in the main duct setup by the circumferential flow introduced by fans 1 and 2, and the confluence of the two streams into the main duct. This effect can be seen in plan view in Figure A.4, which shows the velocity magnitude at the mid-plane of the main duct as the flow swirls in a counter clock-wise direction making about $2 / 3$ of a full rotation along the duct. The location of the sampling section is indicated in Figure A.4 by the vertical line through the duct at left. 


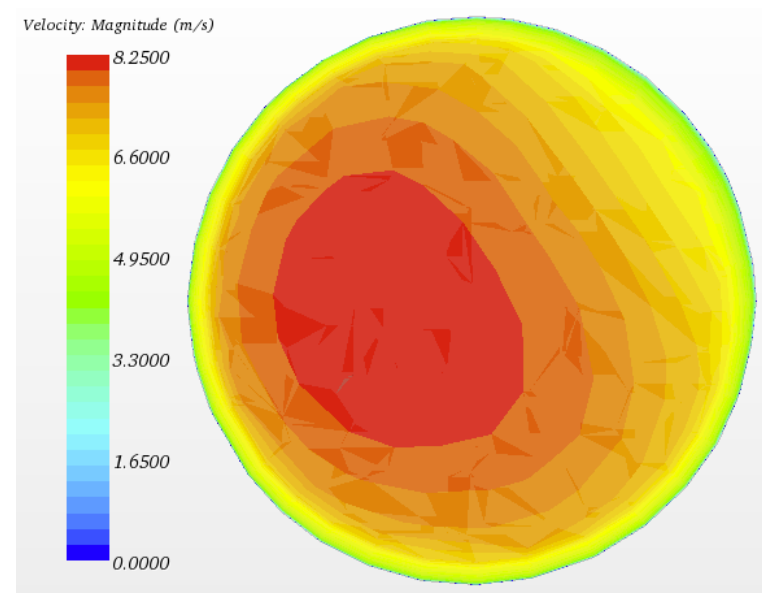

a).

Figure A.3. Velocity magnitude at the sampling section for the modeled a) VT-4, and b) VT-3 test cases.

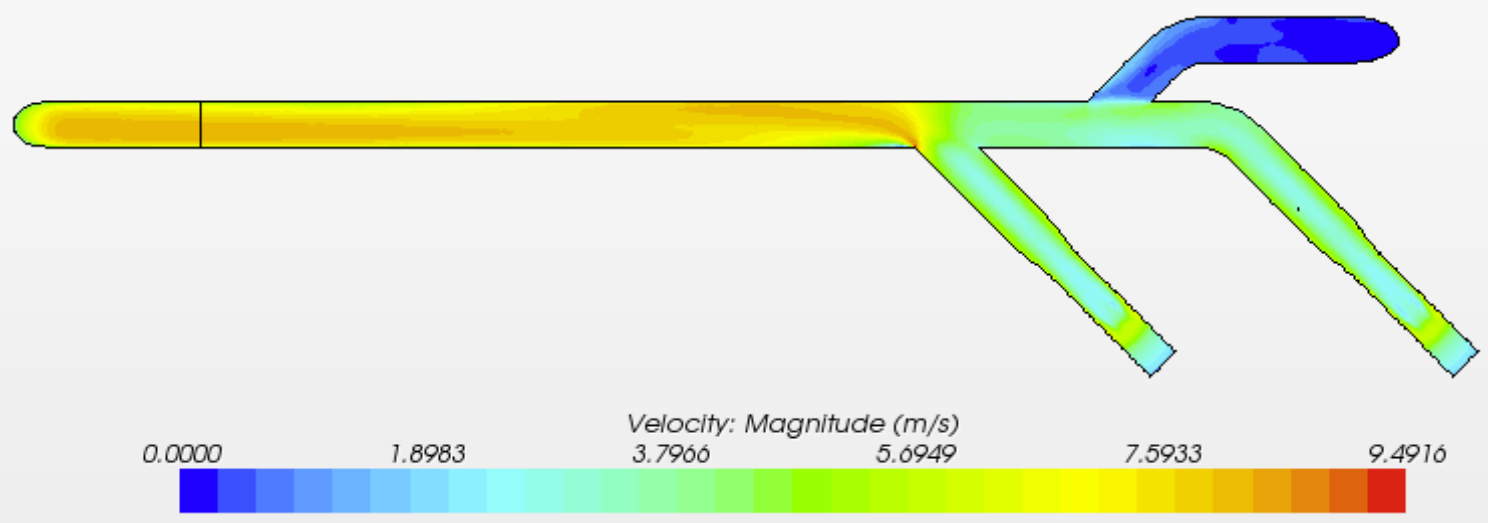

Figure A.4. Velocity magnitude in plan view at mid-plane of the main duct for the modeled VT-4 flow case.

The COV of velocity uniformity for tests VT-3 and VT-4, and the simulation cases representing them are summarized in Table A.1, where it is seen that the COV from testing and from modeling are very similar. Table A.2 summarizes flow angles from tests and the CFD simulations. The modeled flow angles are similar to angles measured in tests with similar flow rates (eg. FA-2 and VT-3, FA-3 and VT-4). As demonstrated by the noise in the flow angle test data (Glissmeyer and Flaherty, 2010) the flow distribution and flow angles are very dynamic, yet the flow angles predicted by the model compare well with the data. These results demonstrate the suitability of the model for simulating flow within the 3410 Building exhaust stack system.

Table A.1. COV for velocity uniformity tests VT-3 and VT-4

\begin{tabular}{|l|l|l|l|l|l|l|l|}
\hline \multirow{2}{*}{ Test } & \multirow{2}{*}{ Flow rate, acfm } & \multicolumn{3}{|l|}{ COV from test, \% } & \multicolumn{2}{l|}{ COV from model, \% } \\
\cline { 3 - 8 } & & Side & Top & All & Side & Top & All \\
\hline VT-3 & 20,450 & 4.3 & 3.6 & 4.1 & 6.1 & 3.9 & 5.0 \\
\hline VT-4 & 12,351 & 2.4 & 3.7 & 3.4 & 7.0 & 3.6 & 5.4 \\
\hline
\end{tabular}


Table A.2. Maximum flow angles from tests and models

\begin{tabular}{|l|l|l|l|l|}
\hline Case & Flow rate, cfm & \multirow{2}{*}{ Data source } & \multicolumn{2}{|l|}{ Maximum flow angle } \\
\cline { 4 - 5 } & & & Side & Top \\
\hline FA-1 & 17,975 & measured & $3.3^{\circ}$ & $11^{\circ}$ \\
\hline FA-2 & 18,350 & measured & $4.3^{\circ}$ & $5.7^{\circ}$ \\
\hline FA-3 & 10,800 & measured & $4.3^{\circ}$ & $5.7^{\circ}$ \\
\hline VT-3 & 20,450 & modeled & $5.4^{\circ}$ & $6.4^{\circ}$ \\
\hline VT-4 & 12,351 & modeled & $6.2^{\circ}$ & $5.2^{\circ}$ \\
\hline
\end{tabular}

\section{Stack Modeling Results}

\section{Flow Angle and Velocity Uniformity}

Operations of the modified three fan exhaust system will involve running two of the three fans at any given time for an expected maximum total flow rate of 31,840 cfm. Modeling cases were run to simulate the two-fan operations to determine the relative performance of each case, and how well each case will meet ANSI/HPSN13.1-2011 standards. Figure A.5 shows velocity magnitude distributions at the sampling section for the three two-fan operation cases. The color scales of the three contour plots match with flow velocities up to $21.25 \mathrm{~m} / \mathrm{s}$ (3650 ft/min mean). Due to a swirl component in the duct flow, the velocity profiles at the sampling/test section are skewed similarly to those of the VT-3 and VT-4 simulation cases. When operating fans 1 and 2 (Figure A.5a), or 1 and 3 (Figure A.5b) the velocity distributions are more skewed and less developed as when operating with fans 2 and 3 (Figure A.5c). The flow is more developed in the latter case due to greater main duct length available with this fan combination. Although the distribution of velocity appears to be more uniform for the case running fans 2 and 3, all cases have similar velocity uniformity COV and maximum flow angles as summarized in Table A.3.

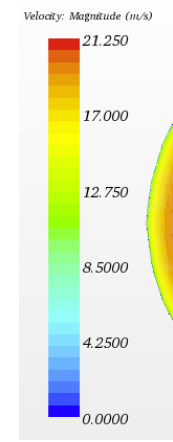

a)

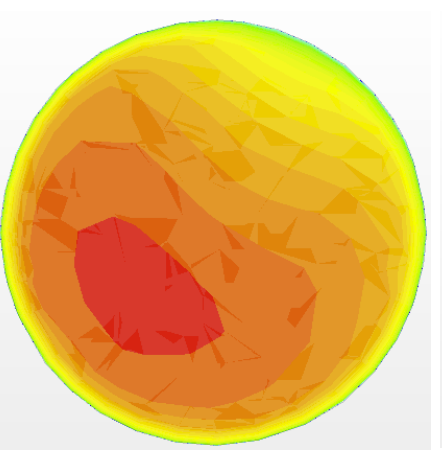

b)

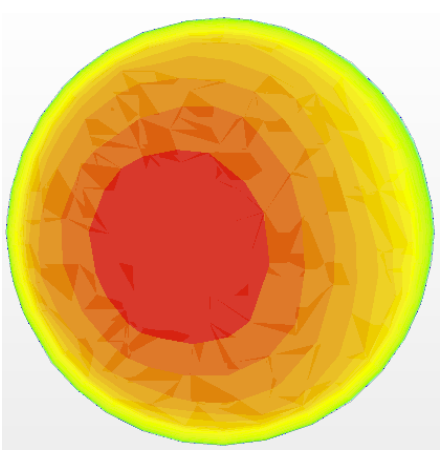

c)

Figure A.5. Velocity magnitude at the sampling section for the modeled flow rate of $31,840 \mathrm{cfm}$, running: a) fans 1 and 2, b) fans 1 and 3, and c) fans 2 and 3. Color scale: BLUE $=0$ to RED $=21.25$ $\mathrm{m} / \mathrm{s}$. 
Table A.3. COV for velocity uniformity and maximum flow angles from CFD modeling.

\begin{tabular}{|l|l|l|l|l|l|l|}
\hline \multirow{2}{*}{$\begin{array}{l}\text { Fans } \\
\text { operating }\end{array}$} & Flow rate, cfm & \multicolumn{4}{|l|}{ Velocity uniformity COV, \% } & \multicolumn{3}{l|}{ Maximum flow angle } \\
\cline { 3 - 7 } & & Side & Top & All & Side & Top \\
\hline $1-2$ & 31,840 & 5.7 & 4.4 & 4.9 & 5.8 & 6.7 \\
\hline $1-3$ & 31,840 & 4.0 & 6.6 & 5.4 & 7.3 & 7.0 \\
\hline $2-3$ & 31,840 & 7.2 & 4.0 & 5.6 & 6.8 & 7.5 \\
\hline
\end{tabular}

\section{Particle and Tracer Gas Distributions (mid-duct release location)}

Particle and tracer gas transport simulations were performed as a part of the $31,840 \mathrm{cfm}$, two-fan cases. Particles were modeled as oil droplets of nominal 10-micron AD, and the SF6 gas was modeled as a gas component in a mixture with the air stream. Tracer particles and tracer gas species were both introduced separately at the release location just downstream of the confluence of the fan ducts (See mid-duct location in Figure A.1).

Figure A.6 shows the particle distributions at the sampling location for the three fan combination cases. The case running fans 1 and 2 (Figure A.6a) has the greatest rotational flow component - due to the close proximity of fan 1 - and the most particle dispersion at the sampling location. The case running fans 1 and 3 (Figure A.6b) has less particle dispersion than with fans 1 and 2, apparently due to minimal swirl introduced by fan 3. The case running fans 2 and 3 (Figure A.6c) has the least swirl and the least particle dispersion of the three cases. Figure A.7 shows the tracer gas distributions at the sampling section for the three fan combination cases. The tracer gas distributions show similar spatial distributions as the particles. The case running fans 1 and 2 (Figure A.6c) is the most mixed. The results presented in Figures A.6 and A.7 indicate an improvement in tracer mixing and dispersion with greater rotational flow in the main duct.

COVs calculated from the distributions of particles and tracer gas are summarized in Table A.4 where it is seen that in many instances the COVs are greater than the maximum acceptable COV of $20 \%$ across the sampling location. Thus with the stack system operating on two fans at 31,840 cfm total flow, the modeling predicts that when injecting tracer gas and/or particles at the mid-duct location, the stack and sampling location will not be in compliance with the ANSI/HPSN13.1-2011 standard with respect to particle distribution and tracer gas mixing.

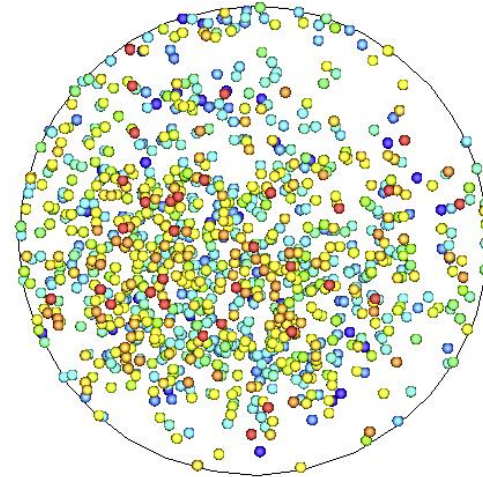

a)

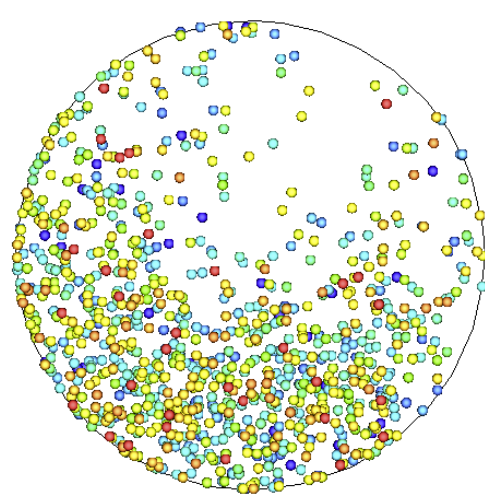

b)

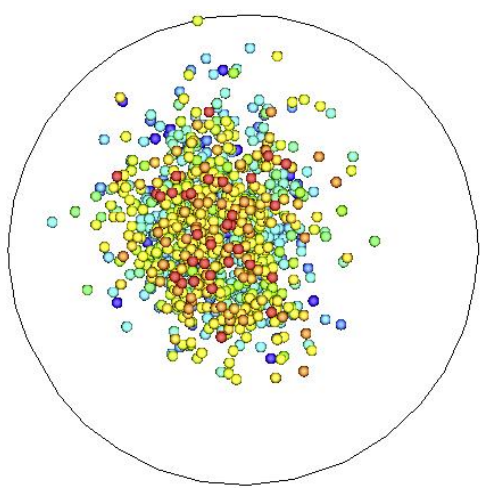

c)

Figure A.6. Particle distributions at the sampling section for a total modeled flow rate of $31,840 \mathrm{cfm}$, running: a) fans 1 and 2, b) fans 1 and 3 , and c) fans 2 and 3. 


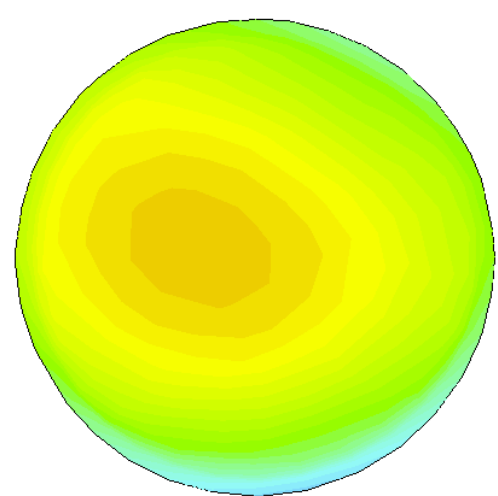

a)

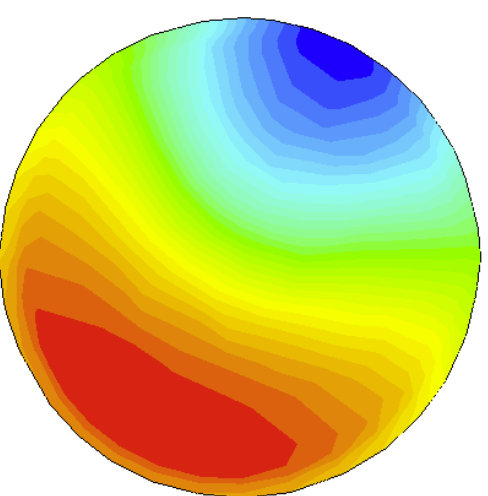

b)

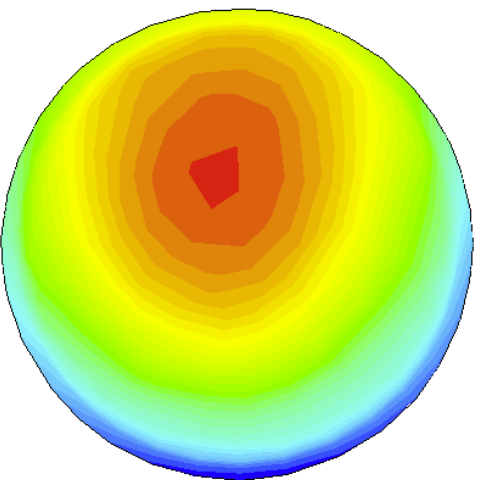

c)

Figure A.7. Tracer gas concentration contours at the sampling section for a total modeled flow rate of 31,840 cfm, running: a) fans 1 and 2, b) fans 1 and 3, and c) fans 2 and 3. Highest concentration (red) is 2.7 times larger than lowest concentration (dark blue).

Table A.4. COV for particle and tracer gas distributions at the sampling section.

\begin{tabular}{|l|l|l|l|l|l|l|l|}
\hline \multirow{2}{*}{$\begin{array}{l}\text { Fans } \\
\text { operating }\end{array}$} & Flow rate, cfm & \multicolumn{3}{|l|}{ Particle COV, \% } & \multicolumn{3}{l|}{ Tracer gas COV, \% } \\
\cline { 3 - 8 } & & Side & Top & All & Side & Top & All \\
\hline $1-2$ & 31,840 & 35 & 39 & 36 & 5.0 & 7.2 & 6.2 \\
\hline $1-3$ & 31,840 & 64 & 28 & 50 & 15.1 & 30.7 & 24.0 \\
\hline $2-3$ & 31,840 & 62 & 54 & 58 & 11.6 & 14.5 & 12.8 \\
\hline
\end{tabular}

\section{Particle and Tracer Gas Distributions (near fan release locations)}

Insufficient mixing and large COV values suggest the tracer release points would be best placed at locations that provide greater duct length for mixing of the tracers within the air streams. The maximum flow case $(31,840 \mathrm{cfm})$ was rerun with tracer injection locations just downstream of the fans. This configuration gives greater duct length for mixing of the tracers than with the mid-duct release location. Three cases were run to examine the effect of using various tracer release locations. The cases included:

1. Operating fans 1 and 2 with a tracer injection location near fan 1 .

2. Operating fans 1 and 2 with tracer injection locations near both fans 1 and 2 .

3. Operating fan 1 only $(15,920 \mathrm{cfm})$ with a tracer injection location near fan 1 .

The calculated COV results from these three cases are summarized in Table A.5. With a single tracer injection point located near fan 1 (Case 1) the insufficient mixing seen with the mid-duct release location persists for both the tracer particles and tracer gas. Case 2, with injection locations near both fans, shows acceptable tracer gas and particle uniformity with overall COVs of 4.1 and 16 respectively. These results indicate that mixing of the tracers within the stream of each fan is achieved, and that blending of the two streams together in the main duct is more challenging. When running only fan 1 at full speed and injecting tracers near fan 1 , as in Case 3 , the mixing of tracers 
within the single fan stream is similar to that of Case 2. The overall tracer gas COV is 5.0, and the overall COV for tracer particles is 18.

These tracer release location simulation results are supported by the testing of Glissmeyer and Droppo, which yielded tracer COV values greater than $20 \%$ at all but the test port furthest downstream, and which showed that tracer gas and particle COVs were smaller when operating one fan than when operating two fans. As shown in Table A.5 the velocity COV for Case 3 was the highest of the three cases. This is another result supported by the testing of Glissmeyer and Droppo, which showed that velocity uniformity was less for one fan operations and improved for two-fan operations.

While the Case 2 simulation results show good velocity COVs, the ANSI/HPSN13.1-2011 standard does not allow simultaneous injection of tracer gas/particles at multiple locations. Additionally, the particle COVs of the best cases presented here are marginally acceptable at best, indicating that additional blending would be desirable to ensure compliance.

Table A.5. COV for velocity, particle, and tracer distributions at the sampling section.

\begin{tabular}{|l|l|l|l|l|l|l|l|l|l|l|}
\hline Case & Total & \multicolumn{3}{|l|}{ Velocity COV, \% } & \multicolumn{3}{l|}{ Particle COV, \% } & \multicolumn{2}{l|}{ Tracer gas COV, \% } \\
\cline { 3 - 12 } & $\begin{array}{l}\text { Flow, } \\
\text { cfm }\end{array}$ & Side & Top & All & Side & Top & All & Side & Top & All \\
\hline 1 & 31,840 & 5.4 & 4.4 & 4.7 & 32 & 51 & 29 & 15 & 39 & 29 \\
\hline 2 & 31,840 & 5.4 & 4.4 & 4.7 & 19 & 17 & 16 & 2.5 & 4.6 & 4.1 \\
\hline 3 & 15,920 & 8.6 & 2.4 & 6.3 & 20 & 18 & 18 & 3.4 & 6.0 & 5.0 \\
\hline
\end{tabular}

\section{Duct with Air Blender}

The addition of an air blender in the main duct is being considered to ensure low COV values at the sampling location for all expected flow operations. The air blender being considered is from Blender Products, Inc. It is a static mixer of 40-inch diameter to match the diameter of the 3410 Building duct. Figure A.8a is a photo of the device, and Figure A.8b shows the CFD model of the device created for and used in the greater stack model that generated the results presented in this section. This section compares modeled results of the duct with total flow rate of $31,840 \mathrm{cfm}$ delivered by two-fan operations, with and without the air blender.

Figure A. 9 shows the effect of the air blender on the distribution of velocity magnitude within the 3410 Building stack with fans 1 and 2 operating. Figure A.9a shows the contours of velocity magnitude in the plan view of the main duct with the air blender installed near the previous location of the mid-duct release point. Within a few duct diameters downstream of the blender, the velocity magnitude is symmetric across the duct and roughly uniform. Figure A.9b shows the contours of velocity magnitude without the air blender. In this latter case the flow swirls slowly downstream and is non-symmetric and non-uniform at the test section.

Figure A.10 shows the effect of the air blender on the distribution of $\mathrm{SF}_{6}$ tracer gas within the 3410 Building stack system. As with the velocity magnitude, the tracer gas concentration is symmetric across the duct and roughly uniform within a few duct diameters downstream of the blender as 
shown in Figure A.10a. Without the air blender the tracer gas follows the air flow pattern and is non-symmetric and non-uniform at the test section (Figure A.10b). At the project planning stage, $\mathrm{SF}_{6}$ tracer was considered to be used. However, after the new tracer nitrous oxide $\left(\mathrm{N}_{2} \mathrm{O}\right)$ was validated prior to the beginning of the retesting project, it was decided that $\mathrm{N}_{2} \mathrm{O}$ would be used for stack testing. Details of the $\mathrm{N}_{2} \mathrm{O}$ tracer method was incorporated in the revised PNNL procedure (Glissmeyer, 2013). An article is being prepared to report new findings.

The counter-rotating inner and outer flows through the air blender serve to mix the air within just a few duct diameters, downstream of which the flow settles into a non-circulating pattern. This effect can be seen in Figure A.11a which shows tracer particle paths through the air blender being quickly dispersed downstream of the device. Figure A.11b shows the same particle paths in plan view. In this expanded view the particle paths within about 3 to 5 duct diameters have been dispersed and are traveling straight down the duct. The particle dispersion is illustrated by Figure A.12, which shows particle distributions at several stations downstream of the air blender. At 1 duct diameter the particles are somewhat scattered, but by 5 diameters the particles are well dispersed. Likewise at 10 diameters and at 14 diameters, where the sampling section is located, the particles are well dispersed within the duct.

Maximum flow angles and velocity, tracer gas, and tracer particle COVs at various stations downstream of the air blender inlet are shown in Figure A.13. The maximum flow angle at 1 duct diameter downstream of the air blender is quite large at $43^{\circ}$, the angle then decreases to about $1^{\circ}$ at 5 diameters, and is less than $1^{\circ}$ at greater distances downstream. Similarly, tracer gas and velocity COVs decrease to quite small values within 5 diameters downstream of the air blender. And COV for the tracer particles are well within compliance values as well. These results indicate that addition of the Blender Products, Inc. air blender to the 3410 Building filtered exhaust stack system will ensure compliance with the ANSI/HPSN13.1-2011 standard.

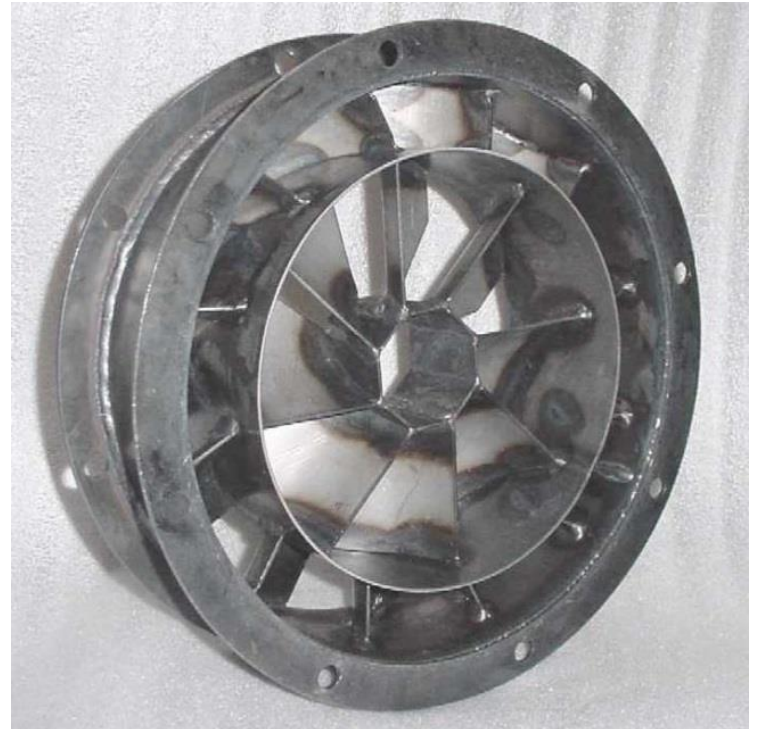

a)

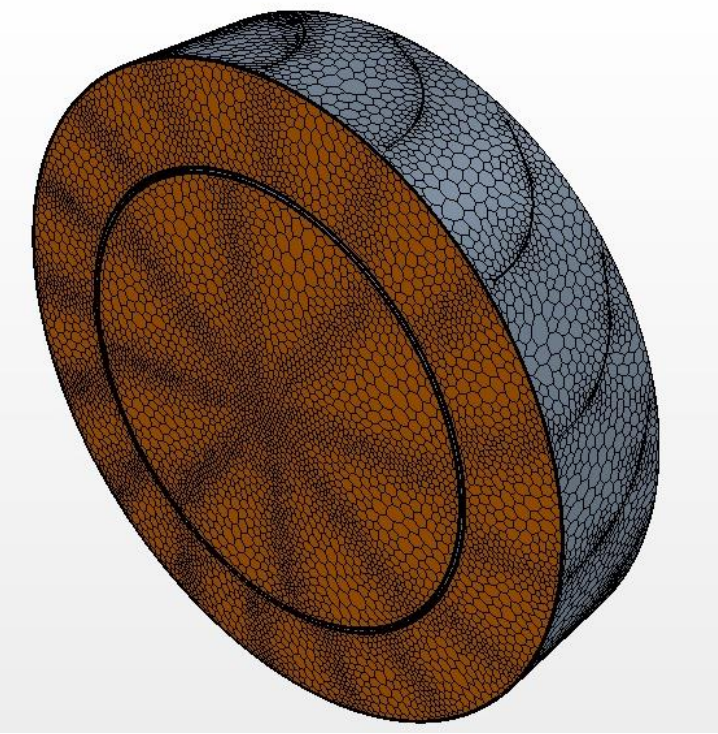

b)

Figure A.8. Static air blender S40C3S: a) photograph of sample device, b) CFD model. 


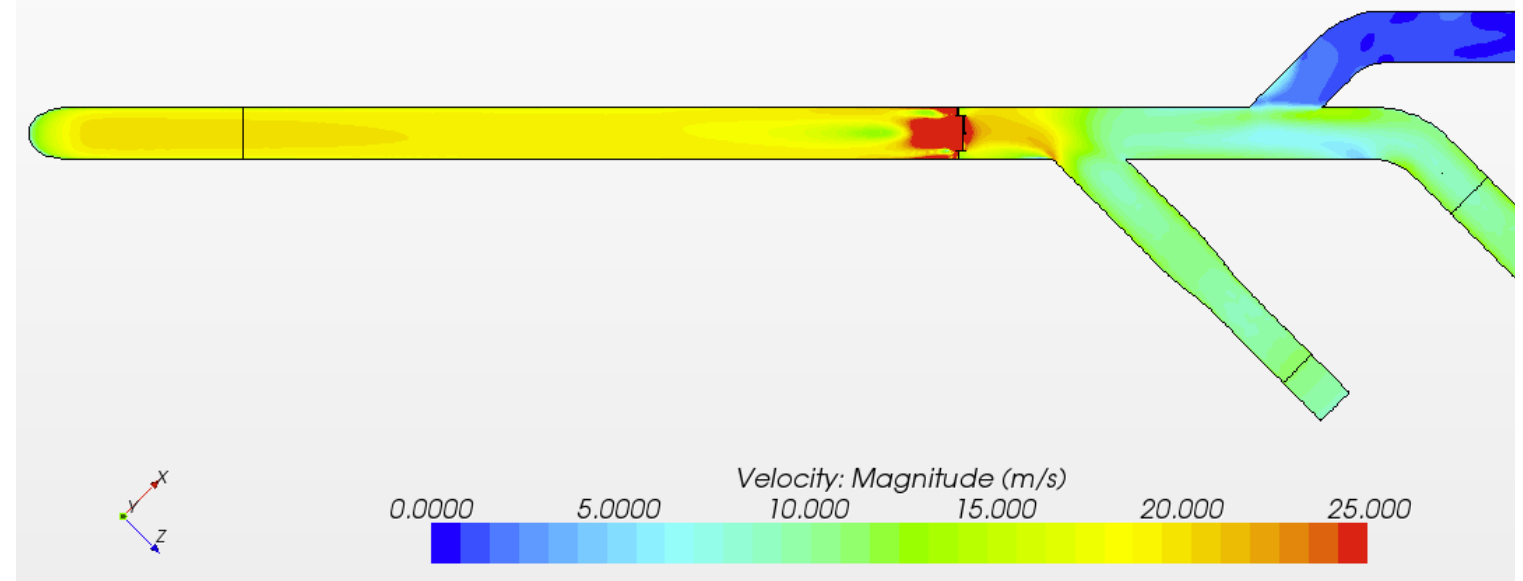

a)

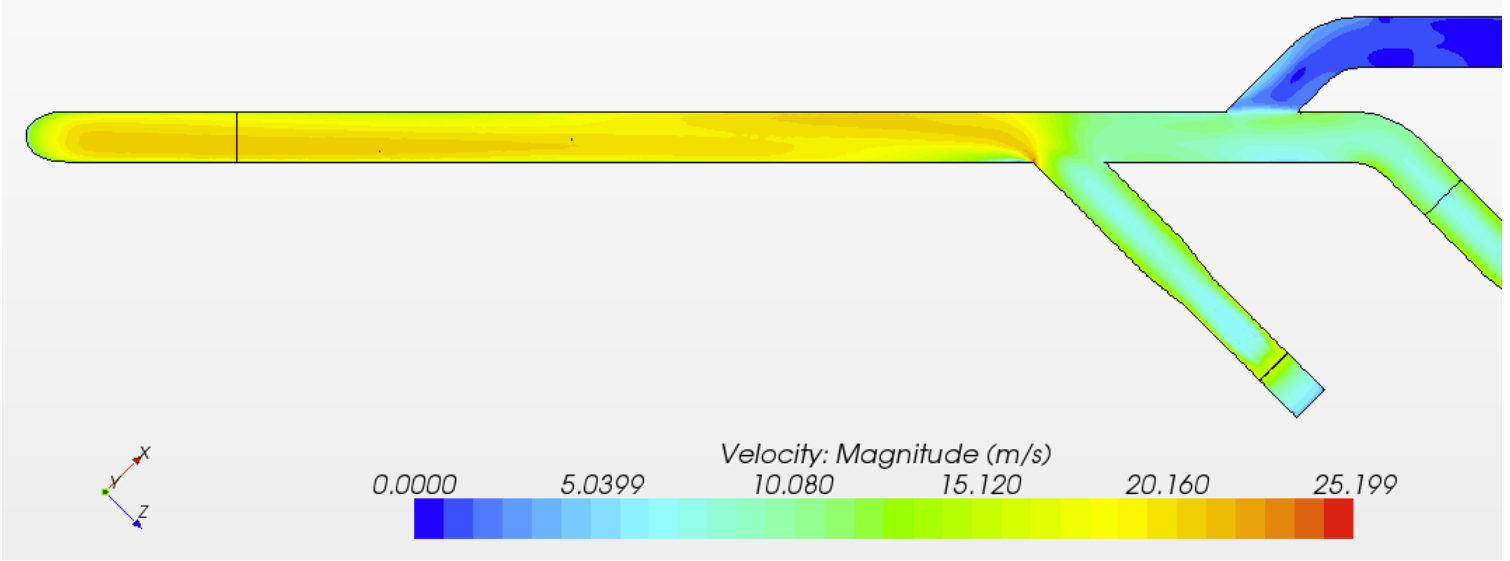

b)

Figure A.9. Contours of velocity magnitude in the plan view for: a) the duct with the air blender installed, b) no air blender. 


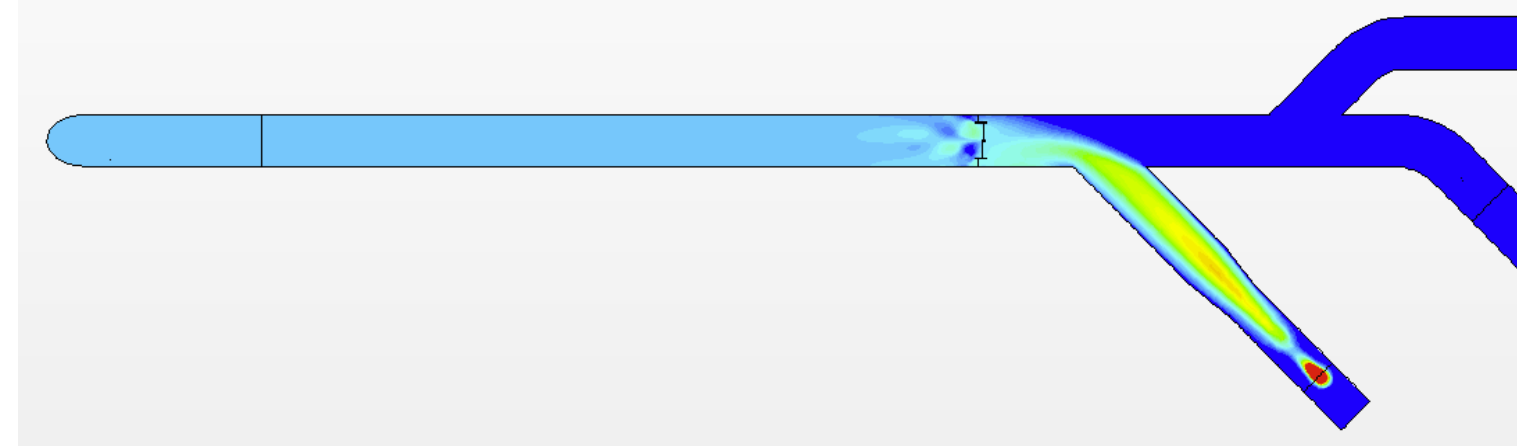

a)

b)

Figure A.10. Contours of $\mathrm{SF}_{6}$ tracer gas concentration in plan view for the duct with: a) the air blender installed, and b) no air blender. 


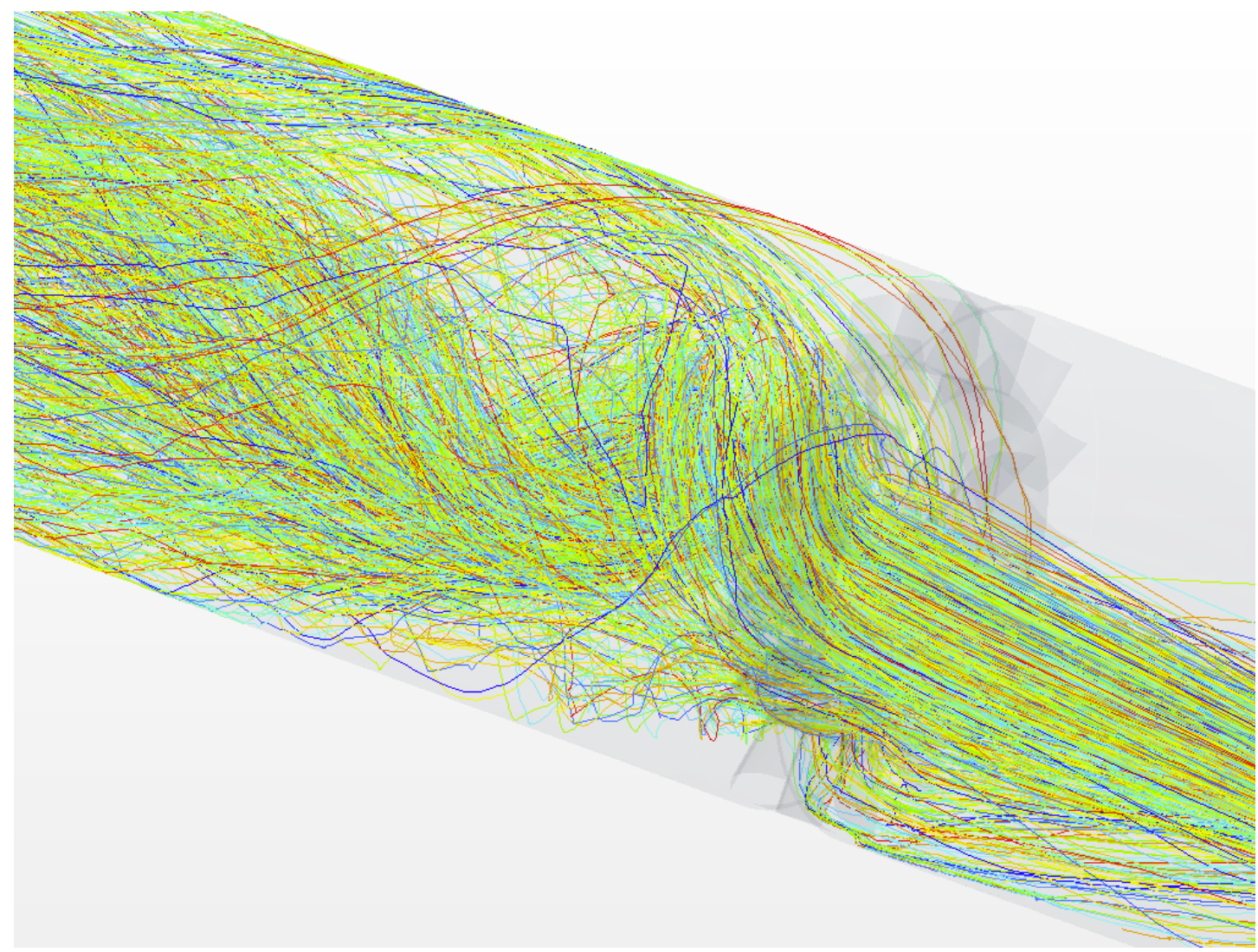

a)

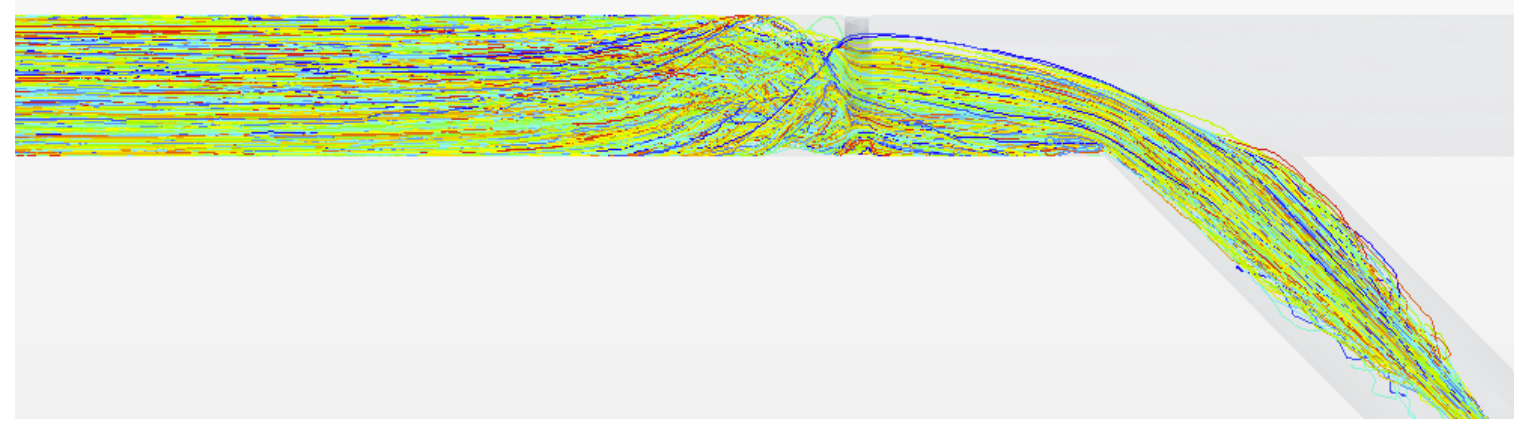

b)

Figure A.11. Tracer particle paths through the air blender: a) 3-D view, and b) plan view. 


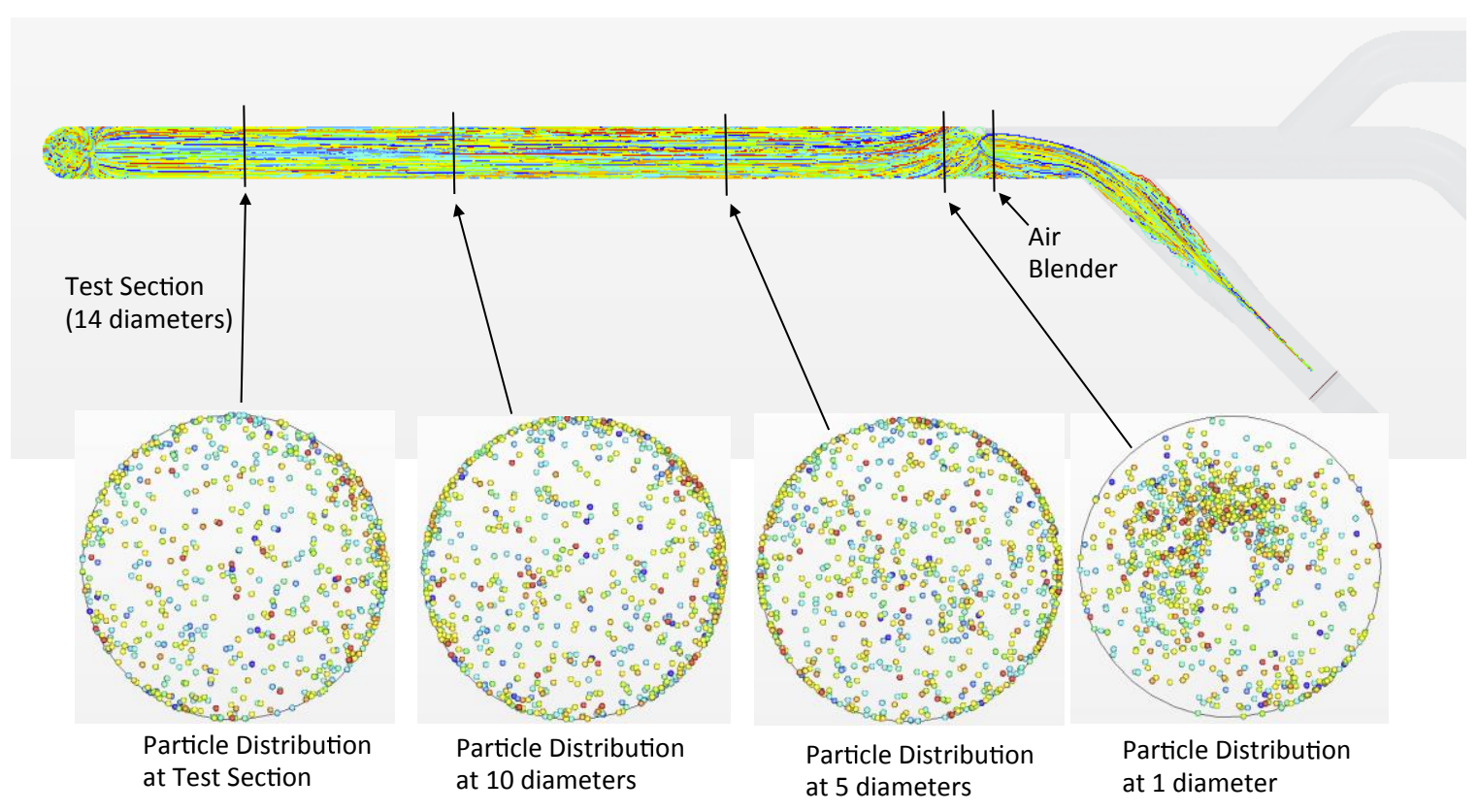

Figure A.12. Tracer particle distributions at several stations downstream of the air blender.

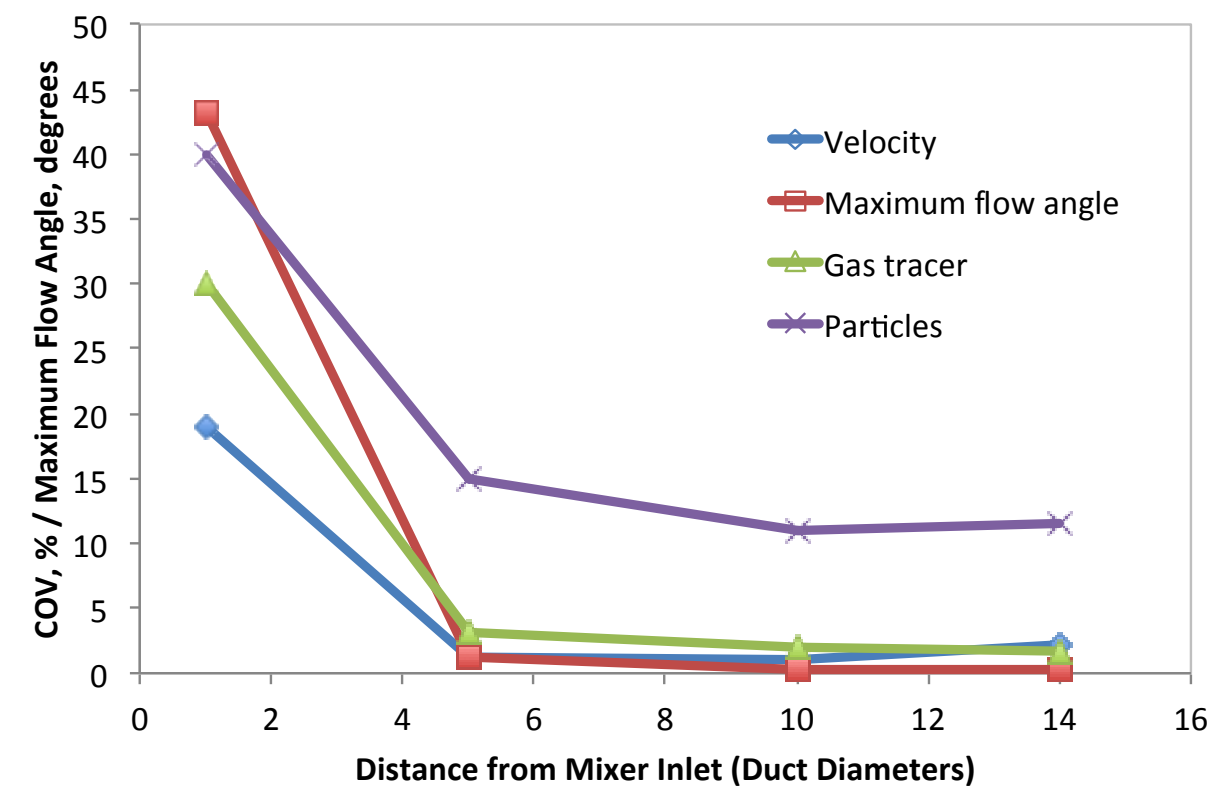

Figure A.13. Maximum flow angle (degrees) and COV for velocity, tracer gas, and tracer particles.

\section{Conclusions}

Based on the CFD modeling of the 3410 Building filtered exhaust stack system the following conclusions are drawn:

- The CFD model provides flow angle and velocity uniformity COV values that are in good agreement with those derived from testing of the actual stack. 
- Modeling results for the maximum total flow of 31,840 cfm predict that differences in the flow distributions at the sampling location will exist depending upon the fan combination used, but that the velocity uniformity COV values should remain well within compliance.

- Simulations of tracer gas mixing and tracer particle dispersion within the duct show that tracer release points are best placed at locations that provide greater duct length for mixing of the tracers within the air streams.

- Simulations examining the effect of using various tracer release locations show that mixing of tracers within the stream of each fan is achieved much more readily than blending of the two fans streams together in the main duct. These simulations also show that tracer COV values are smaller when operating one fan than when operating two fans, and they show that velocity uniformity is less for one fan than for two fans. These results are supported by experimental data.

- Modeling results of the duct with total flow rate of 31,840 cfm delivered by two-fan operations, predict that velocity uniformity, tracer concentrations, and flow angle criteria established by the ANSI/HPSN13.1-2011 standard will be met with the addition of the Blender Products, Inc. air blender.

\section{References}

ANSI/HPS - American National Standards Institute/Health Physical Society. 2011. Sampling and Monitoring Releases of Airborne Radioactive Substances from the Stack and Ducts of Nuclear Facilities. N13.1-2011. Health Physics Society, McLean, Virginia.

CD-Adapco. 2012. User Guide STAR-CCM+ Version 7.02.011.

JA Glissmeyer. 2013, EMS-JAG-01. Rev. 4. Test to Determine Uniformity of a Tracer Gas at a Sampler Probe.

JA Glissmeyer and JE Flaherty. 2010. Assessment of the 3410 Building filtered exhaust stack Sampling Probe Location. PNNL-19562. RPT-STMON-005. Pacific Northwest National Laboratory, Richland, Washington.

JA Glissmeyer and JG Droppo. 2007. Assessment of the HV-C2 Stack Sampling Probe Location. PNNL16611, Pacific Northwest National Laboratory, Richland, Washington.

FP Incropera and DP DeWitt. 1985. Introduction to Heat Transfer, Second Edition. John Wiley and Sons.

BBB Jensen. 2007. Numerical study of influence of inlet turbulence parameters on turbulence intensity in the flow domain: incompressible flow in pipe system. Proceedings Of The Institution Of Mechanical Engineers Part E-Journal Of Process Mechanical Engineering. 221(4): 177-186.

KP Recknagle, ST Yokuda, MY Ballinger and JM Barnett. 2009. Scaled Tests and Modeling of Effluent Stack Sampling Location Mixing, Health Physics, 96(2): 164-174.

DF Young et al. 1997. A Brief Introduction to Fluid Mechanics. John Wiley and Sons. 


\section{Appendix B: Data Sheets}

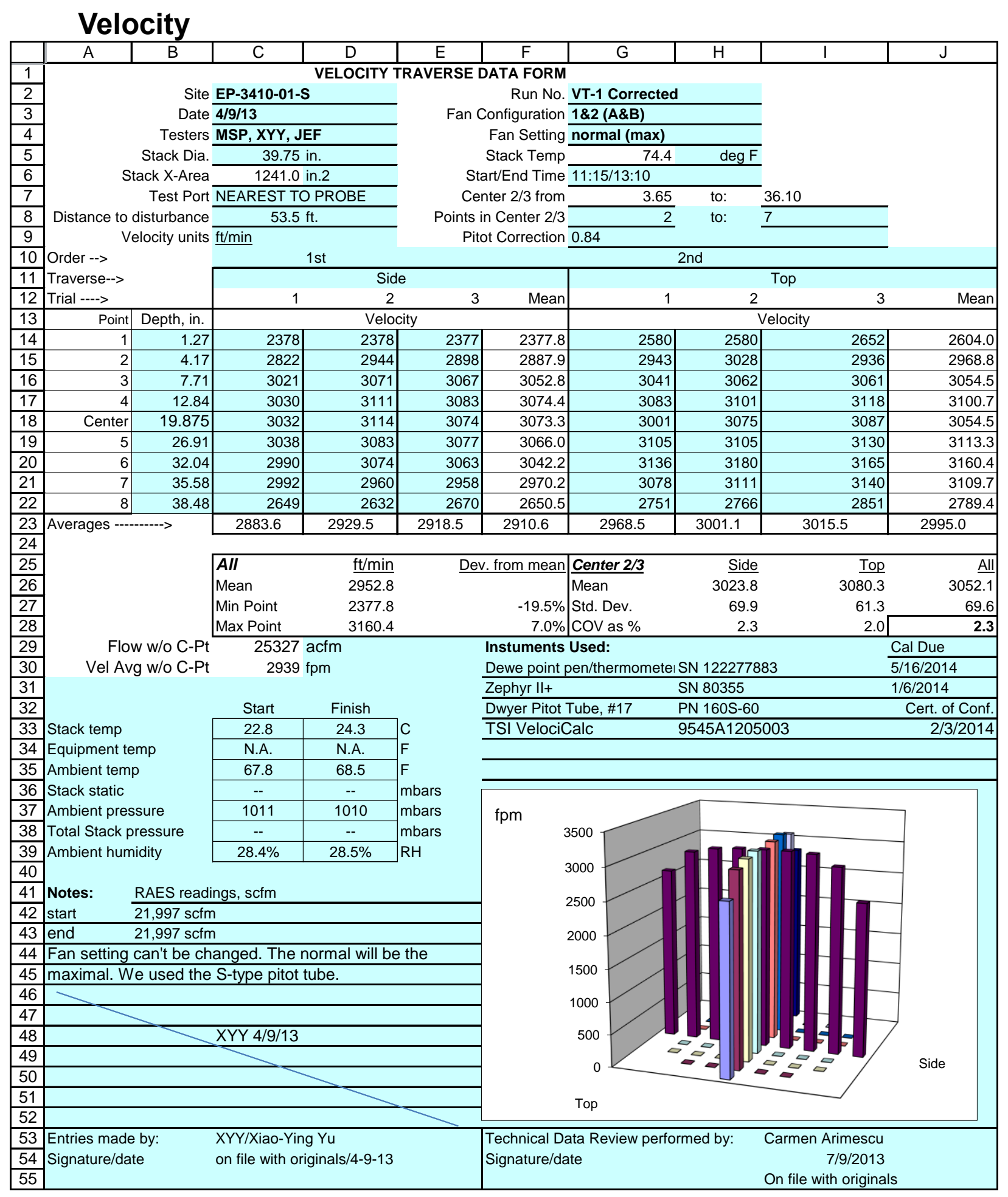




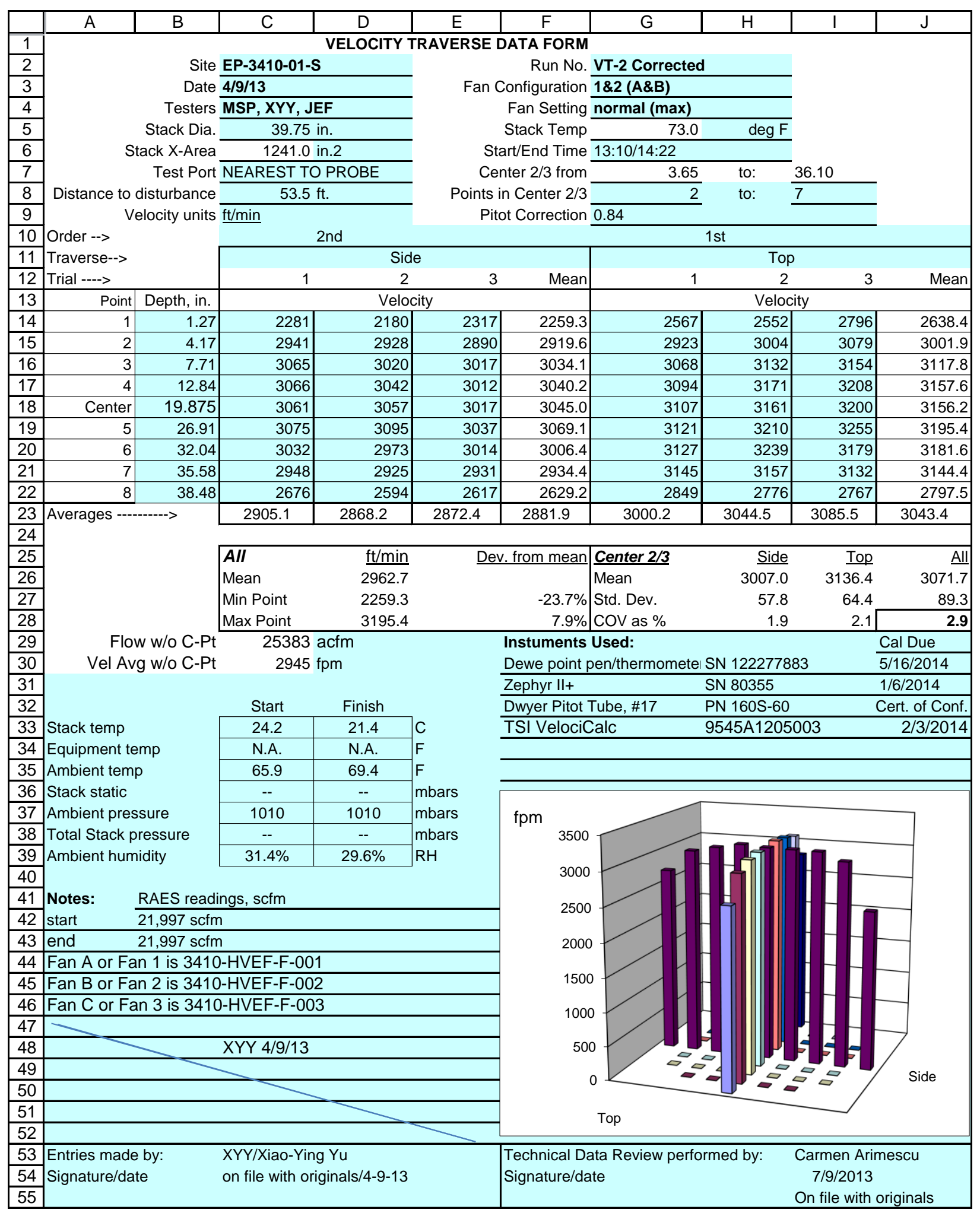




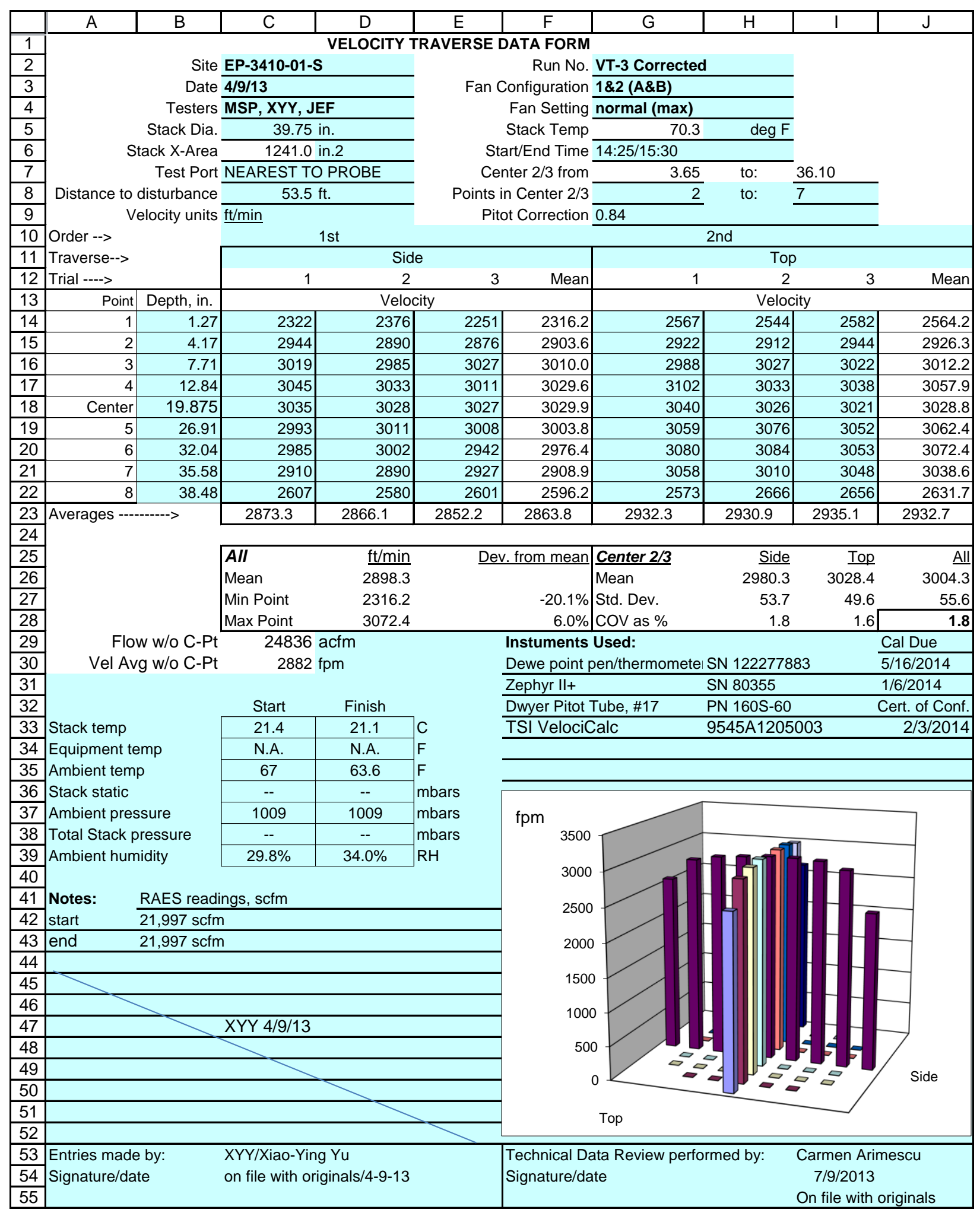




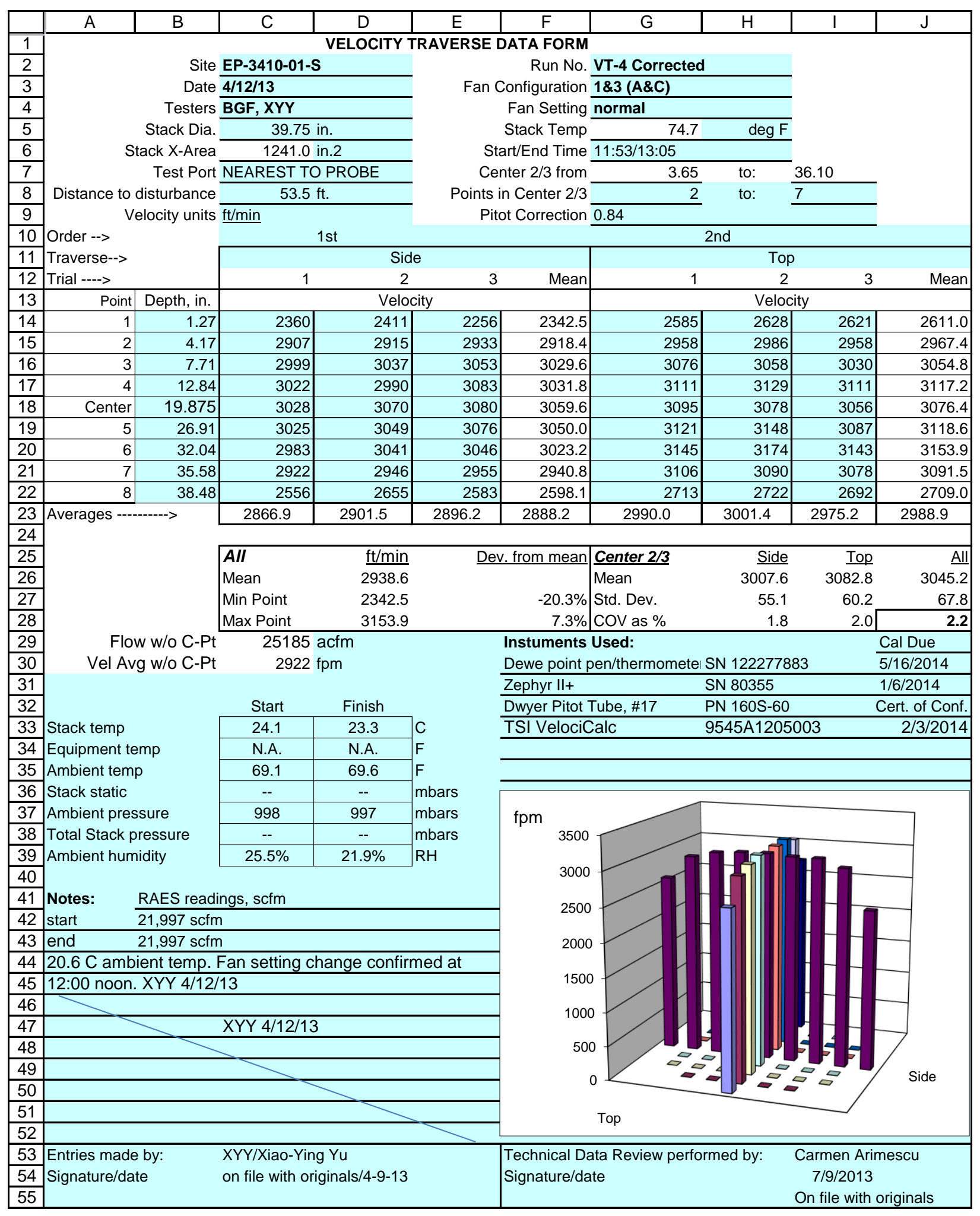




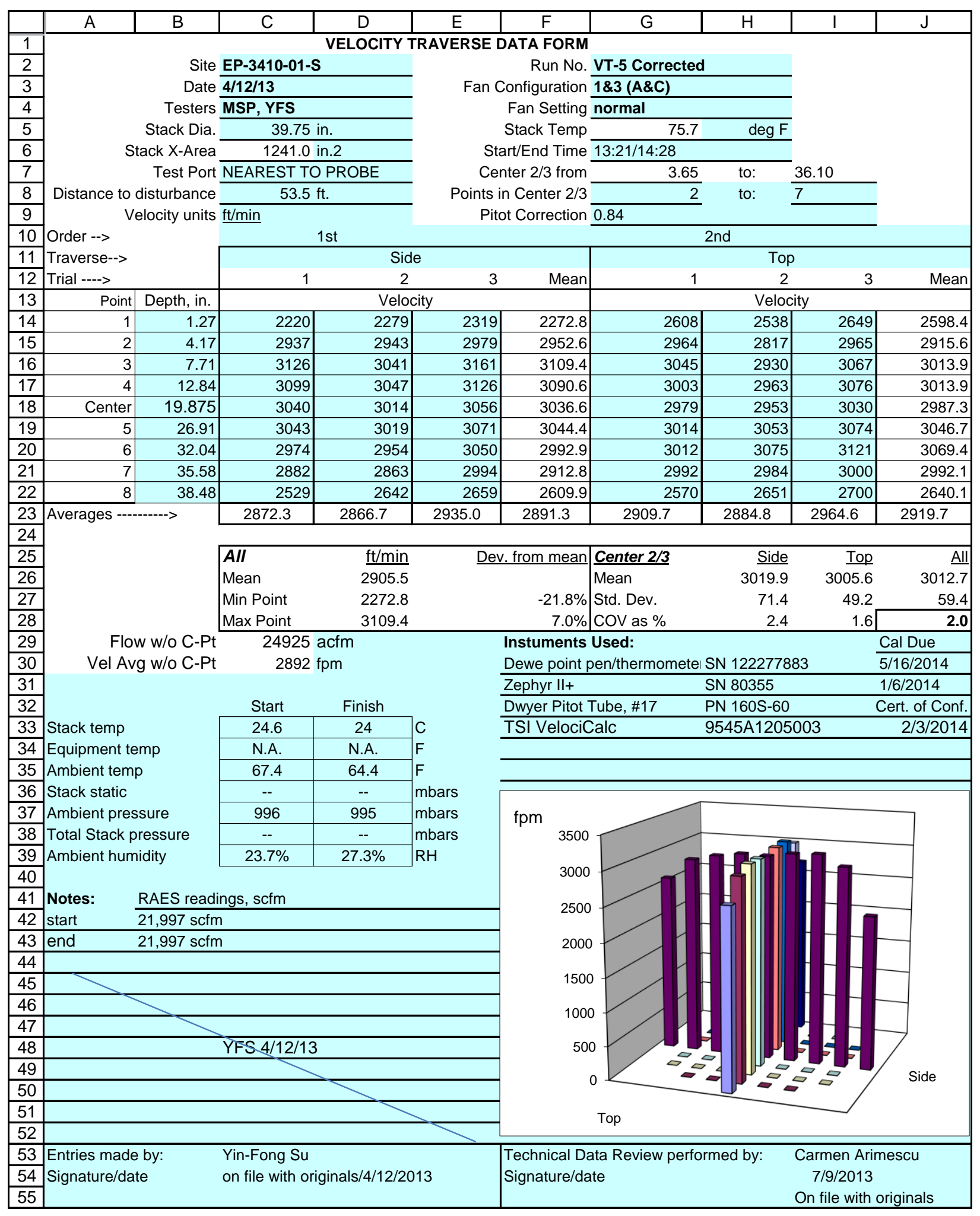




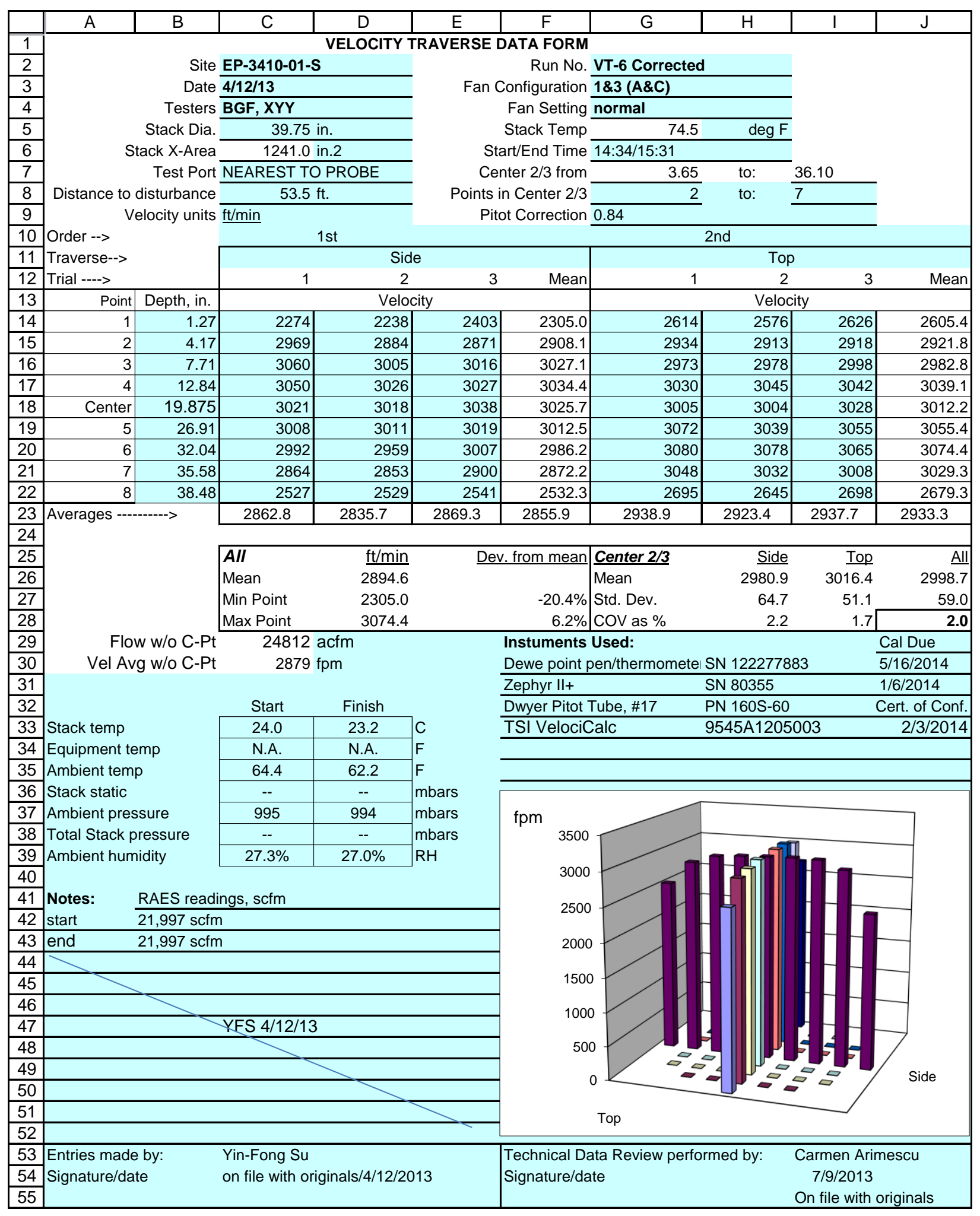




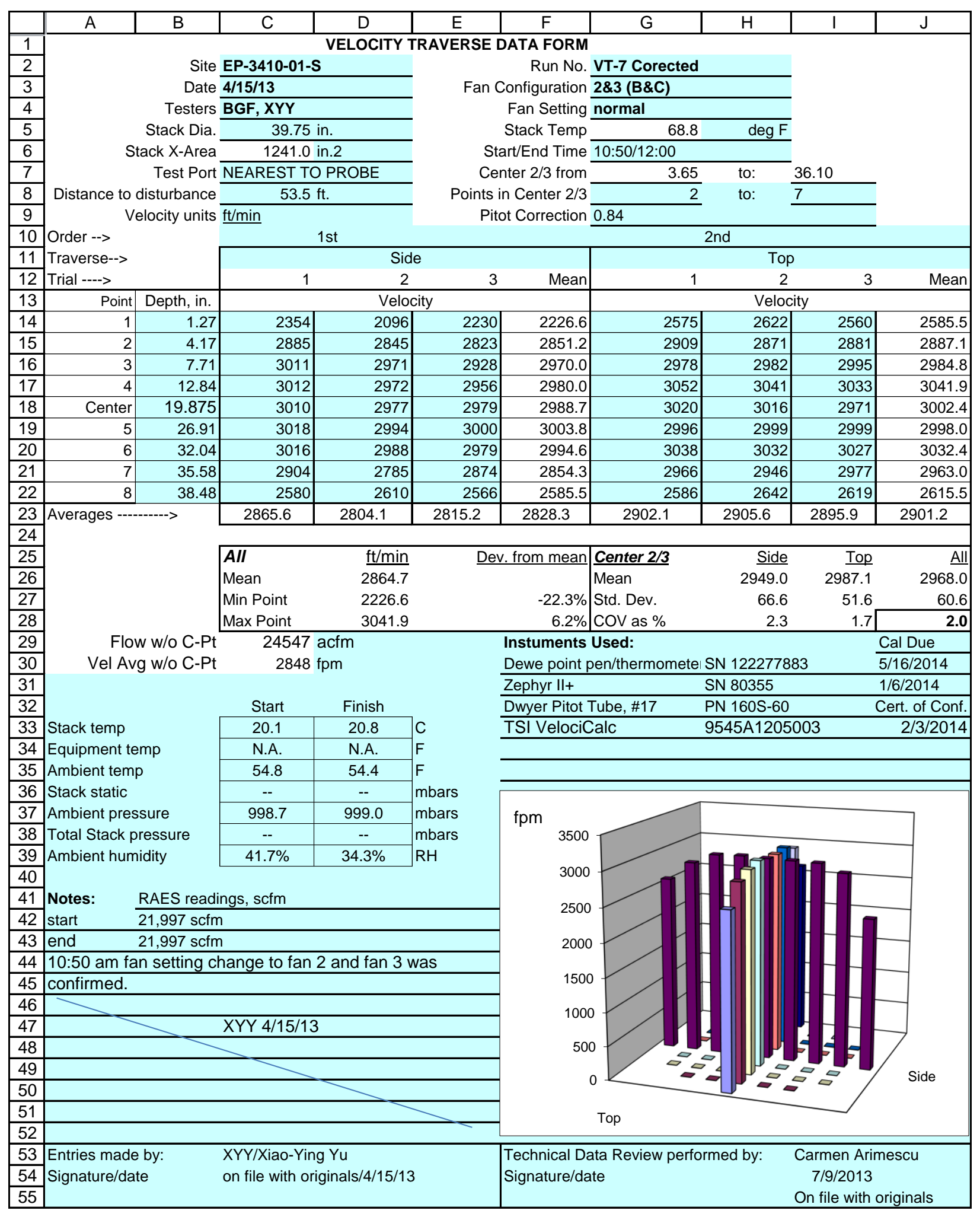




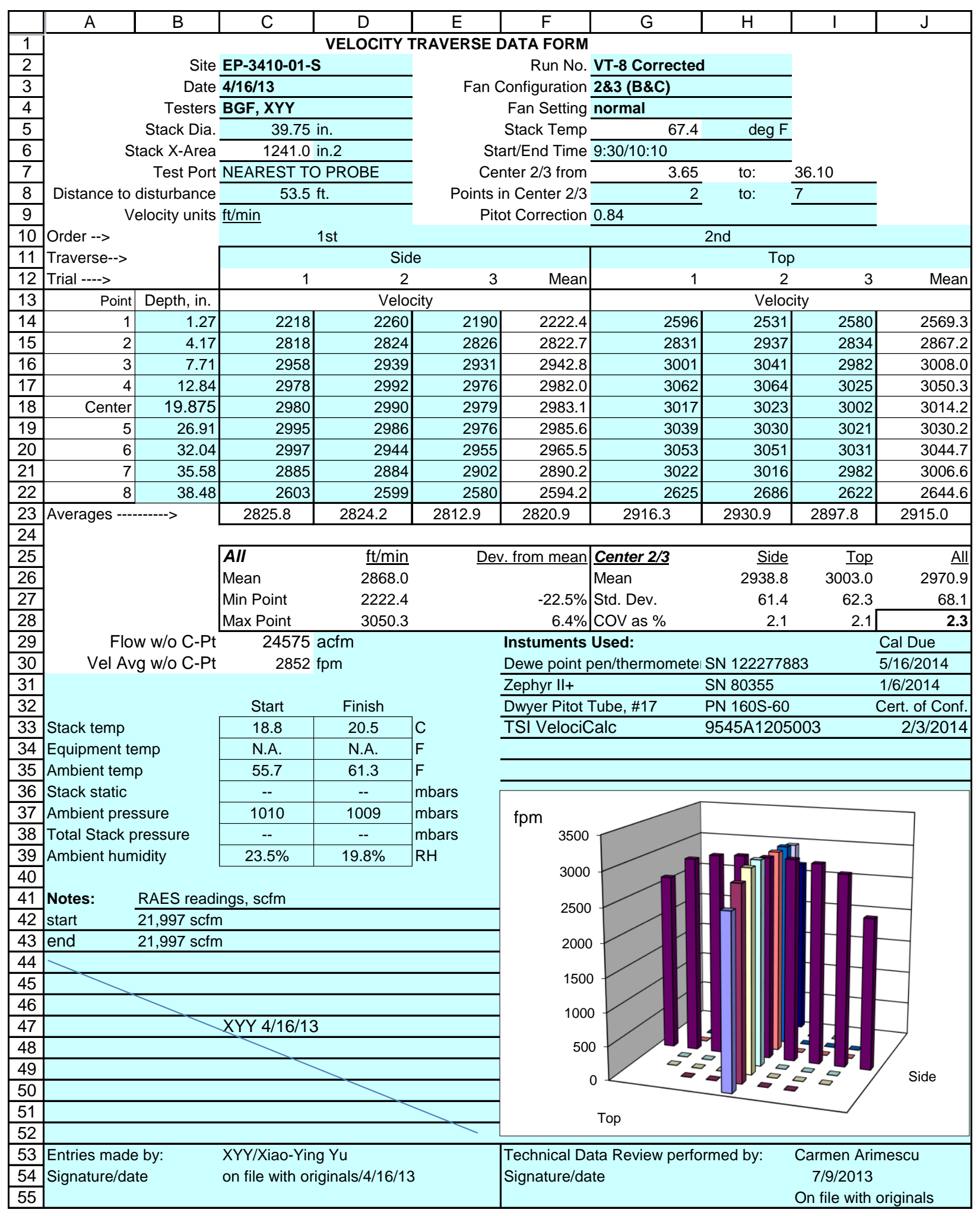




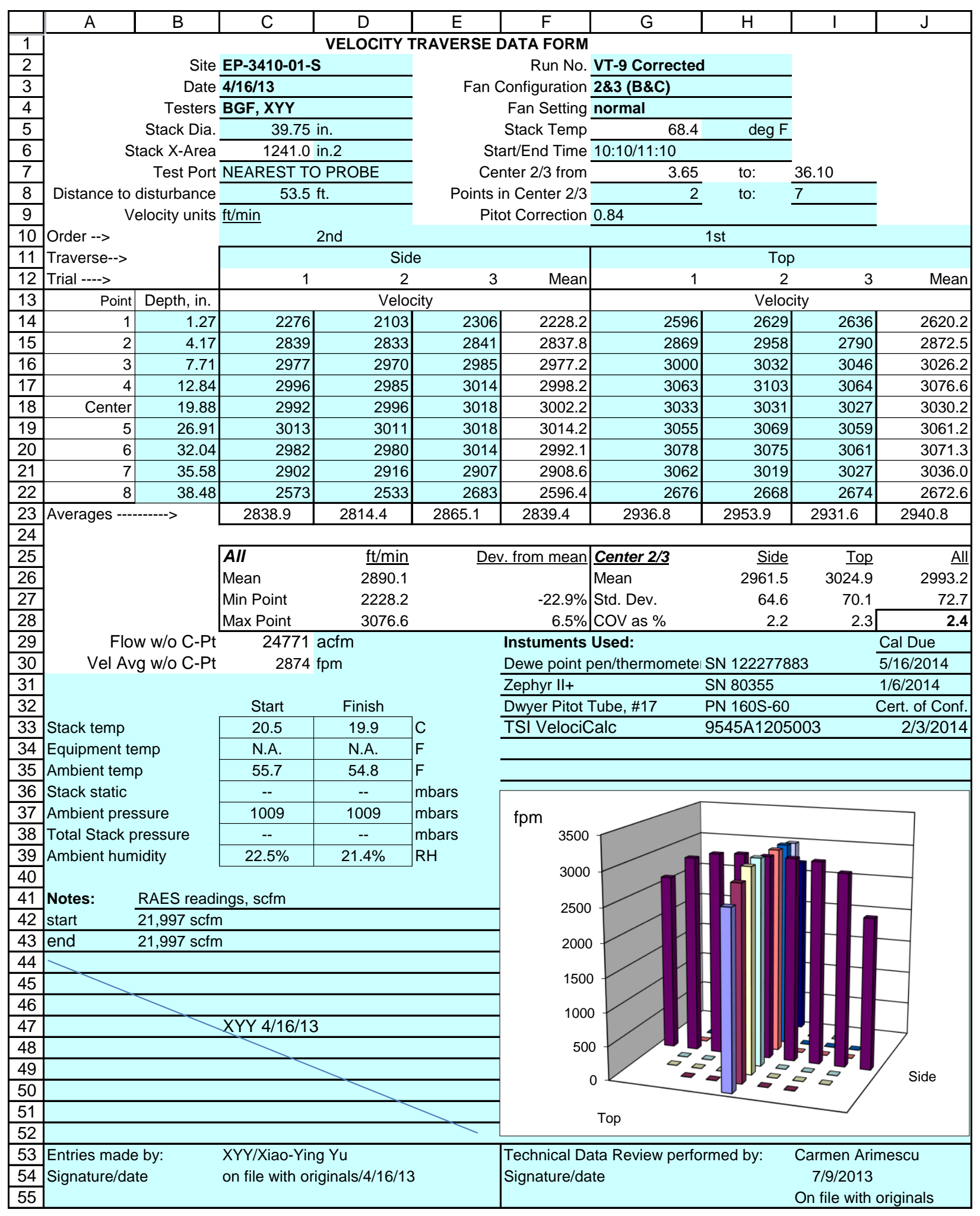




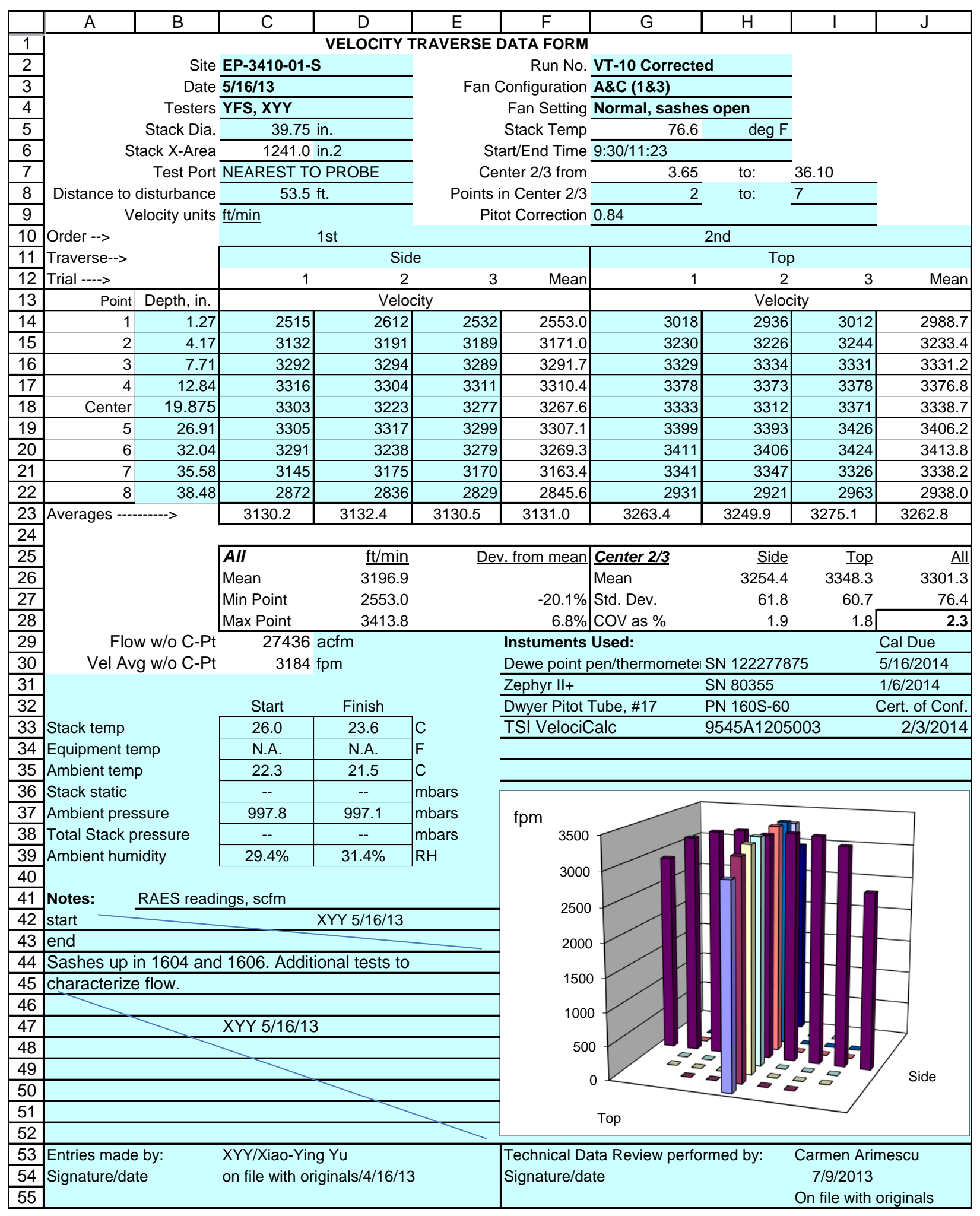




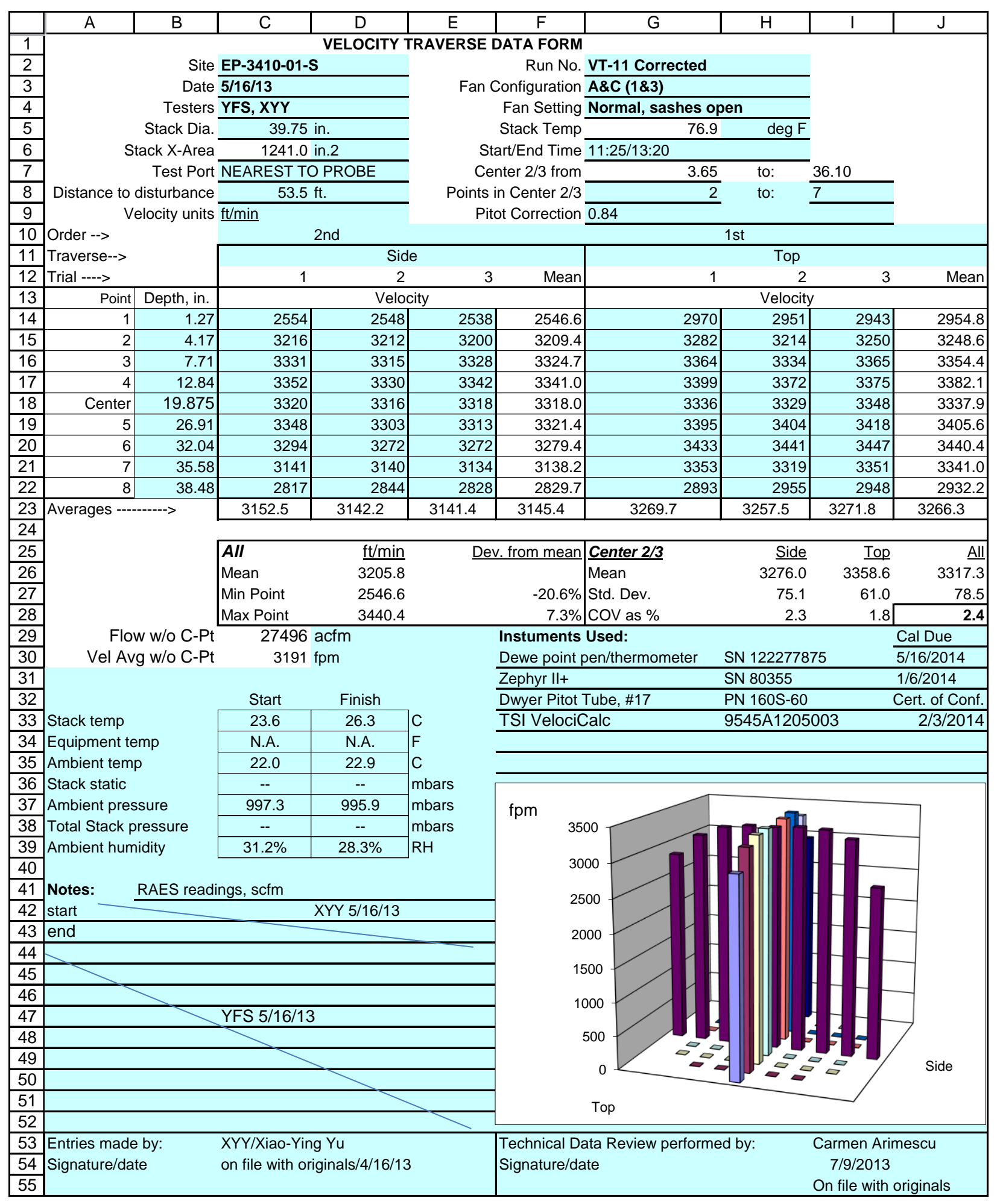




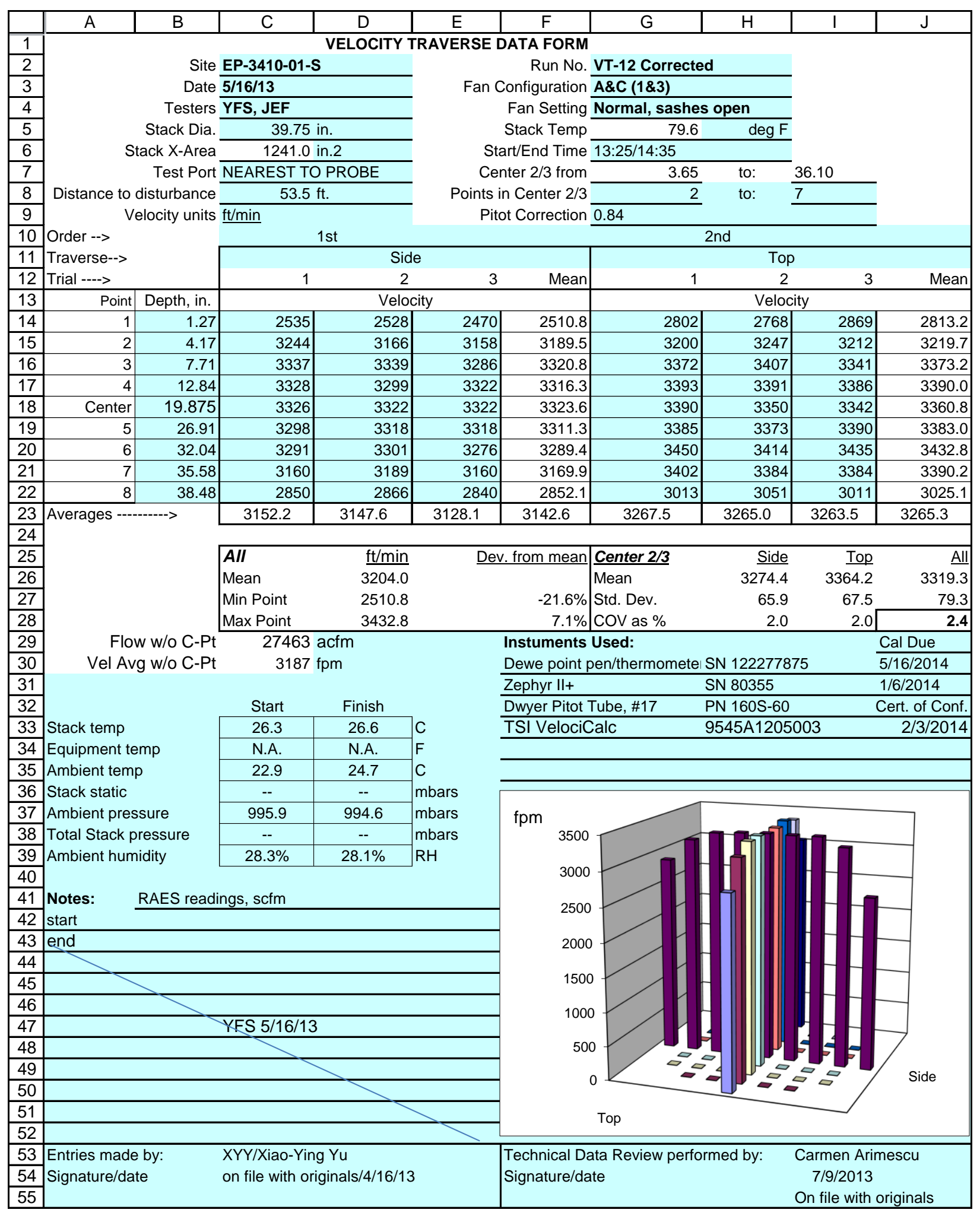




\section{Flow Angle}

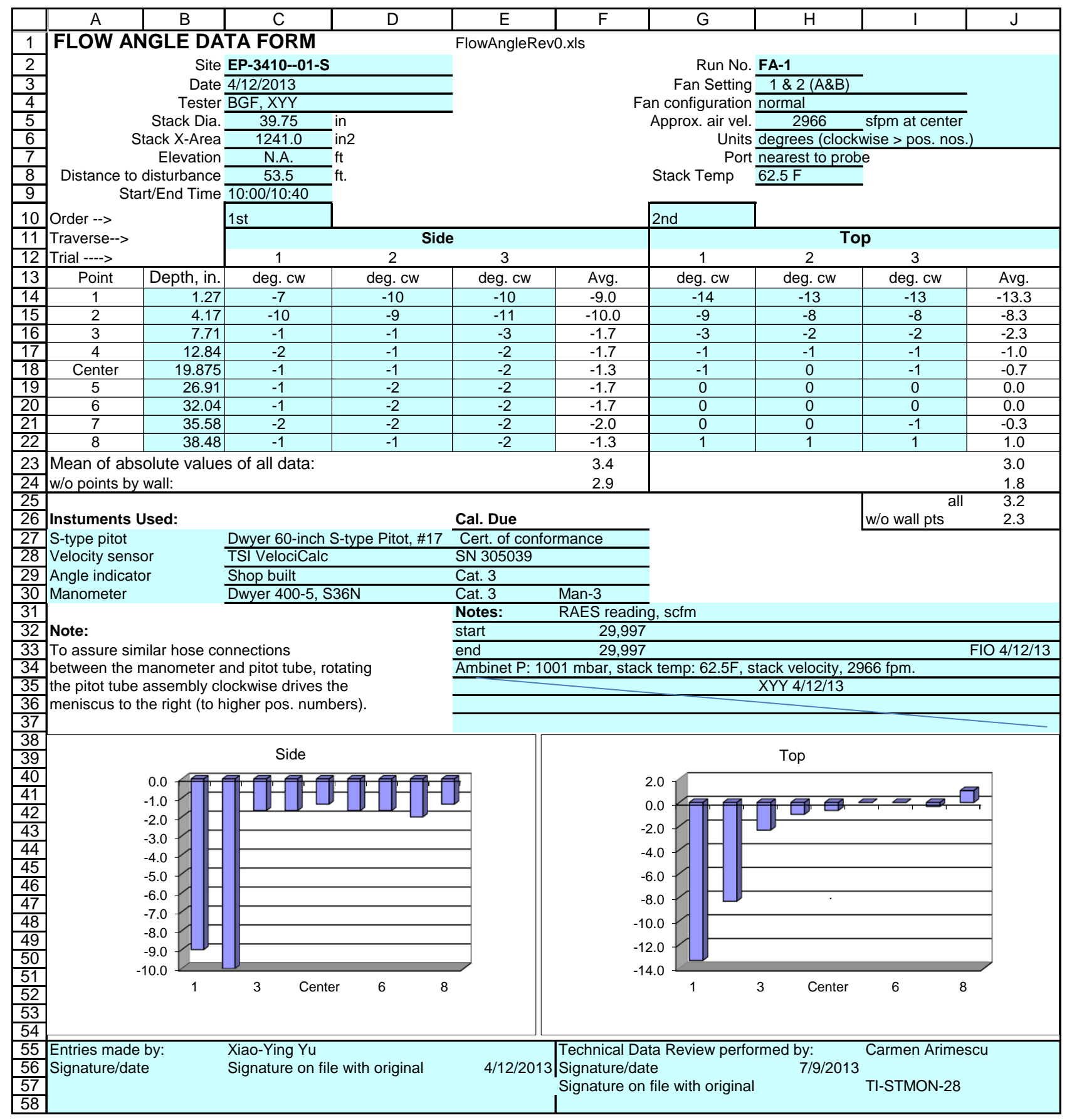




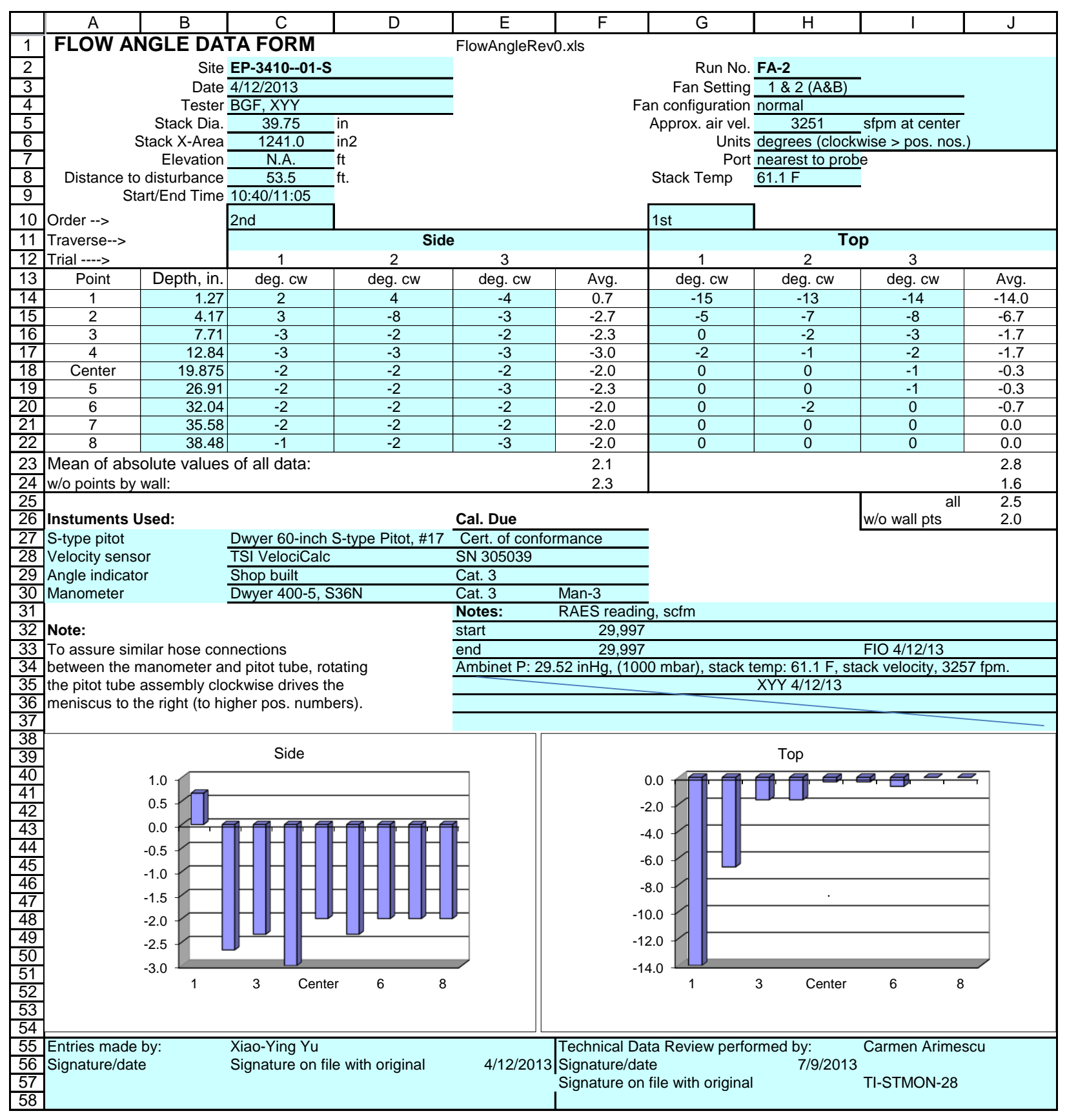




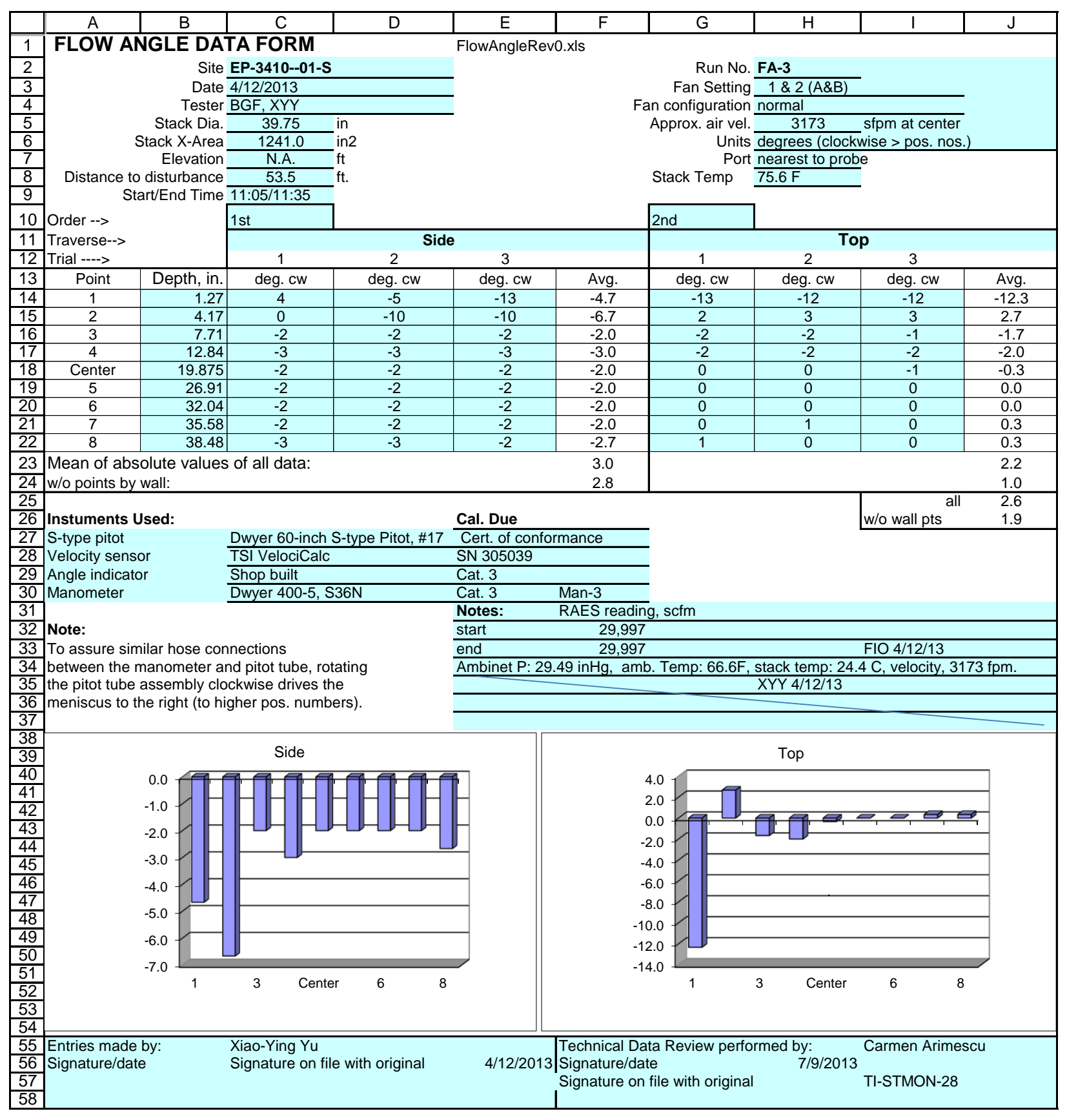




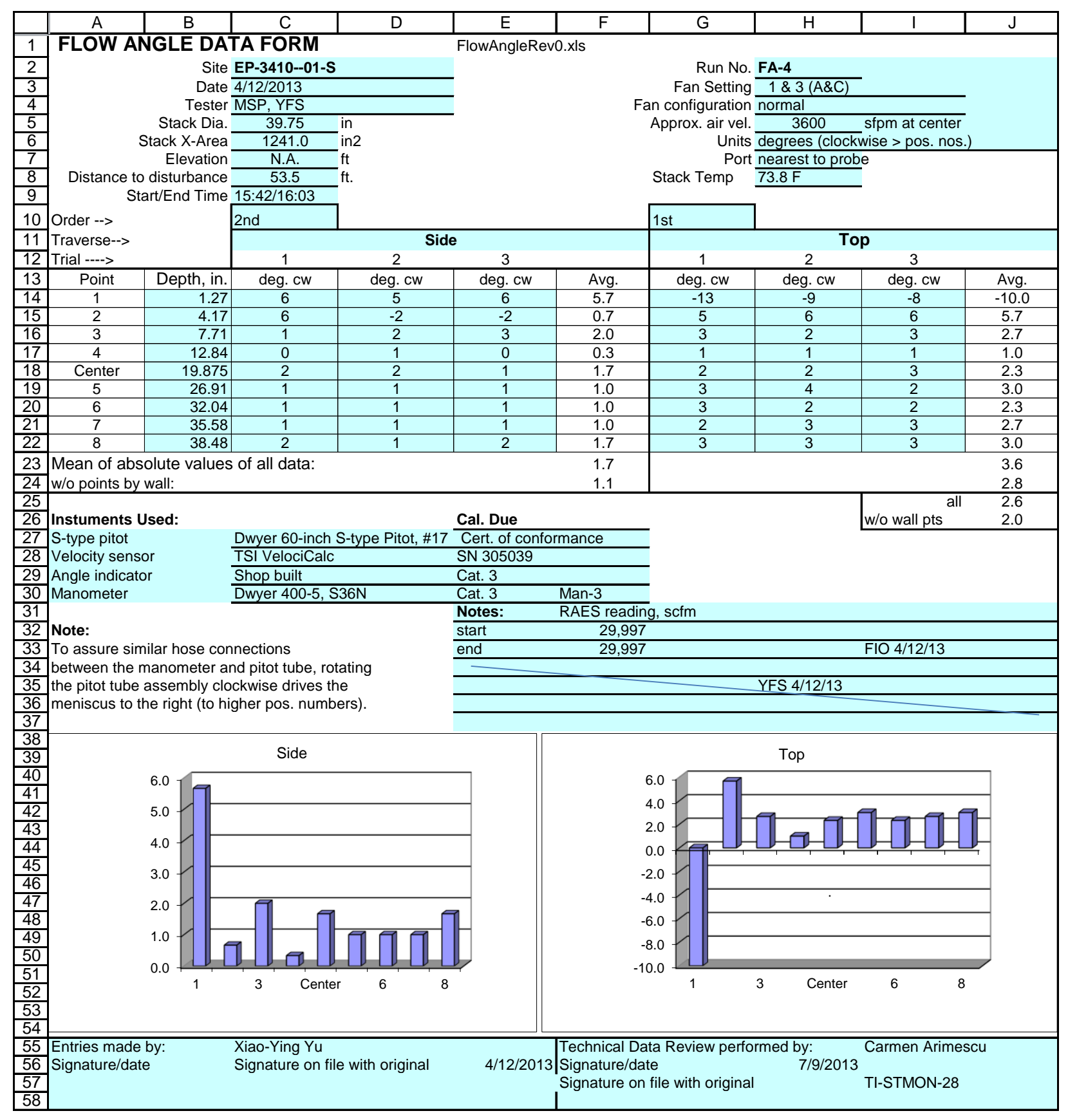




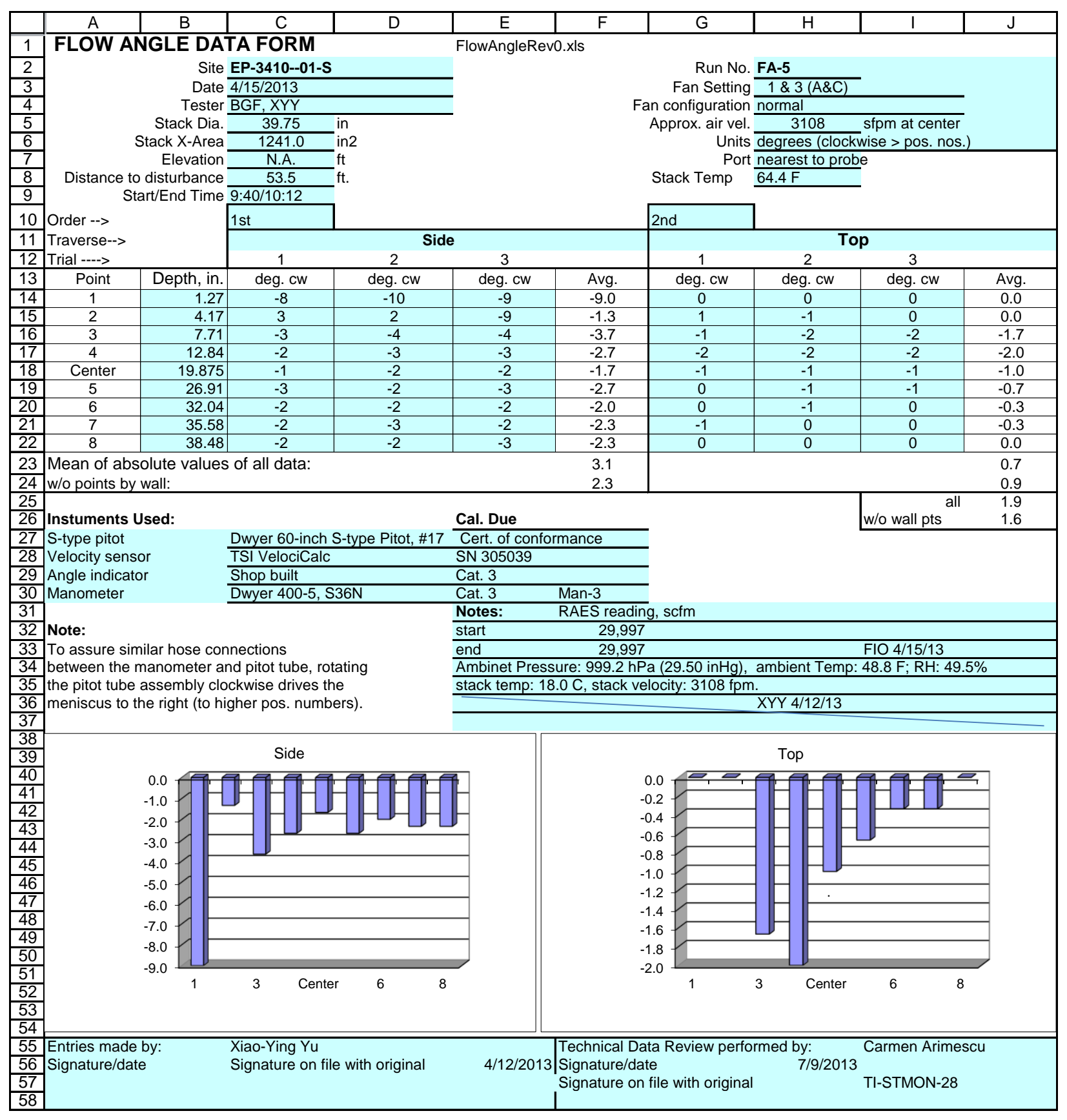




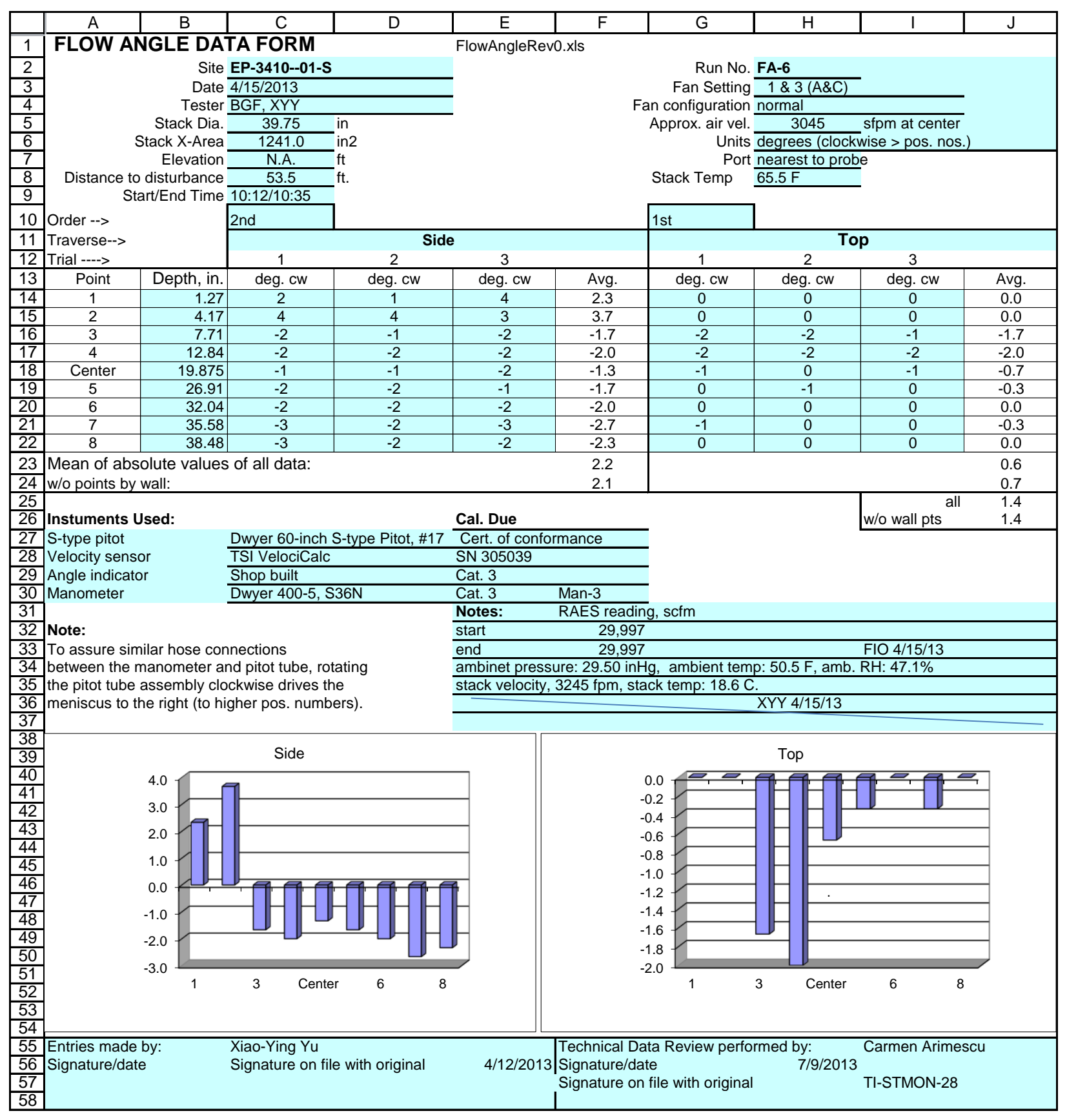




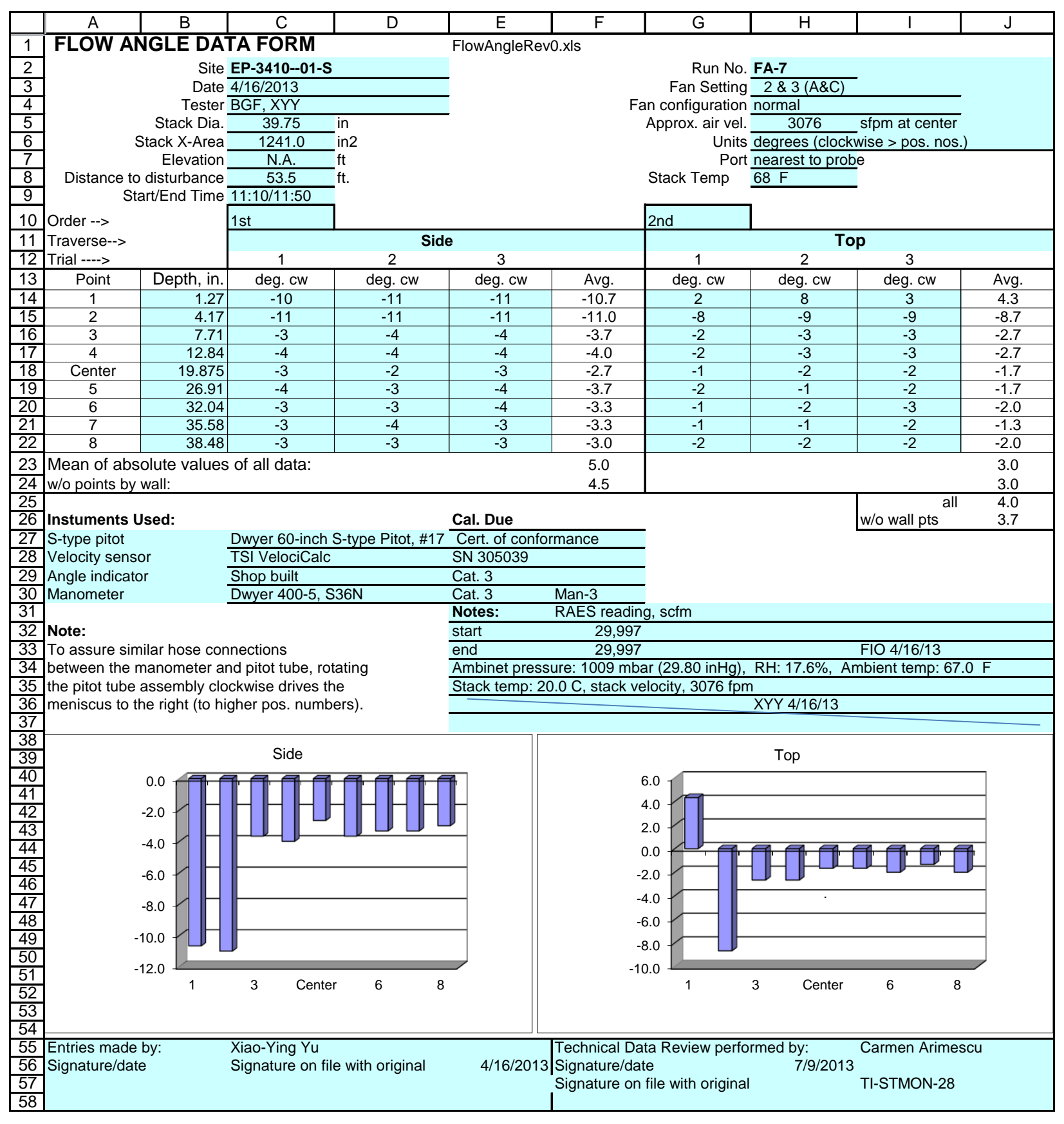




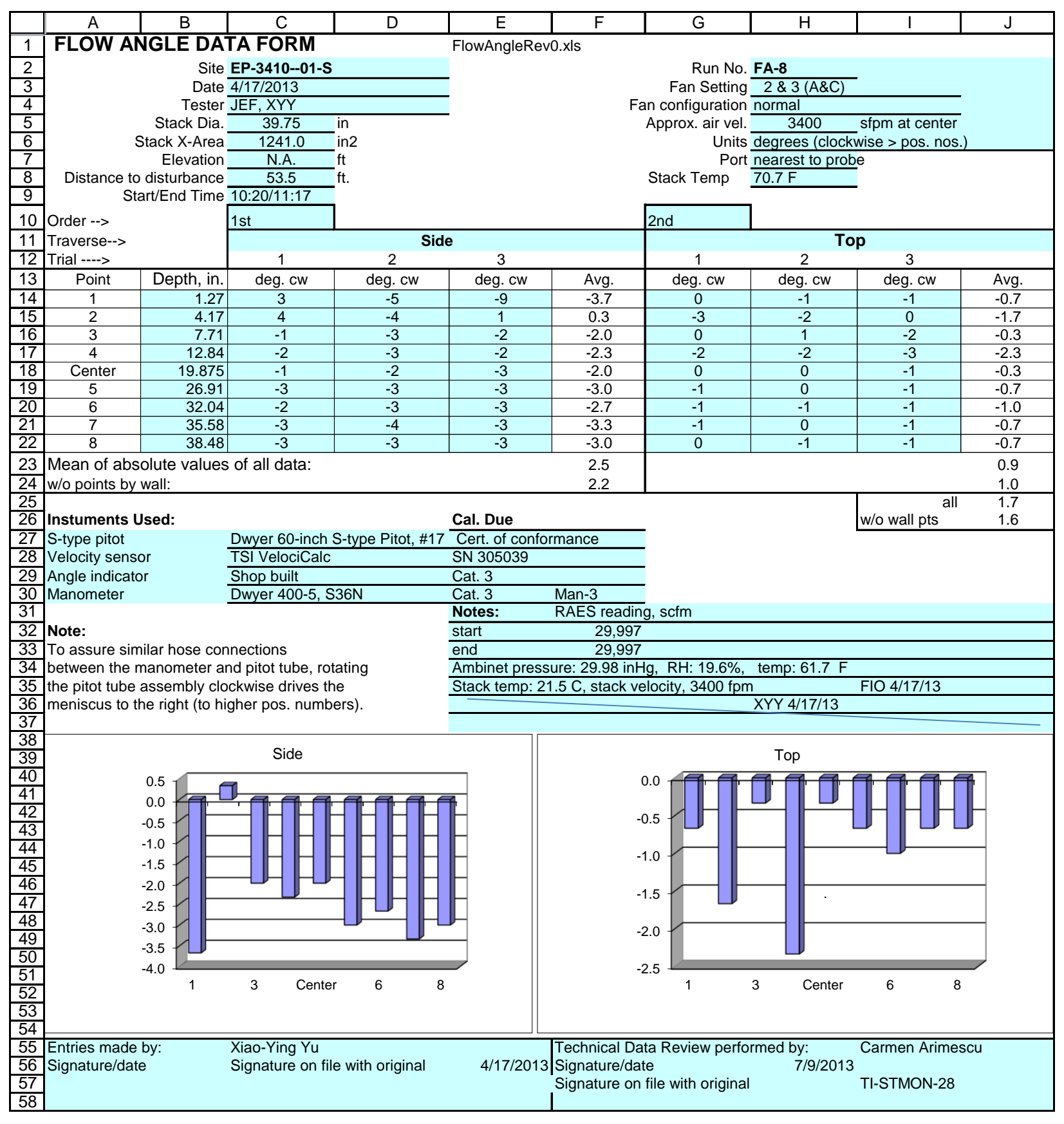




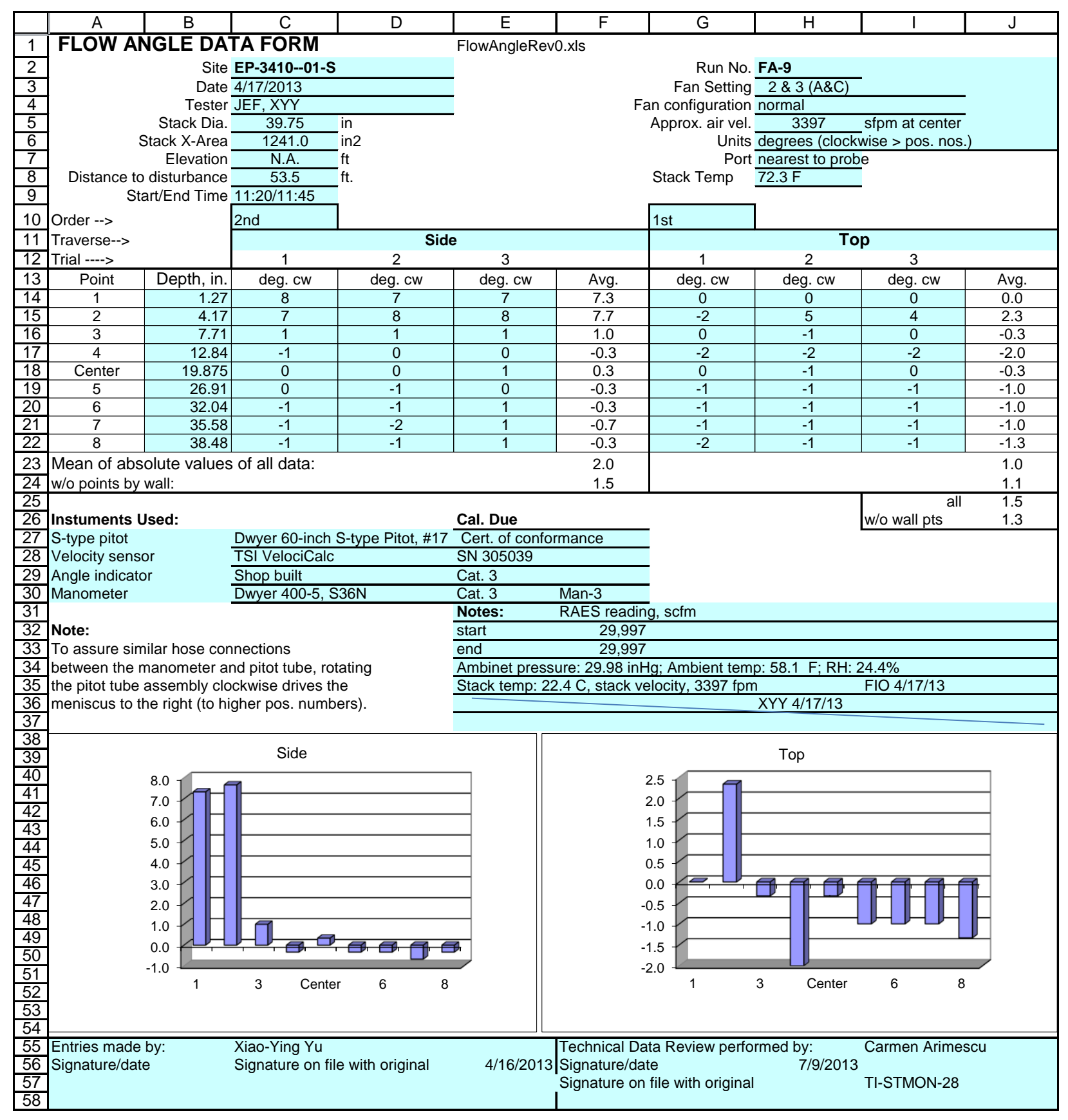




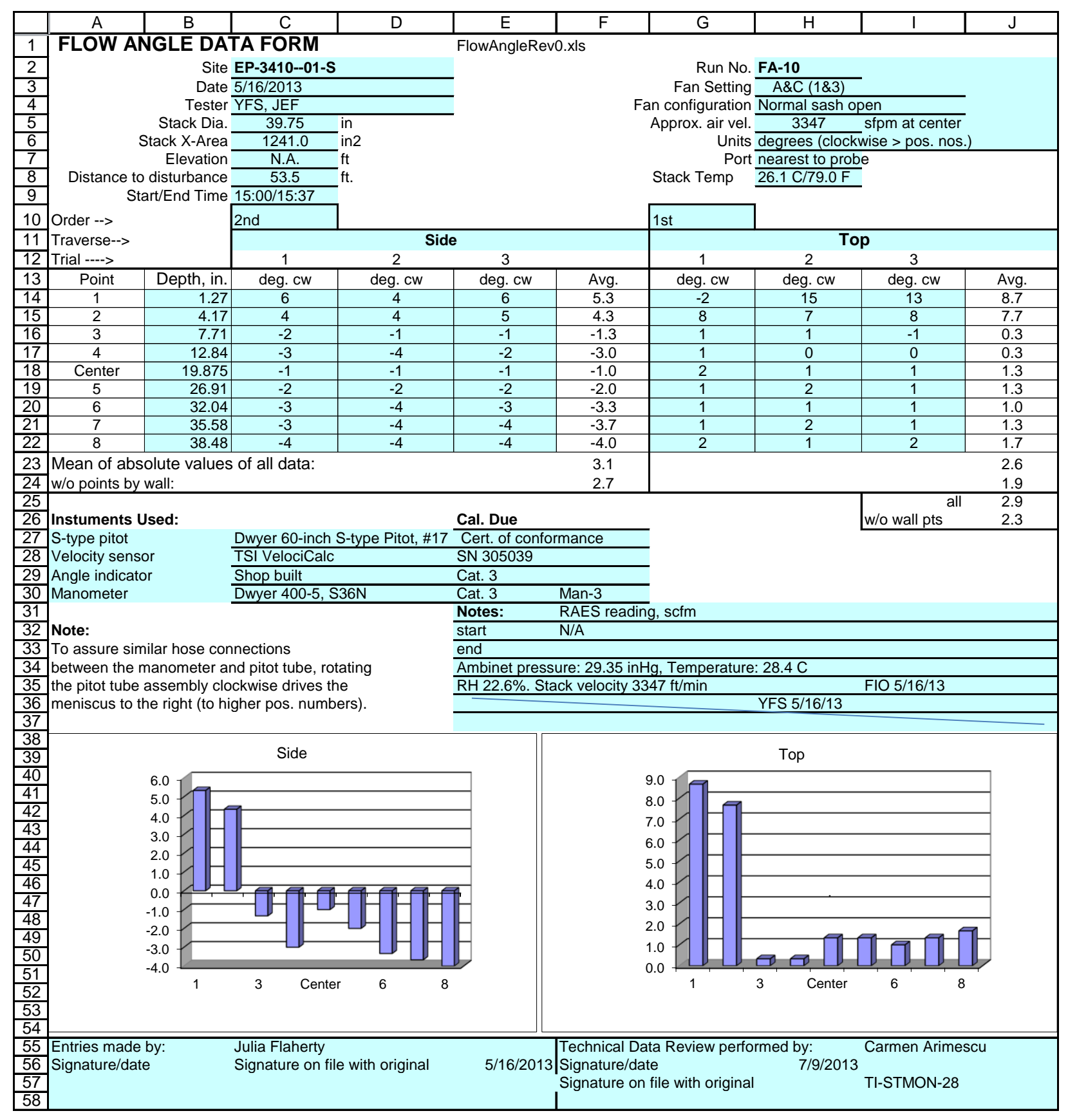




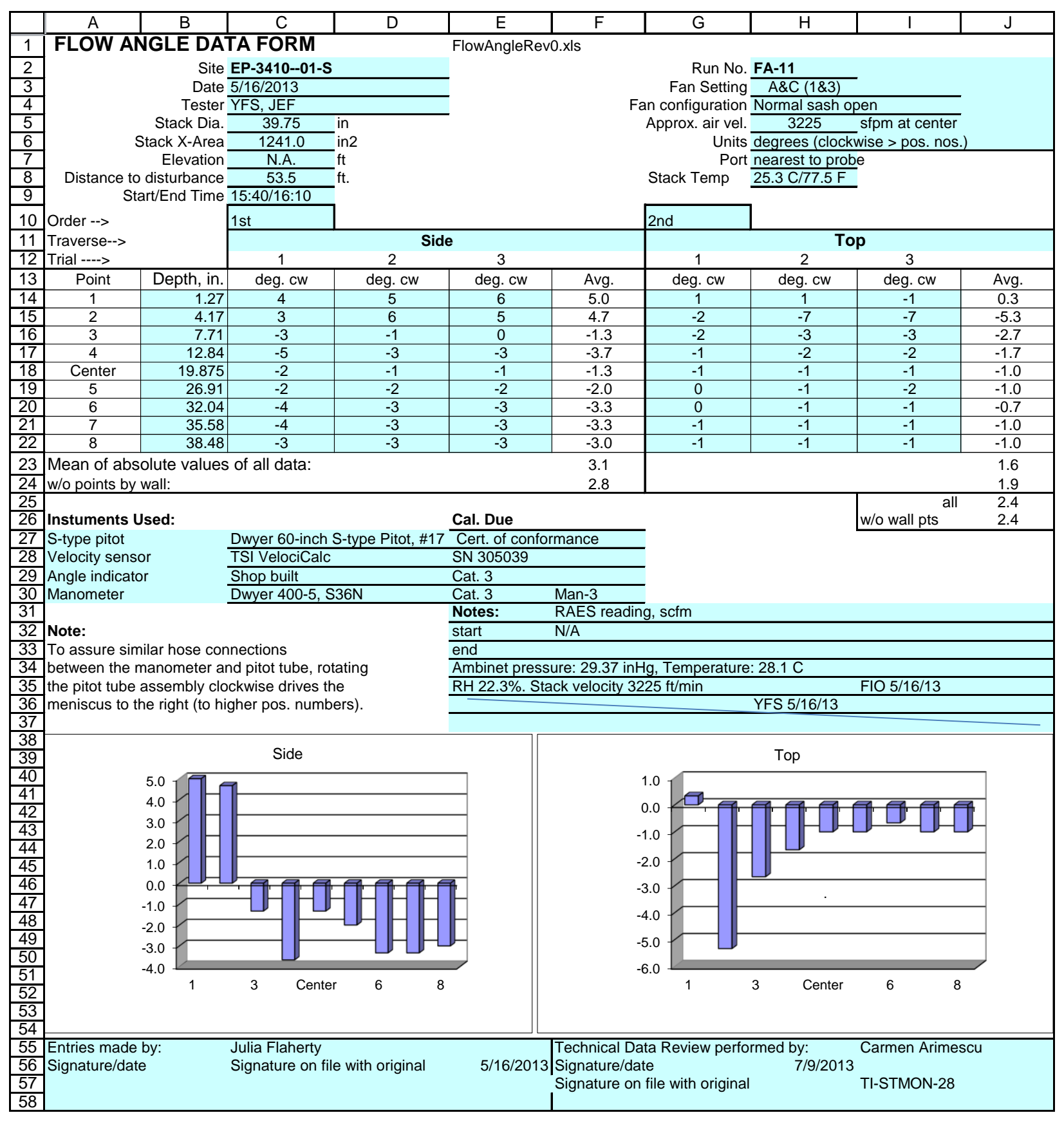




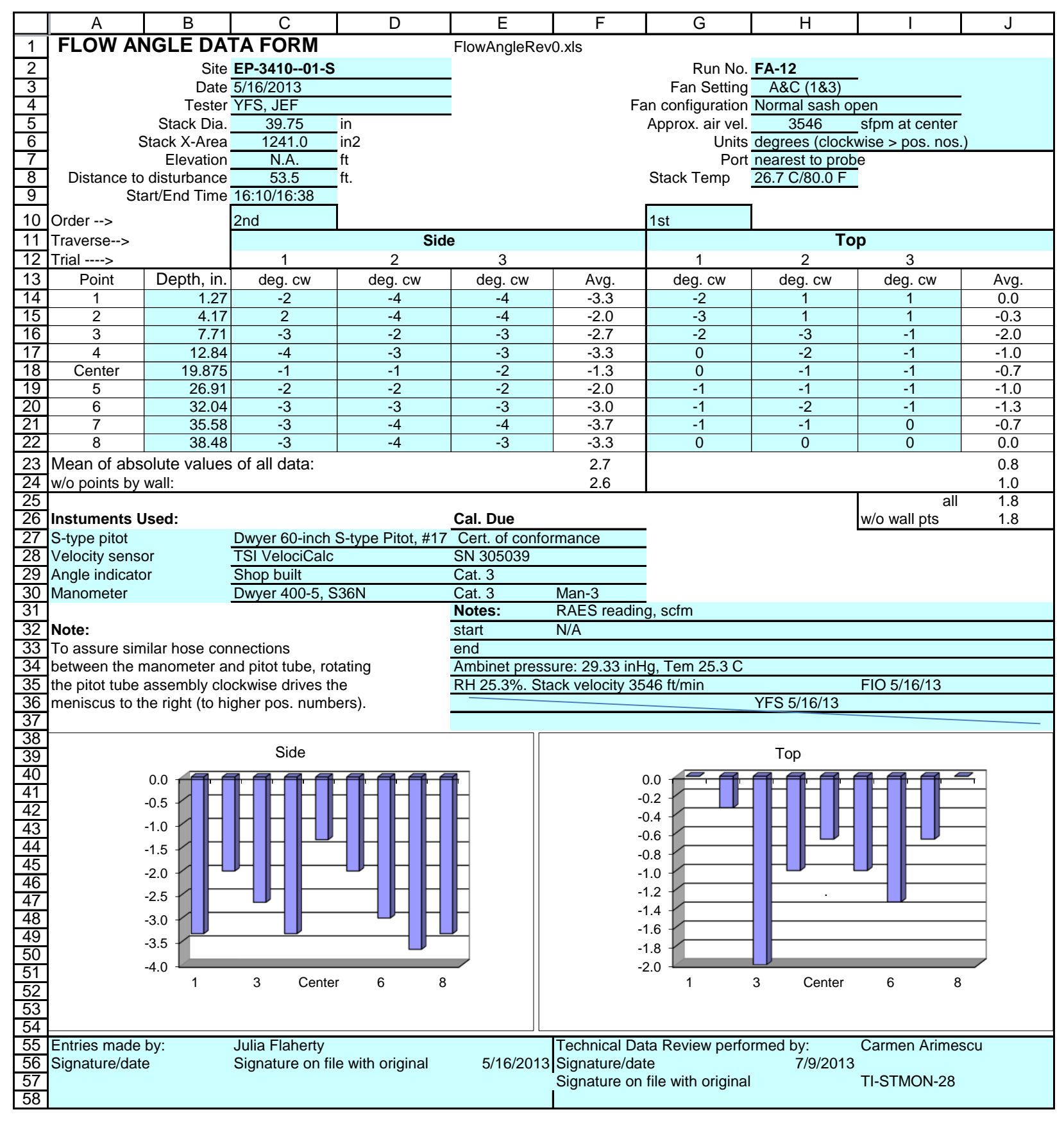




\section{Gas Tracer Uniformity}

\begin{tabular}{|c|c|c|c|c|c|c|c|c|c|c|}
\hline & A & $\mathrm{B}$ & $\mathrm{C}$ & \begin{tabular}{|c|}
$\mathrm{D}$ \\
\end{tabular} & \begin{tabular}{|c|}
$E$ \\
\end{tabular} & $\mathrm{~F}$ & $\mathrm{G}$ & $\mathrm{H}$ & $\mathrm{I}$ & 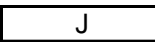 \\
\hline 1 & \multicolumn{8}{|c|}{ TRACER GAS TRAVERSE DATA FORM } & & \\
\hline 2 & \multicolumn{4}{|c|}{ Site EP-3410-01-S } & \multicolumn{4}{|c|}{ Run No. GT-D } & & \\
\hline 3 & & Date & \multicolumn{2}{|l|}{$4 / 24 / 13$} & \multicolumn{4}{|c|}{ Fan Configuration $\mathbf{A \& B ( 1 \& 2 )}$} & & \\
\hline 4 & \multicolumn{4}{|c|}{ Testers XYY, BGF, MSP, YFS } & \multicolumn{2}{|c|}{ Fan Setting } & \multicolumn{2}{|l|}{ normal } & & \\
\hline 5 & \multirow{2}{*}{\multicolumn{2}{|c|}{$\begin{array}{r}\text { Stack Dia. } \\
\text { Stack X-Area }\end{array}$}} & \multicolumn{2}{|c|}{$39.7500 \mathrm{in.}$} & \multicolumn{2}{|r|}{ Stack Temp } & \multicolumn{2}{|c|}{78.53 deg $F$} & & \\
\hline 6 & & & \multicolumn{2}{|c|}{$1241.0 \mathrm{in}^{2}$} & \multicolumn{4}{|c|}{ Start/End Time 11:00/15:03 } & & \\
\hline 7 & \multicolumn{2}{|r|}{ Test Port } & NEAREST TC & J PROBE & & enter $2 / 3$ from & 3.65 & to: & 36.10 & \\
\hline 8 & Distance & to disturbance & 53.5 & inches & Points & in Center $2 / 3$ & 2 & to: & 7 & \\
\hline 9 & Mea & asurement units & ppm N2O & & & Injection Point & $\overline{\text { Junction, center }}$ & & & \\
\hline 10 & Order --> & & $1 \mathrm{st}$ & & & & 2nd & & & \\
\hline 11 & Traverse--> & & & Sid & & & & Bott & tom & \\
\hline 12 & Trial ----> & & 1 & 2 & 3 & Mean & 1 & 2 & 3 & Mean \\
\hline 13 & Point & Depth, in. & & $\mathrm{ppr}$ & & & & $\mathrm{pp}$ & $\mathrm{m}$ & \\
\hline 14 & 1 & 1.27 & 9.59 & 9.96 & 9.53 & 9.69 & 9.70 & 9.55 & 9.65 & 9.63 \\
\hline 15 & 2 & 4.17 & 9.59 & 9.78 & 9.52 & 9.63 & 9.66 & 9.52 & 9.66 & 9.61 \\
\hline 16 & 3 & 7.71 & 9.80 & 9.67 & 9.75 & 9.74 & 9.75 & 9.80 & 9.73 & 9.76 \\
\hline 17 & 4 & 12.84 & 9.72 & 9.71 & 9.60 & 9.68 & 9.59 & 9.65 & 9.58 & 9.61 \\
\hline 18 & Center & 19.88 & 9.65 & 9.79 & 9.65 & 9.70 & 9.69 & 9.70 & 9.45 & 9.61 \\
\hline 19 & 5 & 26.91 & 9.75 & 9.60 & 9.64 & 9.66 & 9.76 & 9.64 & 9.57 & 9.66 \\
\hline 20 & 6 & 32.04 & 9.59 & 9.69 & 9.59 & 9.62 & 9.69 & 9.50 & 9.61 & 9.60 \\
\hline 21 & 7 & 35.58 & 9.70 & 9.61 & 9.67 & 9.66 & 9.57 & 9.34 & 9.65 & 9.52 \\
\hline 22 & 8 & 38.48 & 9.61 & 9.69 & 9.53 & 9.61 & 9.15 & 9.33 & 9.34 & 9.27 \\
\hline 23 & Averages ---- & $-\cdots--->$ & 9.67 & 9.72 & 9.61 & 9.67 & 9.62 & 9.56 & 9.58 & 9.59 \\
\hline 24 & & & & & & & & & & \\
\hline 25 & & & $A I I$ & ppm & & v. from mean & Center 2/3 & Side & Bottom & All \\
\hline 26 & & & Mean & 9.6 & & & Mean & $\overline{9.7}$ & 9.6 & 9.6 \\
\hline 27 & & & Min Point & 9.3 & & $-3.7 \%$ & Std. Dev. & 0.04 & 0.07 & 0.06 \\
\hline 28 & & & Max Point & 9.8 & & $1.4 \%$ & COV as $\%$ & 0.4 & 0.8 & 0.6 \\
\hline 29 & Avg. Conc. & 9.623 & $\mathrm{ppm}$ & & & Instuments U & Used: & & & \\
\hline 30 & Avg. Flow & 28107 & acfm & & & $\mathrm{B} \& \mathrm{~K} 1302 \mathrm{Ga}$ & as Analyzer & 1788615 & & Cat2 M\&TE \\
\hline 31 & & & Start & Finish & & TSI VelociCal & lc SN T9535120300 & & & $12 / 10 / 2013$ \\
\hline 32 & Tracer tank $\mathrm{p}$ & ressure & 800 & 800 & psig & Dew point per & n/thermometer SN 12 & 22277883 & & $5 / 16 / 2014$ \\
\hline 33 & Injection flow & meter & 6.25 & 6.25 & slpm & & & & & \\
\hline 34 & Stack Temp & & 25.8 & 25.9 & ${ }^{\circ} \mathrm{C}$ & & & & & \\
\hline 35 & Mean stack v & elocity & 3107 & 3416 & fpm & & & & & \\
\hline 36 & Sampling flov & vmeter & 5 & 5 & Ipm & & & & & \\
\hline 37 & Ambient pres & sure & 1007 & 1005 & mbar & & 10 & & & \\
\hline 38 & Ambient hum & idity & $20 \%$ & $16.4 \%$ & $\mathrm{RH}$ & & & & & \\
\hline 39 & Ambient Tem & & 23.6 & 21.7 & ${ }^{\circ} \mathrm{C}$ & & 9 & & & \\
\hline 40 & B\&K vapor $\mathrm{cc}$ & rrection & $\mathrm{Y}$ & $\mathrm{Y}$ & $\mathrm{Y} / \mathrm{N}$ & & 8 & & & \\
\hline 41 & Back-Gd gas & & $.42, .47, .45$ & $.38, .41, .38, .4$ & ppm & & 7 & & & \\
\hline 42 & & & $.45, .47$ & 0,37 & & & & & & \\
\hline 43 & No. Bk-Gd sa & imples & 5 & 5 & $n$ & $\mathbf{p}$ & & & & \\
\hline 44 & & & & & & $p$ & 5 & & & \\
\hline 45 & Gas analyze & r checked: & $4 / 24 / 2013$ & & & $m$ & & & & \\
\hline 46 & & & & & & & & & & \\
\hline 47 & Notes: & Sample flow me & eer uit is cubic & ft per hr scfph. & & & & & & \\
\hline 48 & $1 \mathrm{cfph}=0.5 \mathrm{sl}$ & om. For samplin & g 5lpm, use 10 & 0 cfph. Backgr & ound $\mathrm{N} 2 \mathrm{O}$ is & & & & & \\
\hline 49 & $\sim 0.45 \mathrm{ppm}, \mathrm{T}$ & arget $\mathrm{N} 2 \mathrm{O}$ in sta & ack is $\sim 25 \mathrm{ppr}$ & m, i.e., 50 time & ef of & & 1 & & & \\
\hline 50 & background. & & & & & & & & & Side \\
\hline 51 & & & XYY 4/24/12 & & & & & & & \\
\hline 52 & & & 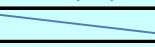 & & & & Bottom & & & \\
\hline 53 & & & & & & & & & & \\
\hline 54 & Entries made & by: & Yin-Fong Su & & & Technical Dat & ta Review performed & by: & Carmen Arimescu & \\
\hline 55 & Signature/dat & & On file with or & riginal & $4 / 24 / 13$ & Signature/date & & On file with $T$ & TI-STMON-030 & \\
\hline 56 & & & & & & & & 9-Jul-13 & & \\
\hline 57 & & & & & & & & & & \\
\hline
\end{tabular}




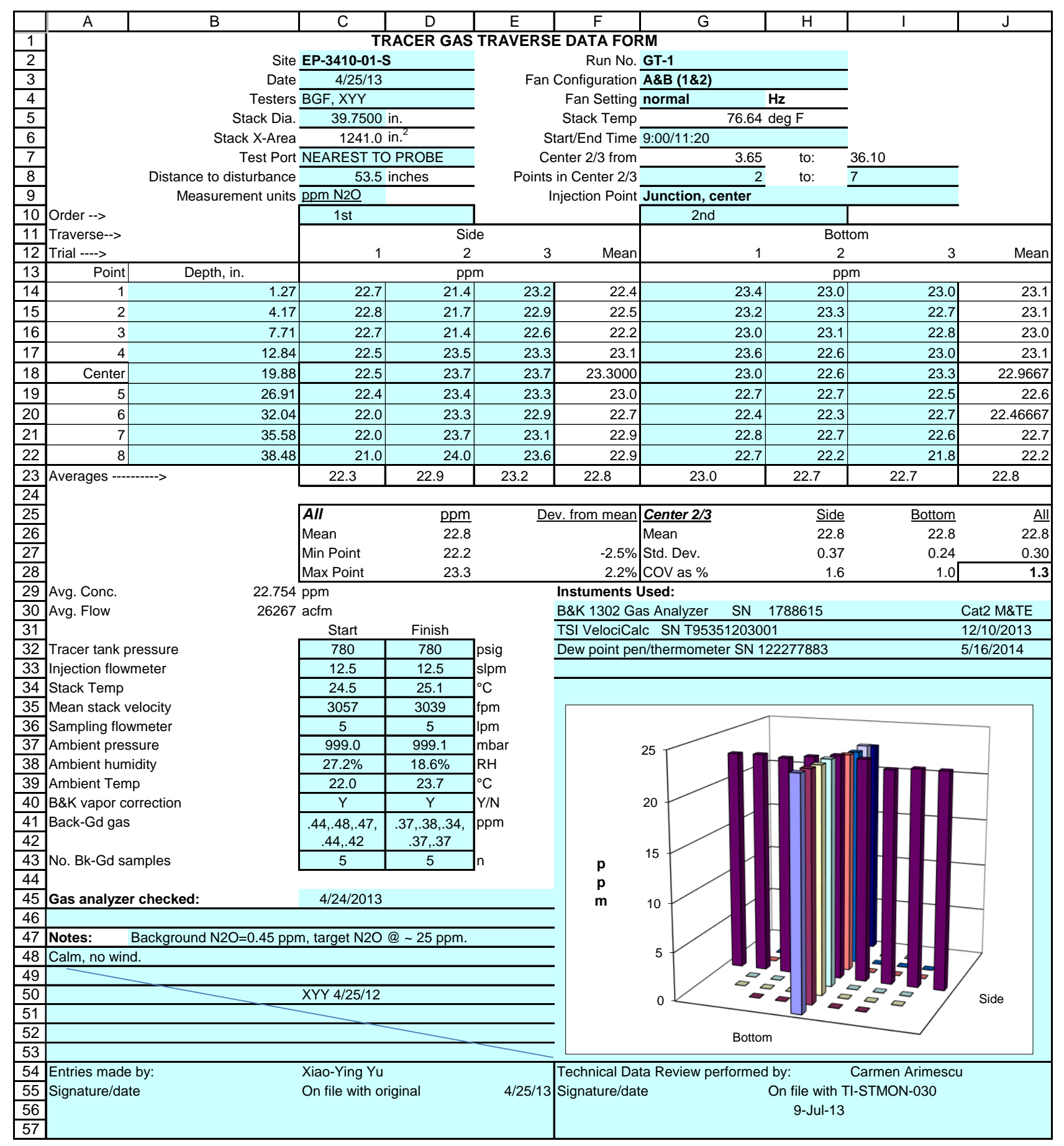




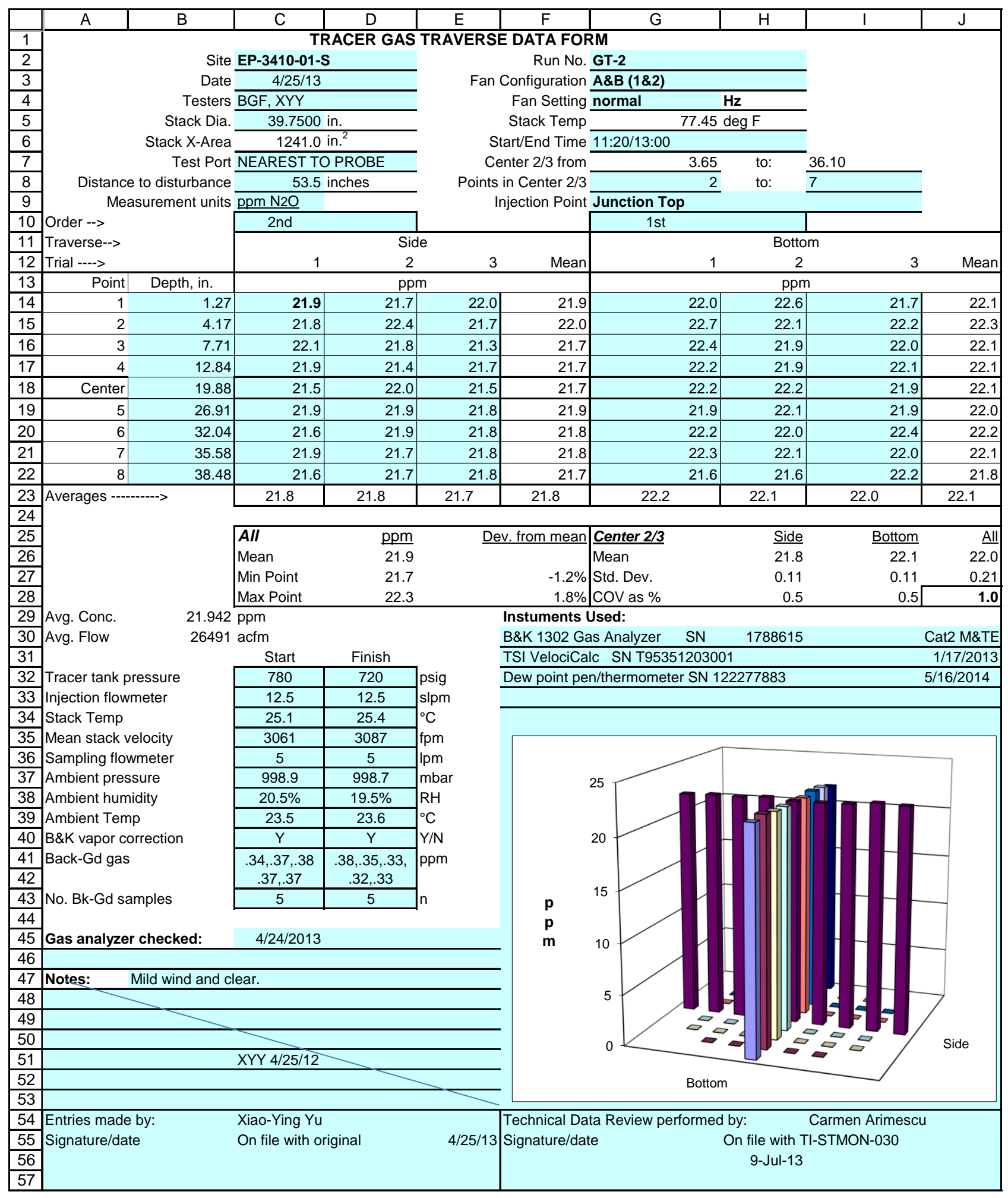




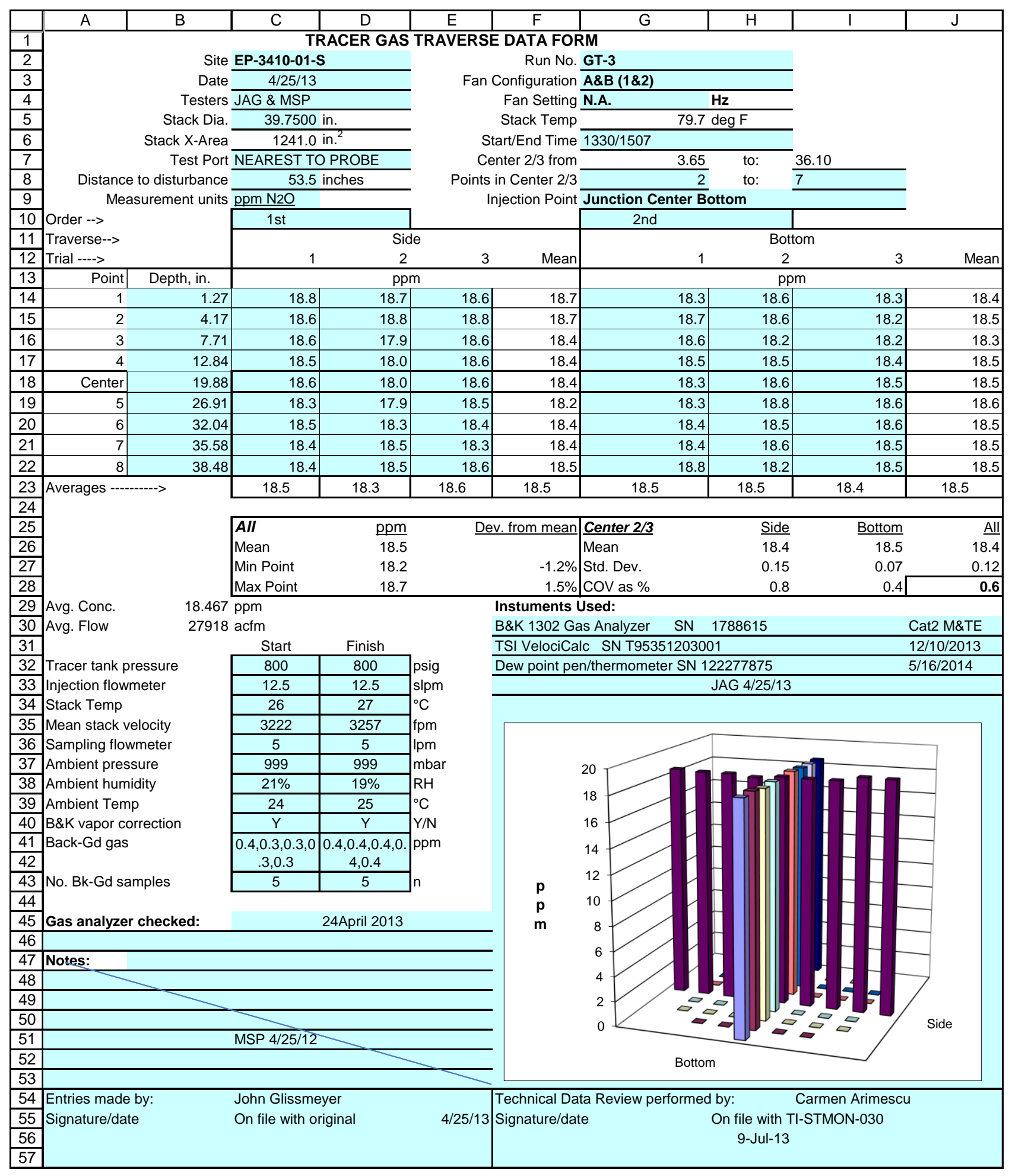




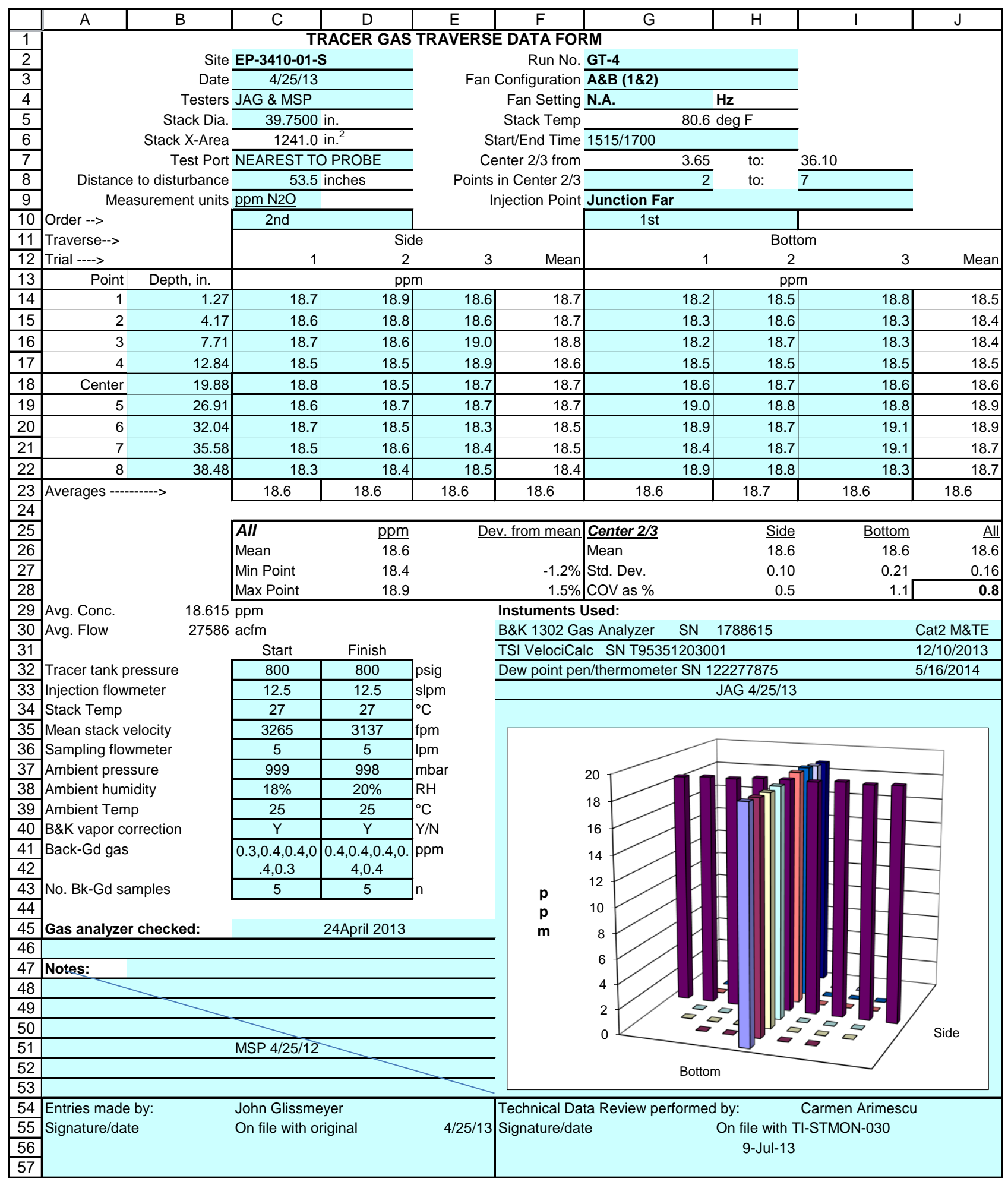




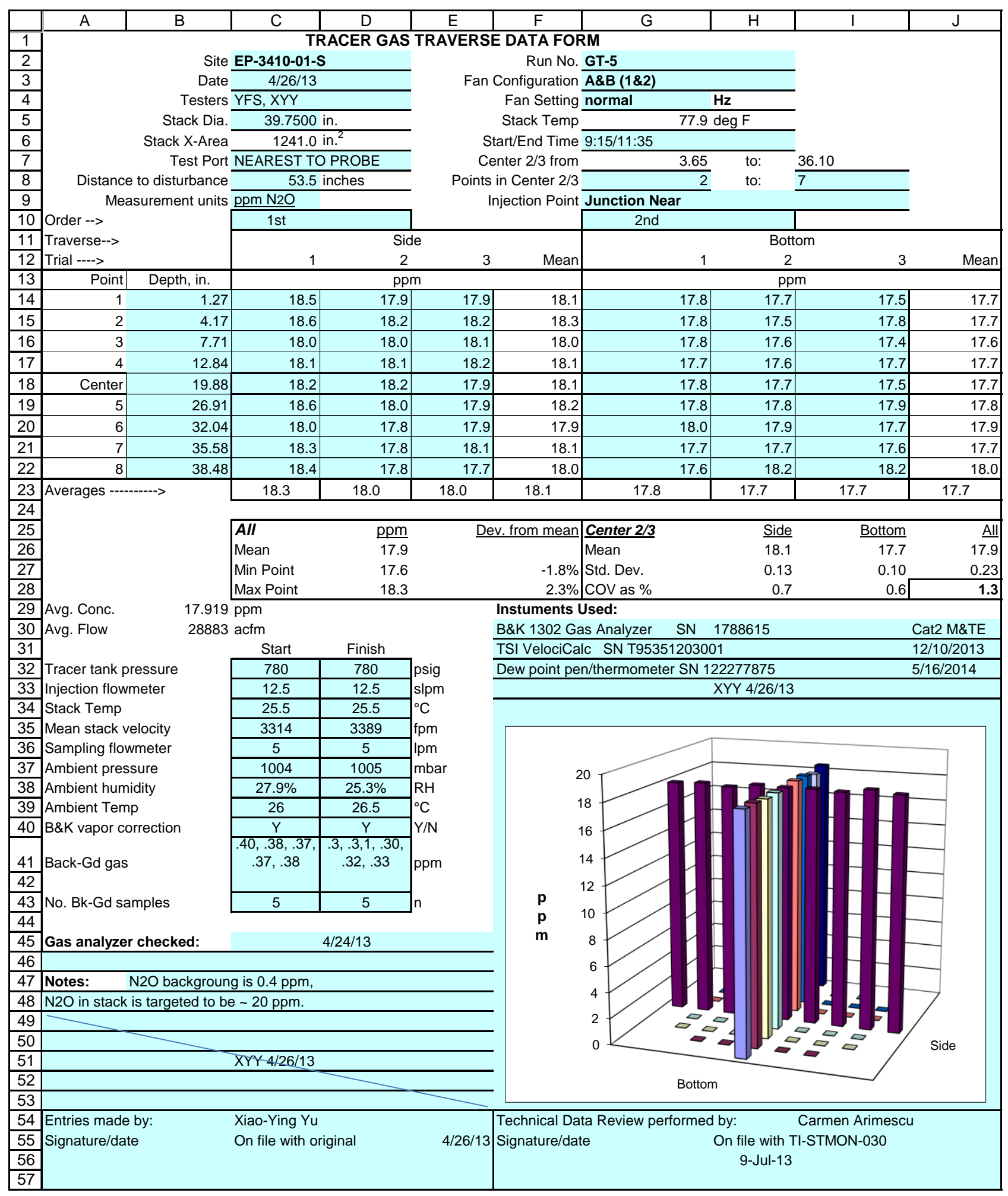




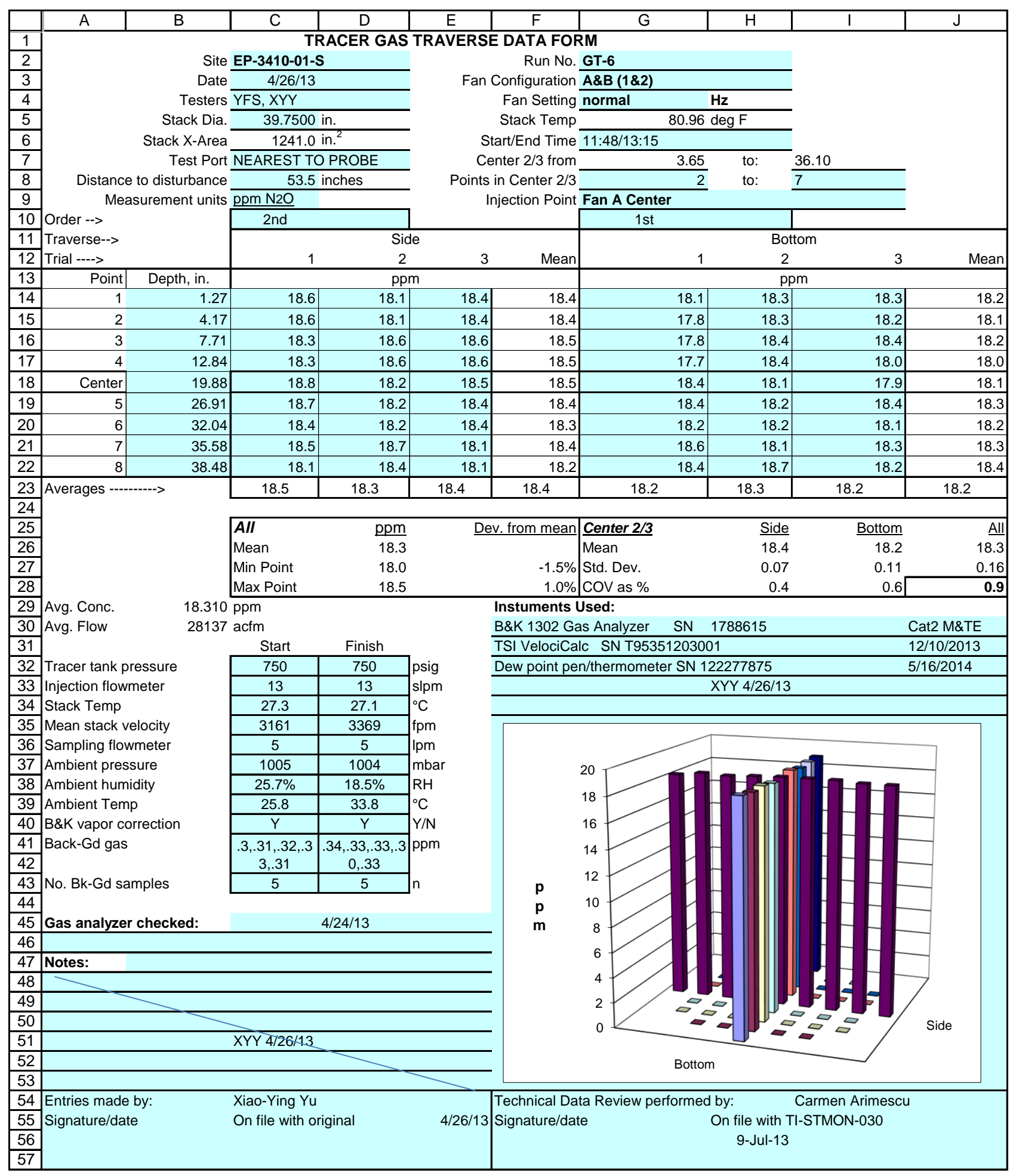




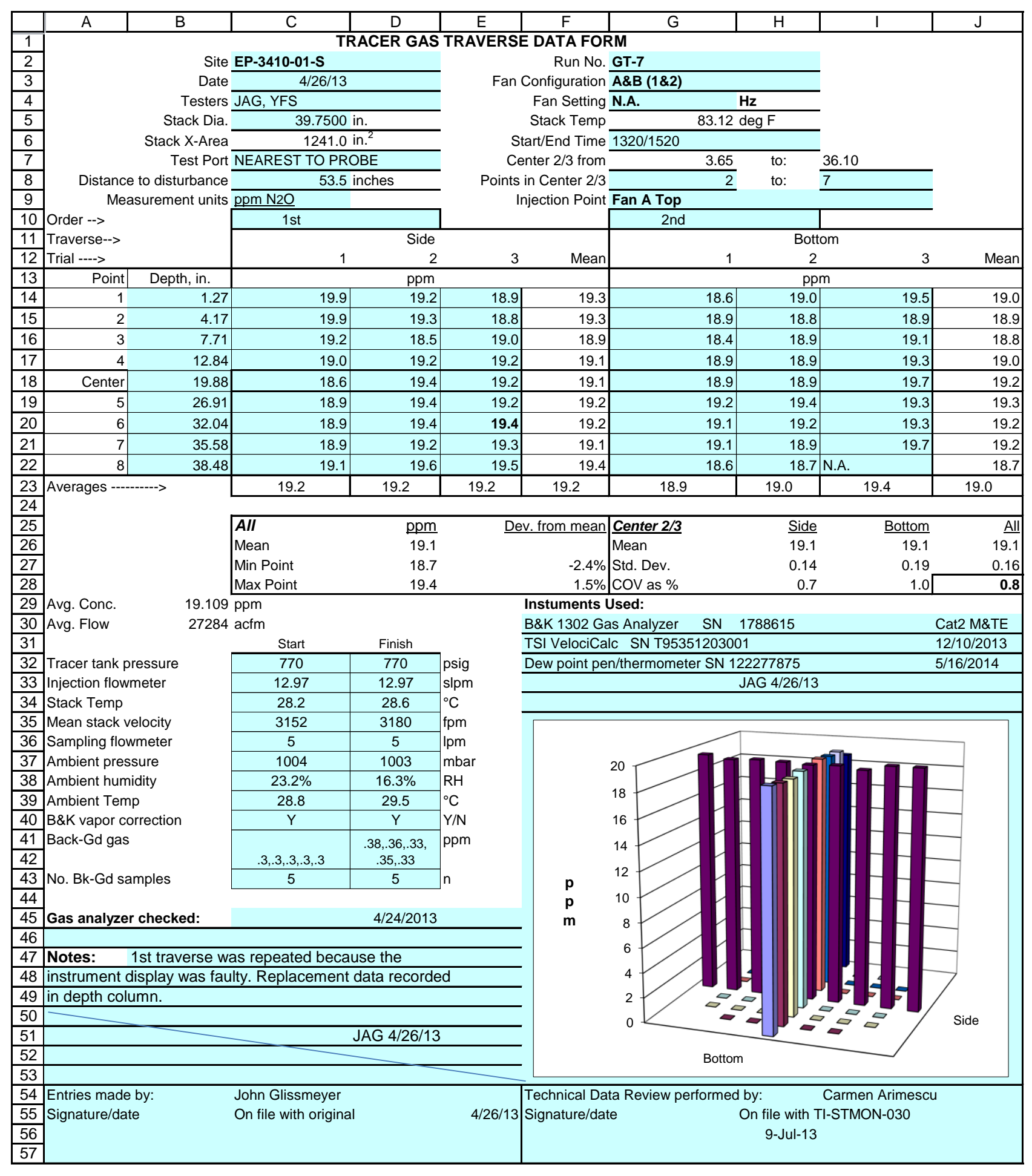




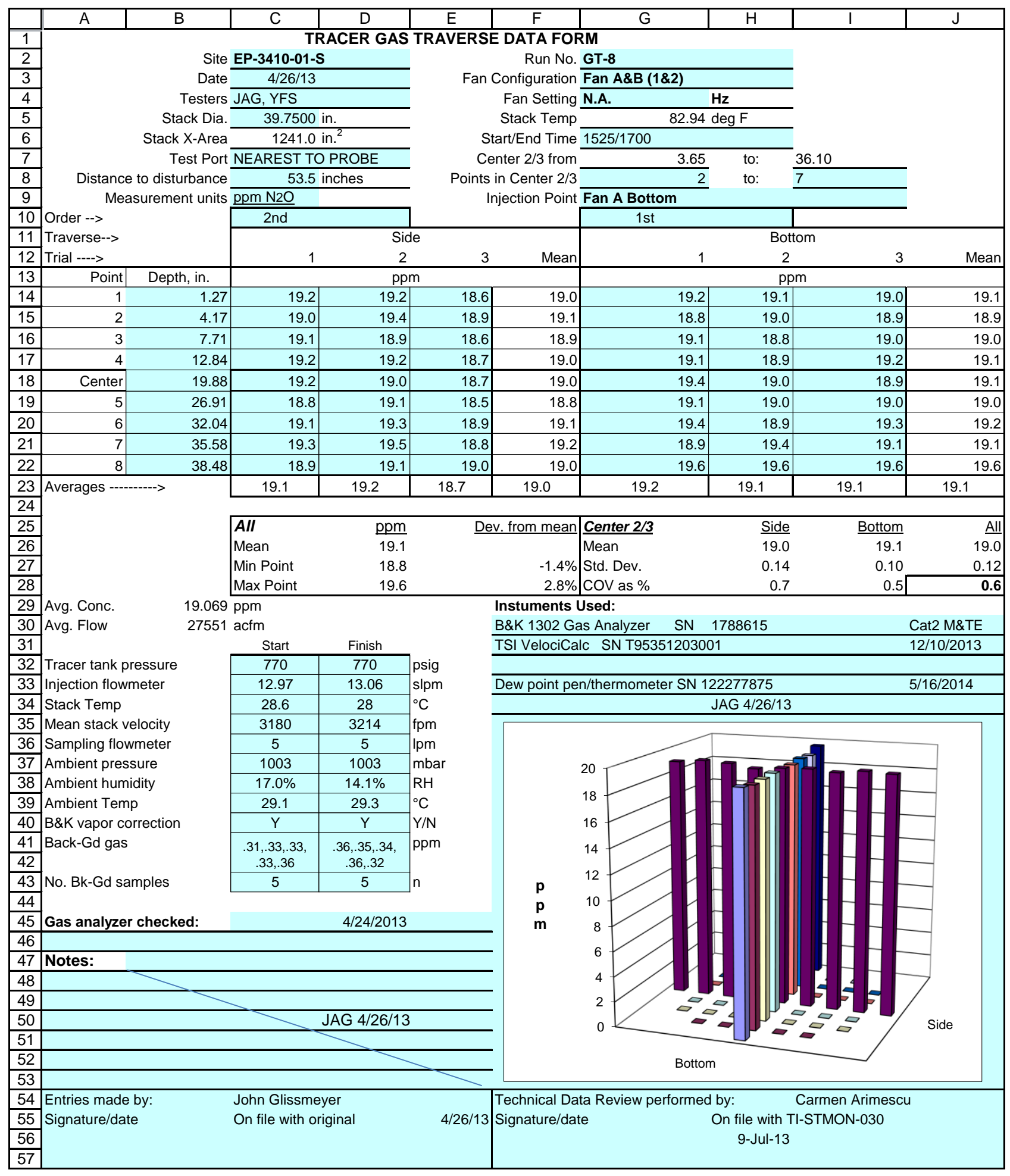




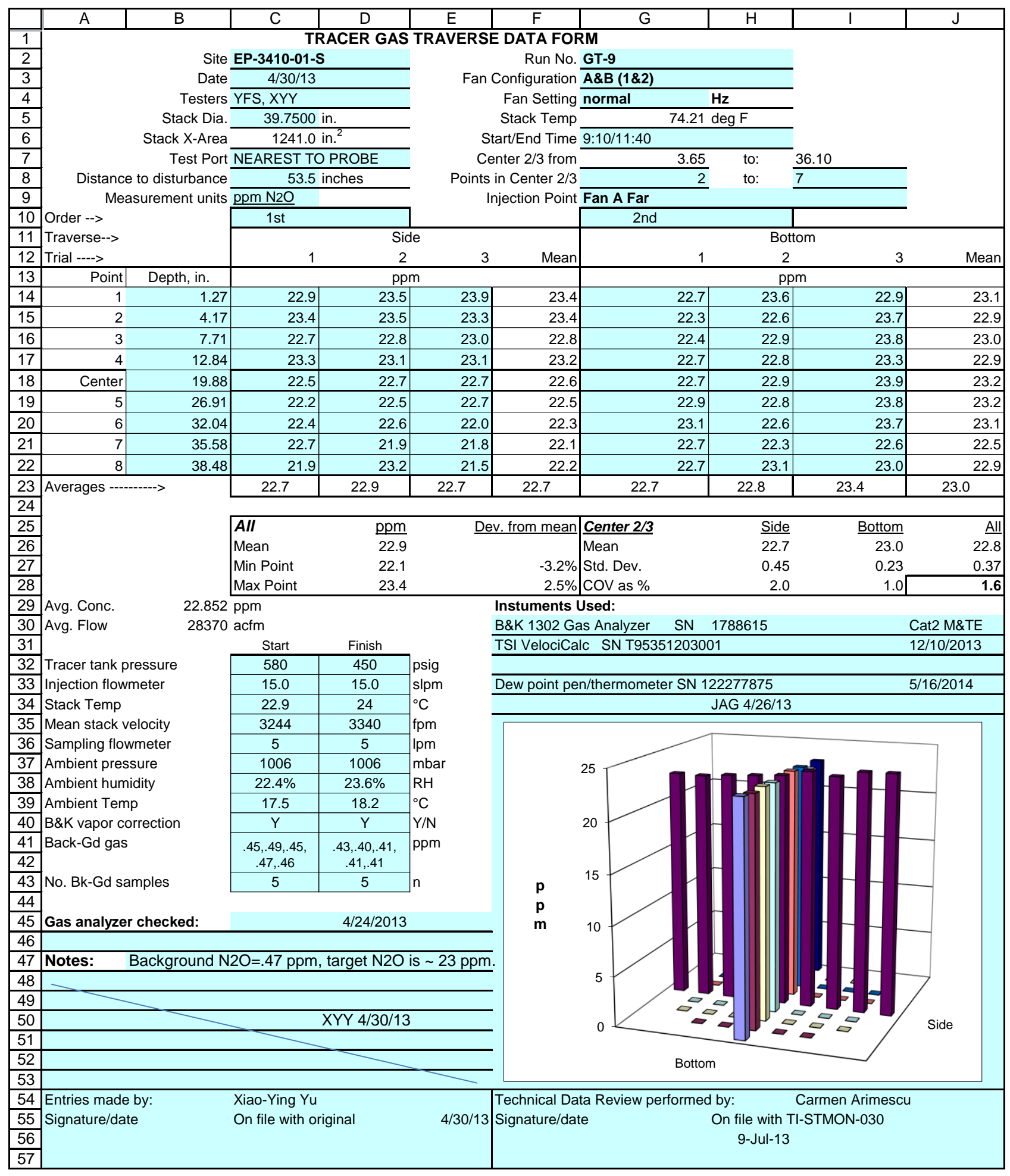




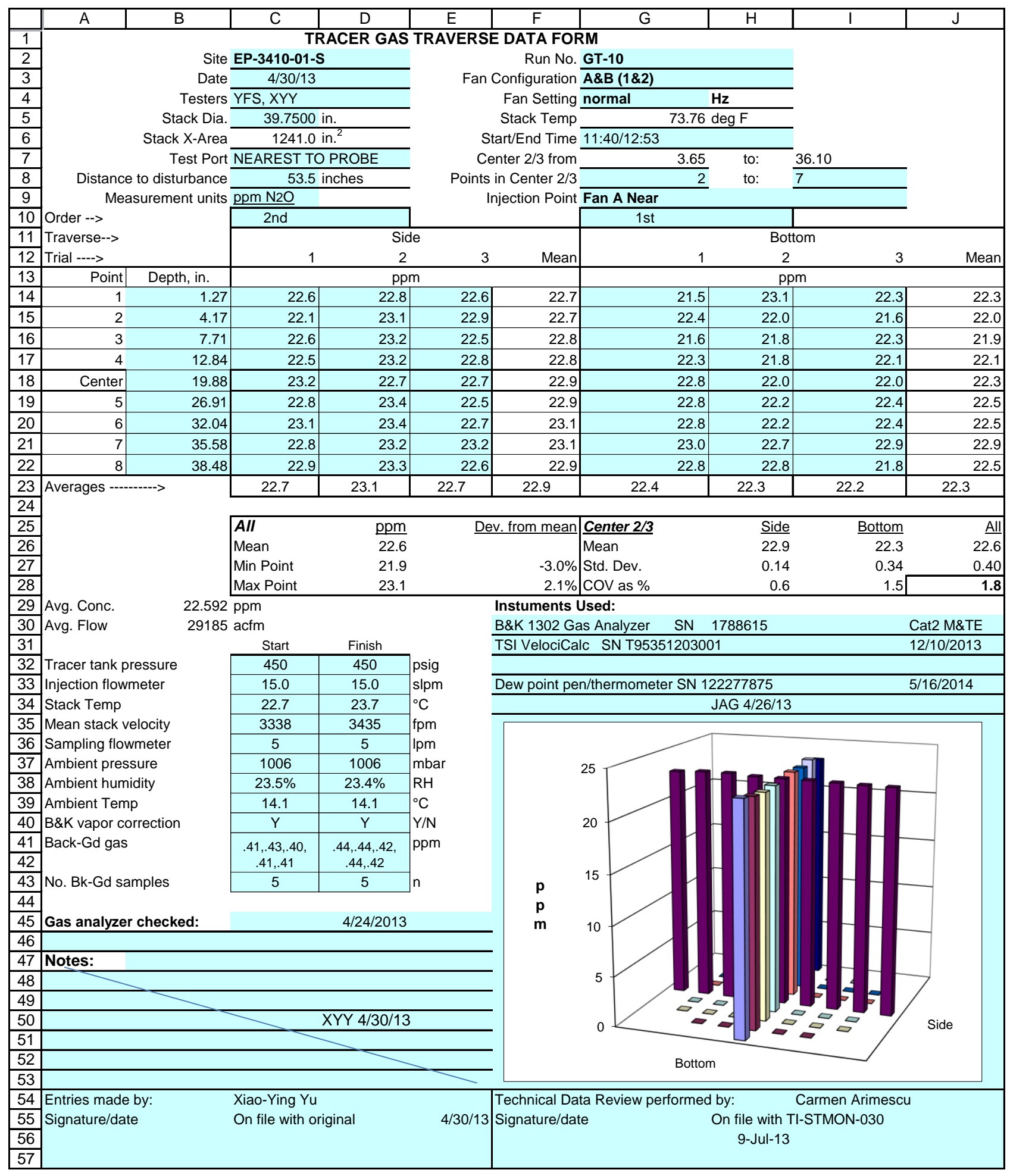




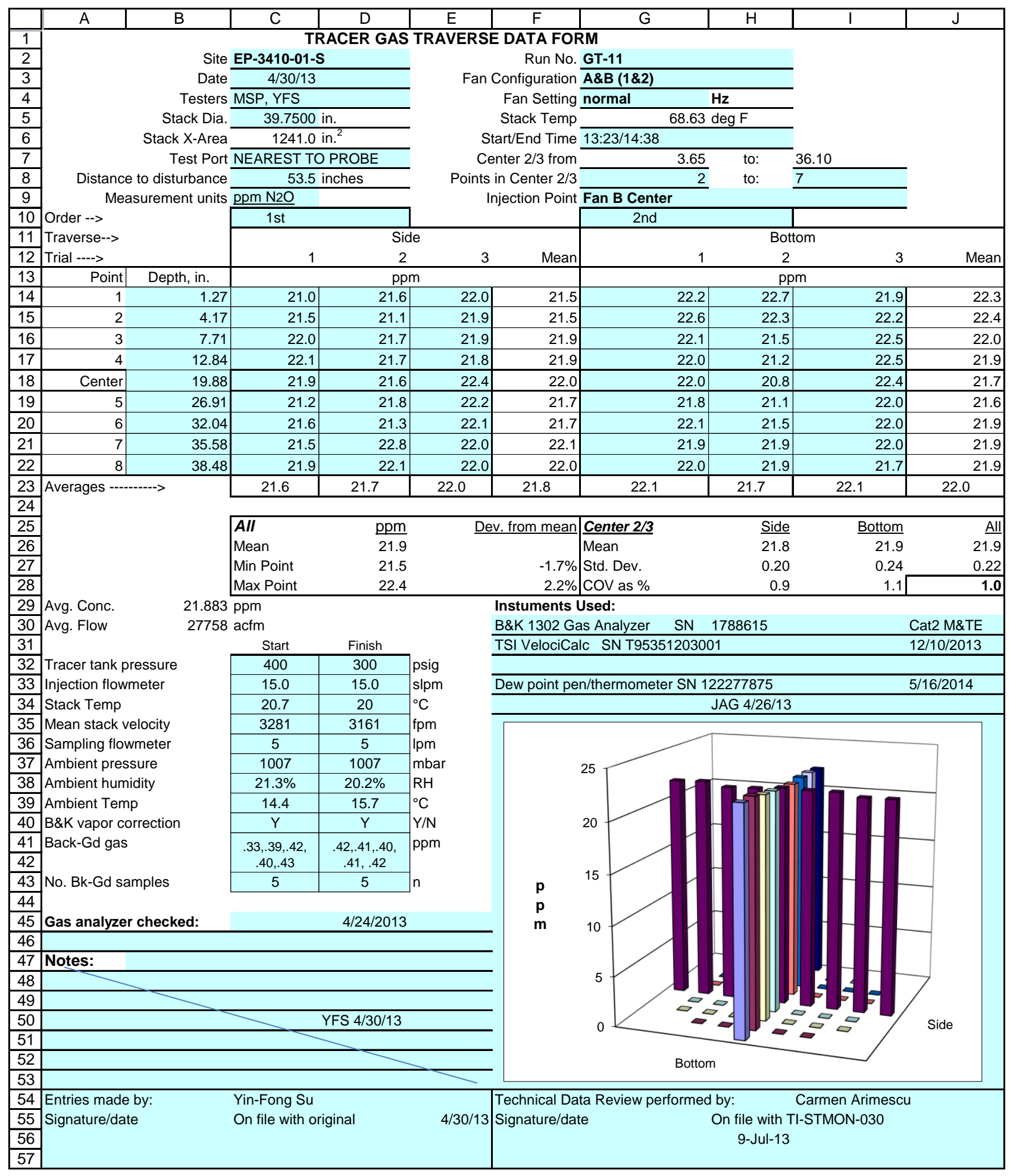




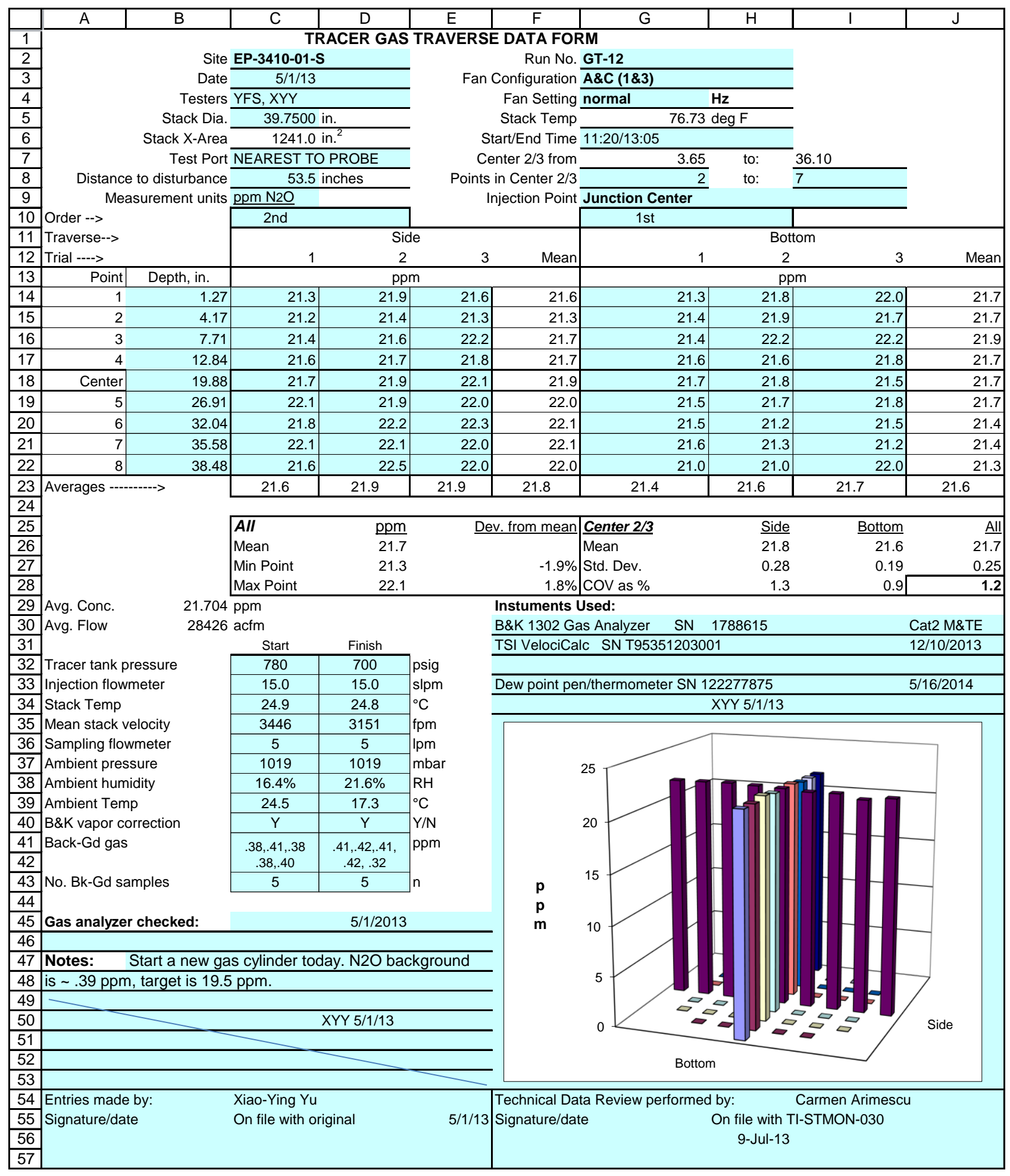




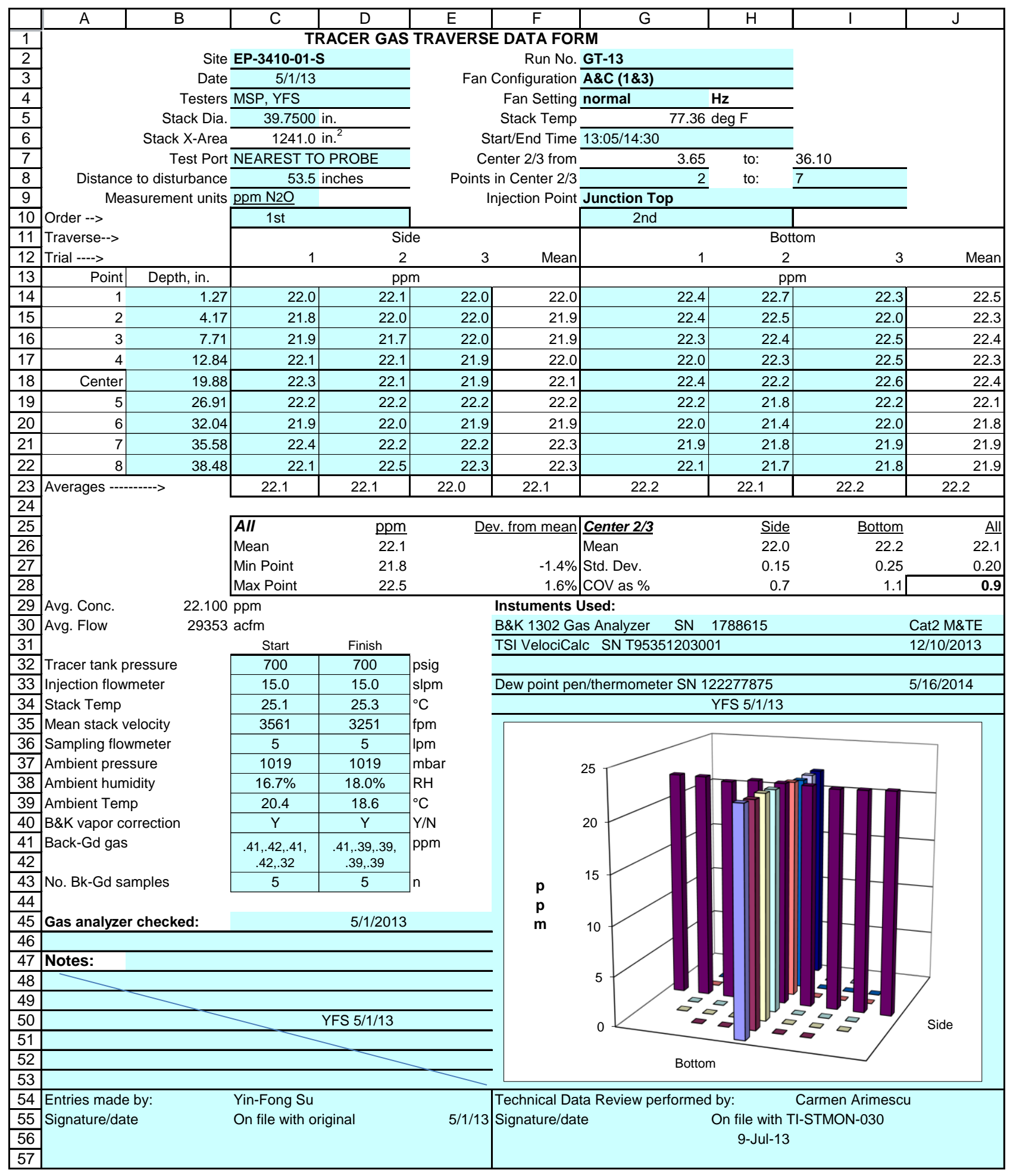




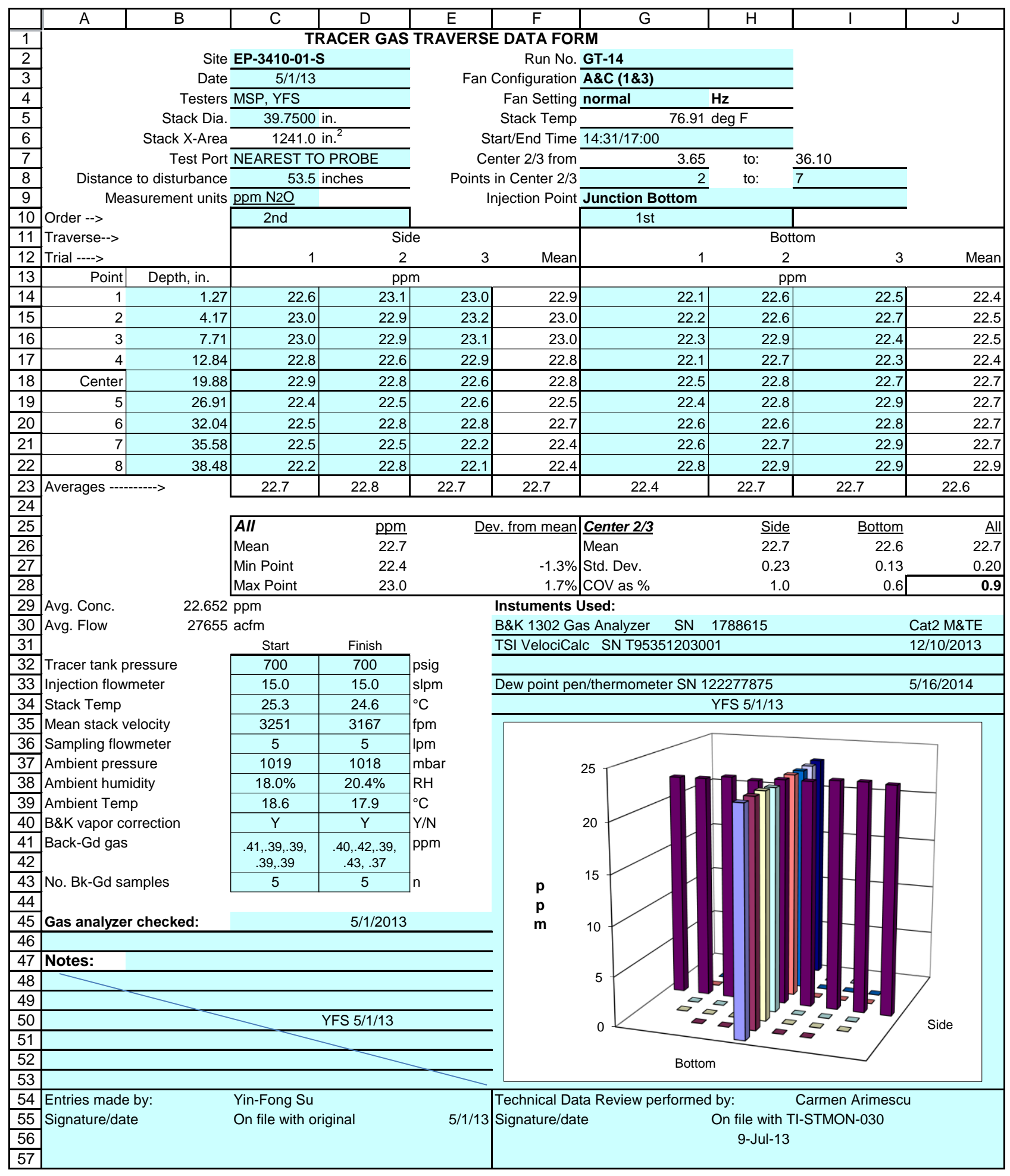




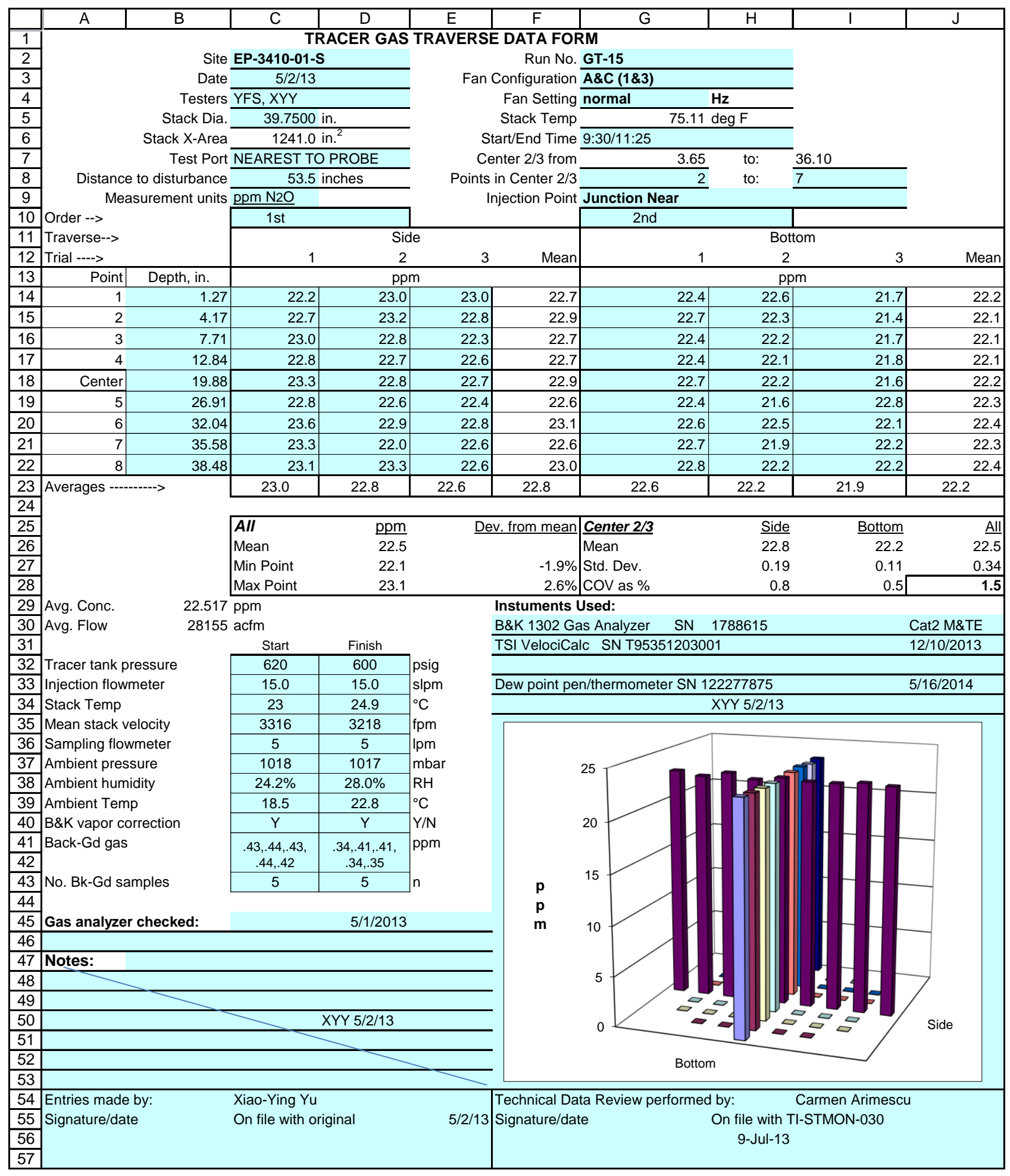




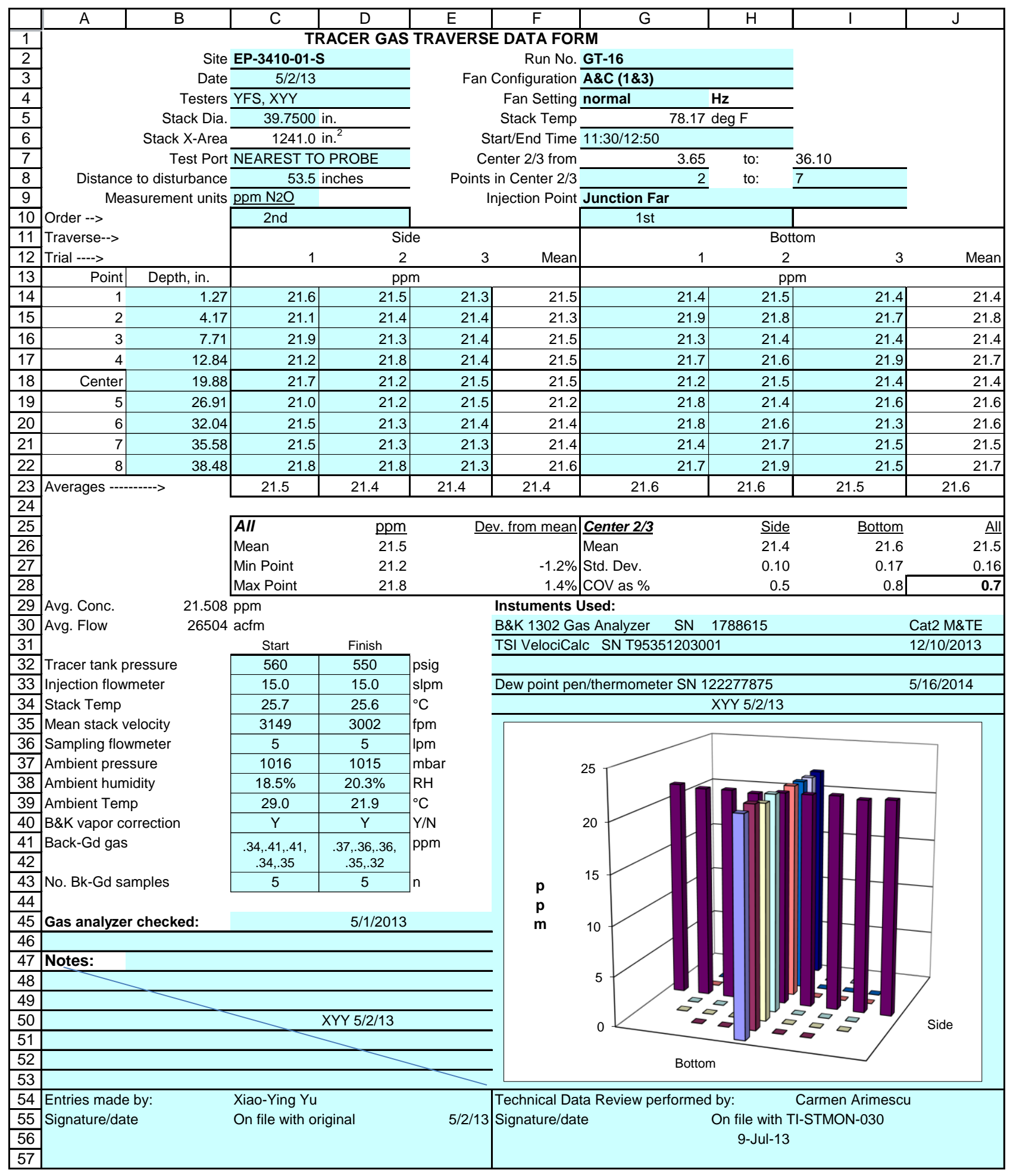




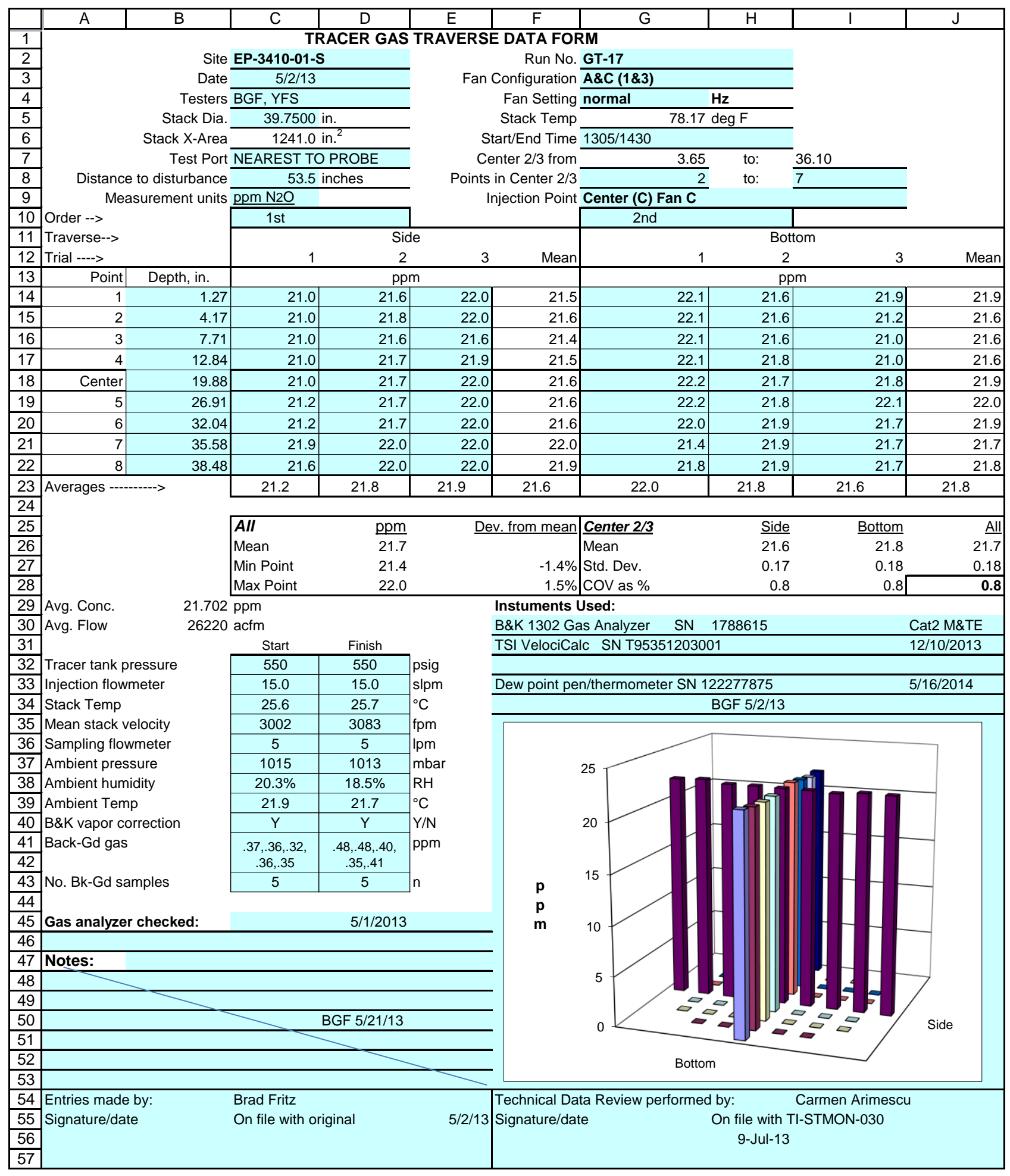




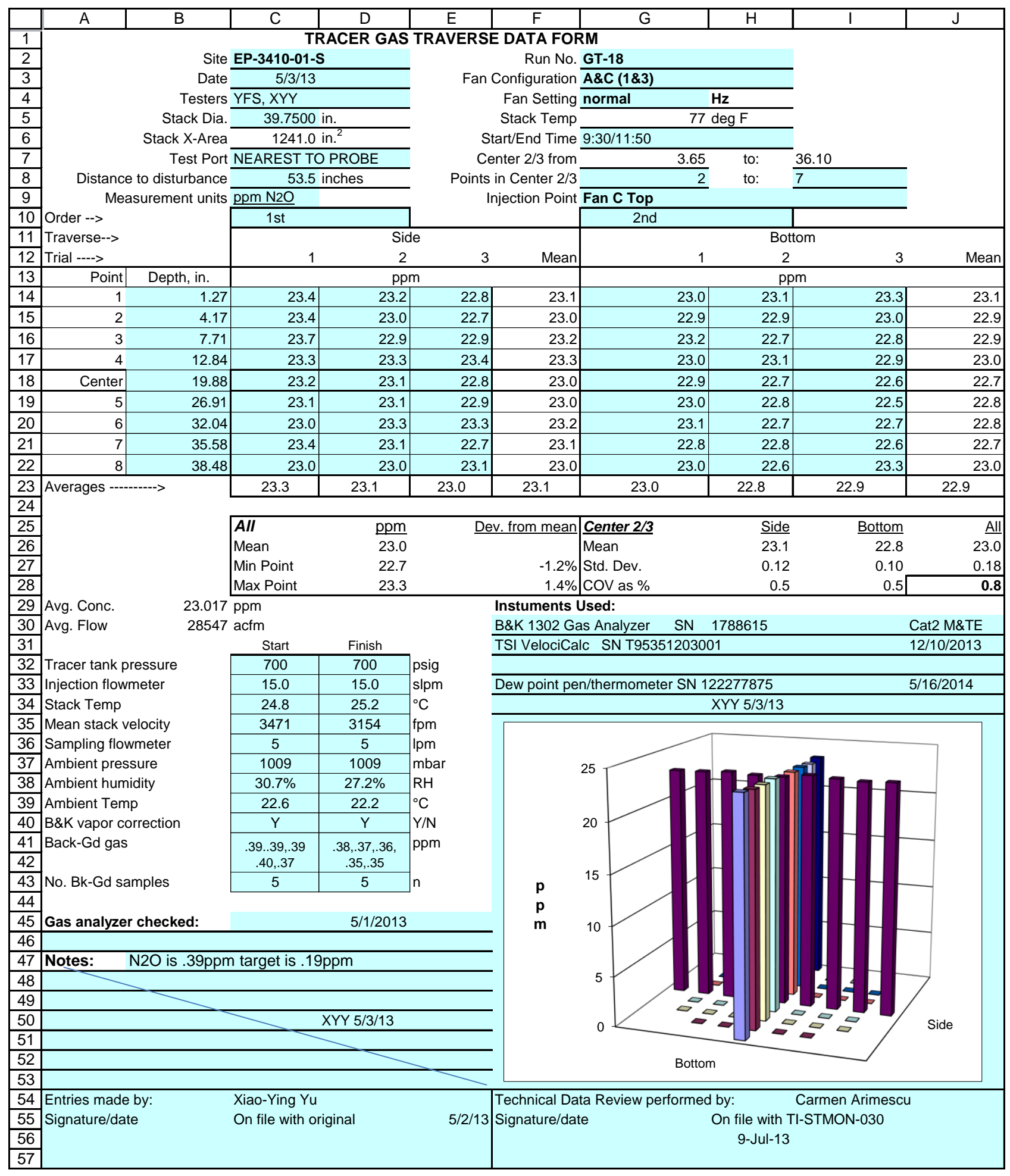




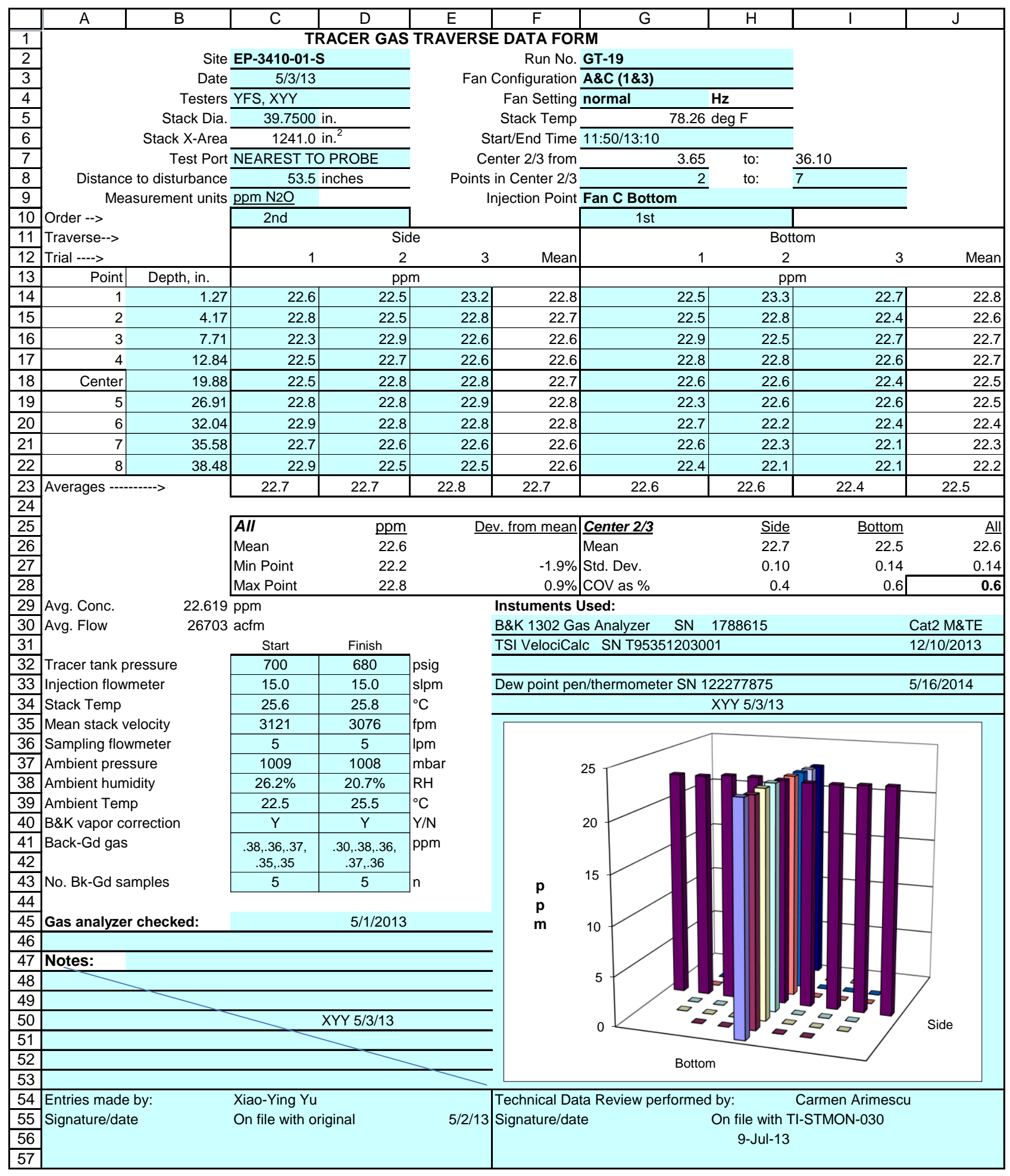




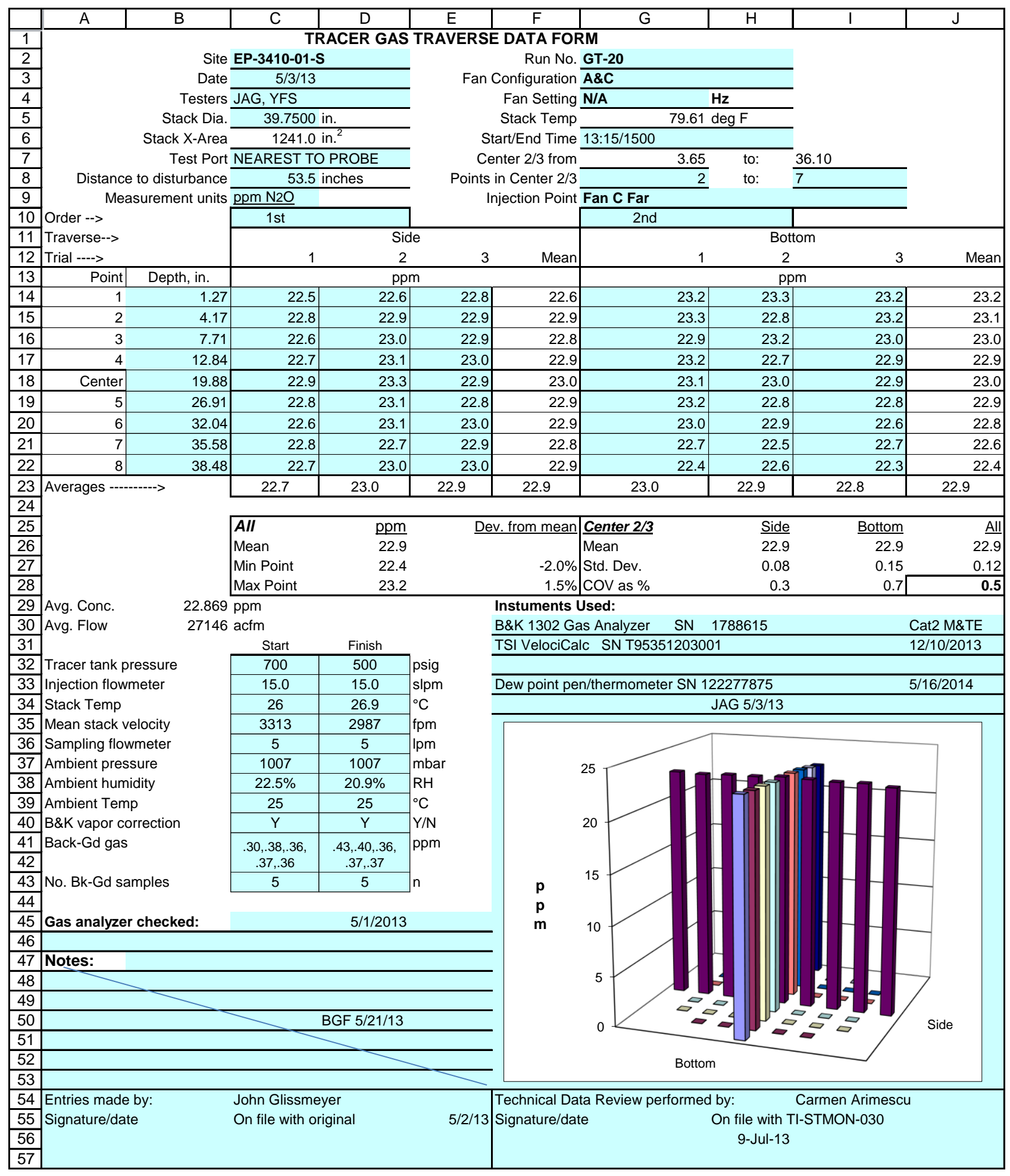




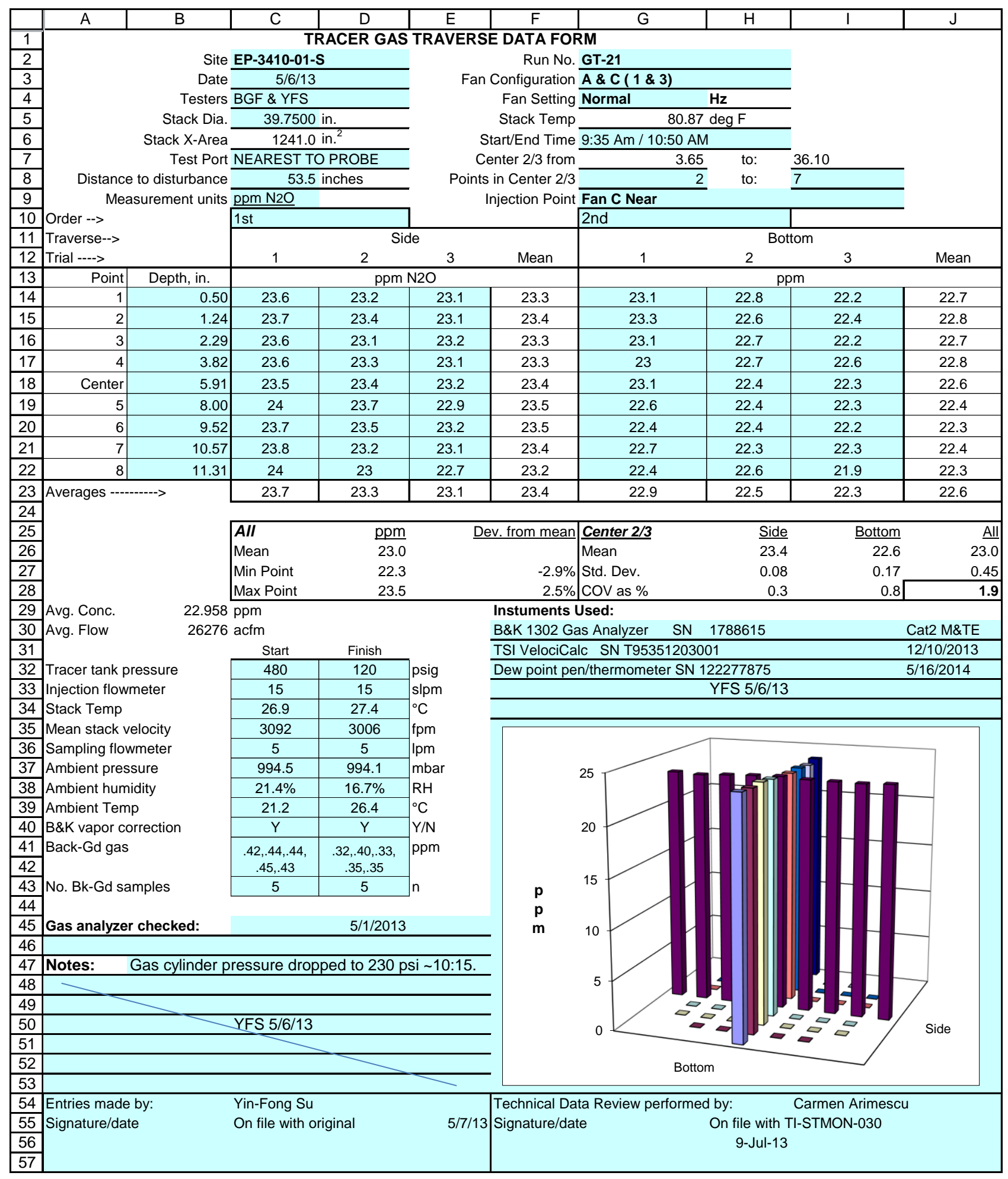




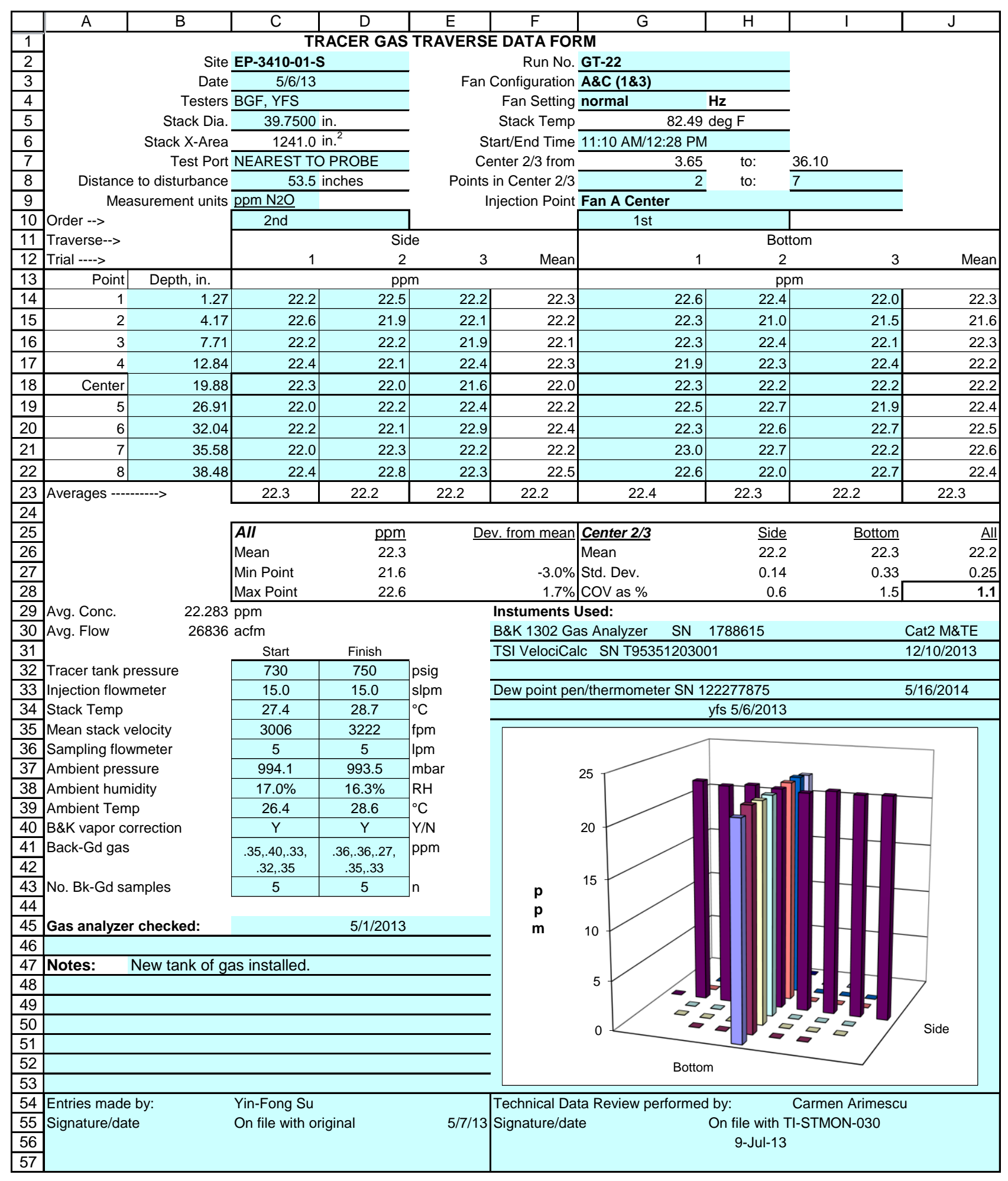




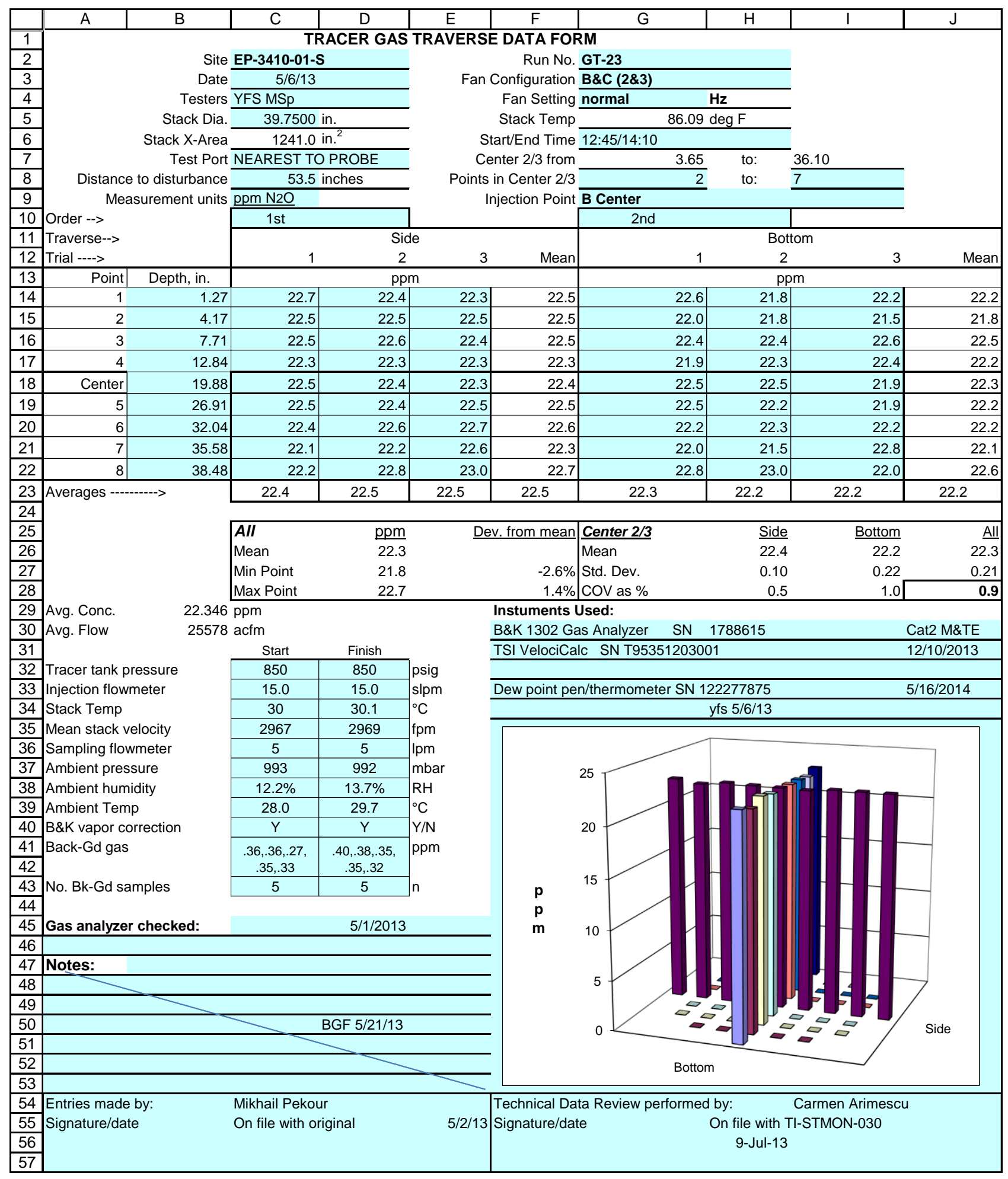




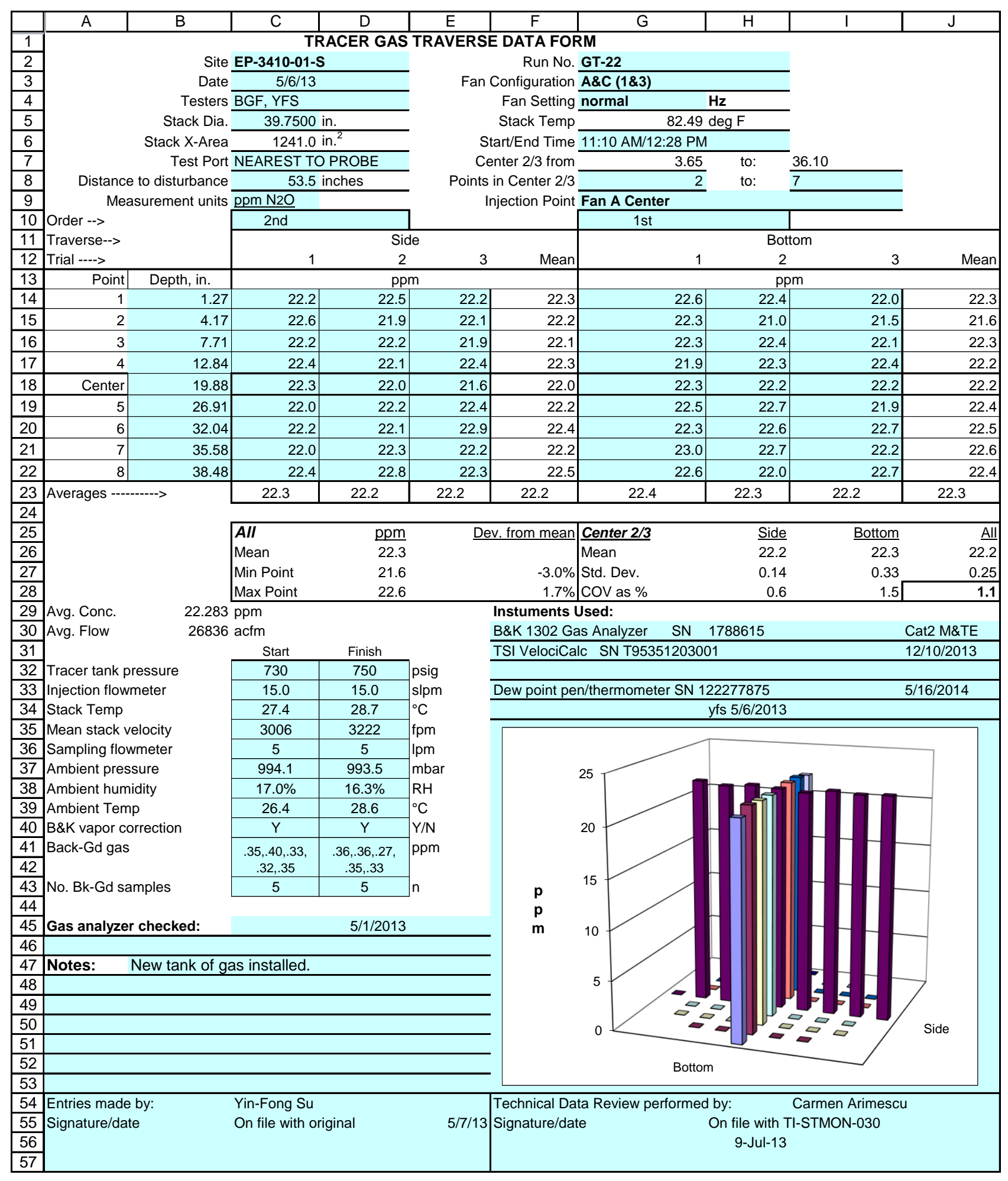




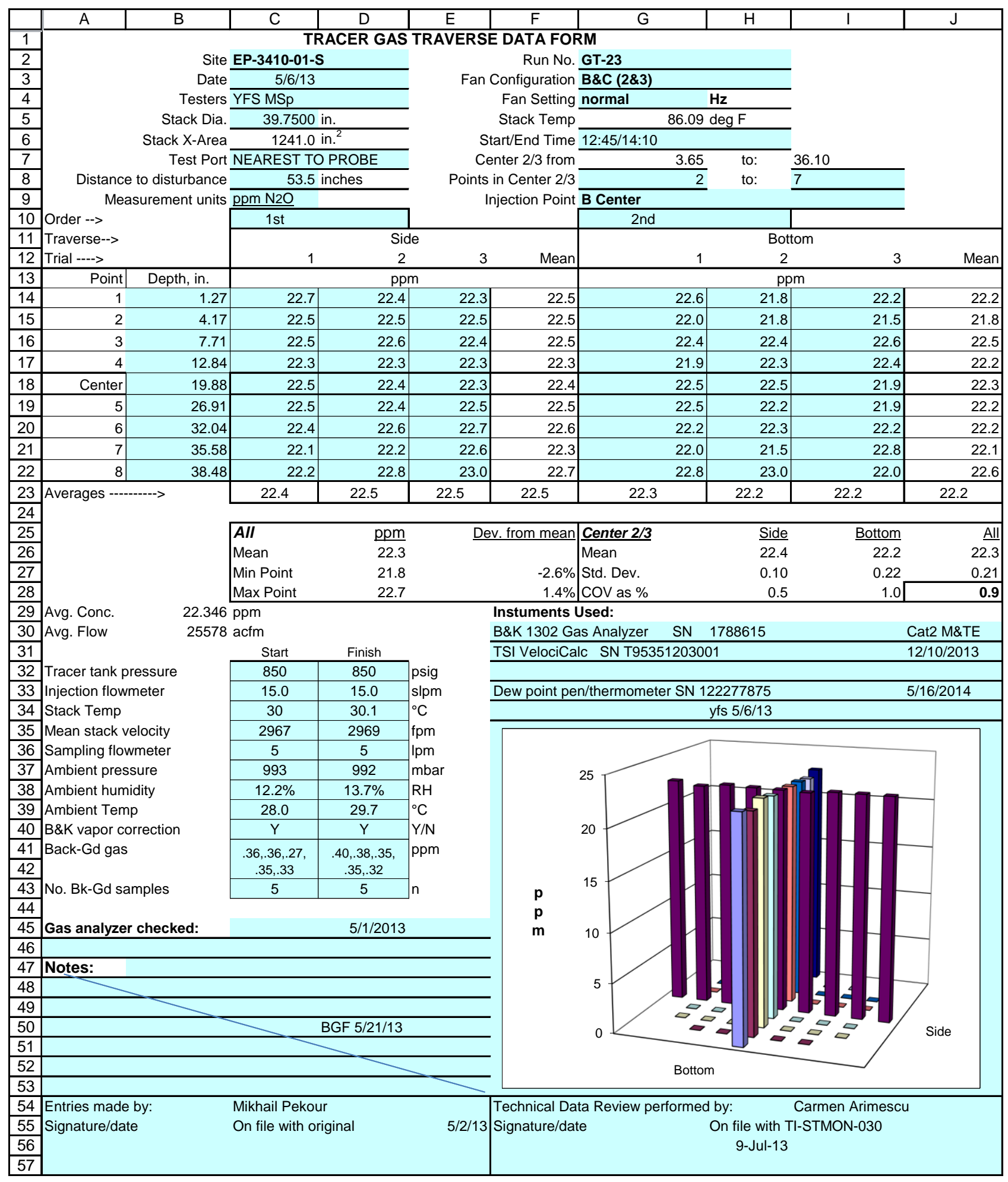




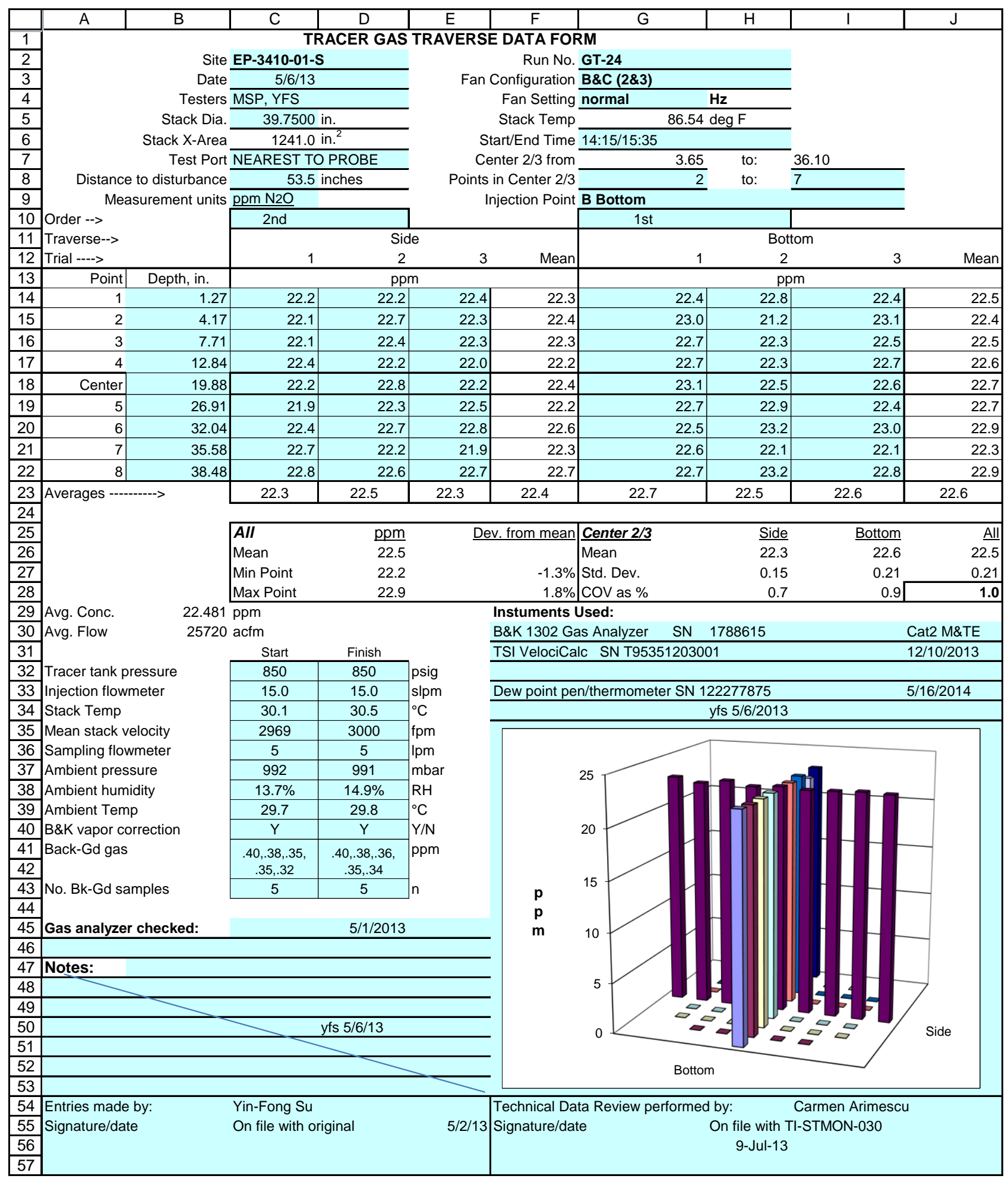




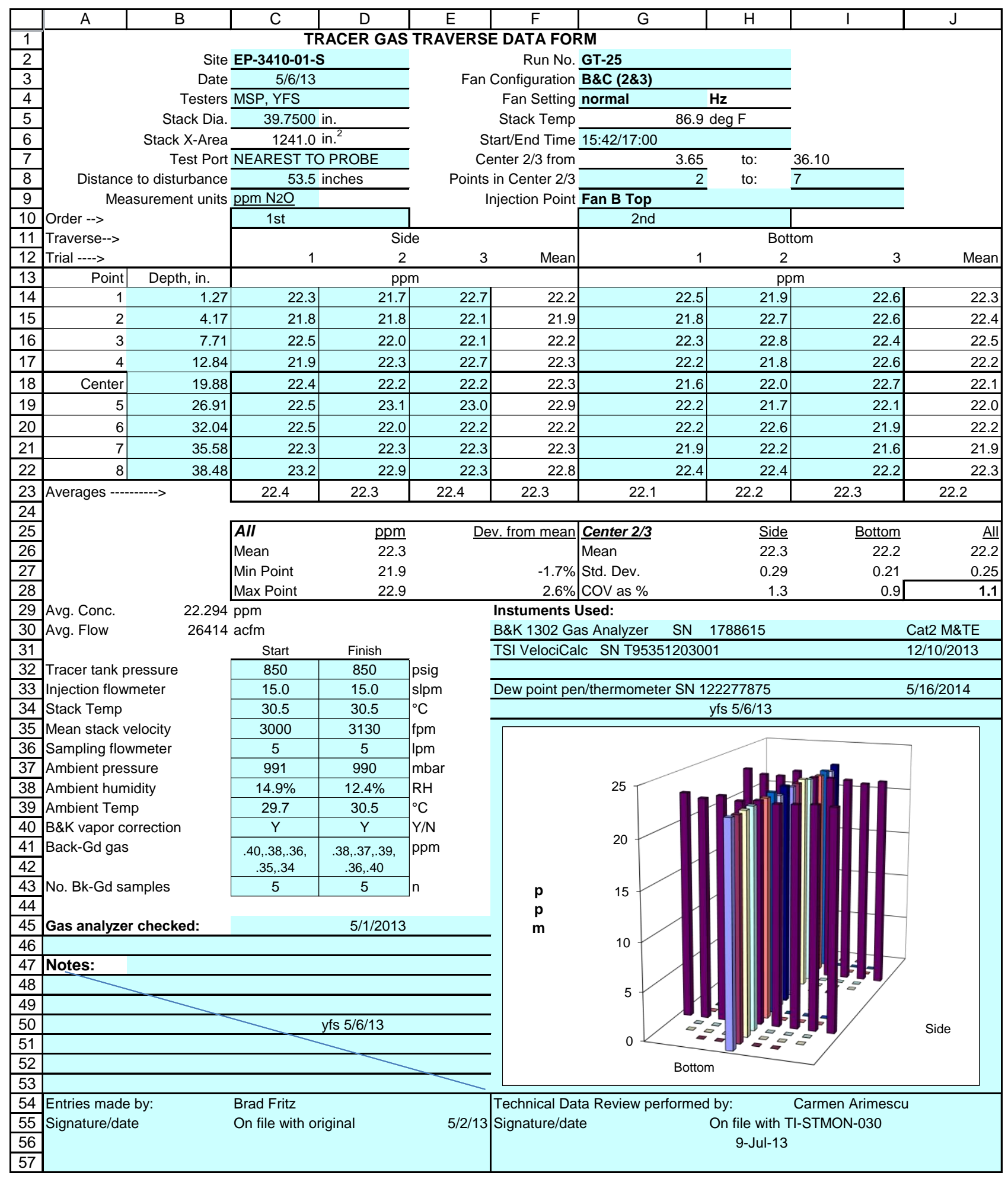




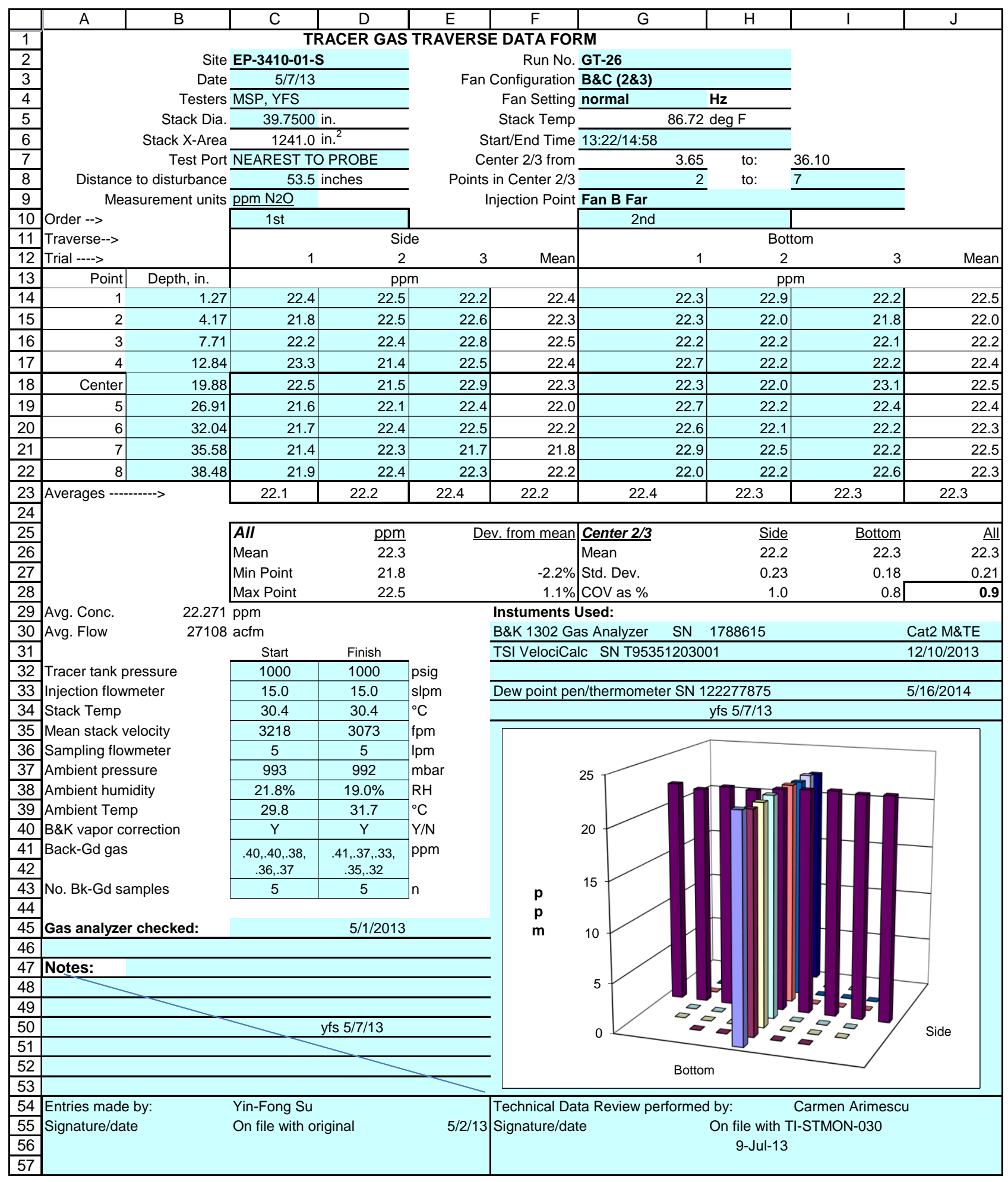




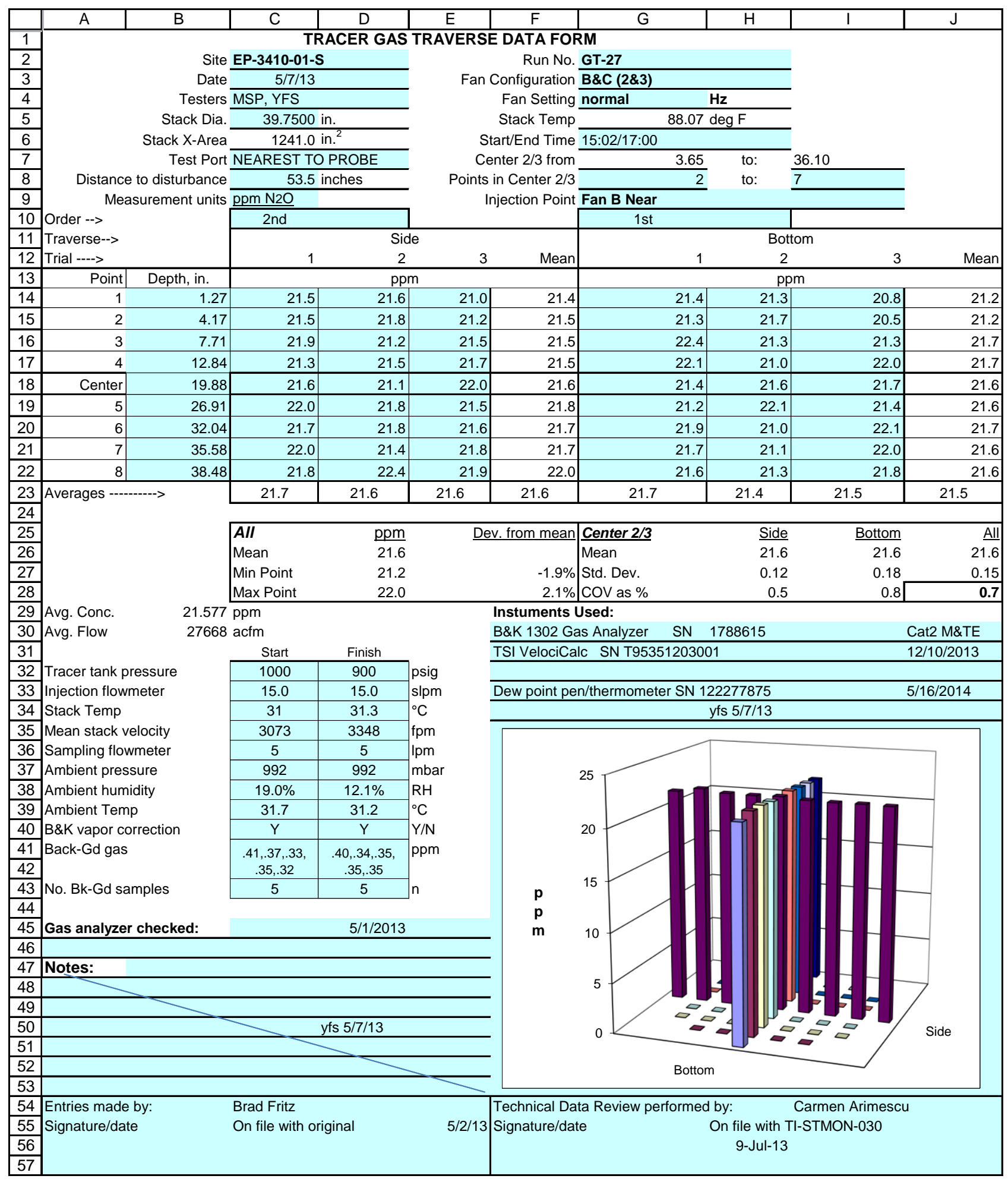




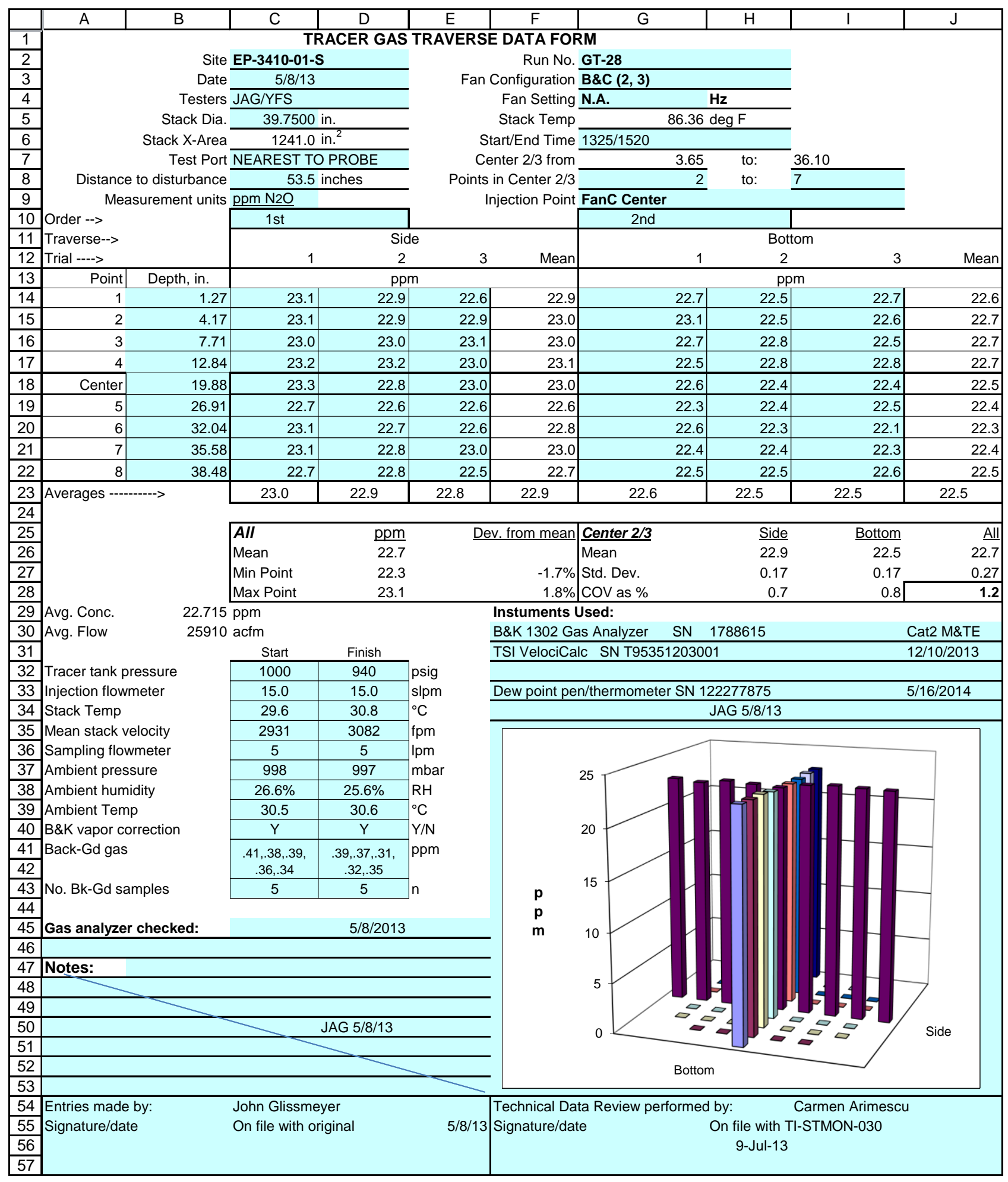




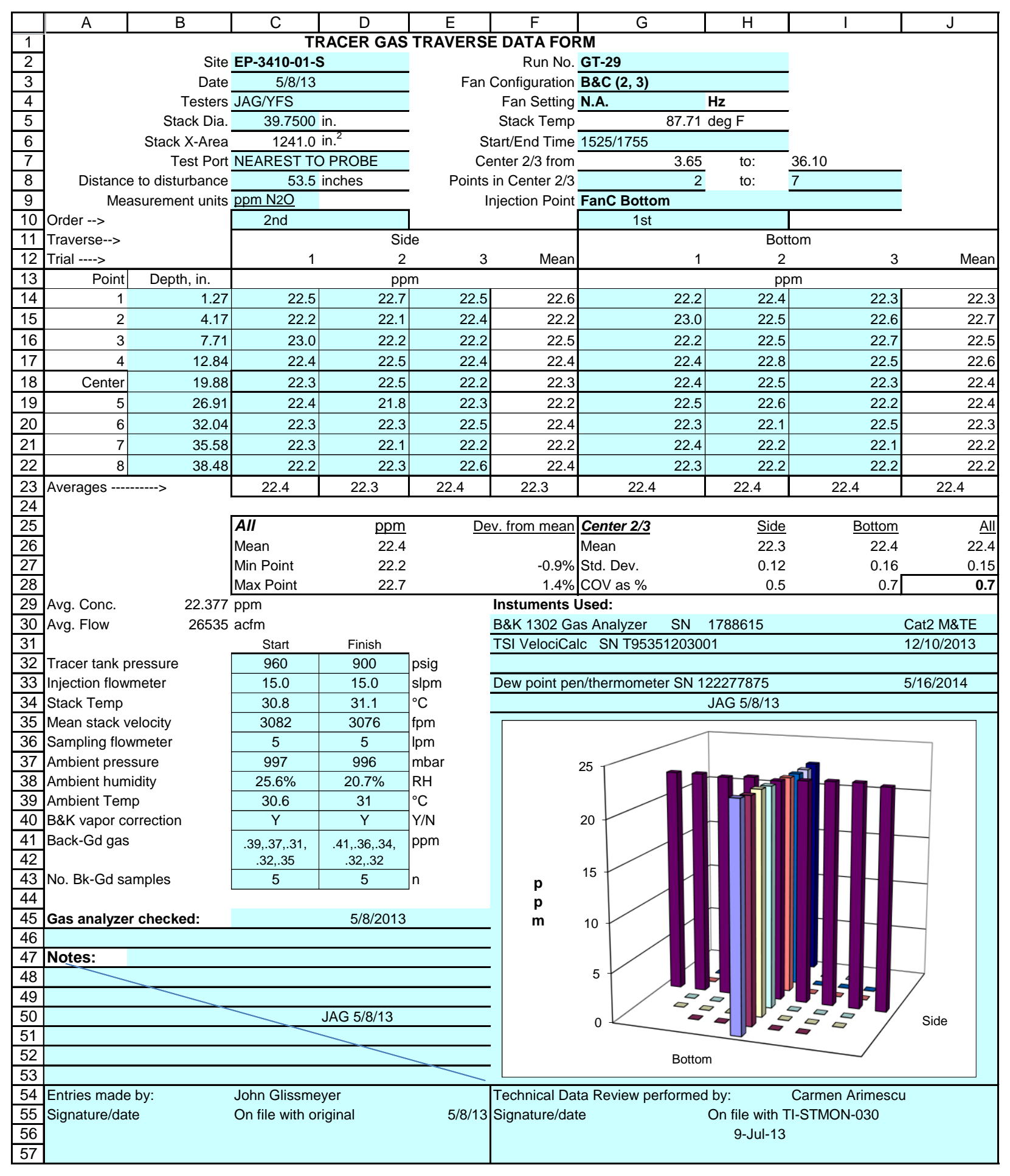




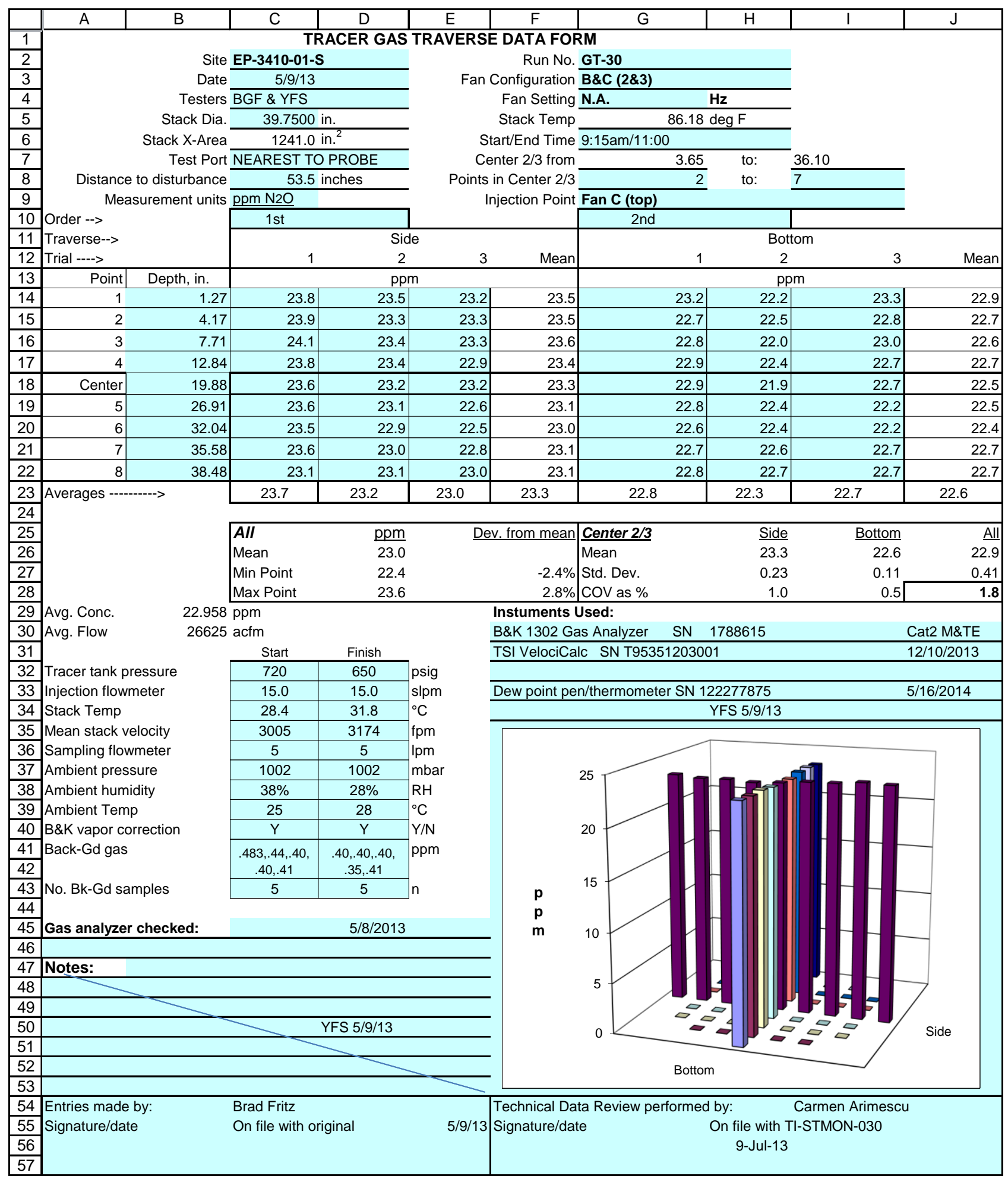




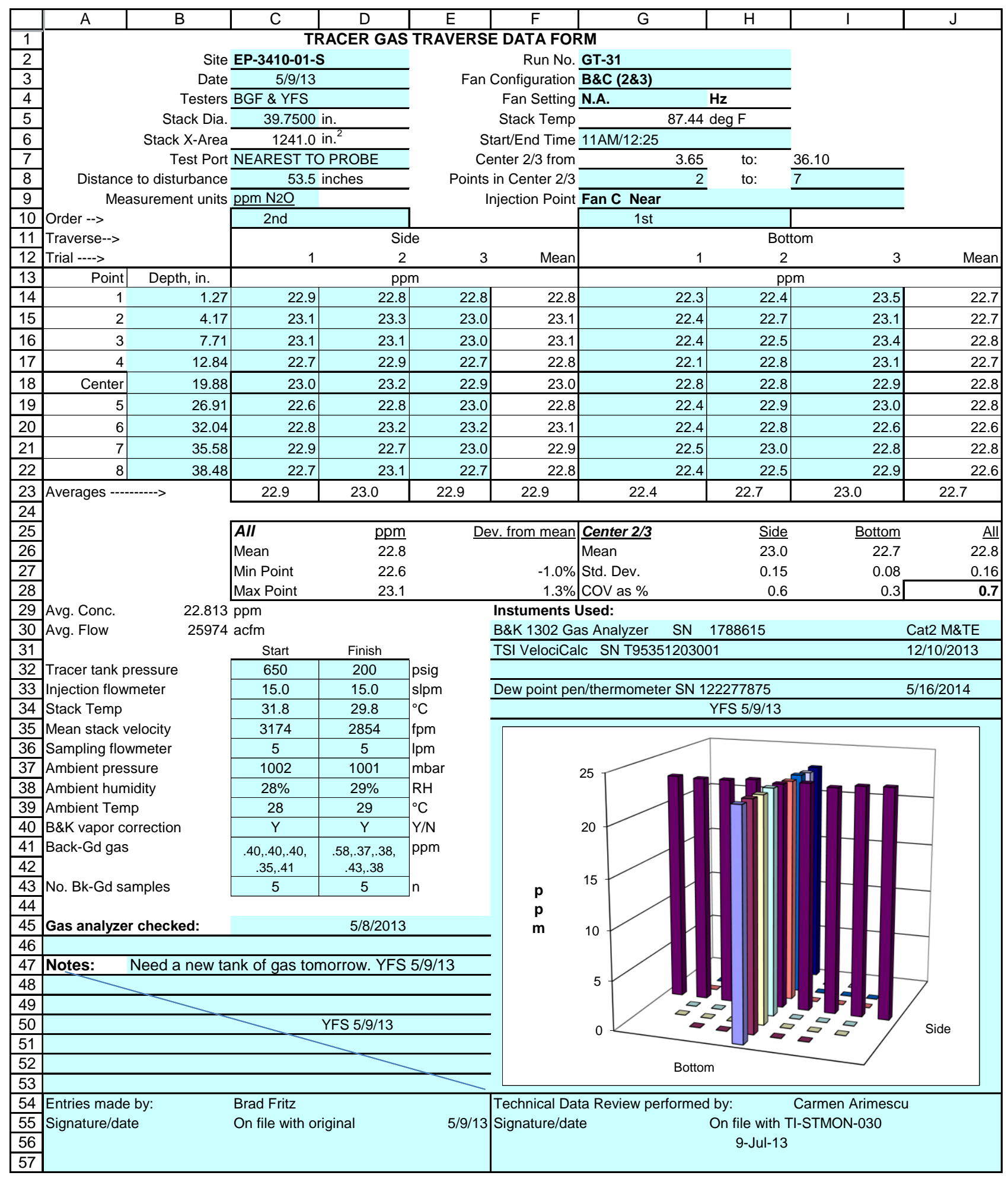




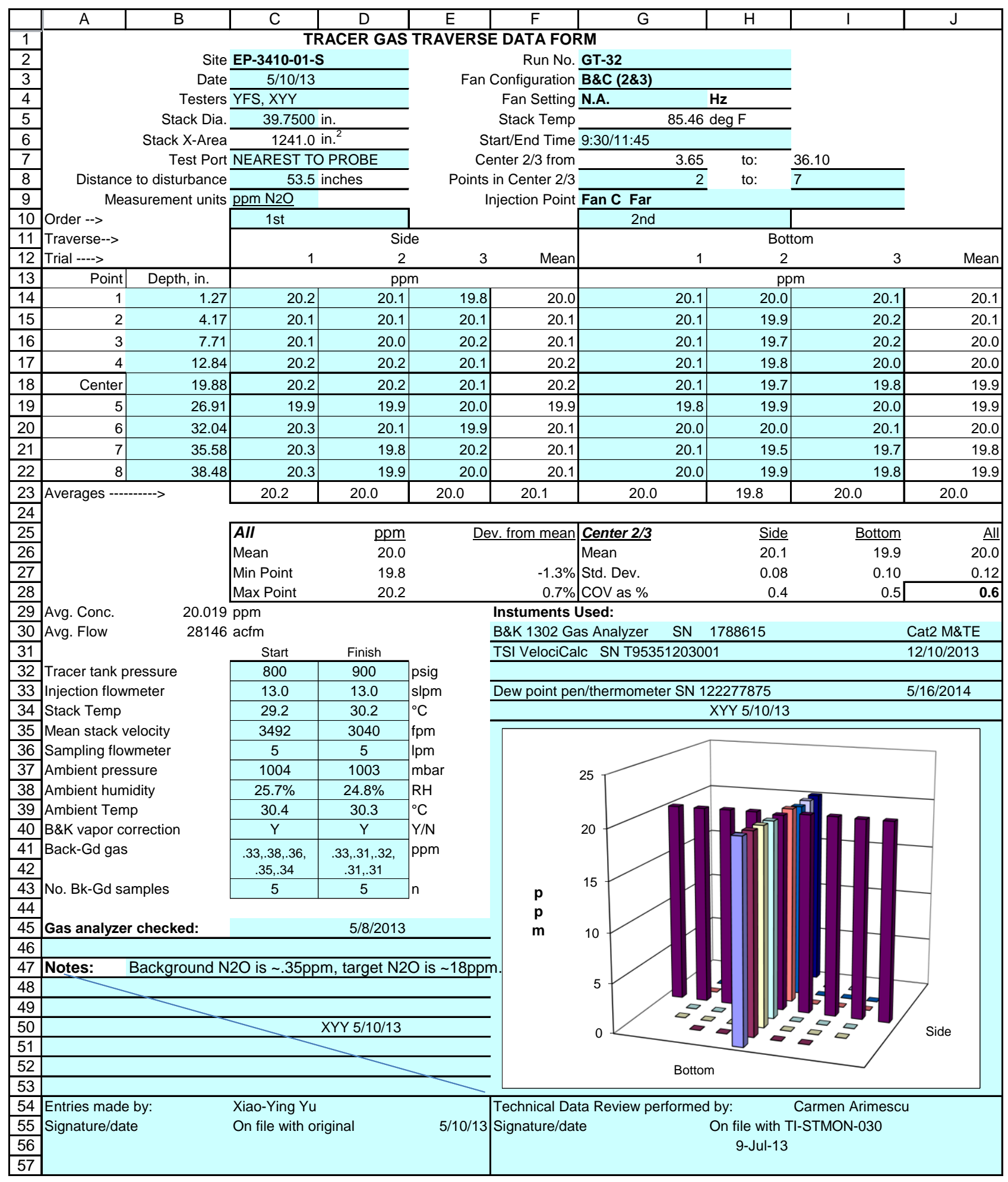




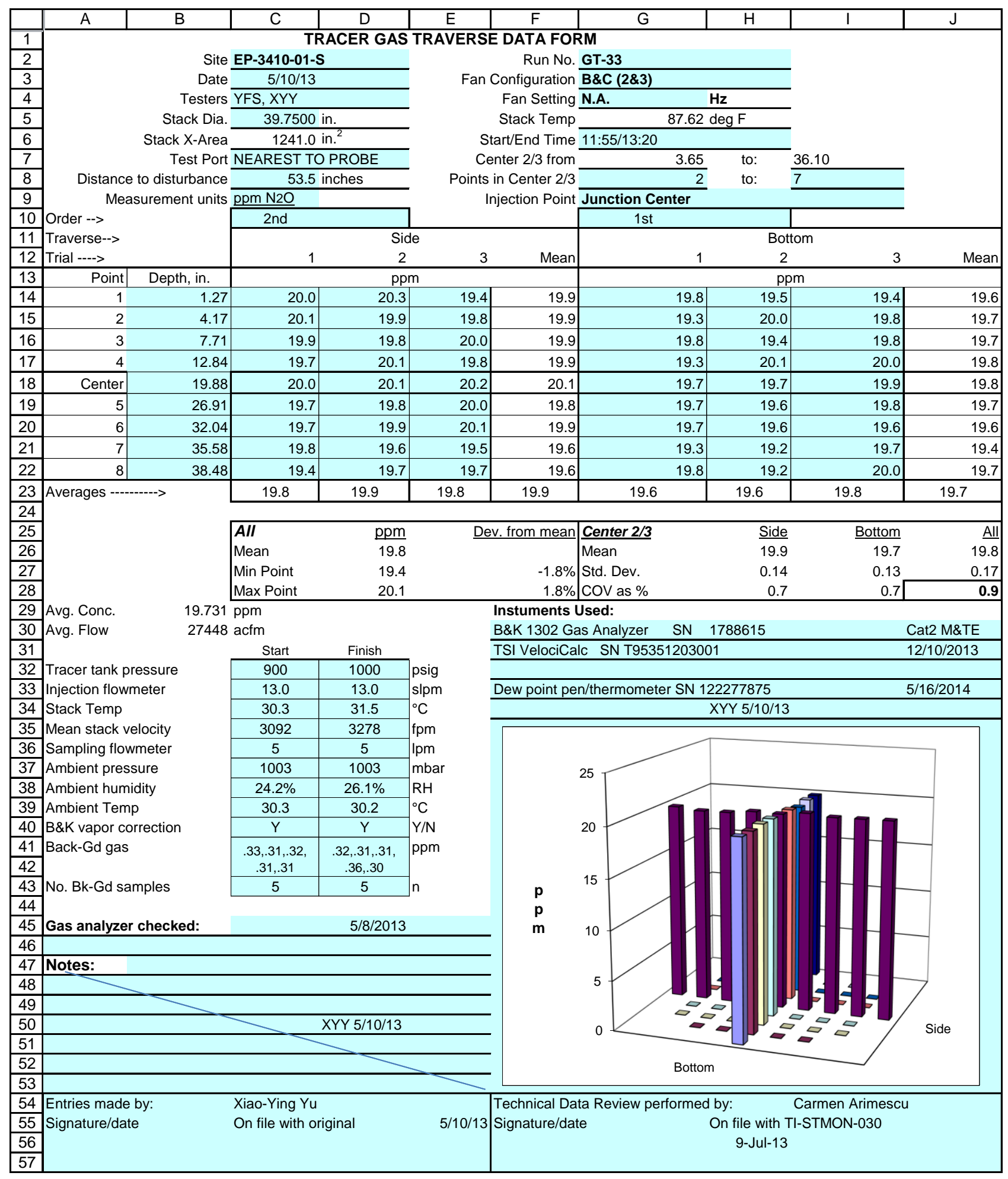




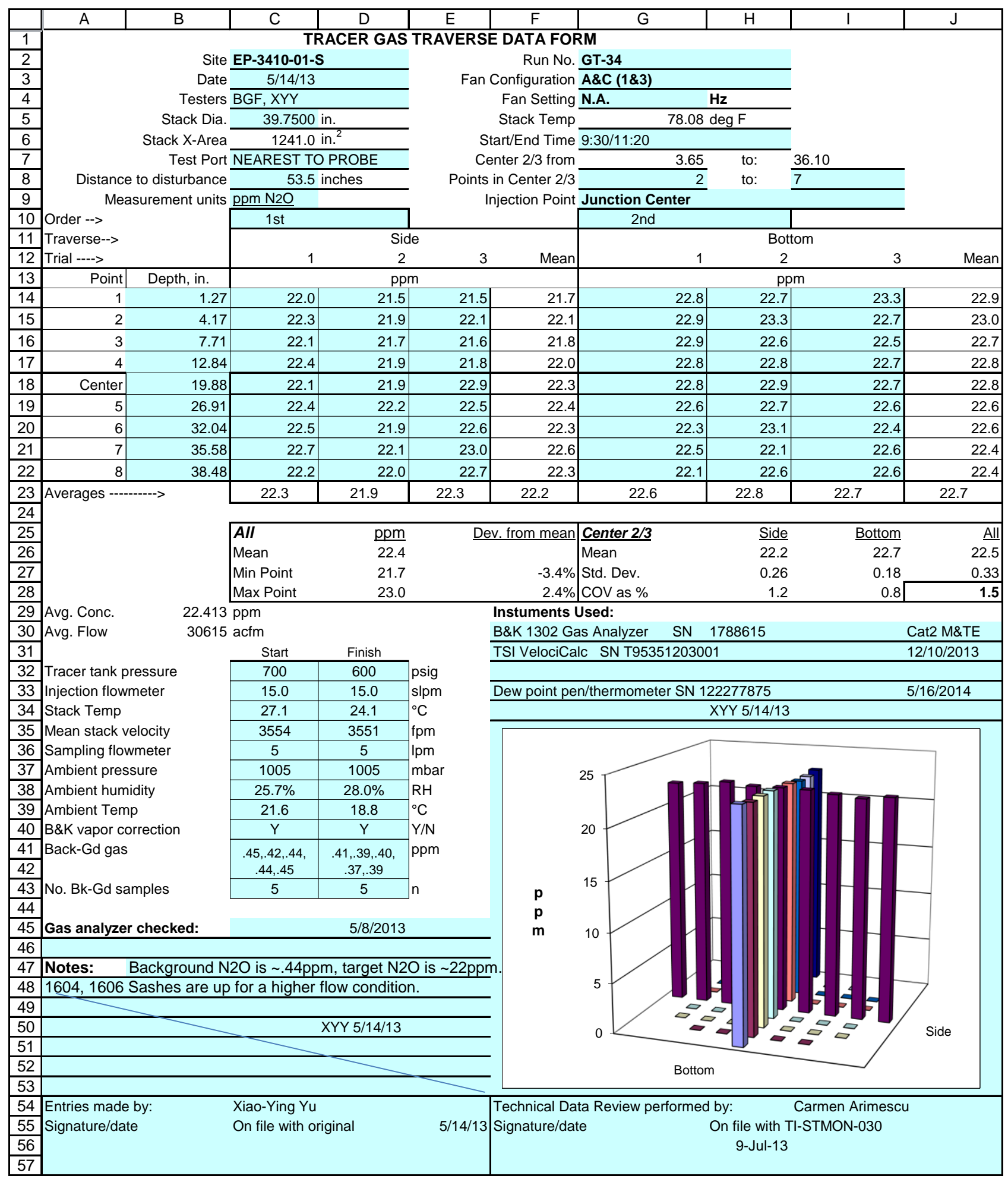




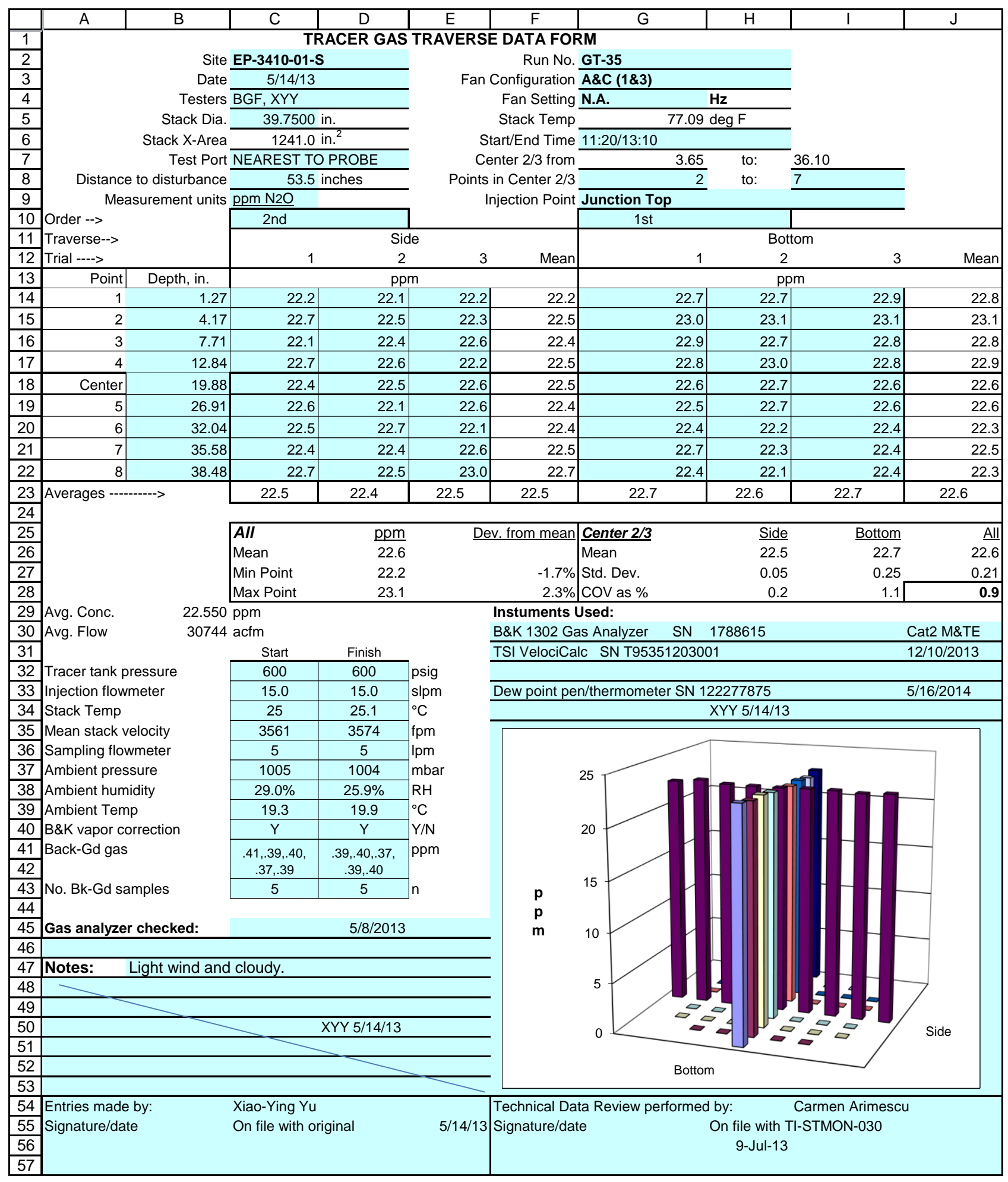




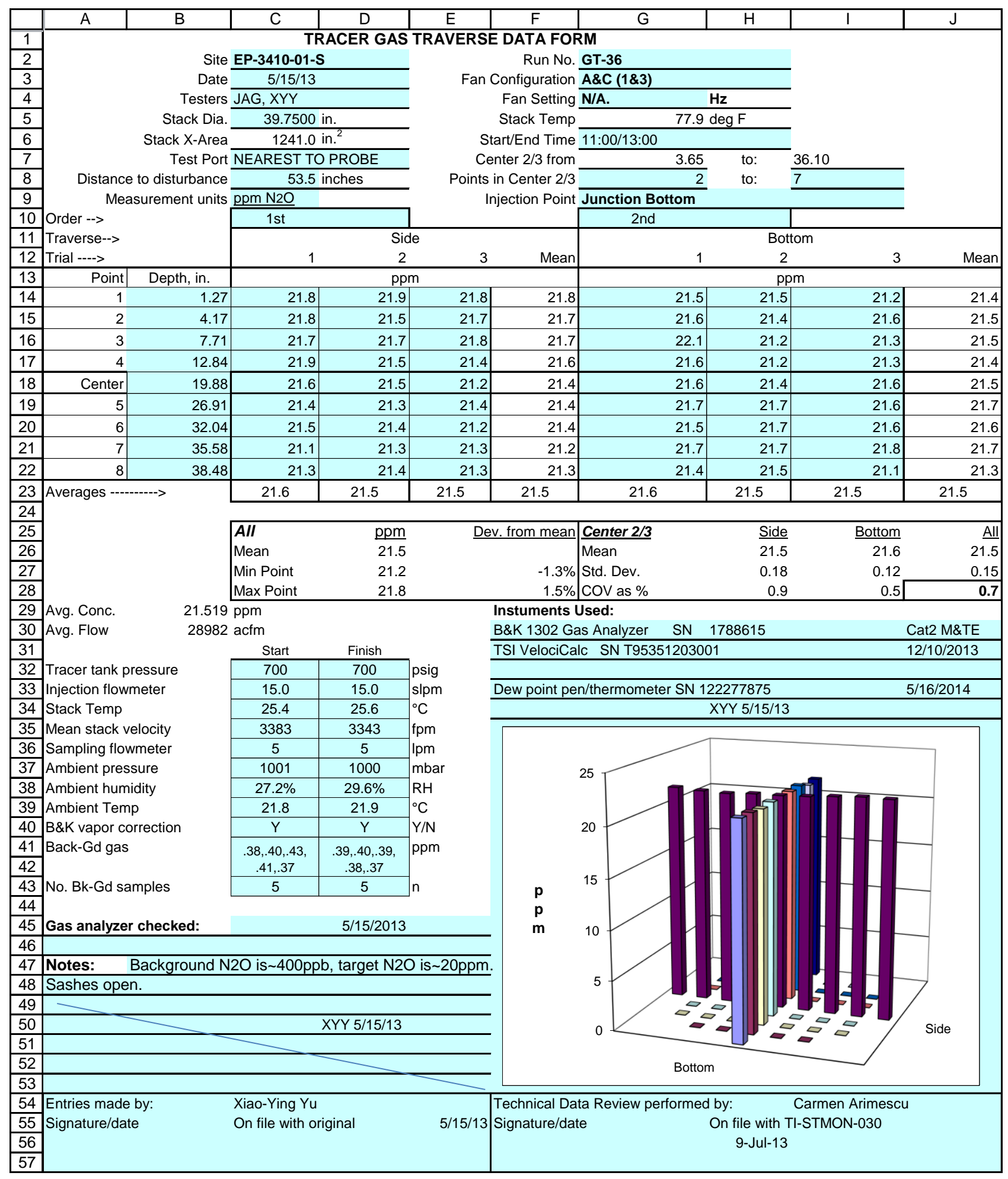




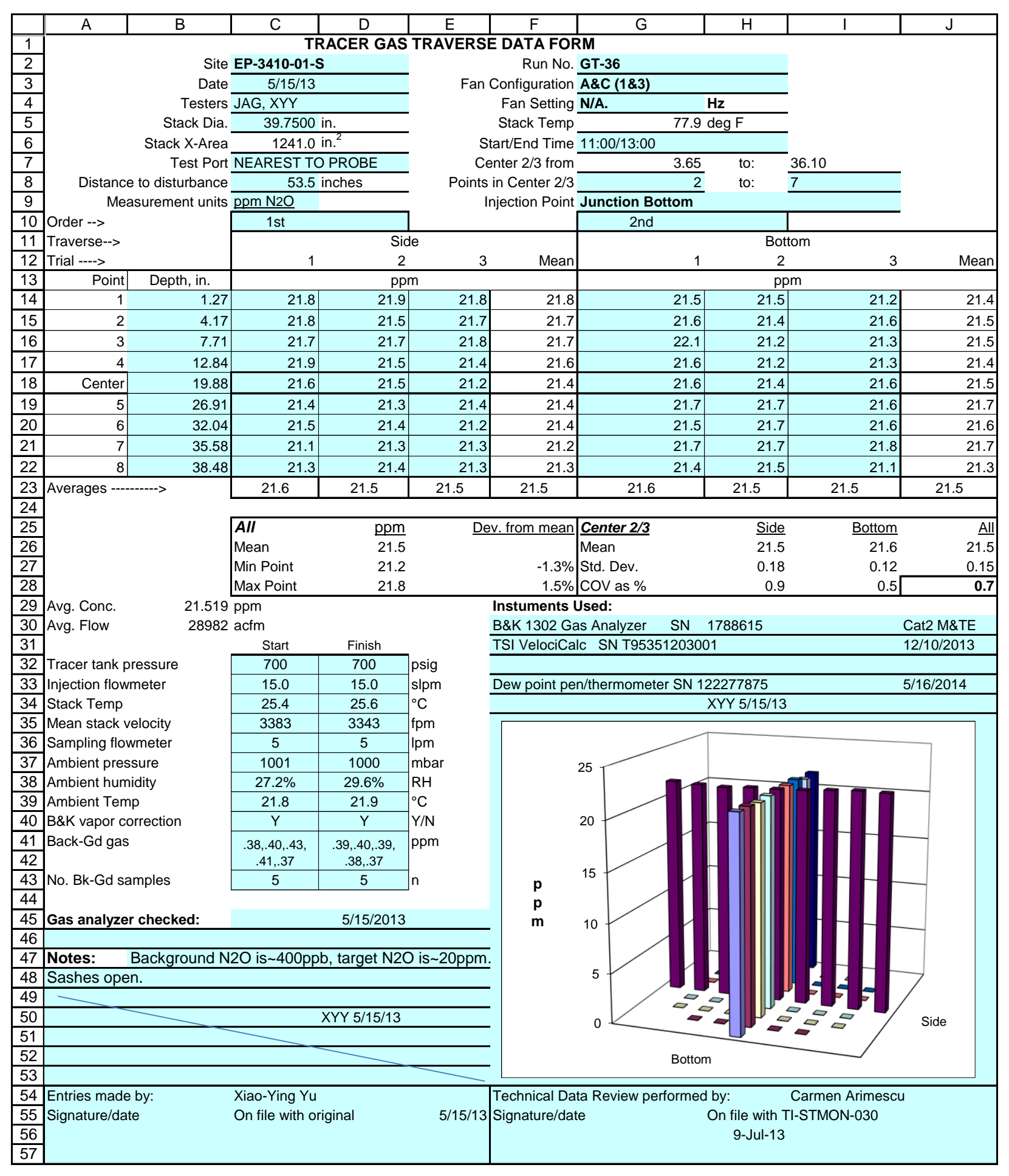




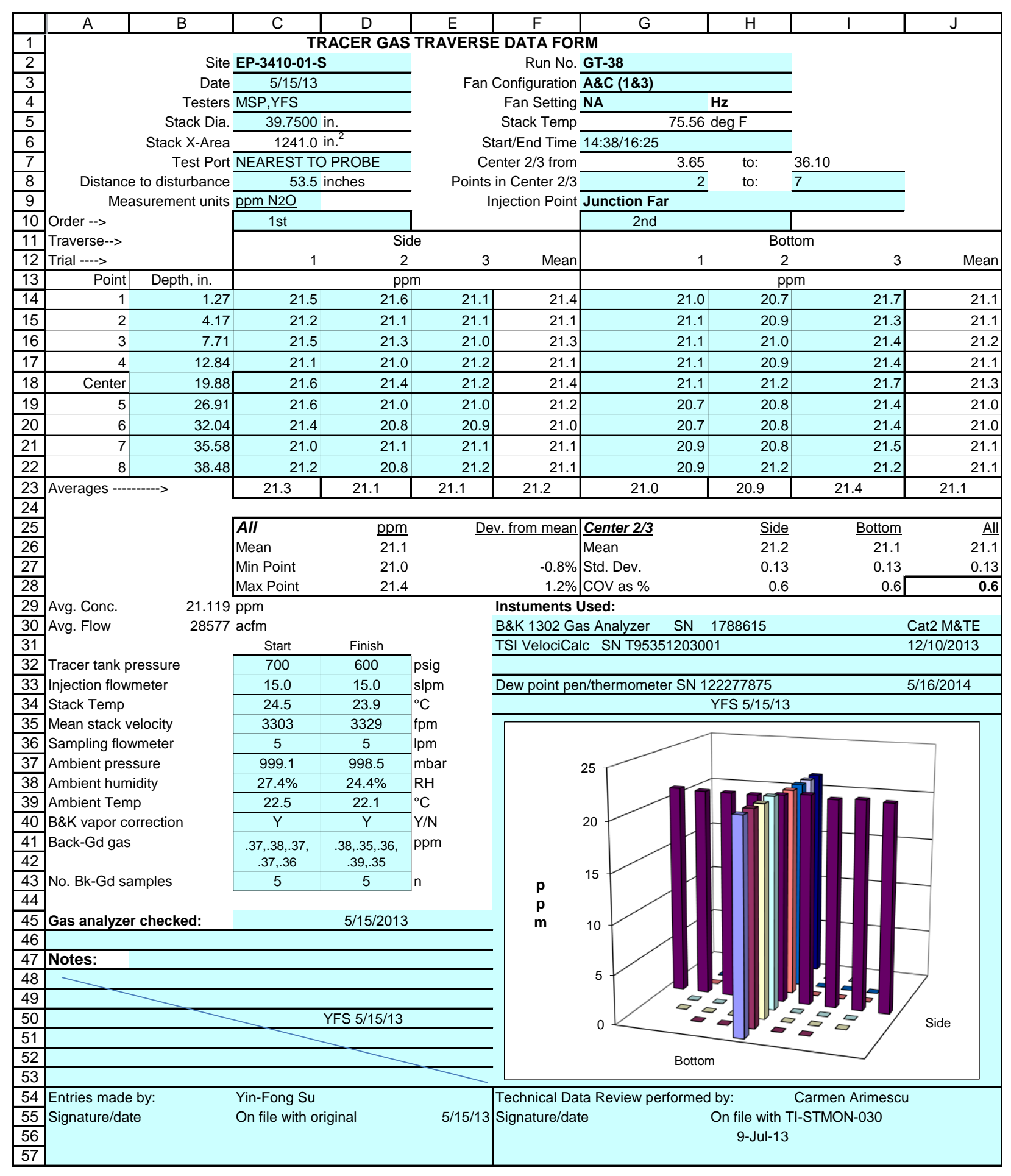




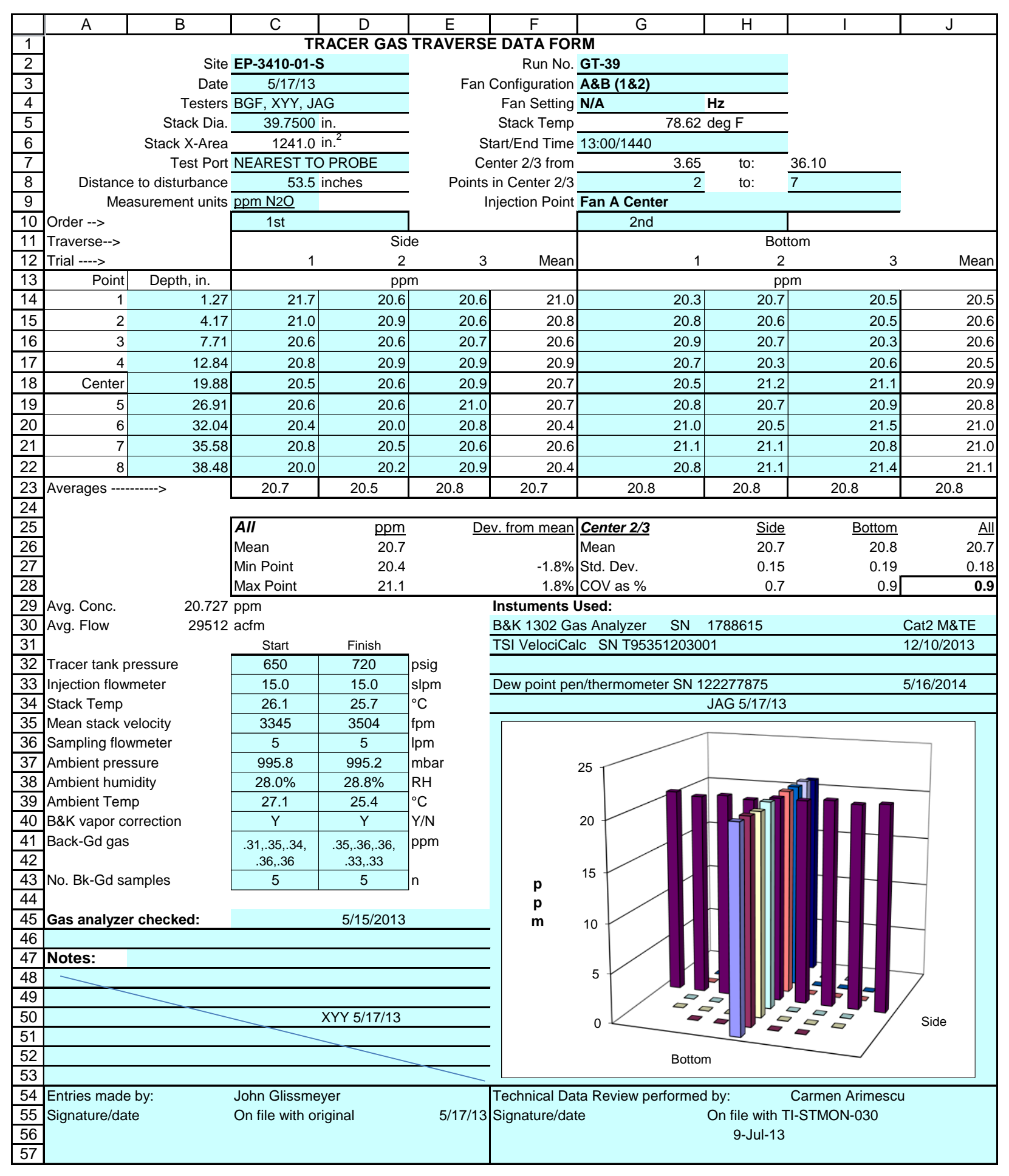




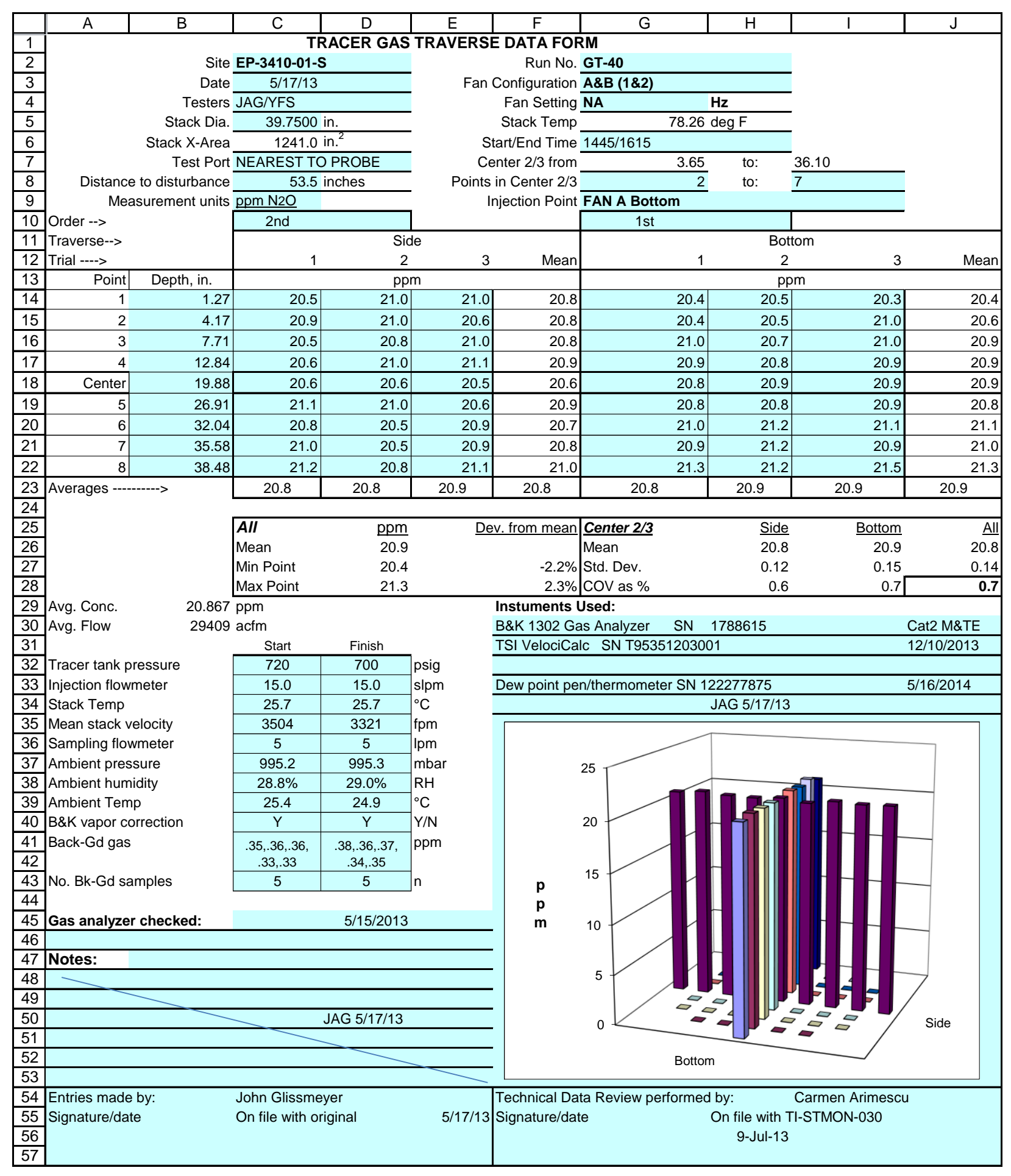




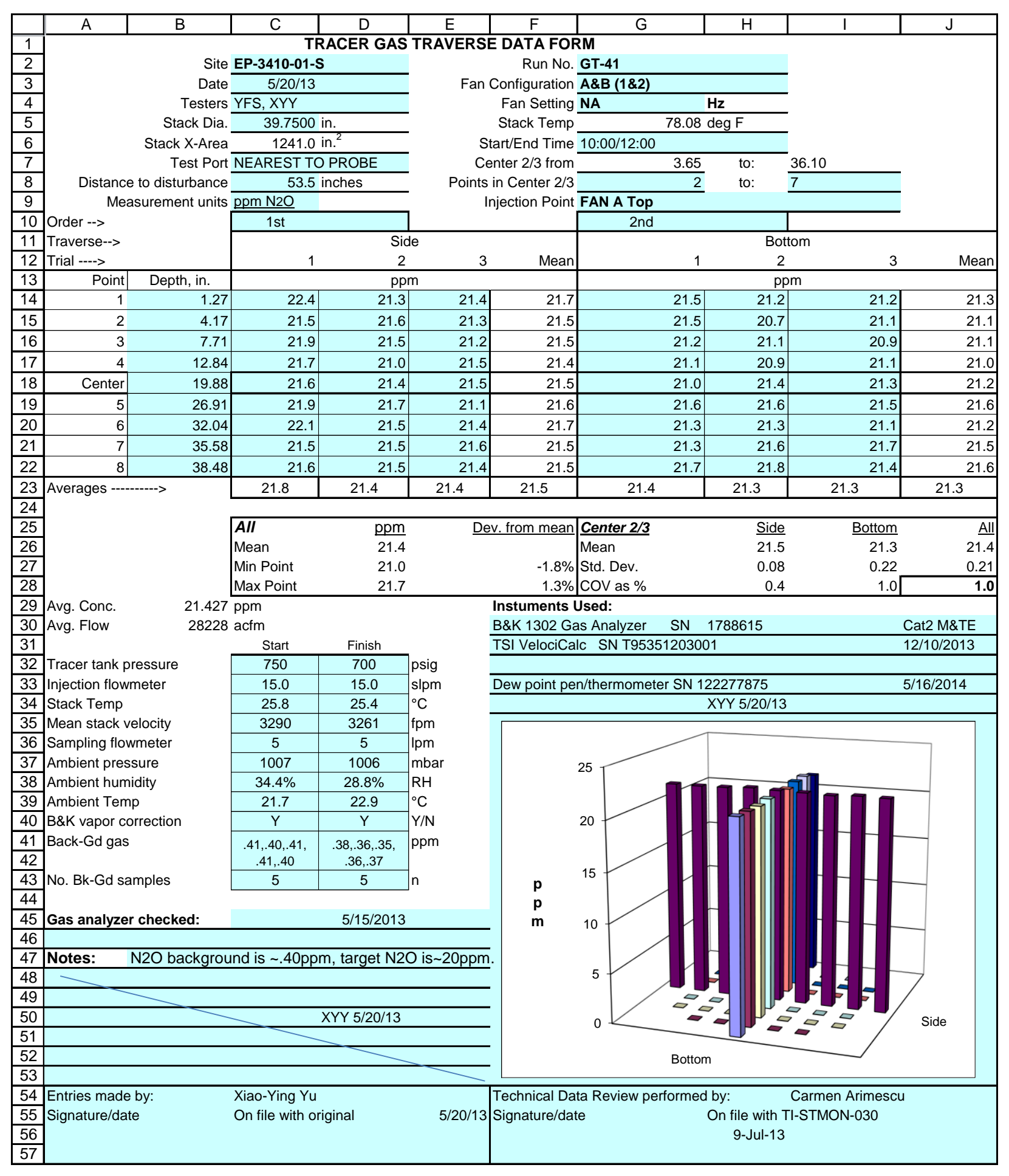




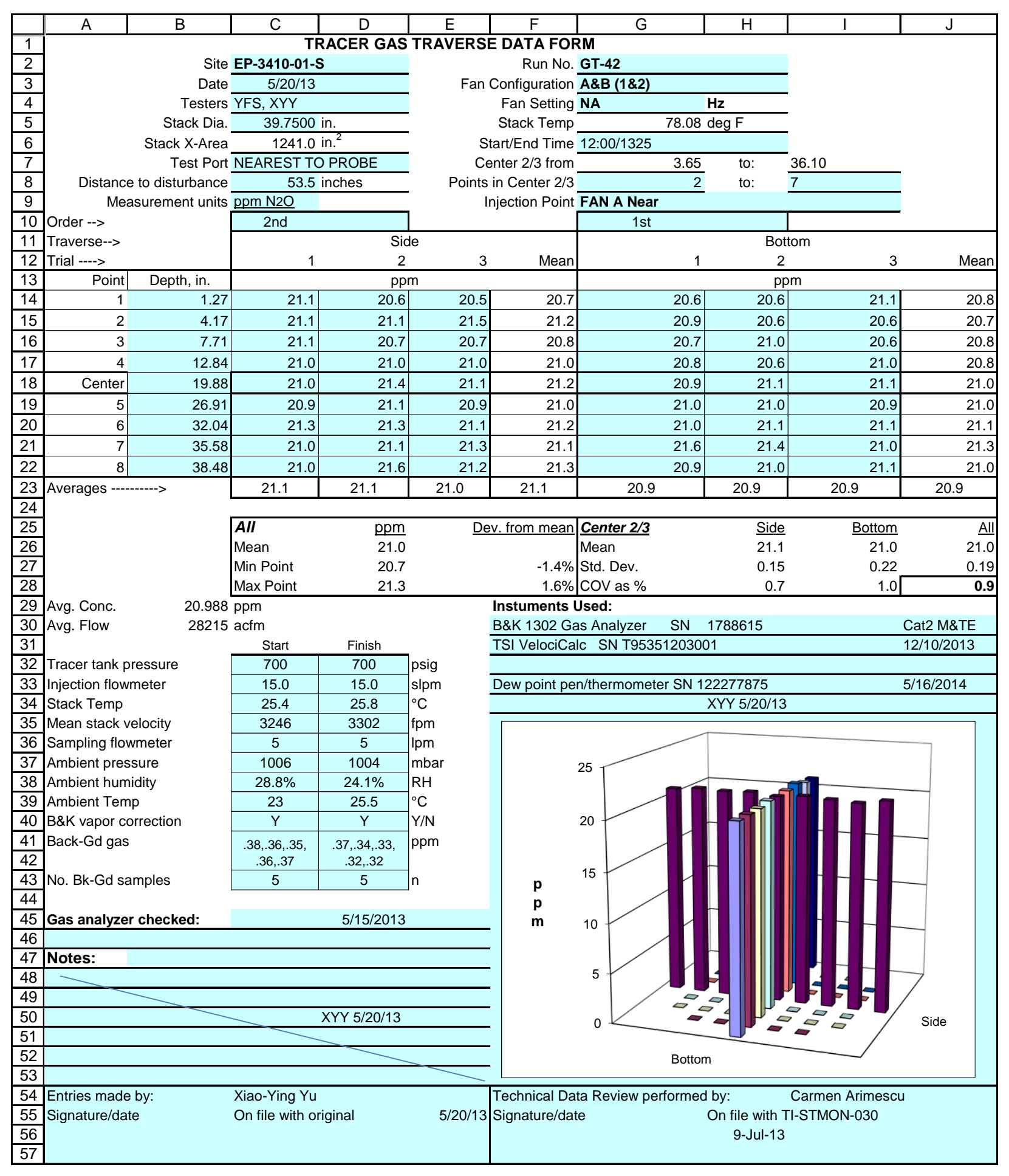




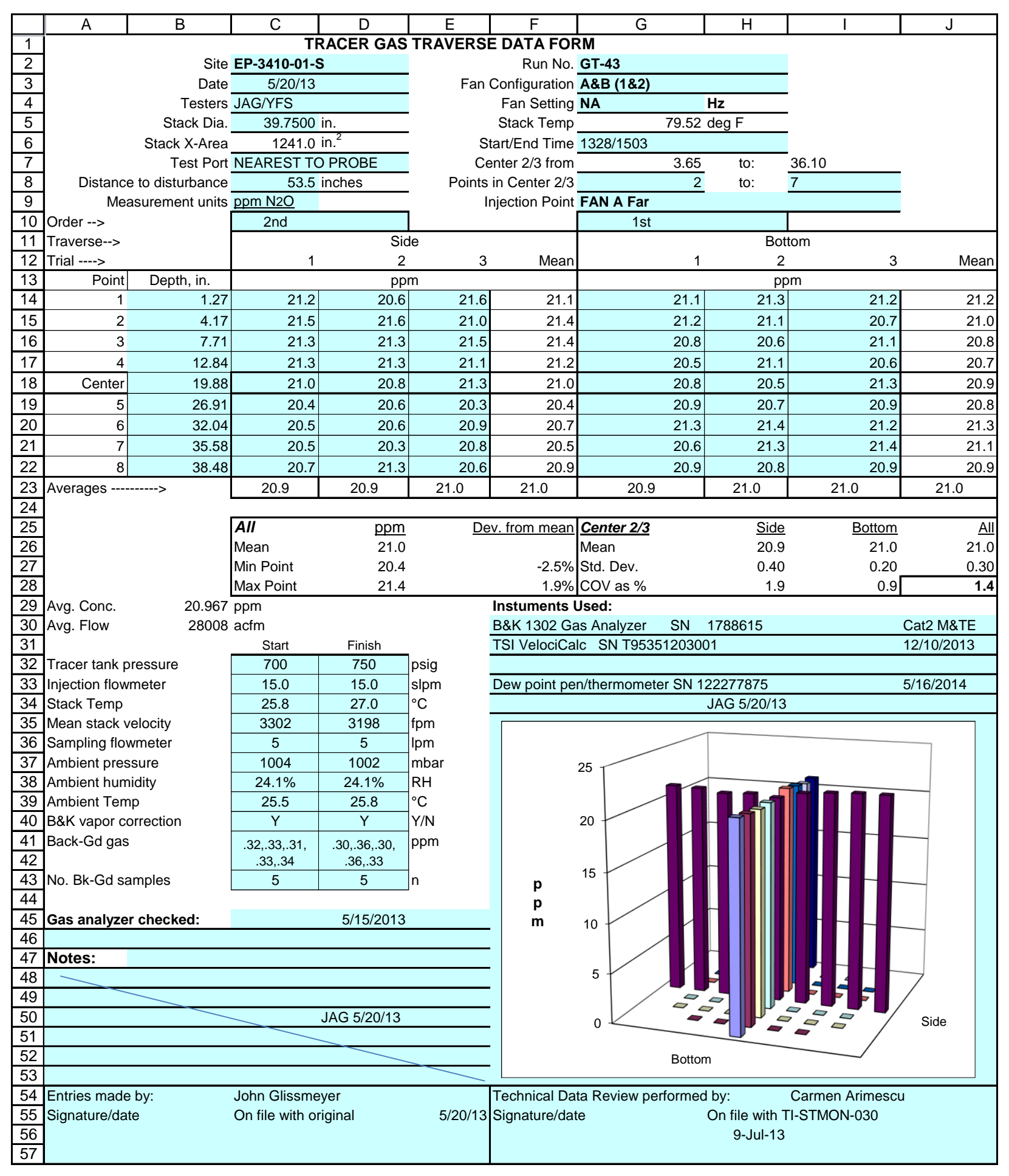




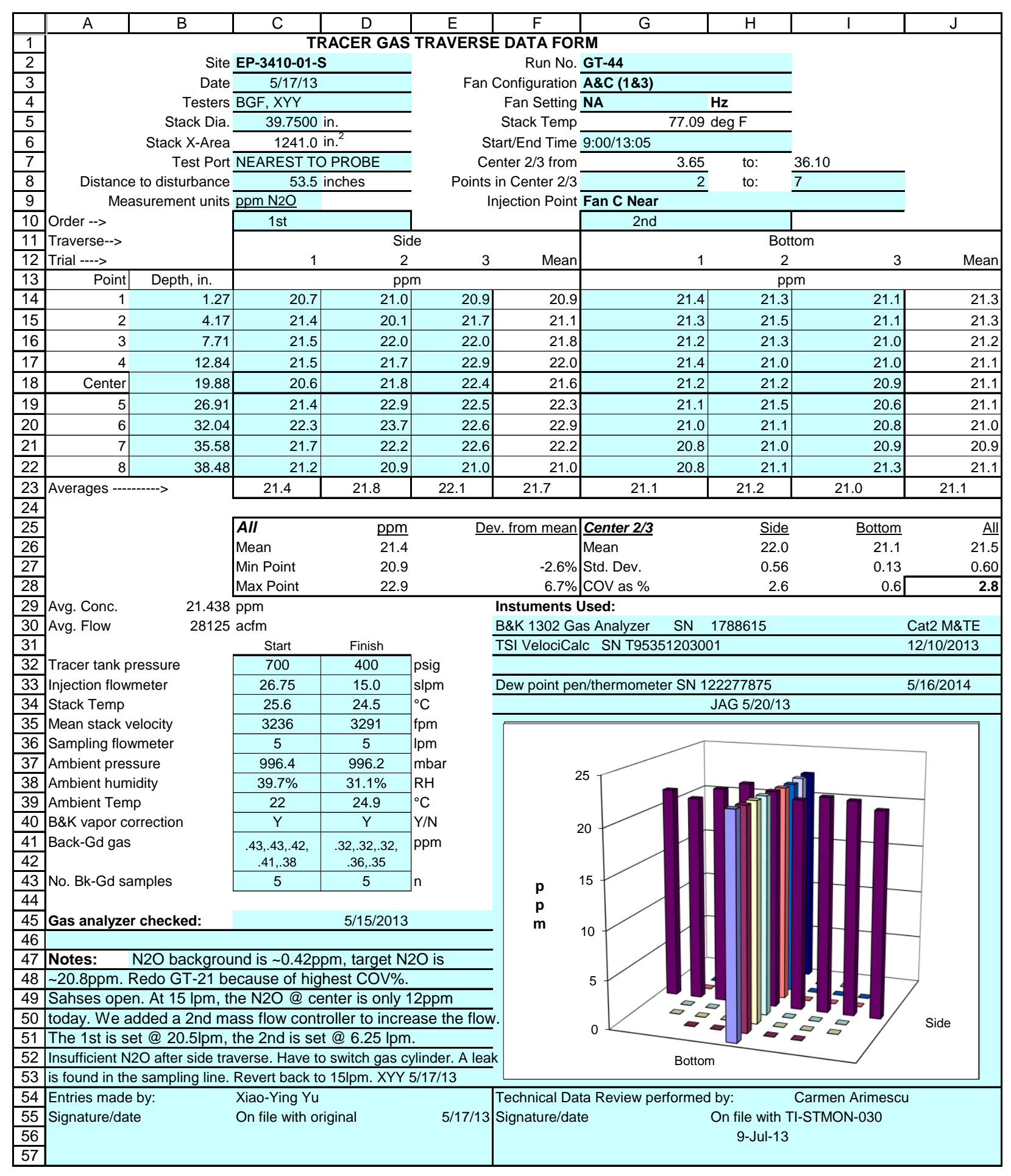




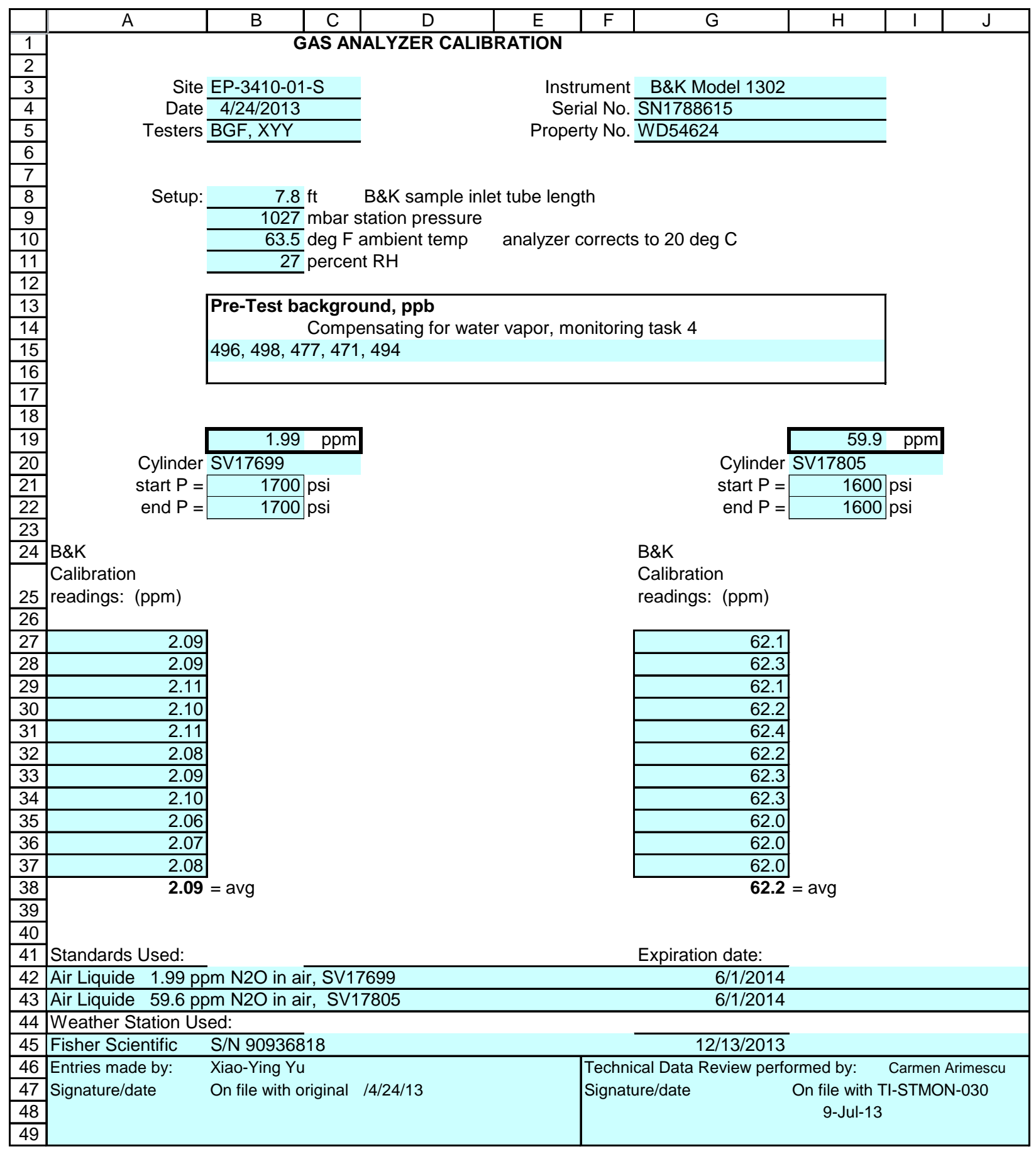




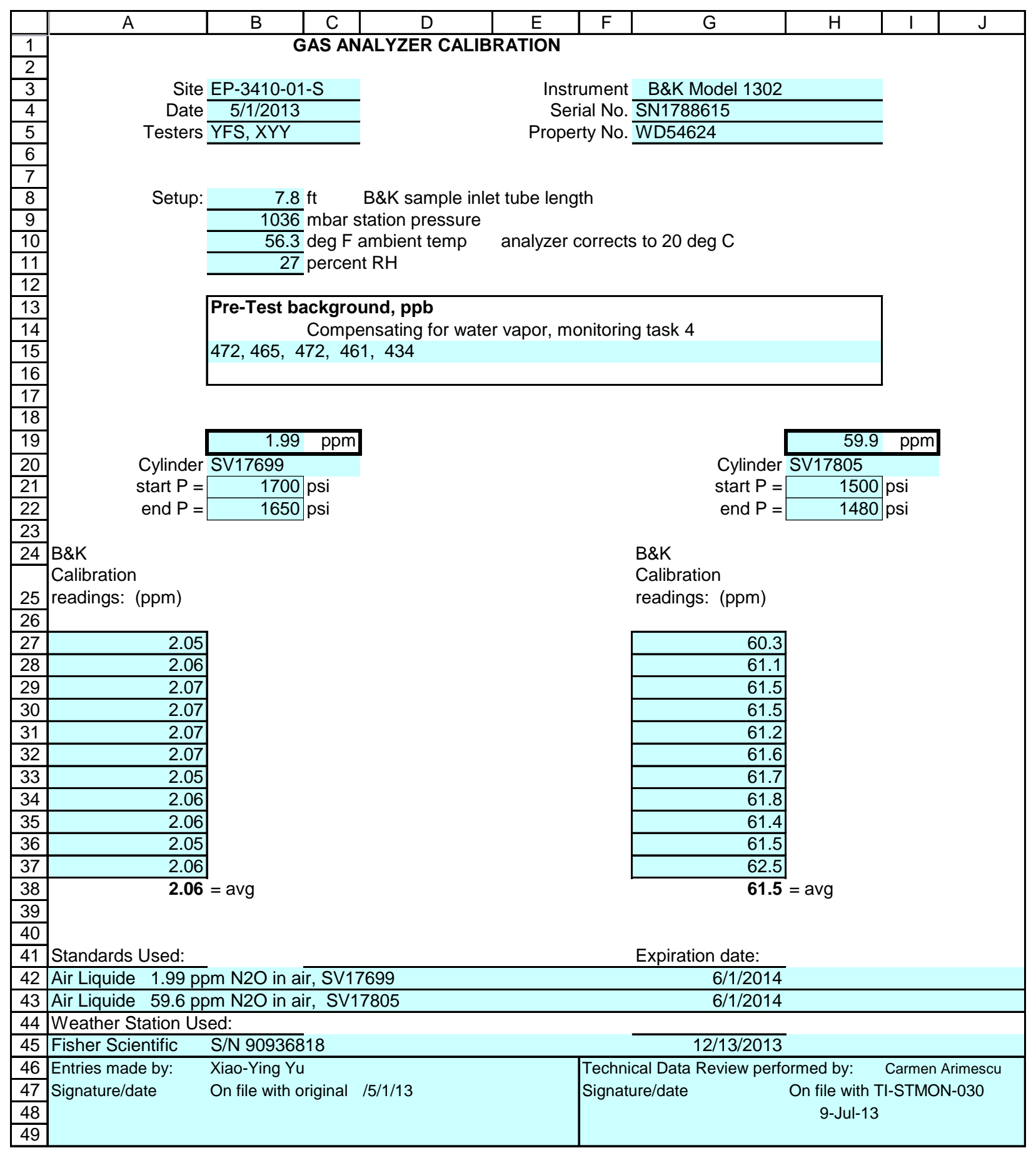




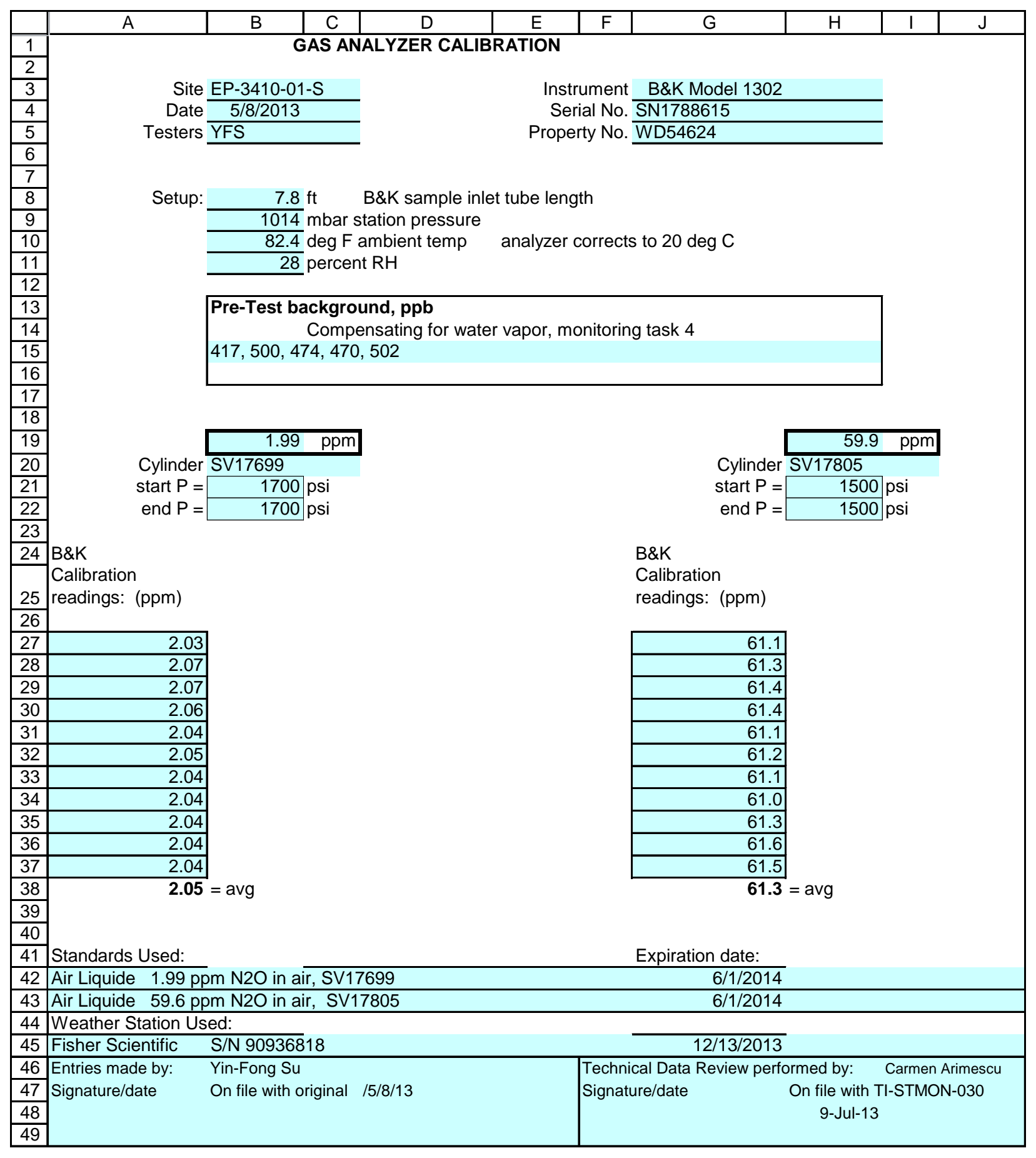




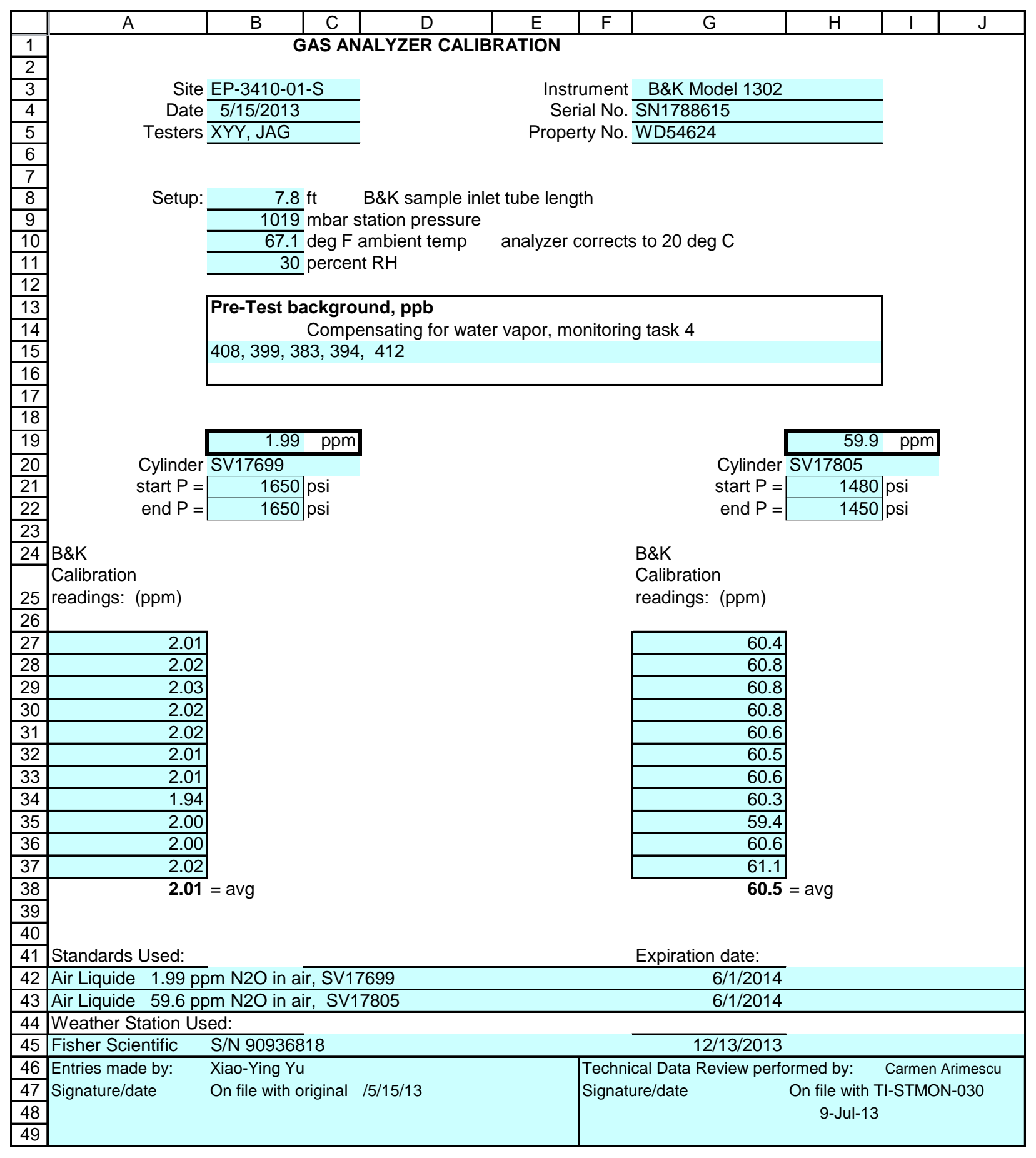




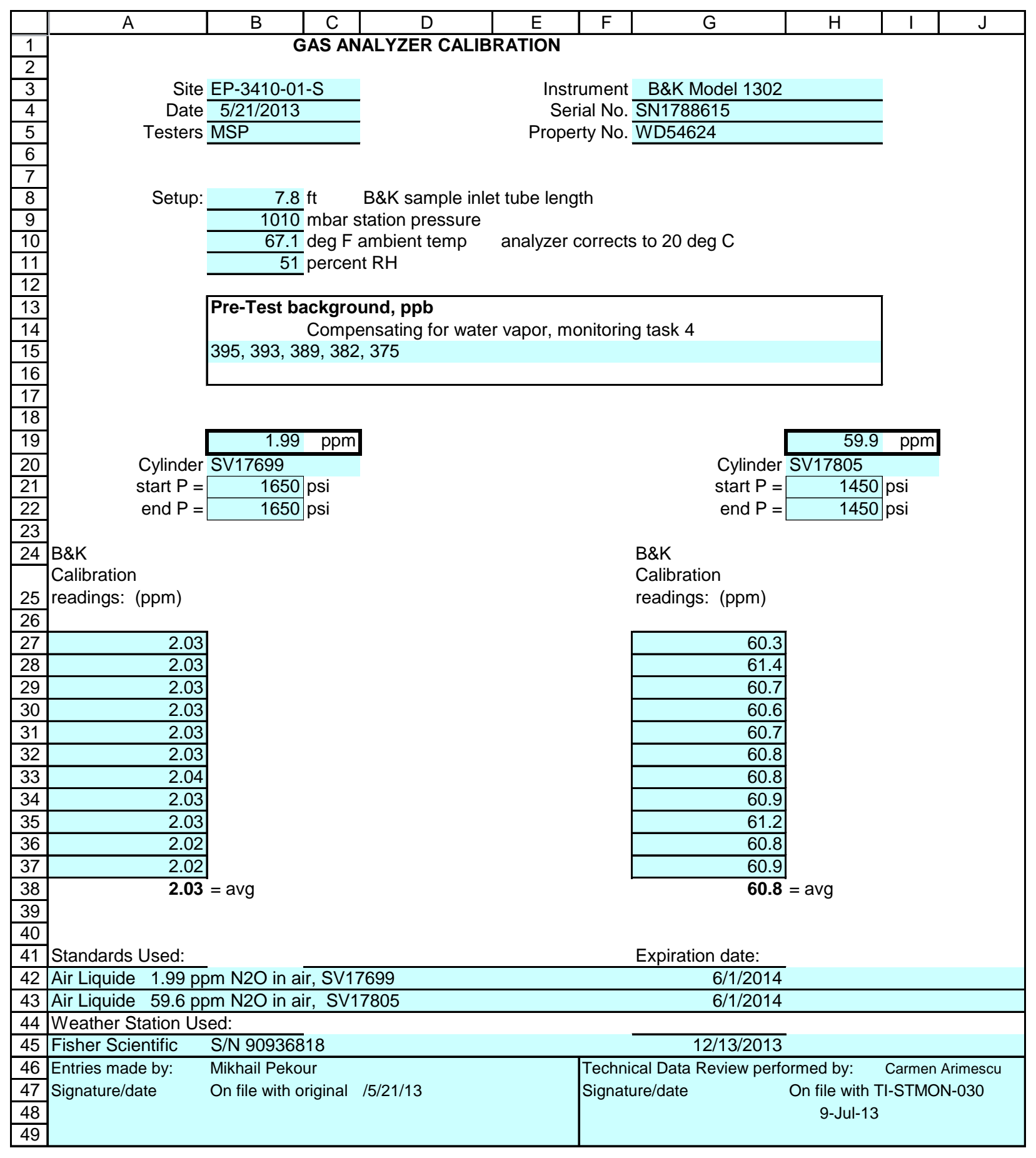




\section{Particle Tracer Uniformity}

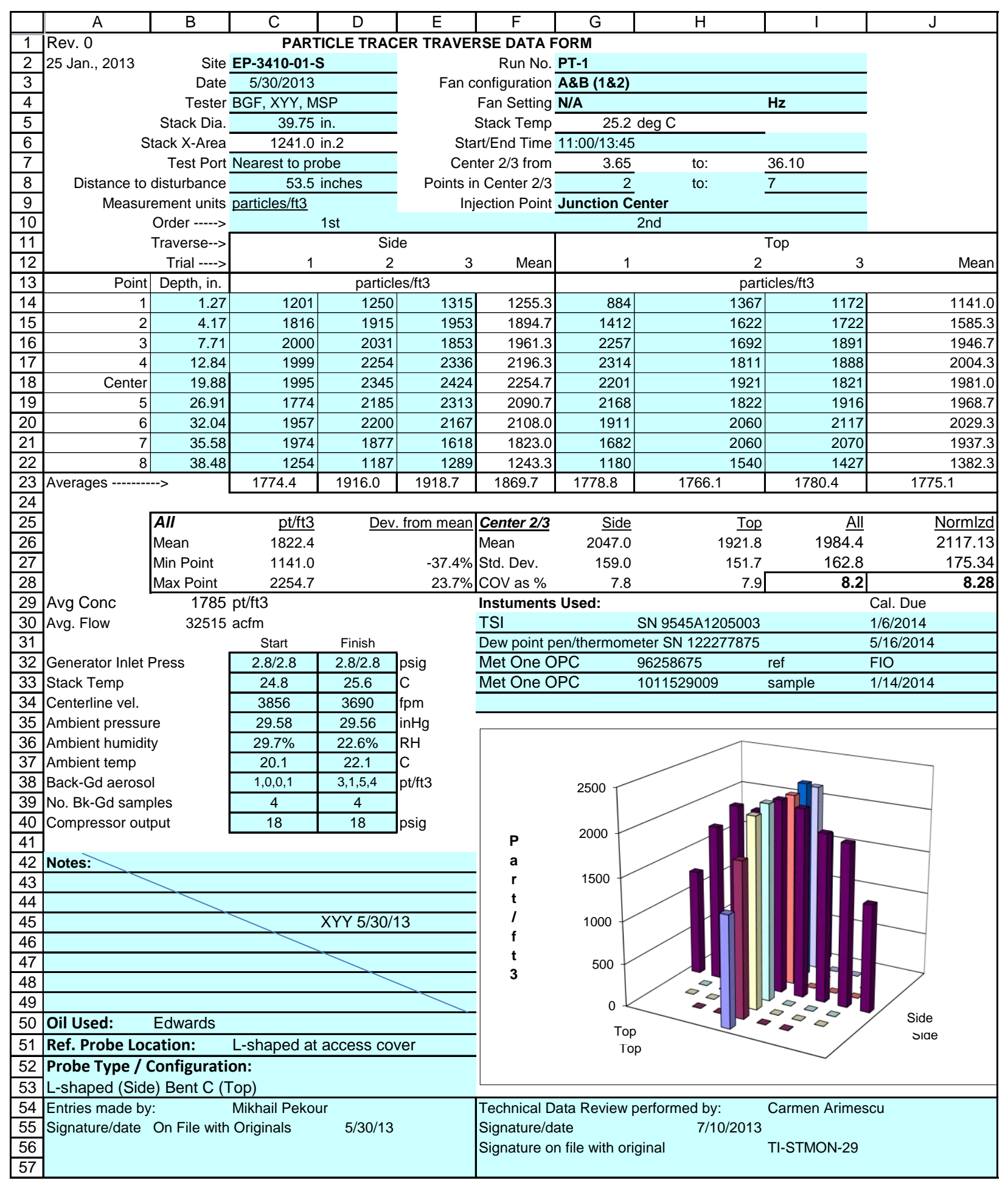




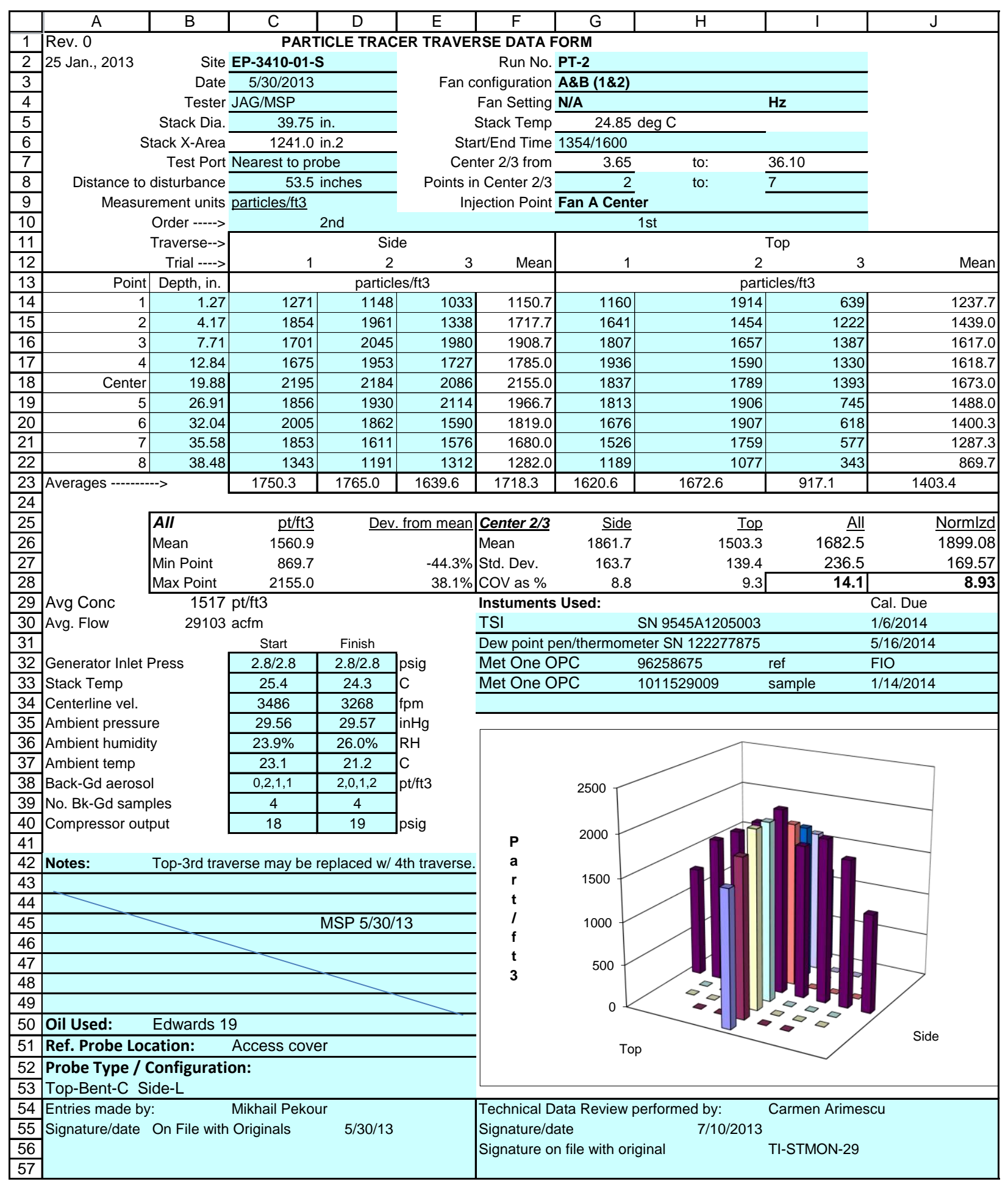




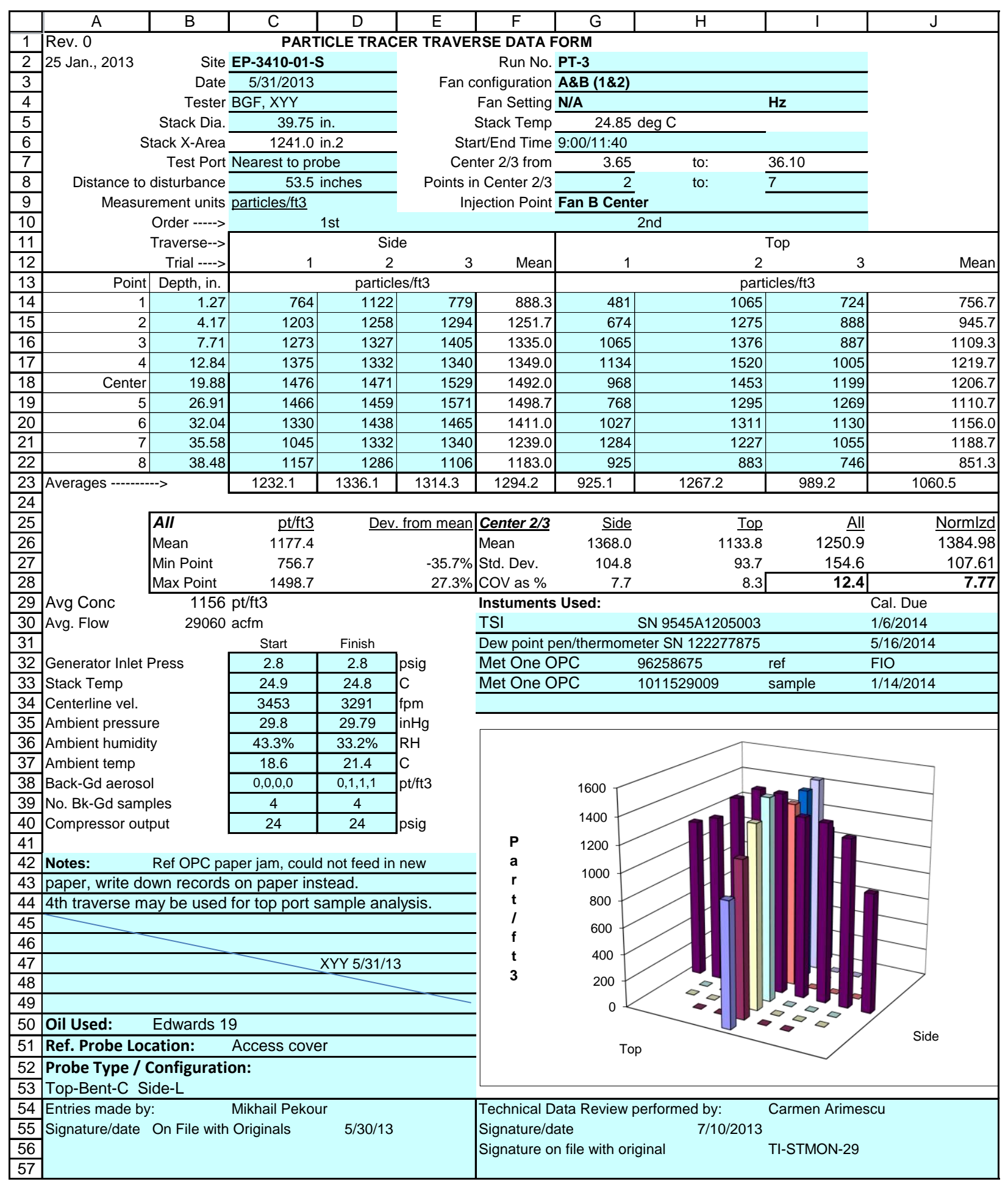




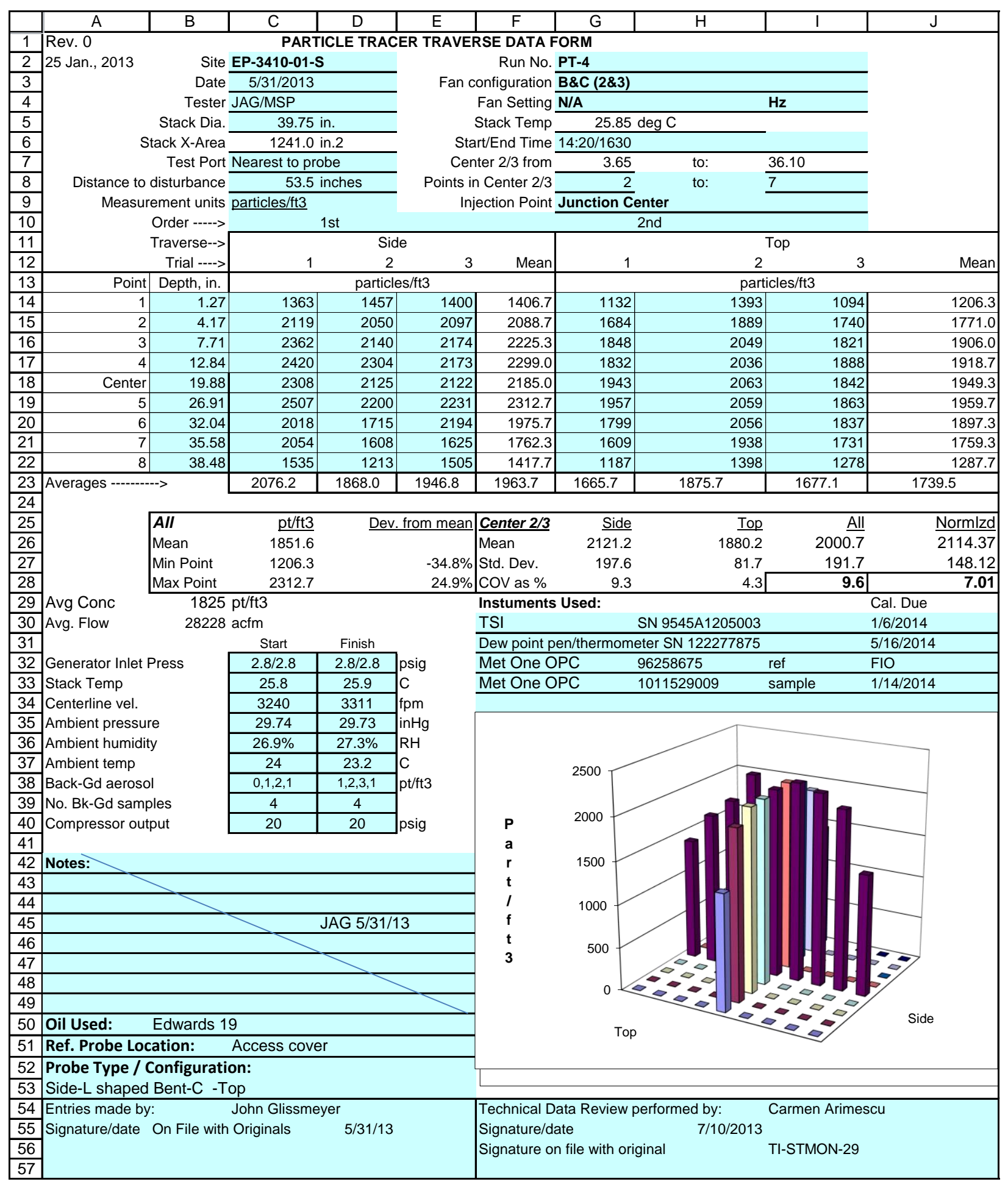




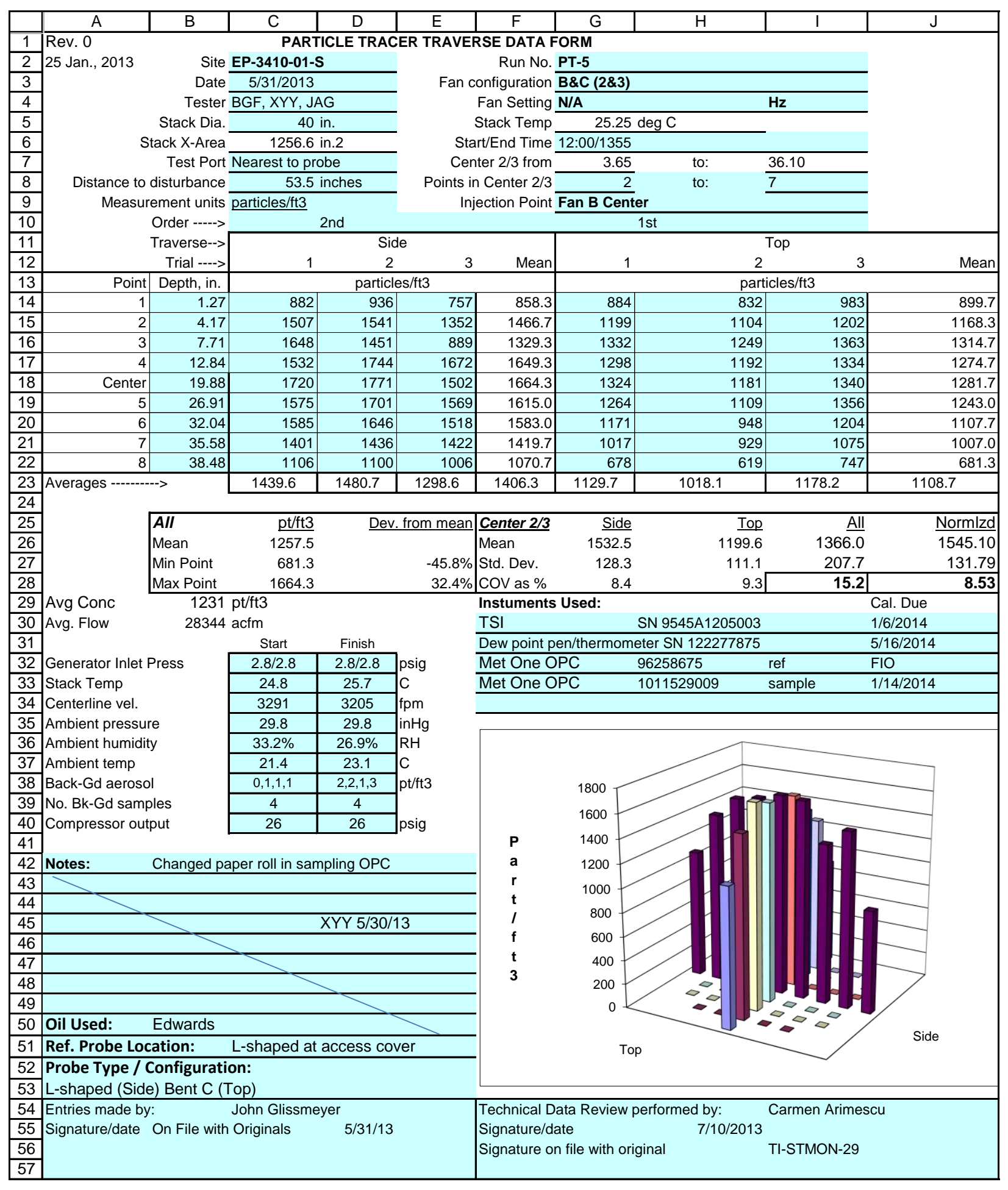




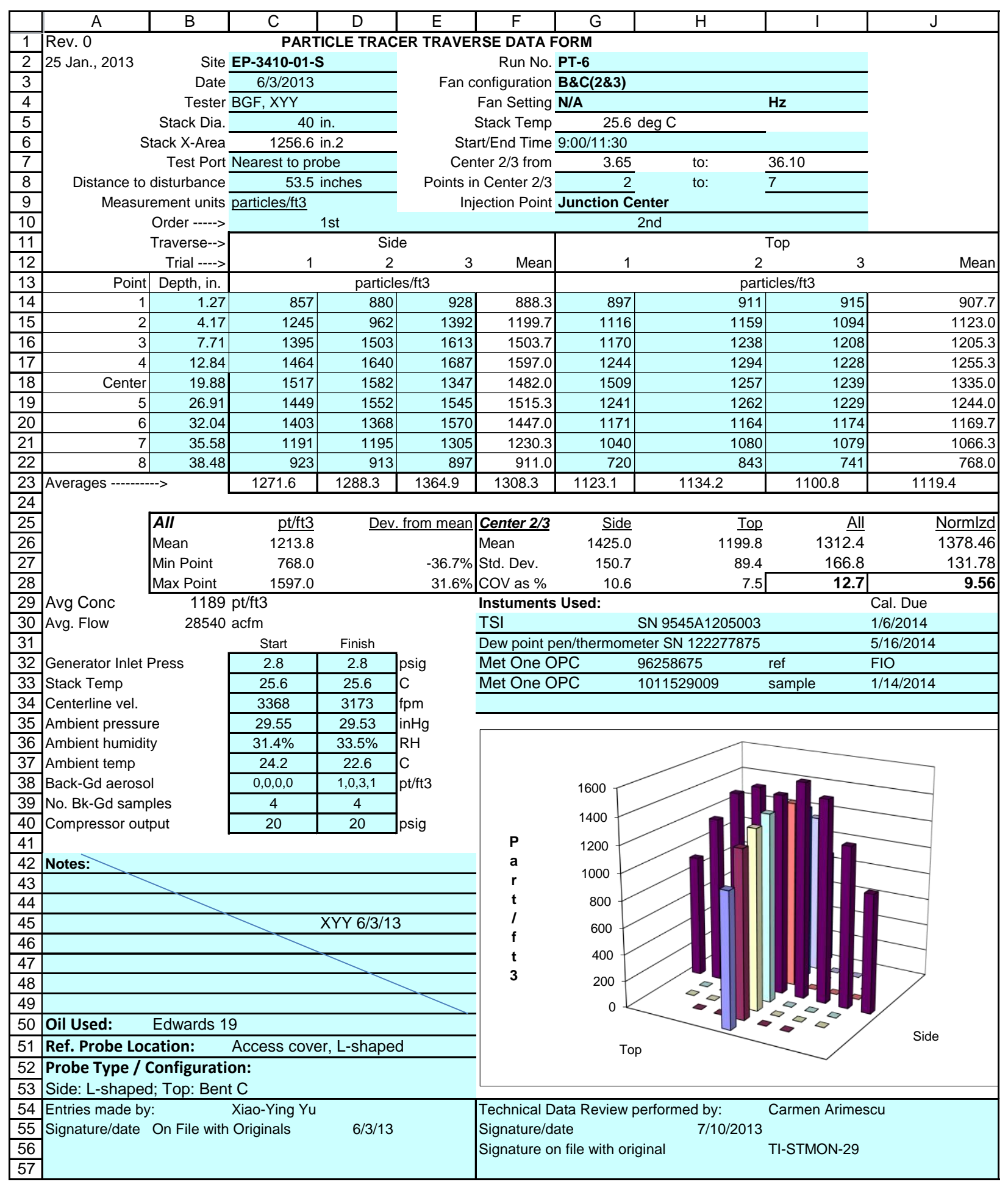




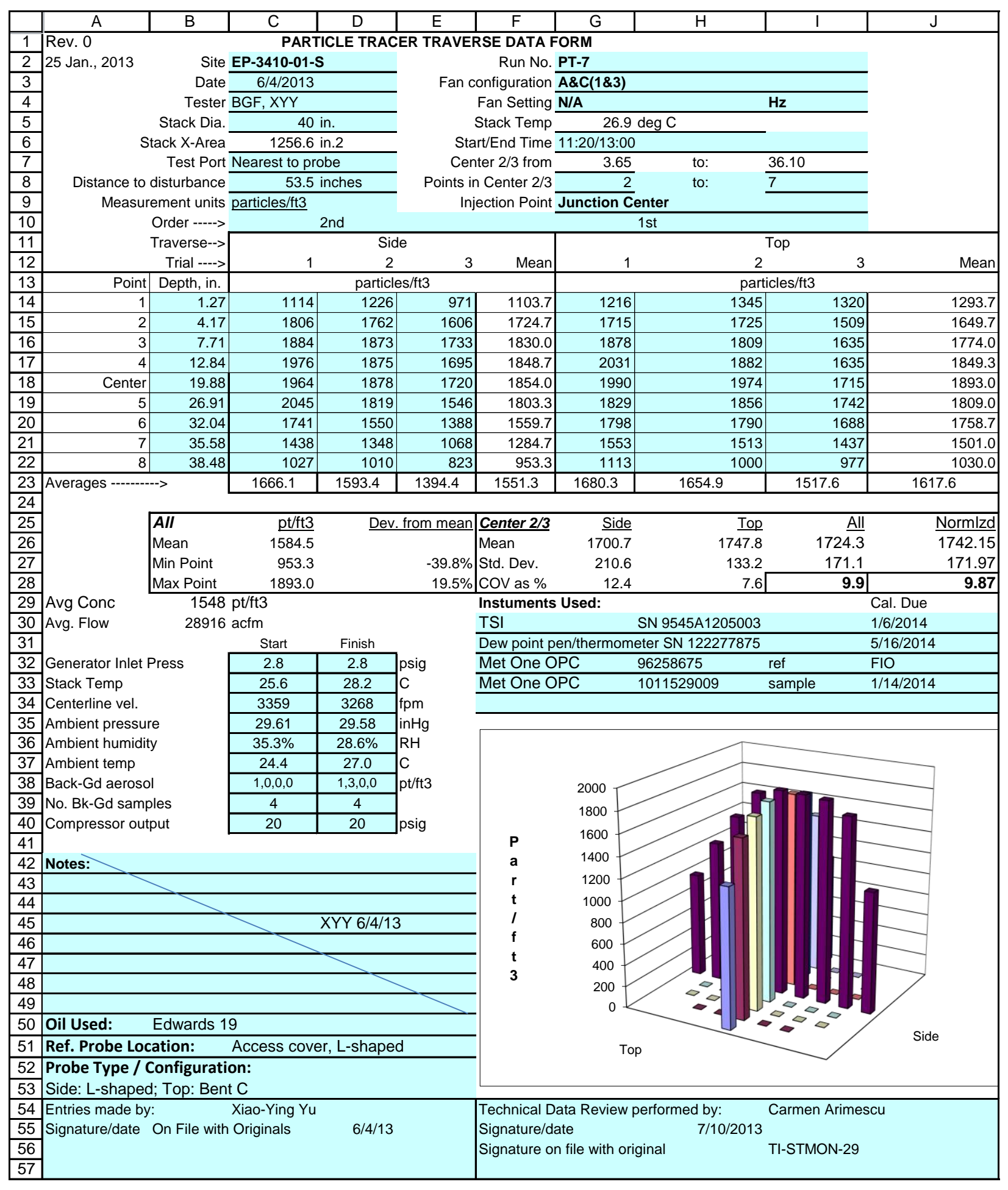




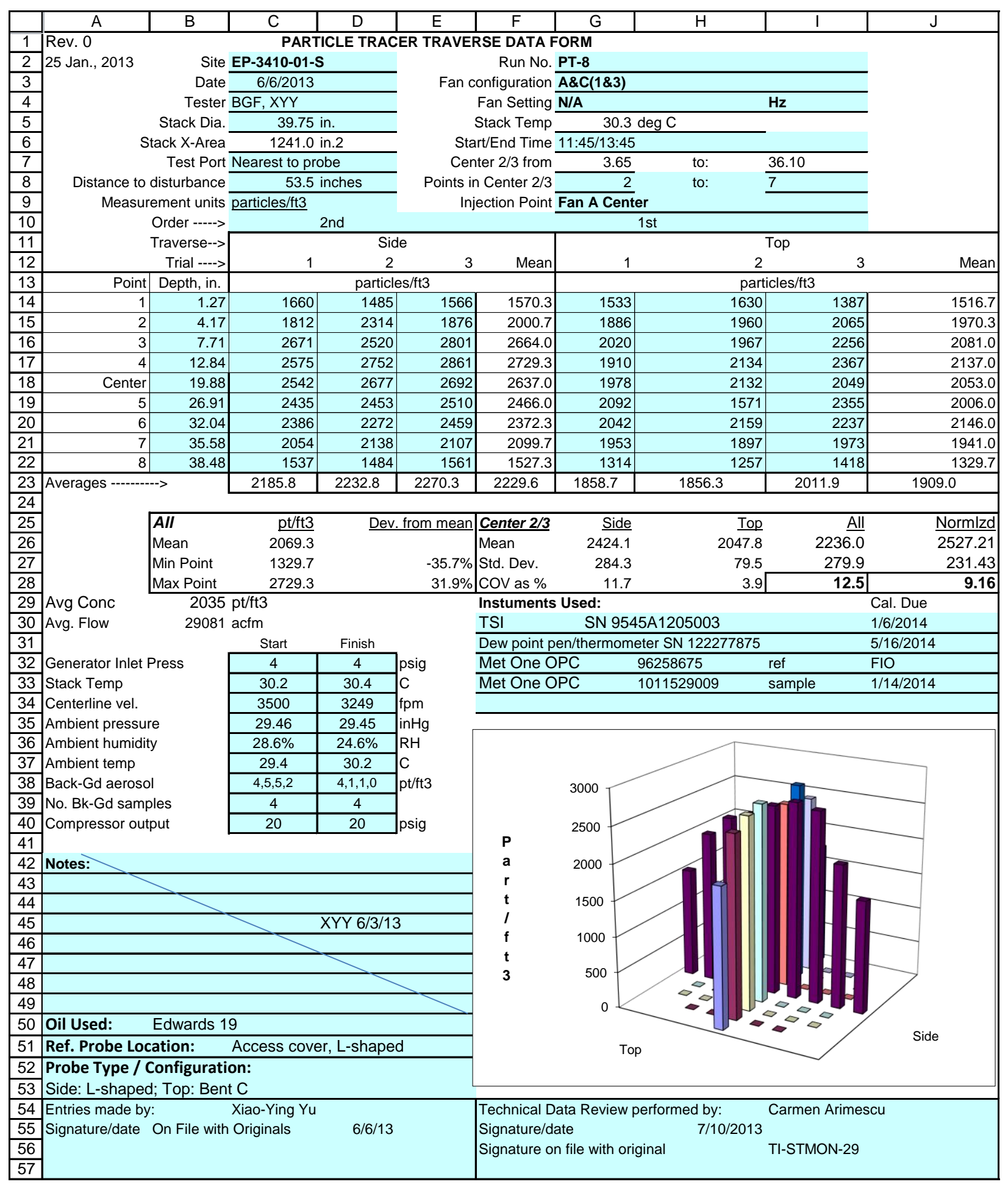




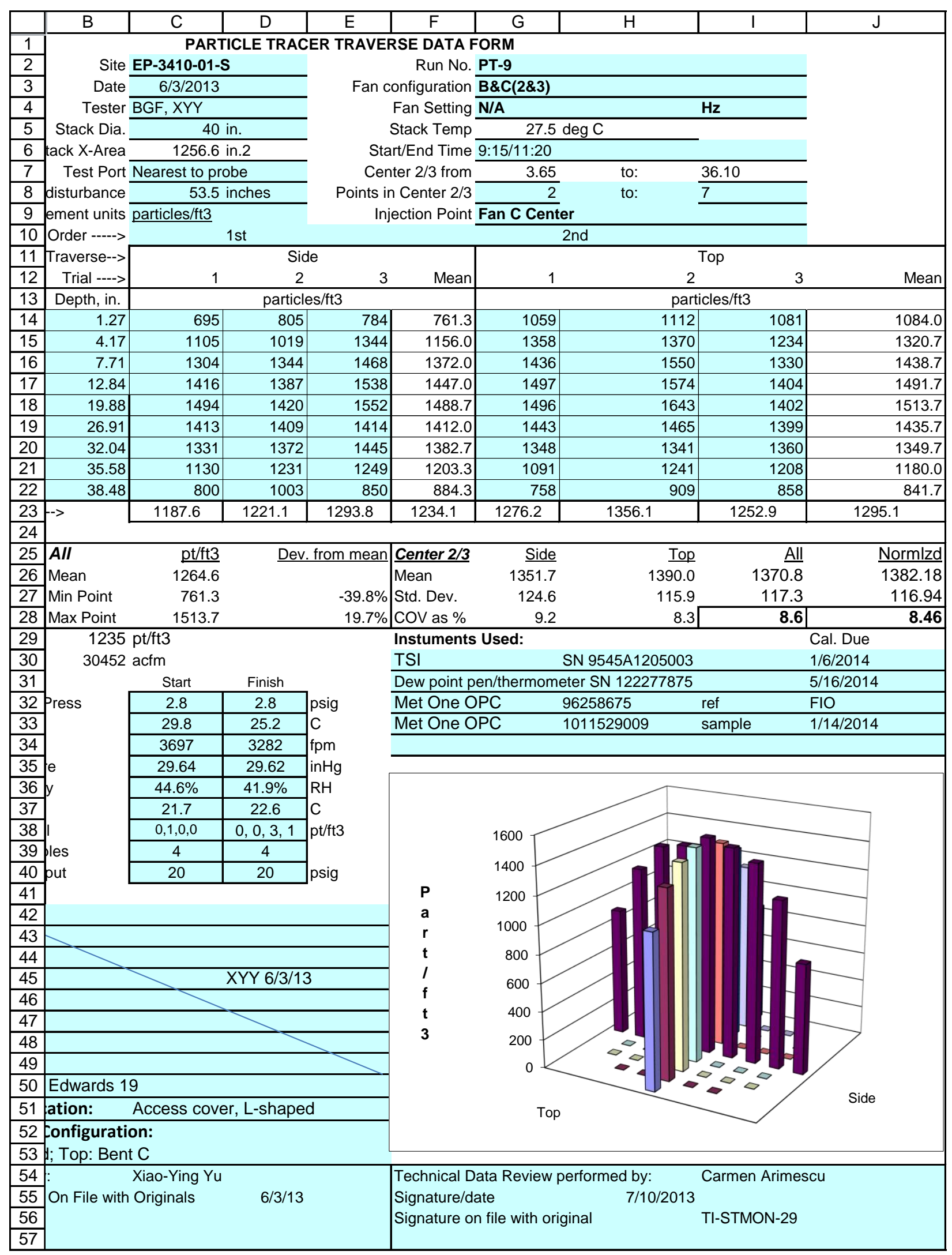




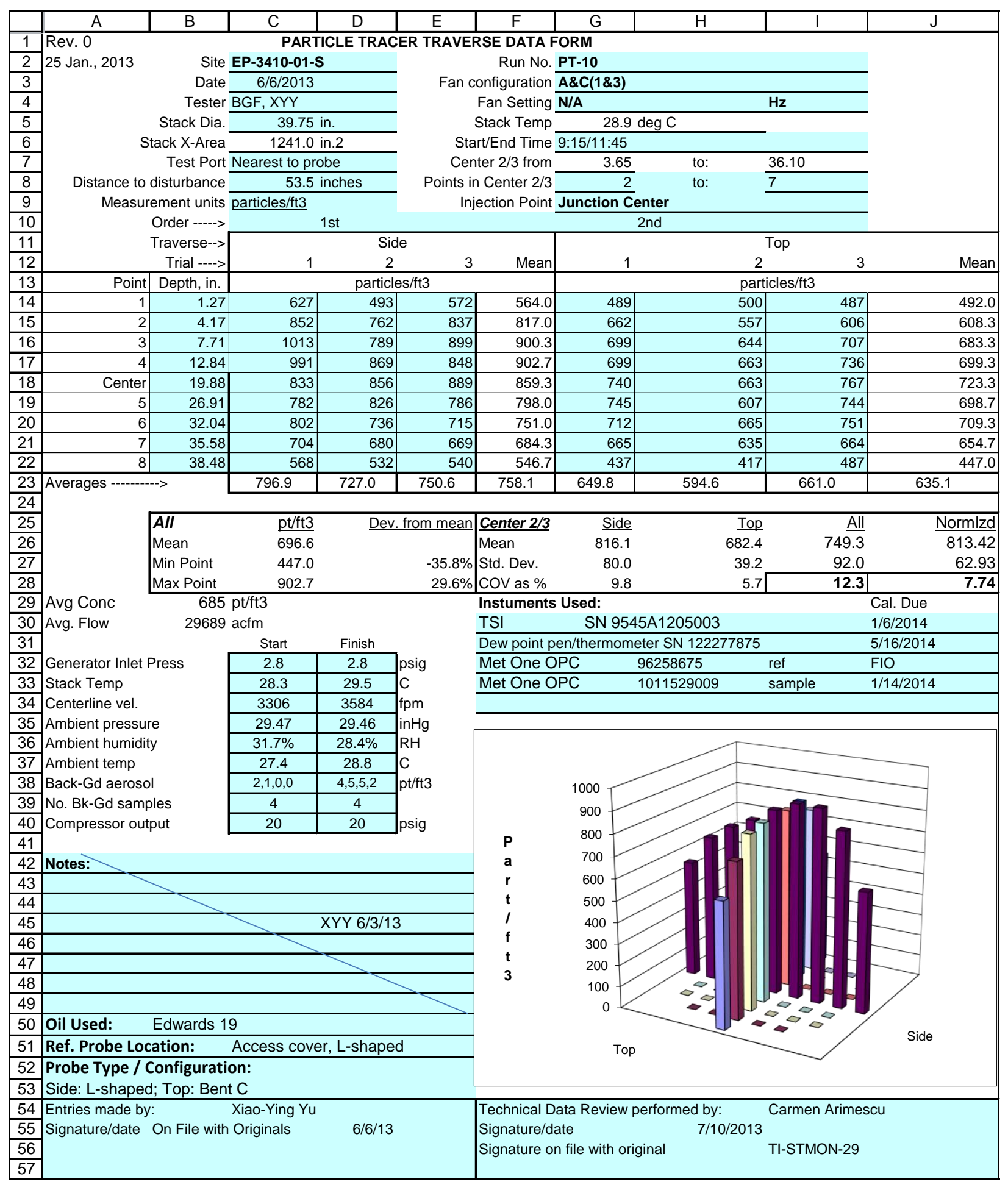




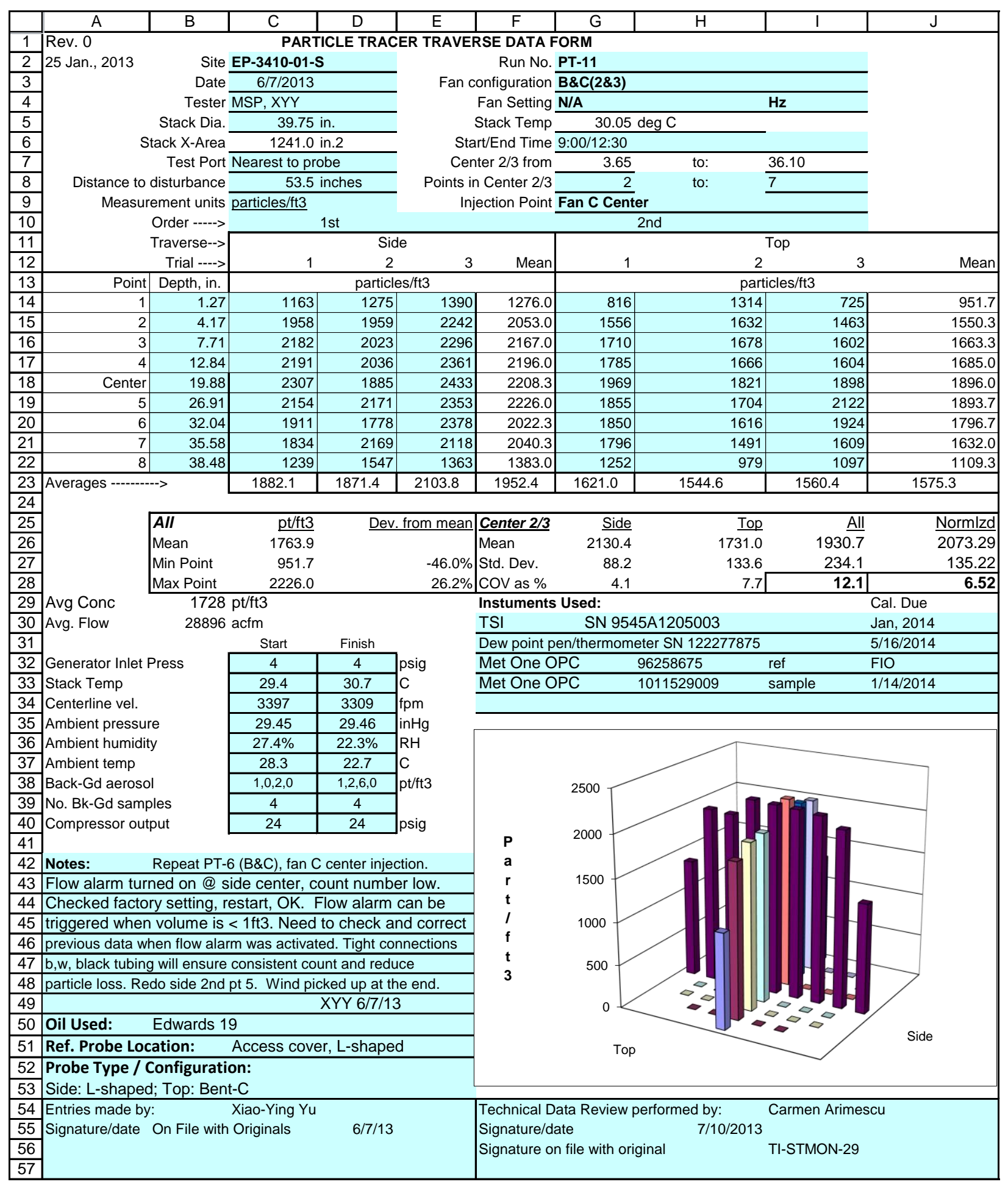


PNNL-23038

RPT-STMON-009

\section{Distribution}

No. of

Copies

\section{ONSITE}

9 Pacific Northwest National Laboratory

JA Glissmeyer (3) K3-54

JM Barnett (2) J2-25

$\mathrm{X}-\mathrm{Y} \mathrm{Yu}$ K9-30

MH Hartzell K8-95

KP Recknagle K7-15

SM Tingey K8-84

BA Greenaway J2-18

Dist. 1 
PNNL-23038

RPT-STMON-009 


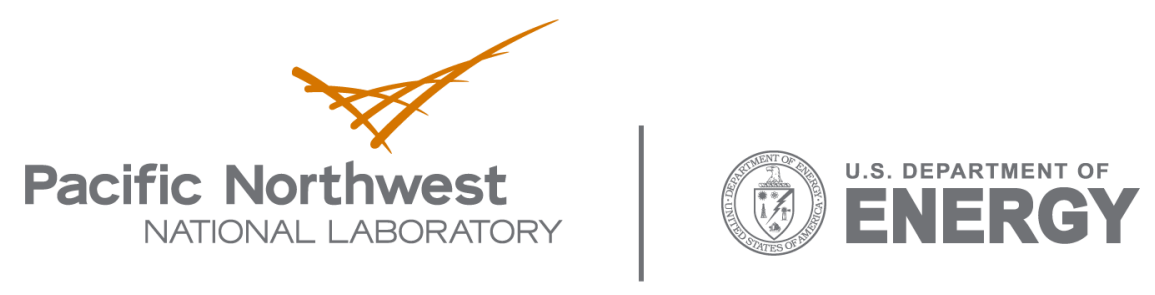

902 Battelle Boulevard

P.O. Box 999

Richland, WA 99352

1-888-375-PNNL (7665)

www.pnl.gov 